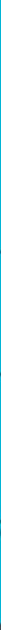

\title{
MULTIMODAL LITERACY IN SCHOOL SCIENCE
}

\section{TRANSDISCIPLINARY PERSPECTIVES ON THEORY, RESEARCH AND PEDAGOGY}

Len Unsworth, Russell Tytler, Lisl Fenwick, Sally Humphrey, Paul Chandler, Michele Herrington and Lam Pham

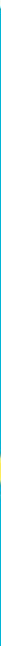




\section{Multimodal Literacy in School Science}

This book establishes a new theoretical and practical framework for multimodal disciplinary literacy (MDL) fused with the subject-specific science pedagogies of senior high school biology, chemistry and physics. It builds a compatible alignment of multiple representation and representation construction approaches to science pedagogy with the social semiotic, systemic functional linguistic-based approaches to the explicit teaching of disciplinary literacy.

The early part of the book explicates the transdisciplinary negotiated theoretical underpinning of the MDL framework, followed by the researchinformed repertoire of learning experiences that are then articulated into a comprehensive framework of options for the planning of classroom work. Practical adoption and adaptation of the framework in biology, chemistry and physics classrooms are detailed in separate chapters. The latter chapters indicate the impact of the collaborative research on teachers' professional learning and students' multimodal disciplinary literacy engagement, concluding with proposals for accommodating emerging developments in MDL in an ever-changing digital communication world.

The MDL framework is designed to enable teachers to develop all students' disciplinary literacy competencies. This book will be of interest to researchers, teacher educators and postgraduate students in the field of science education. It will also have appeal to those in literacy education and social semiotics.

Len Unsworth is Professor in English and Literacies Education and Research Director in Educational Semiotics and Literacy Pedagogy at the Institute for Learning Sciences and Teacher Education, Australian Catholic University.

Russell Tytler is Alfred Deakin Professor and Chair in Science Education at Deakin University, Melbourne, and Fellow of the Academy of Social Sciences Australia.

Lisl Fenwick is Senior Lecturer in Education at the University of South Australia.

Sally Humphrey is Senior Lecturer in Education at the Australian Catholic University. 
Paul Chandler is Senior Lecturer in Education at the Australian Catholic University.

Michele Herrington is Research Fellow in Education at the Australian Catholic University.

Lam Pham is Lecturer in Medical Education in the Faculty of Health, Deakin University. 


\section{Multimodal Literacy in School Science}

Transdisciplinary Perspectives on Theory, Research and Pedagogy

Len Unsworth, Russell Tytler, Lisl Fenwick, Sally Humphrey, Paul Chandler, Michele Herrington and Lam Pham 
First published 2022

by Routledge

4 Park Square, Milton Park, Abingdon, Oxon OXI4 4RN

and by Routledge

605 Third Avenue, New York, NY 10158

Routledge is an imprint of the Taylor o Francis Group, an informa business

(C) 2022 Len Unsworth, Russell Tytler, Lisl Fenwick, Sally Humphrey, Paul Chandler, Michele Herrington, Lam Pham

The right of Len Unsworth, Russell Tytler, Lisl Fenwick, Sally Humphrey, Paul Chandler, Michele Herrington, Lam Pham to be identified as authors of this work has been asserted in accordance with sections 77 and 78 of the Copyright, Designs and Patents Act 1988.

The Open Access version of this book, available at www. taylorfrancis.com, has been made available under a Creative Commons Attribution-Non Commercial-No Derivatives 4.0 license.

Trademark notice: Product or corporate names may be trademarks or registered trademarks, and are used only for identification and explanation without intent to infringe.

British Library Cataloguing-in-Publication Data

A catalogue record for this book is available from the British Library

Library of Congress Cataloging-in-Publication Data

A catalog record has been requested for this book

ISBN: 978-0-367-71404-8 (hbk)

ISBN: 978-1-032-19106-5 (pbk)

ISBN: 978-1-003-15071-8 (ebk)

DOI: $10.4324 / 9781003150718$

Typeset in Galliard

by SPi Technologies India Pvt Ltd (Straive) 


\section{Contents}

List of figures vii

List of tables $\quad \mathrm{x}$

Foreword xi

Preface xiv

Acknowledgements xvii

1 Researching multimodal literacy as core to senior high school biology, chemistry and physics pedagogy $\quad 1$

2 Language, image and multimodal mediation in scientific research and science learning

3 Distinguishing multimodal disciplinary literacy in school science

4 Contextualizing the conditions for multimodal literacy practices in senior high school science

5 Teaching and learning practices for multimodal literacy in science education

6 A framework for infused multimodal disciplinary literacy in school science

7 Multimodal disciplinary literacy in the senior biology classroom

8 Multimodal disciplinary literacy in the senior physics classroom 
vi Contents

9 Multimodal disciplinary literacy in the senior chemistry classroom

10 Design-based research and teacher professional learning about multimodal literacy

11 Student engagement in science learning through multimodal disciplinary literacy

12 Advancing multimodal literacy transdisciplinary research and teaching

Index 


\section{Figures}

1.1 A framework for mapping theoretical orientations to literacy in science and disciplinary literacies

3.1 Principal genres in school science textbooks 42

3.2 Principal genres in school history textbooks 43

4.1 The process of semiosis in transducting from textbook to slowmation construction

4.2 Figures and text on one page of a year 11 physics textbook

4.3 The three representational dimensions core to chemistry conceptions

4.4 Increasing semantic density of representations of molecules across year 11: Jacaranda text Chemistry VCE Units 1 and 2

4.5 Year 11 students using a bridging 'cross and portion' model to calculate concentration when mixing two solutions

5.1 A conceptual map for reviewing pedagogies informed by sociocultural approaches to literacy and learning

5.2 Sequence of processes in guided inquiry pedagogies 92

5.3 The teaching and learning cycle 95

5.4 Image redescription of 'prophase'

6.1 Fundamental bases for multiliteracies infused science education

6.2 Teaching/learning sequences for guided inquiry pedagogy

6.3 Pedagogic synthesis of multimodal disciplinary literacy and scientific practices

6.4 Interweaving directed teaching with scaffolded and student collaborative and independent learning in a pedagogic synthesis of multimodal disciplinary literacy and scientific practices 
6.5 A framework for multimodal disciplinary infused science pedagogy

6.6 Year 12 physics electric motors task

6.7 Alex's explanation of the electric motor

6.8 Kim's explanation of the electric motor

7.1 Student's visual representation of the case study on natural selection

8.1 Embodied representation of the spatial relations between magnetic field and current direction, and force on a wire

8.2 Multimodal orchestration of abstracted spatial relations of magnetic field to current loop, graphical representation and text

8.3 Schematic of an AC generator

8.4 Conceptualizing gravitational energy as the area under a graph of gravitational force vs. distance

8.5 Establishing Faraday's law of electromagnetic induction

8.6 Assessment item requiring a conditional explanation based on coordination of theory and evidence

8.7 Comparison of the top-graded (by the teacher) student response with an $\mathrm{M} 3 \mathrm{~S}$ researcher generated text. The underlined explanatory moves are not duplicated by this student

8.8 (a, b) Examples of student-written text where they express their ideas about features of circuits

8.9 A student's interpretation of a simple circuit using a hydraulic model

8.10 (a) The switch is open. There's a break in the path.

(b) Paulo indicates spatially the separate voltage drops across three lamps. (c) Paulo indicates with a gesture the voltage drop across the lamp, between two points

8.11 Paulo's board work in conjunction with text on PowerPoint. The representations include

(1) the terminology relating to the potential difference,

(2) the PowerPoint slide of textbook summary,

(3) the formula for successive voltage drops across the resistors, (4) a circuit diagram showing resistor arrangement with resistance value annotations, (5) an equivalent circuit clarifying the meaning of $\mathrm{R}_{\mathrm{eq}}$ and (6) the beginnings of a recasting of the voltage relations using Ohm's law

8.12 Worksheet designed to help students analyze resistance combinations 
9.1 Examples of a students' drawings (a) and written texts

(b) that depict the observational dilution phenomena

9.2 (a \& b) Examples of students' drawings that illustrate the submicroscopic scale of the dilution process

9.3 The CPO model that was used for the CPO demonstration activity

9.4 Examples of student's CPO model that represents solution $\mathrm{C}$ as having 2 moles per litre (a) and mathematical fractions (b) that assist the $\mathrm{CPO}$ construction of solution $\mathrm{C}(2 \mathrm{~mol} / \mathrm{L})$

9.5 Examples of a student's CPO model that represents Solution $\mathrm{E}$ as having 4 moles per litre (A)

9.6 A possible initial drawing of 'the mole is 6'

9.7 A possible second drawing of 'the mole is 6'

10.1 Joint construction on transcription that Riya completed with her class

10.2 Information on theme and rheme that Riya provided to her class

10.3 A successful physics poster showing the use of multimodal representation

10.4 Paulo's relating of textual moves to epistemic processes

12.1 Simplified summary of options for the deployment of images and language in infographics

12.2 The greenhouse effect

12.3 Infographic representing the composition and functioning of the ear

12.4 Simplified summary of options for construing field through verbiage in infographics

12.5 Amri's explanation of water as a solvent for sodium nitrate

12.6 Sim's explanation of water as a solvent for sodium nitrate 


\section{Tables}

3.1 Visualizations in different science sub-disciplines on the 2012 New York State Regents Examination

5.1 An overview of foundational guided inquiry models integrating literacy

6.1 Comparison of student responses with a composite of textbook and website explanations of the functioning of an electric motor

8.1 Outline of the electric circuits sequence

8.2 The first two activities of a year 10 kinematics sequence, with a focus on the literacies of data and graphical representations

10.1 A linguistic analysis of content from a highly graded research poster 


\section{Foreword}

I have a confession to make. I have been working on what should be a relatively straightforward writing task - this foreword-for quite some time. Between reading this remarkable volume and then stewing over what I could write that would do it justice, I have extended the task beyond my deadline. Now, the authors and publishers might not agree with me, but I think that my tardiness is justifiable. How could I rush the task when the authors and their teacher collaborators had clearly given so much of their time to the thoughtful synthesis of learning and pedagogical theories across a range of subject areas, epistemologies and methodological approaches? How could I not tarry over the incredibly detailed and nuanced explications of the complexities of literate practice in learning the specialized science domains? How could I skim over the thoughtful analyses of virtually every contextual factor in the work of developing multimodal disciplinary literacies from the role of students' prior knowledge and disciplinary literacy (DL) skills to the influences of high-stakes assessments (and everything in between)? How could I resist a close reading of several case studies that illustrate the multimodality of DL practice, cases that felt familiar and real?

Well, the truth is, I have been selfish with my leisurely read through this remarkable text. I admit my selfishness as part of my apology to the reader for keeping you from this book for so long. Everyone who is interested in language and literacy, in multimodality, in science literacy and in DL more generally should be reading this text. Everyone who cares about secondary school teaching and learning should be reading this text. The volume is specific to natural and physical sciences teaching, to be sure, but I believe that anyone who recognizes that language and representation in all their forms are central not only to learning in the discipline but also to knowledge production itself will benefit from reading this work.

What makes this volume so special? I have hinted at some of the unique features as I offered my excuses for spinning out the time that I took to pore over the chapters. And yet, there is more to say. First, the volume is unique because it carefully delineates and distils complex theoretical perspectives at the outset, all done in a way that invites even the uninitiated reader into conversation. The treatment of the 'foundations of multimodal disciplinary literacy', including perspectives on social semiotics, SFL, multimodality in 
science and DL is thorough. But more powerful is that the presentation of theory is not for the sake of theorizing or sounding grand; rather, the authors use these multiple languages and/or science theories to argue for an integrated perspective on teaching multimodality in science, or what they christen multimodal literacy-infused science pedagogy (MLSIP).

Second, the volume is unique because it derives from a longitudinal designbased research study in which the researchers worked side by side with teachers in a senior high school to enact the MLSIP in their actual classrooms. Together, teachers and researchers designed lessons and units of instruction, enacted and documented what happened in the enactment of those lessons and then iterated on the lessons and units for future teaching. Their work not only produced curricula that ultimately would be more useful to other teachers because they had been tested in actual practice but also the experiences served as professional development for both teachers and researchers. Rather than 'testing' a pre-designed curriculum in a controlled setting and then scaling to thousands of other teachers in the quest for context-proof curriculum that produces 'best practice' and 'best outcomes', these teachers and researchers built curricula that could flex with contexts, with students, and with teachers. The cases they present of how the teachers experienced the process make this volume invaluable.

On that second point, I am also grateful for the careful attention to the social and cultural contexts in which teachers teach and students learn. As noted earlier, the authors took the time to situate the research in an analysis of important influences on what teachers and students were able to do together and why. Far too many researchers and theorists claim sociocultural approaches to their work but then seem to abandon their theories when they begin analyzing data and drawing conclusions. The volume is quite different, with the authors presenting early on in the book an analysis of various contextual factors that, in abstract, can make it challenging for teachers to enact curricula or pedagogy as envisioned. They follow up their analysis with examples that bring those challenges to life while also presenting the teachers' moves and solutions to the challenges they faced.

Finally, the volume is unique because it is so richly detailed and vivid in its translation of linguistic and semiotic theories to questions of disciplinary learning and teaching. The classroom data are grounded and thick with descriptions. They offer applications with which most any physical or natural sciences teacher would resonate, and they foreground the disciplinary knowledge and concepts being learned, making clear the essential role of language and other representations in learning those concepts. When language and literacy scholars approach the teaching of a disciplinary area such as the natural sciences with the argument that science teachers are also teachers of language or of literacy, as some have argued in the past, we risk losing teachers' faith and trust. The work of classroom teachers is to teach the concepts, skills and practices of their discipline; part of the work in advancing multimodal disciplinary science pedagogy lies in engaging teachers in recognizing and valuing the essential work of representations and language in learning science 
concepts, skills and practices. The authors have done an excellent job of this translational work, likely because of the value they placed on teachers as colleagues during their three-year project. The positioning of the disciplinary work as prime, with language and representation in the service of learning concepts, offers a path to enriching teachers' (and students') understandings of the multimodal and linguistic nature of knowledge production and communication in any discipline.

In short, this is a volume that everyone should read. Those who theorize how language and language systems function both in the physical and natural science disciplines and in the learning of those disciplines should read the volume to learn the theories and to see how theory can be translated into curriculum and pedagogy. Those who care deeply about translational and meaningful research can learn how research should be designed to engage teachers in translating theory into practice with integrity to students' learning and to the theories themselves. Finally, those who study practice-and those who make policy - can learn how theories, curricula and education policies (e.g. high-stakes testing) can be informed, massaged, and improved through the study of practice. Indeed, the book is for anyone who cares about teaching, learning and researching. It is a gem that will have a proud place not just on my bookshelf but also on my desk for regular consultation, for years to come.

Elizabeth Birr Moje Dean, George Herbert Mead Collegiate Professor of Education, and Arthur F. Thurnau Professor School of Education, University of Michigan Ann Arbor, Michigan, USA April 29, 2021 


\section{Preface}

This book grew out of the work by the authors as a research team in implementing an Australian Research Council (ARC) funded 'Linkage' project. The aim of the project was to support teachers to develop multimodal disciplinary literacy (MDL) in senior high school science to address educational disadvantage in schools in low socio-economic status (SES) areas where the first language of many students is not English. The Multiliteracies in Senior School Science (M3S) project involved senior high school science teachers and their students in four high schools in low SES areas of Melbourne, Australia. The genesis of the project was partly in response to concern among these schools that many of their students struggled with the MDL of science and a belief within the schools that this may be a limiting factor on students' science results in the external state-government-managed final year examinations. In addition to this practical aim, the research team was motivated to explore the potential for enhancing approaches to multimodal literacy in school science through capitalizing on the commonalities and resolving the tensions between their different theoretical orientations to disciplinary literacy development. Some members of the authoring team (Len Unsworth, Lisl Fenwick and Sally Humphrey) are literacy researchers with an interest in science education, whose work is underpinned by systemic functional linguistics (SFL) and its adaptations to images and other modes of meaning-making such as gesture. Paul Chandler is an academic and former chemistry teacher and Michele Herrington worked as a research fellow on the M3S project. SFL theoreticians and researchers such as Michael Halliday and Jim Martin and their colleagues and students have made prodigious contributions to the linguistic description science discourse, and Jim Martin and the 'Sydney School' SFL community have also developed a genre-based approach to literacy education. Two members of our authoring team for this book, Russell Tytler and his former student Lam Pham, have pursued a representation construction approach (RCA) to science pedagogy generated by Tytler and several of his colleagues, including Vaughan Prain, Peter Hubber and Bruce Waldrip, which draws on science education research following a guided inquiry approach to science pedagogy. The RCA also has a strong social semiotic focus but from a different but complementary perspective to 
that in SFL, creating the possibility of a productive practical and theoretical engagement.

While both SFL and RCA share a social semiotic perspective on literacy and multimodal representation, including recognition of the contribution of Michael Halliday to explicating the nature of science discourse, and the importance of students' knowledge of the form and function of the language resources that construct science discourse, very different views have been expressed about matters such as i) the timing and extent of explicit teaching about language; ii) the nature and role of a metalanguage for talking with students about the form and function of language, image and multimodal representation resources; iii) the significance of prototypical genres or typical structures of types of texts, such as various forms of information reports, procedural recounts and explanations; and iv) the importance of the SFL emphasis on anticipatory guidance through, for example, teachers' modelling the writing of science genres and then jointly constructing similar versions with students prior to their independent creation of such texts, whereas RCA recommended more initial exploratory writing by students followed by shared discussion, consensual re-versioning and ultimate introduction of canonical versions. Common to both research traditions has been the focus of research on science education in primary/elementary and junior secondary schools. As a transdisciplinary research team, we were keen to learn as much as possible about the theoretical bases and evidential support for the two approaches and to explore the room for movement in relation to their differences, especially in the relatively uncharted territory for these approaches in the senior science classroom.

A challenging aspect of our collaboration with the four schools that worked with us was that we were not able to present them from the outset with a fully resolved approach that they would trial. Rather, we discussed with them the principles derived from the previous work from both research traditions and asked them to jointly explore with us approaches to language and learning that are the most productive and viable for their contexts. In the context of senior high school science in Australia, in common with many other countries, the pressure felt by teachers of an externally administered final year examination and highly structured curricula, along with well-established pedagogic traditions in the schools, made some wary of losing precious time for curriculum coverage and examination preparation by committing to the uncertainty involved in seeking ways to infuse multimodal literacy as a core strategy in senior science pedagogy. Nevertheless, with enormous assistance from teachers who were more strongly motivated to accept the challenges and engage intensively with the research team, the project was embraced and sustained over a three-year period.

What we present in this book is the outcome of the impressive professional expertise and sustained engagement of our committed teachers with the research team in negotiating different theoretical perspectives and associated practical pedagogies within social semiotic, situated literacies and 
guided inquiry orientations to multimodal literacy-infused science pedagogy (MLISP) in the senior high school. We have proposed a theoretically and empirically supported framework of principled bases to inform practical planning for teachers' classroom work and productive directions for ongoing research and development. We hope that critical engagement with our MLISP framework will encourage researchers to further investigate the potential we have envisioned for this work to enhance teaching and improve all students' learning and interest in science, especially those confronted by socio-economic disadvantage and the complexities of disciplinary literacy in senior school science. 


\section{Acknowledgements}

The M3S research project that inspired this book was supported by an ARC Linkage Projects grant (LPl60100263) funded by the Australian Government. The views expressed herein are those of the authors and are not necessarily those of the ARC.

The authors and publishers would like to thank the following copyright holders for permission to reproduce material:

Equinox Publishing Ltd 415 The Workstation 15 Paternoster Row Sheffield S1 2BX United Kingdom for:

Figure 3.1 Principal genres in school science textbooks (Martin \& Rose, 2008, pp., p. 167); Figure 3.2 Principal genres in school history textbooks (Martin \& Rose, 2008, p.130); Figure 5.3 The teaching and learning cycle (Rothery, 1994).

Pearson Australia Group 707 Collins St Melbourne, VICTORIA, 3000, Australia, for

Figure 4.2 Figures and text on one page of a Year 11 physics textbook (Moran, 2016, p. 125); Figure 8.1 Embodied representation of the spatial relations between magnetic field and current direction, and force on a wire (Bail \& Moran, 2017, p. 55); Figure 8.2 Multimodal orchestration of abstracted spatial relations of magnetic field to current loop, graphical representation and text (Bail \& Moran, 2017, p. 125); Figure 8.3 Schematic of an AC generator (Bail \& Moran, 2017, p. 126); Figure 8.4 Conceptualizing gravitational energy as the area under a graph of gravitational force vs. distance (Bail \& Moran, 2017, p. 246); Figure 8.5 Establishing Faraday's law of electromagnetic induction (Bail \& Moran, 2017, p. 115); Figure 12.3 Infographic representing the composition and functioning of the ear Rickard, G. (2017, p.108). 
xviii Acknowledgements

Jacaranda-Wiley PO Box 1226 Milton QLD 4064 Australia for

Figure 4.4: Increasing semantic density of representations of molecules across Year 11: Jacaranda text Chemistry VCE Units 1 and 2. (Taylor, Stubbs \& Stokes, 2020, Unit 1, p. 6, p. 197, Unit 2 p 5, p 6); Figure 12.2: The Greenhouse Effect (Lofts \& Evergreen, 2015, p. 228).

The authors would also like to thank the principals and teachers from the collaborating schools in Melbourne Australia. 


\section{Researching multimodal literacy as core to senior high school biology, chemistry and physics pedagogy}

\subsection{Introduction}

Multimodal literacy is increasingly integral to the disciplinary practices of science, with new and evolving semiotic resources enabling the development, validation and enactment of conceptual knowledge (Bezemer \& Kress, 2008; Doran, 2017, 2019; Lemke, 2004; Tang, Won, Mocerino, Treagust \& Tasker, 2020; Tytler \& Hubber, 2010; Tytler, Ferguson \& White, 2020a). The role of representational work in practice and thought within and beyond the laboratory has been established by scholars from a wide range of disciplinary and theoretical perspectives (Gooding, 2006; Latour, 1999; Wise, 2006), and representational tools have been described in terms of the 'inscriptions' that are developed and negotiated in the generation of scientific knowledge by professional scientists (Latour, 1999). While school science education differs significantly from the professional practice of science (Park \& Song, 2019), understandings of the complex processes involved in inscription and the constitutive role of semiosis offer a wide range of possibilities for supporting and assessing the increasingly specialized curriculum learning of senior school subjects such as biology, chemistry and physics (Jones, Turney, Georgiou \& Nielsen, 2020; Patron, Wikman, Edfors, Johansson-Cederblad \& Linder, 2017; Tytler \& Hubber, 2010).

Multimodal disciplinary literacy (MDL) refers to the discipline-specific competences and practices that are recontextualized in school subjects, while multimodal literacy infused science pedagogy (MLISP) refers to the strategies used to develop and use these competences in the classroom. Foundational and ongoing research related to both MDL and MLISP are expanded in subsequent chapters of the book; however, in this chapter, we outline some of the potential areas of ongoing conversation within the literacy and science education community that have been essential in developing transdisciplinary research in both fields. We firstly provide an orientation to research which has advanced understandings of verbal, visual, symbolic and mathematical representations in science and science learning (Doran, 2017, 2019; Ge, Chung, Wang, Chang \& Unsworth, 2014; Hao, 2020; Hao \& Humphrey, 2019; Lemke, 1990, 2004; Doran \& Martin, 2021; Martin, Unsworth \& Rose, in press; O’Halloran \& Lim, 2014). In part 2 


\section{Researching multimodal literacy}

of the chapter, we review motivations for long-standing research interest in infusing literacy and multimodal literacy within senior high school science pedagogy and discuss research perspectives that have contributed to designing pedagogic practices (Rose \& Martin, 2012; Tang et al., 2020 Tytler \& Hubber, 2010; Tytler et al., 2020b; Unsworth, 2001). We argue that effective pedagogic design requires explication of learning theories which inform intersecting fields of science education and multimodal semiotics and a metalanguage which can mediate the interpretations of recontextualized practice (Tang, 2019).

\subsection{Foundations of MDL}

While appreciating ongoing debates around the nature and role of literacy in science, perspectives of MDL begin with understandings of 'fundamental literacy' in science education (Norris \& Phillips, 2003) and of 'disciplinary literacy' in broader literacy research (Fang \& Schleppegrell, 2010; Moje, 2015; Shanahan \& Shanahan, 2008). Fundamental literacy was used originally to refer to the reading and writing that is a necessary basis for science literacy, with the latter concept referring to the 'knowledgeability, learning, and education' of science (Norris \& Phillips, 2003, p. 224). However, greater emphasis on authentic scientific practice has emphasized the interactive and dynamic relationship between these aspects (Yore, 2018). Disciplinary literacy has emerged as a research tradition through recognition of the increasingly specialized ways in which representations are deployed as students' progress through the secondary science years. The competencies involved in disciplinary literacy are seen as distinct from everyday oral language and also from basic and generic literacies that are shared across curriculum areas (Shanahan \& Shanahan, 2008). Foundational studies of verbal language in relation to fundamental and disciplinary literacy have provided important foundations for articulating the role of various modes and the possibilities inherent in these (Ainsworth, 1999), as well as for developing a metalanguage to talk about meaning making (Lemke, 1990; Veel, 1997).

\subsubsection{Verbal language in science}

Applied linguistic studies of written scientific research provide a range of perspectives on the construction of meaning and social context, with varying emphasis given to the weight of meaning carried by the context and discourse patterns of text. Rhetorical theorists (Bazerman, 1988; Latour \& Woolgar, 2013) identified links between the language used in published research articles and the processes and practices of laboratory investigation, including the integration of persuasive and informative functions in writing. Bazerman (1988) argued that this integration was in response to contextual pressures on research scientists to both 'create pictures of the immediate laboratory world' and 'say something new and persuasive' (59). Perspectives from historical and socio-political contexts have allowed rhetorical scholars 
to theorize across many texts, including accounting for how Newton communicated empirical research in ways that 'lent generality and universibility to his claims' (Bazerman, 1988, p. 90). However, in grappling with issues of 'context, agency, and the relationship between style and argument' (Johnstone \& Eisenhart, 2008, p. 5), limited attention has been given to the analysis of language to provide empirical evidence for how discourse constitutes and enacts context.

The social semiotic theory of systemic functional linguistics (hereafter, SFL) is widely used to interpret discourse patterns of texts in scientific research and classrooms (Halliday, 2004; Halliday \& Martin, 1993; Lemke, 1990, 1998). In contrast to rhetorical theories, SFL researchers model context as semiotic systems that are realized through language. Language resources are understood to be distributed across different systems of meanings, which can by and large be mapped onto particular dimensions of context, thus providing the model with significant explanatory power. The level of context relating most closely with language is called register. Dimensions of register include the field, which relates to the topics and activities under investigation; the tenor, which relates to the relationship between composers of texts and their audiences; and the mode, which in written language refers to the ways a text is constructed to constitute the message. Foundational SFL research (Halliday \& Martin, 1993; Lemke, 1990; Veel, 1997) identified a number of characteristic language structures which realize scientific English, including grammatical forms that are distinct from spoken language. The grammatical form, nominalization, for example, which is typically defined as a word 'that has been transcategorized from, for instance, verb to noun class' (Heyvaert, 2003 , p. 67), has been recognized as critical resource for creating a technical field and for carrying forward the momentum of the argument' in the written mode (Halliday, 1998, p. 202). Halliday $(1998,2004)$ also studied the variation of scientific writing over time and found that condensed noun groups became a significant feature of 20th-century scientific communication. This feature, which he described as 'a general drift towards thinginess' (Halliday, 1998 , p. 211), has also been identified in science communication research as 'convenient and even necessary devices for communicating technical information concisely' (Gross, Harman \& Reidy, 2002, p. 169).

Discourse patterns which have been identified in 'adult science' have been found to play a constitutive role in learning science, notwithstanding the influence of different processes involved in its recontextualization (Veel, 1997). Descriptions of genres which accomplish different social purposes have been particularly useful in examining recontextualized science practice in international educational policy (Fang, 2010; Schleppegrell, 2004; Tang \& Putra, 2018). Genre has been understood as a more abstract level of context, which accounts for how choices for tenor, field and mode are mapped onto each other in unfolding discourse (Dreyfus, Humphrey, Martin \& Mahboob, 2016). Martin further defines genre as 'a staged, goaloriented, purposeful activity in which speakers engage as members of our culture' (Martin, 1985, p. 25). Genres for organizing and explaining events 


\section{Researching multimodal literacy}

in school science have received significant attention in recognition of their contribution to 'the creation of new knowledge to account for new phenomena' (Tang \& Putra, 2018, p. 570). In terms of literacy development, Unsworth (2001) has found that particular linguistic resources of written explanations in pedagogic materials can provide a systematic 'textual bridge' from common sense to scientific reasoning (p. 607). For example, grammatical shifts involving reformulations from verb structures which are more common in spoken language (e.g. compress) to noun structures (e.g. from 'compress' to 'compression') are important to build abstract concepts across explanations. By including structural phases to unpack and then repack the noun forms, a written explanation can progressively scaffold the development of knowledge. Much of the genre-based research in school contexts instigated to address challenges faced by diverse learners in writing and reading for the curriculum learning perspectives from sociology (Bernstein, 1990, 2000; Maton, 2013) have increasingly allowed SFL researchers to formulate principles for understanding the semiosis of discipline knowledge and how it develops and accumulates in terms of language and broader semiotic resources (Christie \& Derewianka, 2008; Martin \& Rose, 2008; Unsworth, 2000, 2001; Veel, 1997).

Descriptions of written genres and dimensions of register realized in verbal language provide an important base for exploring the contribution of verbal meanings to multimodal texts and in mapping the expansion of resources across the transition to senior school. Recent SFL studies have focussed on the construal of technical fields in a range of educational contexts (Maton, Martin \& Doran, 2020) and have extended linguistic models to explain 'syndromes of meaning' involved in disciplinary knowledge building, particularly in physics (Doran, 2017, 2019) and biology (Hao, 2020; Hao \& Humphrey, 2019). As we shall explore in the following sections, methods and conceptual frameworks developed through discourse-oriented research have also provided researchers with critical tools for investigating MDL in senior biology, chemistry and physics.

\subsubsection{Multimodality in science}

Extending research from written language to multimodality in school science has emerged from two related strands of research. Firstly, studies of talk in science classrooms by Lemke revealed how the specialized discourse of science develops through oral interactions amongst teachers and students, reflecting complex cultural and historical traditions of problem-solving (Lemke, 1990, 1998). Lemke's (1998) further observation that 'we never make meaning with language alone' (p. 87) has inspired significant investigation of how classroom interactions integrate multiple semiotic modalities in construing scientific reasoning and knowledge building, including artefacts and embodied representation, symbols and maths modes and a range of visual forms (Doran, 2017; Hao \& Hood, 2017; Kress \& Ogborn, 1998; Lemke, 2004). 
A related strand of multimodal research has emerged from studies of images in relation to language in research articles, textbooks or student writing. Social semiotic approaches to this research, which apply Kress and van Leeuwen's (2006) descriptions of the grammar of visual design, foreground the context of communication and the ideology found within signs and attend to meanings made by individual modes, drawing on the concept of 'affordance' (Gibson, 1977) to investigate the 'semiotic potential' of each mode. Using these descriptions, scholars have identified specific representational resources of contributing modes to multimodal texts in science learning, including how each mode may be differently privileged in a culture (Bezemer \& Kress, 2008). Kress (2010) argues, for example, that the mode of spoken language is well suited to construing temporal relations while images are better suited to displaying spatial relations. Likewise, in exploring the semiotic affordances of science textbooks, Bezemer \& Kress (2008) describe the contribution of individual modes such as typography, image, writing and layout and also expand the analytical gaze to different 'semiotic work' that continuous written language or modular layout may involve for the designer and the reader/viewer. Despite these distinctions, however, these authors conclude that 'Text designed for readers to engage with aspects of the world cannot be fully understood without due attention to all modes operating in that text' (Bezemer \& Kress, 2008, p. 25).

Recent studies of science classrooms and resources have drawn on descriptions provided by Kress and van Leeuwen (2006) to distinguish the meanings made by different representations from a multifunctional perspective (Knain, 2015; Danielsson \& Selander, 2016). Danielsson and Selander (2016), for example, developed a framework for multimodal text analysis that includes interaction between resources for ideational meaning making, as well as conveying values. This framework has been used to specify the contribution of semiotic resources deployed in multimodal ensembles created in an elementary physics unit with students in linguistically and culturally diverse classrooms (Jakobson, Danielsson, Axelsson \& Uddling, 2018). Analysis of the role of different modes focussed on the distinct affordances of each to achieving particular discourse functions. For example, models and diagrams were related to visualizing and concretizing abstract phenomena and written language was related to generalizing. While analysis of the form and function of the representations involved was limited to verbal language strategies, e.g. 'unpacking nominalizations and packing processes' (Jakobson et al., 2018, p. 176), the study does draw attention to the complex nature and conduct of literate practice in school science investigation, including the role of transductions from one semiotic mode to another.

\subsubsection{The emerging research field of $M D L$}

The field of MDL builds on foundational linguistic and multimodal research to reveal how multiple representation resources construe complex meaning in school and university disciplines (Doran, 2017; Ge, Chung, Wang, 


\section{Researching multimodal literacy}

Chang \& Unsworth, 2014; Hao \& Hood, 2017; Lemke, 2004; O'Halloran, 2003; O'Halloran \& Lim, 2014; Unsworth, 2020). A shift in focus to how modes are integrated and coordinated to multiply meaning in particular teaching and learning contexts can be traced to Lemke's (1998) proposal for attention to not only the affordances of contributing modes but also the distinctive and overlapping roles of modes to elaborate meanings and provide the redundancy needed for effective learning. Significantly, Lemke (1998) foregrounds the 'close and constant interaction and cross-textualisation amongst semiotic modalities' (27) that construes communication in professional science journal articles.

Lemke's research has encouraged transdisciplinary MDL scholarship which emphasizes a more complex and 'messier' view of the process of scientific inscription than is currently recognized in science and literacy education policy and practice (Tang, 2019). As with studies of verbal language, MDL scholars have found that the verbal, visual, mathematical and symbolic discourse of school science is quite remote from everyday discourse (O'Halloran, 2003; Unsworth, 1999a, 1999b, 2000). Recent studies have extended the discourse oriented metalanguage of systemic functional linguistics to make more direct links to meanings across modes, including images, diagrams, charts and symbols images and symbolic representations (Doran, 2017; Maton, Martin \& Doran, 2020), as well as in animation (Unsworth, 2020; He \& van Leeuwen, 2019) and gesture (Hao \& Hood, 2017). Attention to the co-deployment of modes across unfolding discourse has also enabled analysts to advance understandings of the progressive recontextualization of scientific knowledge through multimodal representations (Airey \& Linder, 2009), which may enable relationships to be made to the 'messy' practice of professional science (Mody, 2015; Tang, 2019). The complex literacy devices scientists involved in achieving the goals of a scientific investigation are known as 'inscriptions' (Latour, 1999). Findings from MDL studies have important implications for how representations are selected, organized, negotiated and practiced for effective teaching and learning and for the knowledge required by teachers to fully exploit the meaning potential of resources beyond language (Forey \& Cheung, 2019; He \& Forey, 2018). Key findings of transdisciplinary studies and their contribution to models designed for supporting MDL in science are elaborated on in subsequent chapters of this volume. In the next section, we provide an overview of critical motivations for transdisciplinary research in pedagogic design and situate foundational models in science education and literacy research in relation to theoretical orientations to language and learning.

\subsection{Towards an MLISP}

In addition to furthering understandings of the role of MDL in senior school science, research by contributing authors of this volume has resulted in the design of a pedagogic framework for MLISP. Research underpinning this framework has built on a long history of collaboration amongst science 
education and literacy researchers to explore the possibilities multimodal representations offer for supporting and assessing students' disciplinary learning (Tang \& Danielsson, 2018; Jones, Turney, Georgiou \& Nielsen, 2020; Tang \& Putra, 2018; Tytler \& Hubber, 2010).

A significant impetus for designing an MLISP framework is a shared commitment amongst researchers to support the learning of culturally and linguistically diverse learners who are increasingly placed in mainstream classes for subject-area learning (Gebhard, 2019). Recognition of the dangers of assuming that all students have already developed the competencies needed 'to notice, interpret and link the meaning across modes independently' (He \& Forey, 2018, p. 202) has motivated research to better understand how explicit instruction of multimodal literacies can be integrated with science inquiry to ensure links are made for content knowledge development (He \& Forey, 2018; Jakobson et al., 2018; Rose \& Martin, 2012; Veel, 1997; Tang \& Danielsson, 2018) and to understand the cultural and linguistic contexts of diverse learners, including the funds of knowledge they bring to their learning and the particular language challenges they face in mainstream science classrooms (De Oliveira \& Lan, 2014; Moje, 2015). This research includes the investigation of how science teachers can be supported to expand their professional knowledge for planning and implementing pedagogy (Yore, 2018), particularly given the growing emphasis on authentic scientific practice in curriculum policy and recognition of the complex literacies involved (Tang, 2019).

The design of an MLISP framework builds on disciplinary literacy approaches that have drawn attention to the limits of approaches that focus on generic skills and strategies in integrating knowledge and practice (Shanahan \& Shanahan, 2008). Science educators have long integrated generic literacy approaches such as content area literacy and language across the curriculum in response to arguments that 'the capacities required to deal with science texts are largely if not entirely the same as those required for texts with different substantive contents' (Norris \& Phillips, 2003, p. 233). However, as we will further discuss in Chapter 3 , increasing recognition that literacy competencies are situated within 'multifaceted sociocultural discourse practices' (Tang, 2015, p. 311) has contributed to a range of 'situated' approaches aimed at inducting students into literacy practices that are represented in the scientific world. Foundational situated models include those that integrate literate dimensions of reading (Palinscar \& Brown, 1984), oral language (Lemke, 1990; Mortimer \& Scott, 2003), writing (Wallace, Hand \& Prain, 2004) and representational construction (Prain \& Tytler, 2012), along with genre-based and multiliteracies models directly informed by the social semiotic theory of systemic functional linguistics (Rose \& Martin, 2012; Unsworth, 2001).

While the bulk of transdisiplinary research in science has focussed on elementary and middle years classrooms, increasing attention to the secondary school context has emerged in response to international research findings that many students do not have access to the more specialized literacies 


\section{Researching multimodal literacy}

needed to progress to senior grades (Nunes, Bryant, Strand, Hillier, Barros \& Miller-Friedmann, 2017). Secondary school students have been found to engage infrequently in literacy activity in science classrooms and are provided with few opportunities for 'indepth metadiscussions about how and why science concepts are represented in particular ways' (Faller, 2017). Students from lower socio-economic status backgrounds and other historically underrepresented groups have been found to experience particular challenges in participating in the types of oral interactions that 'count' in mainstream science classrooms (Archer \& deWitt, 2016) and thus may not receive adequate monitoring and feedback from the teacher. These scholars link these findings to the persistence of a dominant 'white, male and middle class' culture and argue that more equitable participation is crucial for both economic and social justice goals. To ensure equitable participation and achievement in high stakes assessment regimes, secondary science teachers have been called upon to provide specific targeted attention to literacy competences (Nunes et al., 2017), which include challenges of interpreting and using multiple, multimodal representations.

Designing equitable disciplinary multimodal pedagogies to support diverse learners in senior school science subjects is a major motivation for the collaborative research reported in this volume. An essential step towards achieving this goal has been to synthesize and critically evaluate existing approaches to ensure that the designed model is founded on pedagogic principles that can be understood across the transdisciplinary research community. In the following section, we provide a preliminary map of influential approaches and their theoretical foundations in preparation for expanded discussion in Chapter 5.

\subsubsection{Defining and mapping dimensions of pedagogic orientations}

Dialogue amongst researchers involved in the M3S project has highlighted significant synergies in foundational orientations from science education and literacy research, as well as diverging perspectives recognized across research traditions (Hand, Yore, Jagger \& Prain, 2010; Martin, 1999; Norris \& Phillips, 2003; Tang, 2015, 2019; Tytler et al., 2020b; Yore, 2018). To support discussion towards consensus amongst broad foundational perspectives, we present a topographic framing of approaches, which is informed by Bernstein's (1990) research in the sociology of education. This framework will be refined in Chapter 5 to situate and evaluate sociocultural models that are of most relevance to an MLISP framework (Figure 1.1).

Researchers contributing to the Multiliteracies in Senior School Science (M3S) project share a perspective that presupposes that students' learning is social and, therefore, highly influenced by their interactions with others (Vygotsky, 1978). Also shared is an understanding that extending capacities for disciplinary practice requires many different multimodal literate dimensions (Kress \& Van Leeuwen, 2006). These sociocultural perspectives blur the boundaries between approaches informed by social semiotic theories and 


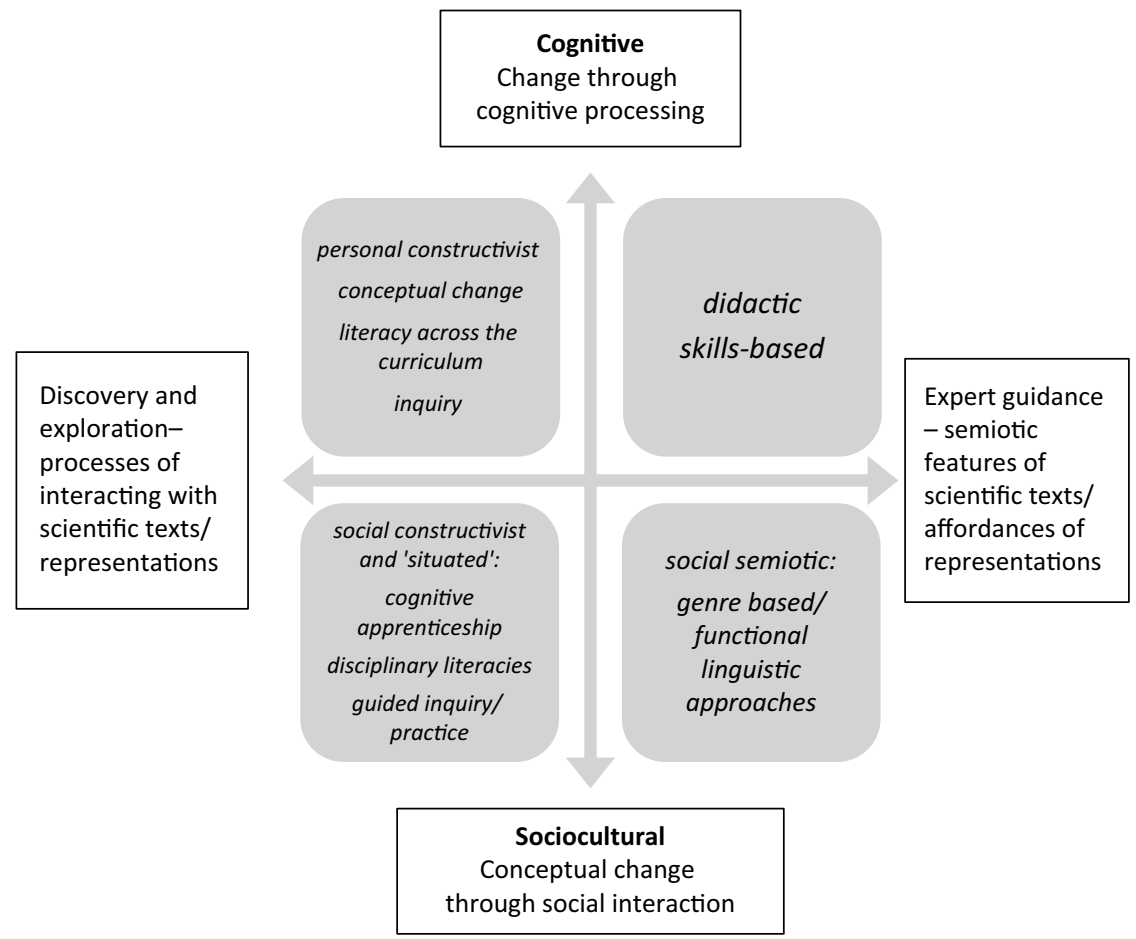

Figure 1.1 A framework for mapping theoretical orientations to literacy in science and disciplinary literacies (adapted from Martin, 1999 after Bernstein, 1990).

those informed by 'situated' learning and literacy (e.g. Gee, 2004; Lave \& Wenger, 1991), as is evident in their positioning in the lower quadrants of Figure 1.1. A distinction is made between these approaches and those that are oriented towards a cognitive perspective, including those that emphasize the individual, their background beliefs, prior experience and intentions in interacting with texts (Prain \& Hand, 2016) and those that emphasize segmented and decontextualized skills and strategies.

Despite these recognized synergies, challenges have arisen in interpreting and synthesizing models and practices which share a sociocultural orientation, in part due to loosely bounded and at times divergent ways of categorizing approaches in the science education and literacy research literature. In the science education literature, categories such as 'constructivist/ cognitive' (Hand et al., 2010) and 'interactive-constructivist' (Yore, 2018), give evidence of the continuing influence of cognitive theories on contemporary approaches. This is not surprising given that many socially oriented models emerged within conceptual change theories to explore how language might be a tool for externalizing cognitive processes to make them accessible (Tytler, 2007), through enculturation (Driver, 1989) or apprenticeship 
(Brown, Collins \& Duguid, 1989). However, as we will discuss in subsequent chapters, inquiry-based models that have incorporated sociocultural perspectives frequently evidence cognitive assumptions that conceptual change is primarily the responsibility of the individual learner and that language is a set of decontextualized forms, functions or skills.

In addition to indistinct boundaries with cognitive approaches, further issues relate to the diverse and potentially divergent approaches categorized as sociocultural. Definitions of this broad orientation typically include attention to the disciplinary practices of science, as well as to cultural aspects of the learner that may impinge on learning, such as socio-economic factors and particularly cultural and linguistic diversity (Hand et al., 2010; Moje, 2007; Tytler, 2007). However, pedagogic models and applications have tended to focus on sociocultural context as either professional science meaning making and practice or 'an advocacy of inclusive cultural border-crossing teaching and learning strategies to support marginalised students' (Hand et al., 2010, p. 50). Situated pedagogies that centralize the cultural and socio-political contexts of diverse learners and are oriented towards challenging normative discourses and constructions of identity (Archer \& deWitt, 2016) have been distinguished from those informed by Vygotsky and categorized as 'critical' in some frameworks (Martin, 1999). While Martin positions genre-based approaches as 'subversive', in their concern to empower non-mainstream groups to recontextualize discursive resources, these and other functional linguistic approaches have also been included in categories emphasizing a 'formal focus on and analysis of linguistic practices and processes' (Hand et al., 2010, p. 50), with critiques including a lack of attention to genres as 'always sites for contestation' (Luke, 1996, p. 318).

The different lenses that have been used to categorize sociocultural approaches in science education and literacy research have frequently attributed to the widely documented 'social turn' in both science education and literacy research (Tang, 2015). However, complex and undertheorized influences of 'linguistic', 'practice' and 'cultural' turns have had a significant impact on how literacy is understood and integrated in science classrooms and drawn attention to the need to bridge theoretical ideas across science education and literacy research traditions (Forman, 2018; Tang, 2019; Yore, 2018). Mapping the relationship amongst approaches from a topographical perspective and appreciating the permeability of boundaries as evidenced in Figure 1.1 is a first step to negotiating a common frame of reference for the guided inquiry and genre-based pedagogies that are foundational to the MLISP framework. This perspective alerts us to potential elisions and assumptions that inevitably occur as new dimensions of theory and practice are progressively disseminated within a research community and adapted for use in other contexts. To orient further discussion in subsequent chapters of both shared and potentially divergent dimensions of foundational situated and social semiotic approaches, this section provides an overview of how relevant aspects of informing sociocultural theories have been interpreted. 


\subsubsection{Interpreting disciplinary practice and semiotic mediation}

In the previous section, we raised potential challenges of identifying pedagogies that follow Gee (2011) in identifying literacy as 'socially purposeful ways where learners interact with multimodal texts within specific historical, cultural and institutional contexts' (Tang, 2019, p. 83). Influential models in the contemporary science education and disciplinary literacy fields have foregrounded professional science practice in defining contexts (Prain \& Hand, 2019), leading to significant debate as to representations of scientific practices in school science policy and potential diverging representations in disciplinary literacy research and policy (Tang, 2019). Tang draws attention to the deliberate shift in curriculum and research away from 'skills' and 'inquiry' to practices that reflect the 'messy' work of professional scientists' (Tang, 2019 p. 85-86). Prain and Tytler (2012) draw direct parallels between the multimodal discursive practices through which students' achieve understanding and a central concept of sociocultural theory, known as semiotic mediation (Vygotsky, 1978). In order to negotiate consensus for an MLISP framework, discussion of interpretations of semiotic mediation and the related concept of scaffolding (Bruner, 1986) has been necessary to understanding potentially diverging emphases in the nature, extent and timing of 'explicit instruction' and 'guidance' needed to support students' discursive engagement with scientific practices (Tytler et al., 2020b).

Despite a perceived bias towards verbal language in Vygotsky's theorizing (Witte, 1992 - in Cazden, 1996, p. 180), contemporary sociocultural pedagogies are increasingly informed by interpretations of mediation as multimodal in nature (Gee, 2004; Prain \& Tytler, 2012; Tang \& Danielsson, 2018). From this perspective, the construction of meaning in science disciplines is conceptualized as a process of semiosis that coordinates the use of language and other systems of visual and symbolic signs (Doran, 2017, 2019; Halliday, 1978). Drawing on Lemke's (2004) contention that different modal representations open up new meanings, Prain and Tytler (2012) argue that the coordination of different modes can constrain students' attention to specific meanings to mediate scientific discovery practices. For example, the mediating strategy of transduction, (Kress, 2010) involves reformulating meanings from one mode to another. This understanding of transduction is closely related to interpretations of scaffolding as the temporary support of external tools in limiting 'degrees of freedom' or 'protecting attentional focus' (Shvarts \& Bakker, 2019), which in broader literacy education, have long informed broader literacy strategies such as providing graphic outlines or diagrams as notetaking guides for reading (Grellet, 1981).

While the role of representation construction and transduction strategies are integral to the semiotic mediation underpinning the MLISP framework, interpretations of the nature of social interaction in Vygotskian views of learning and conceptions of scaffolding have also needed to be negotiated. Vygotsky (1978) proposed a 'zone of proximal development' conceived as 


\section{Researching multimodal literacy}

the learning that 'awakens a variety of internal developmental processes that are able to operate only when the child is interacting with people in his environment and in cooperation with his peers'. The metaphor of scaffolding, in addition to its conception as an external semiotic tool in transduction activity, is also used widely to interpret the nature of adult guidance offered to learners in these interactions. Some interpretations of scaffolding emphasize the support of peers in communities of practice (Lave \& Wenger, 1991), with the adult as facilitator. Other interpretations promote the role and expertise of the teacher, who initially takes the lead in performing aspects of the task that the child cannot do (Shvarts \& Bakker, 2019). At extremes of the horizontal continuum shown in Figure 5.1, these might be represented as a focus on the teacher as 'guide on the side' or as 'sage on the stage'.

The second aspect of scaffolding that requires negotiation relates to the literate dimension that is the focus of the support offered by the teacher in teaching activity called modelling. Modelling has been interpreted as support for the gradual internalization of routines and procedures available to the learner (Applebee, 1984), which in the context of writing may involve making visible what writers $d o$ when they write for specific purposes. This interpretation contrasts with modelling interpreted as explicit instruction of and about the semiotic resources used to create texts and representations. At extremes, these may be contrasted as a focus on literacy as process or a focus on literacy as product, however, divergent interpretations are not always evident in glosses such as 'literate practice'.

The significance of diverging interpretations of sociocultural theories to pedagogic design has been well documented in the research literature (Cazden, 1996; Prain \& Hand, 2019; Shvarts \& Bakker, 2019). Situated pedagogic applications have foregrounded peer interaction in literacy activity, with the teacher as the facilitator of learning and instruction as occurring 'in situ' (Hand et al., 2010). Models informed by systemic functional linguistics have followed Painter (1986) in interpreting scaffolding as the 'anticipatory' or 'expert guidance' by the teacher in interactions with learners and stressed the 'visibility' of semiotic features of texts (Rose \& Martin, 2012). Models within this tradition have also been influenced by prominent educational theorist, Lisa Delpit, who argues that students from backgrounds outside the 'culture of power' need to be 'allowed the resource of the teacher's expert knowledge, while being helped to acknowledge their own "expertness" (Delpit, 1988, p. 296). Models that are foundational to the MSLIP framework recognize the contribution of teacher and student expertise to building knowledge, inherent in metaphors of apprenticeship. Nevertheless, as we will discuss in subsequent chapters of this volume, emphases of some literate dimensions in foundational models and their applications have tended to elide crucial aspects of these roles. We recognize that recontextualizing theories of learning as pedagogic practice is a complex design process and pedagogic models must be assessed in terms of their contribution to encouraging the production, rather than reproduction of knowledge (Hasan, 1996) and above all to supporting equitable achievement of all learners in senior school science. 


\subsection{Advancing transdisciplinary research in infused multimodal disciplinary literacies}

Understandings of theory and research related to the centrality of multimodality in science and the contexts and mediation of science learning are critical for articulating and addressing the semiotic challenges of scientific literacies (Bezemer \& Kress, 2008; Lemke, 2004; Unsworth, 2001). Social semiotic analysis, social justice motivations and sociocultural theories of learning provide a rationale for the infusion of MDL within senior high school biology, chemistry and physics and a foundation for the transdisciplinary research which informs this volume. This research responds above all to findings that the verbal, visual, mathematical and symbolic discourse of school science is quite remote from everyday discourse and that multimodal literate practice has significant implications for equity (O'Halloran, 2003; O'Halloran \& Lim, 2014; Unsworth, 1999a, 1999b, 2000).

While descriptions of multimodal disciplinary literacies in science are still in the initial stages of development (but see Doran, 2019, Martin et al., in press; Unsworth, 2020), those informed by systemic functional linguistics provide significant resources for visibility in instruction and assessment. Applying these descriptions effectively to create a classroom metalanguage for senior biology, chemistry and physics, however, depends upon sharing understandings of ways of talking in science, social semiotics and literacy education. This calls for greater attention in teacher education to the expertise required across intersecting fields of science education and multimodal semiotics. Just as critical analysis of foundational principles of researchers' disciplinary methods and approaches opens space for shared concerns and potential chasms to be revealed, so too a metalanguage must enable dialogue about the role of the teacher in orchestrating practical activity with literacy support to make apparent and enlist student commitment to the purposes of literacy refinement. Building such a metalanguage depends on 'elbow to elbow' collaboration with teachers as they shape activities to challenge, support and refine students' language practices.

\subsection{Outline of volume}

In Chapter 1 of the volume, we have provided an orientation to the research that has informed understandings of MDL in science and science learning and reviewed motivations and research perspectives for infusing literacy and multimodal literacy within senior high school science pedagogy.

Chapters 2-5 elaborate the theoretical and socio-political contexts for integrating MDL in senior science subjects as a prelude to an MLISP framework proposed in Chapter 6 for infusing MDL development throughout all phases of science teaching and learning sequences. In Chapter 2, we discuss the implications for pedagogy, and for the characterization of science disciplinary literacy, of attending to the semiotic practices by which scientific knowledge is created, involving series of representational inventions 


\section{Researching multimodal literacy}

and passes that transfer material substances into textual forms (Gooding, 2006; Latour, 1999). Chapter 3 provides foundational descriptions of key semiotic resources which distinguish multimodal discourses of these disciplines and open an argument for the development of a metalanguage that can be shared between students and teachers to support the development of these distinctive disciplinary literacies. Chapter 4 articulates the particular contextual challenges presented for students and teachers in the high stakes assessment environment of senior secondary biology, chemistry and physics, including challenges for researching disciplinary literacies at these levels and challenges of supporting culturally and linguistically diverse students who have had limited experience and schooling in the interpretation and production of multimodal textual forms. In Chapter 5, we elaborate on pedagogic approaches designed to support student development of literacies in science, drawing attention to areas of actual and potential consensus amongst situated approaches of guided inquiry and guided practice in science education and genre-based/functional linguistic approaches.

Informed by the extensive theoretical and pedagogic research articulated in Chapters 1-5, Chapter 6 progressively builds a framework for MLISP, drawing on our previous chapters to highlight commonalities amongst the different research perspectives and the bases on which we believe divergences might be reconciled. The framework, which includes strategies and discursive moves for incorporating multimodal representation as core to their pedagogic strategy, seeks to facilitate the apprenticing of students into the epistemology of science, as well as acknowledging and addressing the complexity of the senior high school curriculum and contextual challenges.

Chapters 7 through 9 illustrate and extend upon the ways in which various aspects of the MDL framework link to and inform a variety of literacy strategies developed by classroom teachers working with researchers in year 11 and 12 classrooms in biology, chemistry and physics. The chapters detail the planning, implementation and outcomes of the teaching/learning experiences over sequences of sessions dealing with specific topics in each of the three subject areas. The description, analysis and discussion of the interventions show how the framework informs and provides pedagogic options rather than prescriptions for the conduct of classroom and laboratory work. Examples of student work indicate the efficacy, challenges and potential of further research and professional development deriving from the framework.

Chapters 10 through 12 discuss, respectively, (a) the impact on teacher professional learning of their engagement in the design-based research throughout the three years of the project that informed the development of this book; (b) the nature of the engagement of the students in science learning specifically in relation to their experience of multimodal disciplinary development as fully integrated into their classroom work in biology, chemistry and physics; and (c) the significance of the transdisciplinary approach demonstrated in this book for further research and development of MDL in relation to issues such as the rapidly changing nature of the multimodal and digital representations in science that students need to both interpret and 
create, including infographic texts with visualizations as the rhetorical locus, science animations and immersive virtual reality. From this perspective, we conclude the book by envisioning the possibilities and potential of extending and maintaining a collaborative transdisciplinary research-based teaching culture to sustain a future-oriented MDL infused science pedagogy.

\section{References}

Airey, J., \& Linder, C. (2009). A disciplinary discourse perspective on university science learning: Achieving fluency in a critical constellation of modes. Journal of Research in Science Teaching, 46(1), 27-49. https://doi.org/10.1002/tea.20265

Ainsworth, S. (1999). The functions of multiple representations. Computers of Education, 33, 131-152.

Applebee, A. N. (1984). Contexts for learning to write: Studies of secondary school instruction. Norwood, NJ: Ablex.

Archer, L., \& DeWitt, J. (2016). Understanding young people's science aspirations. London: Routledge.

Bazerman, C. (1988). Shaping written knowledge: The genre and activity of the experimental article in science (Vol. 356). Madison: University of Wisconsin Press.

Bernstein, B. (1990). Class, codes and control 4: The structuring of pedagogic discourse. London: Routledge.

Bernstein, B. (2000). Pedagogy, symbolic control and identity: Theory, research, critique. London: Rowman \& Littlefield.

Bezemer, J., \& Kress, G. (2008). Writing in multimodal texts: A social semiotic account of designs for learning. Written Communication, 25(2), 166-195.

Brown, J. S., Collins, A., \& Duguid, P. (1989). Situated cognition and the culture of learning. Educational Researcher, 18(1), 32-42.

Bruner, J. (1986). Actual minds, possible worlds. Cambridge: Harvard University Press.

Cazden, C. (1996). Selective traditions: Readings of Vygotsky in writing pedagogy. In D. Hicks (Ed.), Discourse, learning and schooling (pp. 165-186). Cambridge: Cambridge University Press.

Christie, F., \& Derewianka, B. (2008). School discourse Learning to write across the years of schooling. London: Continuum.

Danielsson, K., \& Selander, S. (2016). Reading multimodal texts for learning. A model for cultivating multimodal literacy. Designs for Learning, 8, 25-36.

Delpit, L. (1988). The silenced dialogue: Power and pedagogy in educating other people's children. Harvard Educational Review, 58(3), 280-299. https://doi. org/10.17763/haer.58.3.c43481778r528qw4

de Oliveira, L. C., \& Lan, S.-W. (2014). Writing science in an upper elementary classroom: A genre-based approach to teaching English language learners. Journal of Second Language Writing, 25, 23-39.

Doran, Y. J. (2017). The discourse of physics: Building knowledge through language, mathematics and image. London: Routledge.

Doran, Y. (2019). Building knowledge through images in physics. Visual Communication, 18(2), 251-277.

Doran, Y. J., \& Martin, J. R. (2021). Field relations: Understanding scientific explanations. In K. Maton, J. R. Martin, \& Y. J. Doran (Eds.), Teaching science: Knowledge, language, pedagogy (pp. 105-133). London: Routledge. 


\section{Researching multimodal literacy}

Dreyfus, S. J., Humphrey, S., Mahboob, A., \& Martin, J. R. (2016). Joint construction in the SLATE project. In Genre pedagogy in higher education (pp. 240-262). London: Palgrave Macmillan.

Driver, R. (1989). The construction of scientific knowledge in school classrooms. In R. Millar (Ed.), Doing science: Images of science in science education (pp. 83-106). London: Falmer Press.

Faller, E. (2017). Reading and writing as scientists? Text genres and literacy practices in girls' middle-grade science. Journal of Adolescent \& Adult Literacy, 61, 5. https://doi.org/10.1002/jaal.698

Fang, Z. (2010). Language and literacy in inquiry-based science classrooms, grades 3-8. Thousand Oaks, CA: Corwin.

Fang, Z., \& Schleppegrell, M. (2010). Disciplinary literacies across content areas: Supporting secondary reading through functional language analysis. Journal of Adolescent and Adult Literacy, 53(7), 587-597.

Forey, G., \& Cheung, L. M. E. (2019). The benefits of explicit teaching of language for curriculum learning in the physical education classroom. English for Specific Purposes, 54, 91-109.

Forman, E. A. (2018). The practice turn in learning theory and science education. In D. Kritt (Eds.), Constructivist education in an age of accountability. Cham, Switzerland: Palgrave Macmillan. https://doi.org/10.1007/978-3-31966050-9_5

Gebhard, M. (2019). Teaching and researching ELLs' disciplinary literacies systemic functional linguistics in action in the context of U.S. school reform. London: Routledge.

Ge, Y.-P., Chung, C.-H., Wang, K.-H., Chang, H.-P., \& Unsworth, L. (2014). Comparing the images in Taiwanese and Australian science textbooks by grammar of visual design: An Example of biological classification. Chinese Journal of Science Education, 22(2), 109-134.

Gee, J. P. (2004). Language in the science classroom: Academic social languages as the heart of school-based literacy. In E. W. Saul (Ed.), Crossing borders in literacy and science instruction perspectives in theory and practice (pp. 13-32). Newark, DE: International Reading Association/National Science Teachers Association.

Gee, J. P. (2011). An introduction to discourse analysis: theory and method (3rd ed.). New York: Routledge.

Gibson, J. J. (1977). The theory of affordances. In R. Shaw \& J. Bransford (Eds.), Perceiving, acting and knowing (pp. 67-82). Hillsdale, NJ: Lawrence Erlbaum Associates.

Gooding, D. (2006). From phenomenology to field theory: Faraday's visual reasoning. Perspectives on Science, 14(1), 40-65.

Grellet, F. (1981). Developing reading skills: A practical guide to reading comprehension exercises (lst ed.). Cambridge: Cambridge University Press.

Gross, A., Harman, J., \& Reidy, M. (2002). Communicating science: The scientific article from the 17th century to the present. Oxford and New York: Oxford University Press.

Halliday, M. A. K. (1978). Language as social semiotic: The social interpretation of language and meaning. London: Arnold.

Halliday, M. A. K. (1998). Things and relations. In J. R. Martin \& R. Veel (Eds.), Reading science: Critical and functional perspectives on discourses of science (pp. 185-235). London and New York: Routledge. 
Halliday, M. A. K. (2004). The language of science. In J. J. Webster (Ed.), The collected works of M.A.K. Halliday, volume 5. London: Continuum.

Halliday, M. A. K., \& Martin, J. R. (Eds.). (1993). Writing science: Literacy and discursive power. London: Falmer Press.

Hand, B., Yore, L., Jagger, S., \& Prain, V. (2010). Connecting research in science literacy and classroom practice: A review of science teaching journals in Australia, the UK and the United States, 1998-2008. Studies in Science Education, 46(1), March, 45-68.

Hao, J. (2020). Analysing scientific discourse from a systemic functional linguistic perspective: A framework for exploring knowledge building in biology. London: Routledge.

Hao, J., \& Hood, S. (2017). Valuing science: The role of language and body language in a health science lecture. Journal of Pragmatics. https://doi.org/10.1016/j. pragma.2017.12.001

Hao, J., \& Humphrey, S. (2019). Reading Nominalisations in Senior Science. Journal of English for Academic Purposes special edition on Halliday, 42, 100793.

Hasan, R. (1996). Literacy, everyday talk and society. In R. Hasan \& G. Williams (Eds.), Literacy in society (pp. 377-424). London: Longman.

He, Q., \& Forey, G. (2018). Meaning-making in a secondary science classroom: A systemic functional multimodal discourse analysis. In K.-S. Tang \& K. Danielsson (Eds.), Global developments in literacy research for science education (pp. 183-202). New York: Springer.

He, Y., \& van Leeuwen, T. (2019). Animation and the remediation of school physics-a social semiotic approach. Social Semiotics, 30, 1-20.

Heyvaert, L. (2003). Nominalization as grammatical metaphor: On the need for a radically systemic and metafunctional approach. In A.-M. Simon-Vandenbergen, M. Taverniers, \& L. Ravelli (Eds.), Grammatical metaphor: Views from systemic functional linguistics (pp. 65-100). Amsterdam \& Philadelphia: Benjamins.

Jakobson, B., Danielsson, K., Axelsson, M., \& Uddling, J. (2018). Measuring time. Multilingual elementary school students' meaning-making in physics. In K. S. Tang \& K. Danielsson (Eds.), Global developments in literacy research for science education (pp. 167-182). Cham, Switzerland: Springer.

Johnstone, B., \& Eisenhart, C. (2008). Rhetoric in detail: Discourse analyses of rhetorical talk and text. Amsterdam/Philadelphia: John Benjamins.

Jones, P., Turney, A., Georgiou, H., \& Nielsen, W. (2020). Assessing multimodal literacies in science: Semiotic and practical insights from pre-service teacher education, Language and Education, 34(2), 153-172. https://doi.org/10.1080/ 09500782.2020 .1720227

Knain, E. (2015). Scientific literacy for participation: A systemic functional approach to analysis of school science discourses. New York: Springer.

Kress, G. (2010). Multimodality. A social semiotic approach to contemporary communication. London: Routledge.

Kress, G., \& Ogborn, J. (1998). Modes of representation and local epistemologies: The presentation of science in education. SISC Working Papers, 2, 2-22.

Kress, G., \& van Leeuwen, T. (2006). Reading images: The grammar of visual design (2nd ed.). London/New York: Routledge.

Latour, B. (1999). Pandora's hope: Essays on the reality of science studies. Cambridge, MA: Harvard University Press.

Latour, B., \& Woolgar, S. (2013). Laboratory life: The construction of scientific facts. Princeton, NJ 08540 United States: Princeton University Press. 


\section{Researching multimodal literacy}

Lave, J., \& Wenger, E. (1991). Situated learning: Legitimate peripheral participation. Cambridge, New York: Cambridge University Press.

Lemke, J. (1990). Talking science: Language, learning and values. Norwood, NJ: Ablex.

Lemke, J. (1998). Multiplying meaning: Visual and verbal semiotics in scientific text. In J. R. Martin \& R. Veel (Eds.), Reading Science: Critical and functional perspectives on discourses of science (pp. 87-113). London: Routledge.

Lemke, J. (2004). The literacies of science. In E. W. Saul (Ed.), Crossing borders in literacy and science instruction: Perspectives on theory and practice (pp. 33-47). Newark, DE: International Reading Association.

Luke, A (1996). Genres of power? Literacy education and the production of capital. In R. Hasan \& G. Williams (Eds.), Literacy in Society (pp. 302-338). London: Longman.

Martin, J. (1985). Factual writing: Exploring and challenging social reality. Geelong, Victoria: Deakin University Press.

Martin, J. R. M. (1999). Mentoring semogenesis: 'Genre-based' literacy pedagogy. In F. Christie (Ed.), Pedagogy and the shaping of consciousness: Linguistic and social processes (pp. 123-155). London: Cassell (Open Linguistics Series).

Martin, J. R., \& Rose, D. (2008). Genre relations: Mapping culture. London: Equinox Pub.

Martin, J. R., Unsworth, L., \& Rose, D. (in press). Condensing meaning: Imagic aggregations in secondary school science. In G. Parodi (Ed.), Multimodality: From corpus to cognition. London: Bloomsbury.

Maton, K. (2013). Knowledge and knowers: Towards a realist sociology of education. London: Routledge.

Maton, K., Martin J. R., \& Doran Y. J. (Eds.). (2020). Studying science: Knowledge, language, pedagogy. London: Routledge.

Mody, C. C. M. (2015). Scientific practice and science education. Science Education, 99(6), 1026-1032. https://doi.org/10.1002/sce.21190

Moje, E. B. (2015). Doing and teaching disciplinary literacy with adolescent learners: A social and cultural enterprise. Harvard Educational Review, 85(Summer 2015), 2; ProQuest pg. 254.

Moje, E. B. (2007). Chapter 1 Developing socially just subject-matter instruction: A review of the literature on disciplinary literacy teaching. Review of Research in Education, 31(1), 1-44.

Mortimer, E., \& Scott, P. (2003). Meaning making in secondary science classrooms. UK: McGraw-Hill Education.

Norris, S. P., \& Phillips, L. M. (2003). How literacy in its fundamental sense is central to scientific literacy. Science Education, 87(2), 224-240.

Nunes, T., Bryant, P. Strand, S. Hillier, J., Barros R., \& Miller-Friedmann, J. (2017). Review of SES and science learning in formaleducational settings a reportprepared for the EEF and the royal society. University of Oxford /Education Endowment Foundation. https://www.gov.uk/government/publications/research-review-series-science/ research-review-series-science

O'Halloran, K. (2003). Intersemiosis in mathematics and science: Grammatical metaphor and semiotic metaphor. In A.-M. Simon-Vandenbergen, M. Taverniers, \& L. Ravelli (Eds.), Grammatical Metaphor (pp. 337-366). Amsterdam/Philadelphia: John Benjamins.

O'Halloran, K., \& Lim, V. (2014). Systemic functional multimodal discourse analysis. In S. Norris, \& C. Maier (Eds.), Texts, images and interactions: A reader in multimodality (pp. 137-154). Berlin: Mouton de Gruyter. 
Painter, C. (1986). Writing to mean: Teaching genres across the curriculum. Applied Linguistics Association of Australia (Occasional Papers), 9, 62-97.

Palinscar, A. M., \& Brown, A. (1984). Reciprocal teaching of comprehensionfostering and monitoring activities. Cognition and Instruction, 1(2), 117-175. https://doi.org/10.1207/s1532690xci0102_1

Park, W., \& Song, J. (2019). Between realism and constructivism: A sketch of pluralism for science education. In E. Herring, K. Jones, K. Kiprijanov, \& L. Sellers (Eds.), The past, present, and future of integrated history and philosophy of science (pp. 228-247). New York: Routledge.

Patron, E., Wikman, S., Edfors, I., Johansson-Cederblad, B., \& Linder, C. (2017). Teachers' reasoning: Classroom visual representational practices in the context of introductory chemical bonding. Science Education, 101, 887-906. https://doi. org/10.1002/sce. 21298

Prain, V., \& Hand, B. (Eds.). (2019). Theorizing the future of science education research, contemporary trends and issues in science education 49, Springer Nature Switzerland. https://doi.org/10.1007/978-3-030-24013-4_2

Prain, V., \& Hand, B. (2016). Learning science through learning to use its languages. In B. Hand, M. McDermott, \& V. Prain (Eds.), Using multimodal representations to support learning in the science classroom (pp. 1-10). Cham Heidelberg New York Dordrecht London: Springer.

Prain, V., \& Tytler, R. (2012). Learning through constructing representations in science: A framework of representational construction affordances. International Journal of Science Education, 34(17), 2751-2773.

Rose, D., \& Martin, J. R. (2012). Learning to write, reading to learn: Genre, knowledge and pedagogy in the Sydney school. Sheffield: Equinox.

Schleppegrell, M. J. (2004). The language of schooling: A functional linguistics perspective. Mahwah, NJ: Erlbaum.

Shanahan, T., \& Shanahan, C. (2008). Teaching disciplinary literacy to adolescents: Rethinking content-area literacy. Harvard Educational Review, 78(1), 40-59.

Shvarts, A., \& Bakker, A. (2019). The early history of the scaffolding metaphor: Bernstein, Luria, Vygotsky, and before. Mind, Culture, and Activity, 26(1), 4-23. https://doi.org/10.1080/10749039.2019.1574306

Tang, K.-S. (2015). Reconceptualising science education practices from new literacies research. Science Education International, 26(3), 307-324.

Tang, K.-S. (2019). Scientific practices as an actor-network of literacy events: Forging a convergence between disciplinary literacy and scientific practices. In V. Prain \& B. Hand (Eds.), Theorizing the future of science education research (pp. 83-98). Springer.

Tang, K.-S., \& Danielsson, K. (Eds.). (2018). Global developments in literacy research for science education (pp. 1-11). Cham, Switzerland: Springer.

Tang, K.-S., \& Putra, G. B. S. (2018). Infusing literacy into an inquiry instructional model to support students' construction of scientific explanations. In K. S. Tang \& K. Danielsson (Eds.), Global developments in literacy research for science education (pp. 281-300). Rotterdam, The Netherlands: Springer.

Tang, K.-S., Won, M., Mocerino, M., Treagust, D., \& Tasker, R. (2020). Multimodal affordances of immersive virtual reality for visualising and learning molecular interactions. In L. Unsworth (Ed.), Learning from viewing and creating animations in science education: Innovative developments in semiotic and educational research (pp. 75-102). Cham, Switzerland: Springer.

Tytler, R. (2007). Re-imagining science education engaging students in science for Australia's future. Camberwell, Victoria: Australian Council for Educational Research. 


\section{0}

Tytler, R., \& Hubber, P. (2010). A representation-intensive signature pedagogy for school science. Paper presented at the Australian Association for Research in Education, Melbourne.

Tytler, R., Ferguson, J., \& White, P. (2020a). A representation construction pedagogy of guided inquiry for learning data modelling. Learning: Research and Practice, 6(1), 5-18.

Tytler, R., Ferguson, J., \& White, P. (2020b). Constructivist and sociocultural theories of learning. In V. Dawson, G. Venville, J. Donovan (Eds.), The Art of Teaching Science (pp. 35-49). New York: Routledge.

Unsworth, L. (1999a). Explaining school science in book and CD ROM formats: Using semiotic analyses to compare the textual construction of knowledge. International Journal of Instructional Media, 26(2), 159-179.

Unsworth, L. (1999b). Teaching about explanations: Talking out the grammar of written language. In A. Watson \& L. Giorcelli (Eds.), Accepting the literacy challenge (pp. 189-204). Sydney: Scholastic.

Unsworth, L. (2000). Investigating subject-specific literacies in school learning. In L. Unsworth (Ed.), Researching language in schools and communities: Functional linguistic perspectives (pp. 245-274). London: Cassell.

Unsworth, L. (2001). Teaching multiliteracies across the curriculum: Changing contexts of text and image in classroom practice. Buckingham, UK: Open University Press.

Unsworth, L. (Ed.).(2020). Learning from animations in science education: Innovating in semiotic and educational research. Cham, Switzerland: Springer.

Wallace, C. S., Hand, B. B., \& Prain, V. (2004). Writing and learning in the science classroom (Vol. 23). Springer Science \& Business Media Dordrecht, Netherlands: Kluwer Academic Publishers, http://www.loc.gov/catdir/enhancements/fy0821/2004042130-t.html

Wise, N. (2006). Making visible. Isis, 97(1), March, 75-82.

Veel, R. (1997). Learning how to mean - scientifically speaking: Apprenticeship into scientific discourse in the secondary school. In F. Christie \& J. R. Martin (Eds.), Genre and Institutions: Social processes in the workplace and school (pp. 161-195). (Open Linguistics Series) London: Pinter.

Vygotsky, L. (1978). Mind in society. Cambridge, MA: Harvard University Press.

Yore, L. D. (2018). Commentary on the expanding development of literacy research in science education. In Global Developments in Literacy Research for Science Education (pp. 379-397). Cham, Switzerland: Springer. 


\section{Language, image and multimodal mediation in scientific research and science learning}

In this chapter, we argue a case that learning in science can be productively viewed as a process of induction into scientific discursive practices and that on this basis, science classroom discourse needs to reflect the multimodal disciplinary literacies through which scientific knowledge is built. We explore literature identifying the semiotic basis on which scientific knowledge is built and the implications for a classroom practice that involves students in the creation and interpretation of scientific texts. In this exploration, we draw on social semiotic principles developed in the traditions of multimodal language-related research in science education and in linguistic traditions, particularly systemic functional linguistics.

\subsection{Multimodality in science reasoning and knowledge building}

In Chapter 1, we argued that multimodal representational work is central to science. A growing body of research confirms this centrality in both the reasoning and knowledge building of the scientific community. More than three decades ago, Latour (1986) argued that the emergence of scientific thought was shaped by the development and negotiation of 'inscriptions': representational tools that could be combined, manipulated, transposed into figures or interpreted in writing and reproduced to be disseminated and conscripted in ongoing knowledge building. In Laboratory Life, Latour and Woolgar (1979) focussed on the role of scientific instruments as 'inscription devices' with the purpose of transforming material substance into transportable and malleable figures that can be systematically organized to produce literacy products in the form of scientific papers. Latour (1999) argues that the generation of scientific knowledge must be understood through the transformation of material substances and processes into theory through a series of 'representational passes'. As illustrative of this process, he studied the process by which scientists working on soil profiles at the rainforest-savanna boundary in the Amazonian basis converted their raw data into scientific papers. The process involved a series of representational re-descriptions, starting with their ordering of soil samples into ordered box compartments, then creating a coloured chart and numbering system, thence to a table that was the transportable inscriptional form they took back to their Parisian

DOI: $10.4324 / 9781003150718-2$ 
laboratory to generate a scientific paper. This multimodal, representational re-description process, through which data is generated, negotiated, refined and justified in a process of theory construction, is a core feature of scientific knowledge building.

Gooding (2004) described, consistent with Latour's analysis, the central role of representational improvisation, translation and refinement in scientific discovery processes. For instance, in his analysis of Michael Faraday's notebooks describing his investigations of the interactions of electricity and magnetism, he describes the scientist's successive inventions of magnetic field representations as plausible explanations for the patterns he observed. Gooding's analysis of Faraday's and other scientific discovery work revealed a recurring pattern of visual reasoning and dimensional enhancement and reduction. In Faraday's work, this involved chains of diagrams involving the reduction of complex observations in real time to abstracted 3D images and then adding a temporal dimension to imagine a time-sequence process within which the $3 \mathrm{D}$ abstracted pattern becomes one temporal instant before reduction to an abstracted 2D pattern (see Prain \& Tytler, 2013). Gooding (2006) showed the inventive nature of Faraday's diagrams and also $3 \mathrm{D}$ models he constructed which acted as dual-material/theoretical models.

Gooding (2006) argued that these material, symbolic and digital representations, rather than acting as passive records of abstracted and resolved ideas and theories, are critically important tools for reasoning in science. Klein $(2001$, p. ix) similarly argues, through a study of the historical development of chemical formulae in the early 1800s, that the symbolic manipulations associated with representational work and refinement are distinct from observable phenomena, and "actively contribute to meaning" (p. ix) rather than simply communicate already resolved ideas. Further, in this process of inventing and transforming representations, scientists reason through informal processes, such as metaphoric association or visual and spatial pattern recognition, possibly more so than the formal logic traditionally associated with scientific processes (Gooding, 2006; Klein, 2006).

Contemporary studies of science teams and laboratory practices (Nersessian, 2008, 2010) similarly show how models are constructed through complex cycles of data generation, representation and re-representation to develop explanations and theories. Pickering (1995) describes a 'mangle of practice' in which scientific knowledge is built in an emergent 'dance of agency' between the material and theoretical. In this process, models that are visual, embodied, material and metaphoric are coordinated (p. 23) and adapted to develop explanations of material nature, which itself must be manipulated alongside these models to arrive at an emergent and justifiable resolution.

These accounts indicate the complex and dynamic processes through which scientists invent models as representational systems to explain phenomena. These processes involve the imaginative construction and manipulation/ transformation of representations across modes which can be material, visual, textual or symbolic. Increasingly, in contemporary scientific work, these 
representations are digital in nature, including, for instance, false colour and composite microwave images of large-scale astronomical objects, abstracted representations of large data arrays, including 3D-coloured graphical nets, combined graphical and false colour synchrotron images of chemical maps (Prain \& Tytler, 2012 p. 7). Elkins (2011, p. 149) argues the increasing role of visual representations in knowledge generation and communication within most fields, characterizing fields such as biochemistry and astronomy as 'image obsessed'. Further, as argued previously, this process of knowledge building through visualization and model generation involves perceptual and metaphorical reasoning that moves beyond formal logic. The implications of these changing perspectives on scientific discovery processes for how we conceive of a school science education is the question we take up in the next section.

\subsubsection{School learning as induction into science literacy practices}

Sociocultural theorists for some time have argued the situated nature of cognition (Brown, Collins \& Duguid, 1989) in which knowledge is viewed as fundamentally situated as part of the activity, context and culture in which it is developed. This can be true not only of applied learning in informal settings, or apprenticeship in trades, but also in disciplinary communities and in schools. Brown, Collins and Duguid (1989) propose a model for teaching and learning in schools as a process of 'cognitive apprenticeship' that attempts to overcome the restrictions on meaningful learning imposed by the culture of schools and classrooms. Building on these notions, Lave and Wenger (1991) proposed a view of 'situated learning' as a process of legitimate peripheral participation in a community of practice. For learning science, this would involve students being guided to move from a position of peripheral involvement in scientific discursive practices in a topic to increasing participation and eventual mastery of these practices. The discursive practices of science, in this sense, would include accepted language forms (technical terms and grammar), investigative practices, written text genres such as reports and the use of evidence in constructing and justifying explanations. In this view, the science classroom becomes a community of practice (Lave \& Wenger, 2002; Wenger, McDermott \& Snyder, 2002; Wenger, 2011 ) in which the teacher guides students to increasingly develop competence in a way that has also been characterized as an apprenticeship process (Rogoff, 2008). Disciplinary learning in schools, from this perspective, can be productively viewed as a process of induction into disciplinary discursive practices. This does not imply that students will duplicate in all respects the practices of science. Bernstein (1996), writing from a sociology of education perspective, described how discipline-specific knowledge is converted to educational knowledge in a 'recontextualization' process through which curricula and teaching resources are created (see also Chapter 1). However, while the focus on the discursive practices of science must accommodate the realities of schooling and the curriculum, the resources students bring to 


\section{Language, image and multimodal mediation}

their learning and the need to progressively develop students' disciplinary literacy competence, we argue, alongside the researchers described above, that classroom practices must necessarily reflect the ways that knowledge and practices are built in the discipline.

The critique of traditional school culture as potentially restrictive for meaningful learning implied by Brown, Collins and Duguid (1989) relates to its pursuit of knowledge in science that lacks alignment with the situated knowledge and practices represented in the scientific world outside the classroom. Responding to this critique, the analyses of contemporary views of scientific knowledge building as fundamentally constituted by multimodal discursive practices becomes of central importance for framing advice to teachers and school systems about the organization of learning in classrooms. During the early 2000s, there was an increasing interest in scientific literacy (Bybee, 1997; Goodrum, Hackling \& Rennie, 2001) which concerned a perspective that school science should prepare all students for a productive engagement with science ideas in their adult lives. Norris and Phillips (2003), in an influential paper, linked the achievement of such a literacy with the development of a fundamental literacy, thus aligning the concerns of science educators with those of linguists and literacy specialists with disciplinary interests. The 'writing to learn' project (Prain, 2006; Wallace, Hand \& Prain, 2004) aligned with these views, and this soon transformed into a recognition of and concern for multimodal literacies (Prain \& Waldrip, 2006; Prain, Tytler \& Peterson, 2009; Tytler, Prain \& Peterson, 2007).

\subsubsection{Disciplinary literacy as multimodal}

Norris and Phillips (2003) argue that rather than focussing exclusively on declarative aspects of scientific knowledge, supporting real understanding of science must involve supporting students to become literate in the sense of being able to interpret, evaluate and represent scientific claims. Achieving disciplinary literacy in science thus involves an apprenticeship in discursive practices for thinking, acting and representing scientific claims. These literacy practices are distinctive to science (Gee, 2004; Linder, Östman \& Wickman, 2007; Moje, 2007; Shanahan \& Shanahan, 2008) and inherently multimodal. Duschl (2008) argues that they should involve not only the ability to interpret and generate science text that communicates findings but should also involve a degree of meaningful immersion in the epistemic process of science knowledge building, including investigative processes and their rationale. These disciplinary literacy practices should also involve an understanding of the rationale for this disciplinary enterprise (Hurd, 1998).

Recognition of the multimodal nature of scientific disciplinary literacy and classroom teaching and learning practices has triggered increased interest in the processes of semiosis that underpin the construction of meaning in classrooms and for individuals. We adopt the perspective of applied linguists and semioticians who describe the construction of meaning through 
a process of semiosis that coordinates the use of language and other systems of visual and symbolic signs (Halliday, 1978; Halliday \& Matthiessen, 1999; Kress, 2003; Kress, Jewitt, Ogborn \& Tsatsarelis, 2001; Ogborn, Kress, Martins \& McGillicuddy, 1996; Peirce, 2010). The social semiotics of Peirce (1931-1959) has informed the construction and interpretation of classroom practices that focus on multimodal representational processes (Tytler, Prain, Hubber \& Waldrip, 2013). We consider disciplines as having developed particular forms of semiosis that reflect complex cultural and historical traditions of problem-solving (Lemke, 1990, 2004). In translating disciplinary knowledge and practice into classroom contexts, these semiotic traditions are key to framing content and pedagogy (Prain \& Tytler, 2012). Lemke's (1990) treatment of the key mediating role of talk in learning science opened up important new directions in the analysis of the role of language generally in science learning and the complex multimodal interpretation required of students in classroom learning of science. Chemistry educators customarily draw on Johnstone's triangle describing the way chemical understandings and practices require the translation across and coordination of macro, sub-micro and symbolic representational systems (Talanquer, 2011). Airey and Linder (2009) argue that fluency in a 'critical constellation' of representational modes, including spoken and written language, mathematics, images and gesture and tools and activities, is a necessary condition to gaining disciplinary ways of knowing. Kozma and Russell (2005) in their study of expert and novice chemistry problem-solvers point to the fundamental role of representations/visualizations and their coordination, in developing representational competence through which laboratory processes can be understood.

Social semiotic research includes a diverse range of approaches to the analysis of science classroom teaching and learning processes and discursive practices. Systemic functional linguistics (Halliday, 1978; Halliday \& Martin, 1993) and genre-based approaches (Parkison \& Adendorff, 2004) focus on the interpretation and mastery of textual features associated with particular discursive practices. Taxonomic structural analyses of visual language focus on the features of diagrams (Kress, Jewitt, Ogborn \& Tsatsarelis, 2001; Park, Chang, Tang \& Treagust, 2020; Tang, Won \& Treagust, 2019). Sociocultural perspectives on science discourse (Gee, 2004; Moje, 2007) and poststructural multimedia semiotics and discourse analysis (Lemke, 2004) focus on classroom factors that affect students' engagement with and learning of science. Underpinning these approaches is a broadly shared view that learning in science needs to be conceptualized as a process of scaffolding the distinctive multimodal literacies of the discipline (Moje, 2007; Tytler, Prain \& Hubber, 2018; Unsworth, 2001) through which knowledge is created, learnt, justified and communicated in the classroom as in disciplinary practices. This includes support for students to develop competence in a range of specific genres specific to the different sciences, involving processes such as scientific report writing, constructing explanations and engaging in argumentation and constructing data recording and modelling processes. 


\subsubsection{Disciplinary literacy through participation in practice}

A strong strand of research based on this conception of learning as the development of scientific disciplinary literacy takes as its starting point the principle that to achieve such literacy, students need in some sense to participate meaningfully in pedagogical processes that strongly reference those of practising scientists (Ford \& Forman, 2006; Prain \& Tytler, 2012). Researchers in this area include Keys, Hand, Prain and Collins (1999); Moje (2007); Lehrer and Schauble (2006); Duschl (2008); and Tytler, Prain, Hubber and Waldrip (2013). These approaches advocate the configuration of the classroom community such that students engage with authentic knowledge-producing activities that include experimental design, observations, representational invention involving scientific reasoning and claim making. In this process, students 'learn to switch between material, verbal, written, visual, mathematical and 3D modelling modes, including digital form, and coordinate these in generating and justifying scientific explanations' (Tytler, Prain \& Hubber, 2018 , p. 304). In the translation of disciplinary knowledge-building practices into curriculum and classroom settings, the differences in the agency of students compared to scientists need to be acknowledged, alongside the need to accommodate progression in the development of these literacies and the complexity of classroom contexts. Nevertheless, a key concern in this recontextualization is the need to maintain a focus on building students' capabilities to engage with authentic disciplinary explanatory, problemsolving and knowledge-building processes.

How can we characterize these explanatory knowledge-building processes in science and science classrooms? From a pragmatist semiotic perspective (Peirce, 1931-1959), meaning making, or semiosis, proceeds through the construction and coordination of systems of signs or multimodal representations. Pragmatist accounts of understanding recognize the situated and contextual nature of problem-solving and learning (Peirce, 1931-1959, Wittgenstein, 1972) so that understanding a concept or process entails the effects of applying this to practical settings. This perspective emphasizes the use-value of knowledge so that an understanding of animal diversity, for instance, is conceptualized as involving access to and competence in applying representational resources such as classification schemes, drawings and lists of diverse structures, and tallies and distribution descriptions (Tytler, Haslam, Prain \& Hubber, 2009). These perspectives thus emphasize the importance of student participation in explanatory, problem-solving and claim-making practices in developing disciplinary literacy. In supporting students to participate in these practices, we need to acknowledge the different resources that diverse student cohorts bring to the classroom. The provision of structured pathways to learning the literacies underpinning these knowledges and practices must thus include attention to this diversity. This is particularly so for addressing the needs of students outside the 'culture of power' (Delpit, 1988, p. 296) to have the resource of the teacher's expert knowledge. 
Prain and Tytler (2012) in their theory of representation construction affordances (RCA) argue that the multimodal discursive practices through which the scientific community comes to generate knowledge, and through which students in science classrooms achieve understanding, operate through the productive constraints offered by particular representational modes. From a Vygotskian perspective, this implies that the particular modes have distinctive mediating roles and that the mediating role of the teacher crucially involves purposeful task selection around modal affordances, as well as their role in explicit unpacking of intended meaning. Thus, for instance, creating and interpreting line drawings operates to productively constrain attention on specific spatial and visual relations between parts that can be glossed over or unnoticed in gestural or written textual descriptions of phenomena (Ainsworth, Prain \& Tytler, 2011; Tytler, Prain, Aranda, Ferguson \& Gorur, 2020). Prain and Tytler argue for a productive alignment between scientific discovery practices and classroom pedagogical practices on the basis of the commonalities of semiotic (the use of symbolic and material tools), epistemic (knowledge-building practices) and epistemological (meaning making through multimodal discursive practices) processes in both contexts. These authors demonstrate how developing a pedagogy based on students constructing, evaluating and refining representational tools, aligned with scientific discovery practices, can lead to enhanced knowledge not only of the conceptual entities and inquiry processes of science (Hubber, Tytler \& Chittleborough, 2017; Tytler, Prain, Hubber \& Waldrip, 2013) but also metarepresentational competence (diSessa, 2004) developed through explicit attention in the pedagogy to the form and function of representations as explanatory tools. These discussions of the form and function of representations, and explicit attention to their imaginative and communally negotiated nature, are evidenced, for instance, in the creation and negotiation of different representations of the molecular bases of evaporative processes (Prain \& Tytler, 2012) or negotiated refinement of conventions for arrows representing forces in a variety of situations (Hubber, Tytler \& Haslam, 2010). In this latter case, for instance, the teacher guided students towards conventions of force arrows that denote strength, point of application and, through increasingly complex force situations, how forces can act in concert in different ways. In later chapters, we will explore ways in which this 'explicit attention' can be enacted by teachers, in particular contexts, as a form of metalanguage.

This disciplinary literacy approach based on students engaging in multimodal discursive practices (Tytler, Prain \& Hubber, 2018) assumes of teachers that they have a sufficient grasp of the multimodal representational conventions of science to engage with students' representational approximations to move the communal negotiation forward to a productive resolution. In reporting on this process, there has been a tendency for researchers to focus on student learning, but a number of studies have made explicit the pedagogical moves by which teachers can support students' discursive engagement with scientific practices and ideas (Lehrer, Schauble \& Lucas, 2008; 
Lehrer, 2009; Tytler, Ferguson \& White, 2020). Developing and drawing attention to the particular semiotic tools and processes by which teachers can move students towards a resolution of productive representational forms is one aim of the Multiliteracies in Senior School Science (M3S) study.

The RCA theory, while emphasizing the alignment between scientific discovery practices and classroom pedagogical processes, did not assume an exact equivalence. Clearly, the teacher, as a disciplinary expert charged with inducting students into appropriate discursive practices, has no equivalent in professional scientific practice. Articulating the role of the teacher in supporting such induction is key to any programme of supporting disciplinary literacy development. The semiotic mediation process by which learning is supported in a classroom can be interpreted through different readings of Vygotsky (Cazden et al., 1996) in relation to the mediating role of semiotic tools, such as language and image (Halliday \& Martin, 1993; Waldrip, Prain \& Carolan, 2010), and of the teacher as 'expert other' (Painter, 2017), guiding students towards disciplinary literacy competence through multiple processes which have been variously described as 'induction', 'acquisition', 'instruction' and 'development' and 'apprenticeship'. From a Vygotskian (1978) view, the teacher mediates learners' access to disciplinary knowledge through orchestrating multimodal languages and other material meaning-making resources. In relation to equity, we note sociological perspectives that recognize the limits of 'implicit pedagogies' in meeting the needs of students from low socio-economic status backgrounds (Bernstein, 1975). Informed by this review and more recent descriptions, we propose a principled definition of scaffolding, which recognizes that students develop 'deliberate semantics - deliberate structuring of the web of meaning' (Vygotsky, 1986 p.182) involved in multimodal disciplinary literacy processes through social mediation. Such mediation includes macro-level framing of tasks to micro-level guidance of representational refinement (Rose \& Martin, 2012; Tang \& Danielsson, 2018), which requires interaction with 'expert others'. While Vygotsky almost certainly viewed this mediation as occurring through verbal and written language, contemporary perspectives on disciplinary literacy include a wide range of multimodal and material resources in this process of semiosis managed by the teacher. Further, recent research (Martin \& Maton, 2013) has shown how dialogue patterns underpinning this process of semiotic mediation differ across subjects and year levels.

It is clear that language demands in the sciences increase markedly in the senior years, in terms of the sophistication of textual structures, in terminology, in the density and detail in diagrams and in the coordination of text and image. This implies changing demands on the semiotic mediation process, with teachers needing to articulate for students a set of discursive practices and language resources that are further removed from everyday experience than is the case for the primary and lower secondary years. This raises the further question of how the process of students learning science by engaging in scientific investigative, representation construction and modelling practices might look in the senior years' environment where language demands and 
discursive practices become much more complex, specific and counterintuitive, and the curriculum becomes more structured and condensed around the demands of high-stakes external assessment. What demands does this place on semiotic mediation processes, in an environment where teachers need to support the development of more complex and technical multimodal literacies? Further, what are the implications of this increasing literacy complexity for semiotic mediation for students with particular needs.

These questions imply a need to focus more sharply on the nature of these multimodal literacies in ways that can support teachers to respond to these increasing literacy demands. Here, we turn again to the literacy research tradition represented by systemic functional linguistics scholars (Halliday \& Martin, 1993) who take as their starting point the functional purposes of language in use and genre-based literacy traditions which focus on the particular structures of text, including multimodal text, for different communicative purposes. This approach, based in systemic functional linguistics (SFL), emphasizes the need for students to engage with the features of multimodal scientific text and has foregrounded the analysis of multimodal semiotic resources as a way to clarify these for teachers and students to be able to enact these in their own productions.

There is no fundamental contradiction between these two literacy traditions. The first, representation construction approach, while not focussing on an explicit analysis of multimodal textual structures, does involve teachers in expert guidance of student literacy practices. The second approach focusses explicitly on textual structures and tends to pay less attention than the first to scientific discovery practices, placing more attention on the teacher as expert other, compared to the greater focus on student activity and agency in the guided inquiry approach. The M3S project has taken as its point of departure the fundamental insights represented by these two traditions, and in particular how the two traditions might productively speak to each other in the particular context of senior school science. The M3S team consists of researchers from both these traditions, and part of the power of the project, and the position of this book, entails the bringing together of these perspectives to work with teachers to develop a pedagogy that infuses multiliteracies within an engaging classroom practice.

\subsubsection{Genre-based disciplinary literacy research}

In this section, we articulate the nature of SFL and genre-based approaches that inform the M3S project. This body of research in the social semiotic tradition focusses on supporting students to engage with the structures of scientific multimodal text and the variety of genres through which scientific knowledge is developed and communicated. The approach is described in more detail in Chapter 3 and will be further articulated in Chapters 5 and 6.

Halliday and Martin (1993) recognized that the epistemic distinctiveness of science as a worldview, a body of knowledge and a form of inquiry with various technical specifications is indivisible from the development 
over several centuries of a range of purpose-built features of language use. Through analysis of various historical and contemporary instances of scientific argument and textual examples, they argued persuasively that specific grammatical resources of English have been used to construct and represent the specialized knowledge of science as disseminated in science communities. Similarly, they described how various genres have been developed to provide appropriate macro-structures to represent scientific reasoning, argument and discourse and that these linguistic aspects represent the epistemic essence of science as a discipline and field of study.

From this viewpoint, in the recontextualizing process by which curriculum is designed to progressively induct students into scientific disciplinary literacy practices, students need to learn the assumptions, conventions and purposes of scientific writing as the basis for understanding what counts as scientific method, explanation and justification, as well as the underlying history and rationale of this writing. Researchers in this tradition have focussed on the discipline-specific structural and functional features of types of science writing and science curriculum writing (Halliday \& Martin, 1993; Unsworth, 2001), their subject-specific vocabulary and the student knowledge required to understand and reproduce these genres (Martin \& Veel, 1998; Unsworth, 2001; Veel, 1997). Martin and Veel (1998), and others, argue that students will learn effectively the conventions and meanings of these particular language practices through an explicit pedagogy entailing detailed analysis of linguistic features of textual examples, joint construction of genres with their teacher and through a teacher focus on key textual function/form relationships and their rationale. Unsworth (2001) described the mediating role of the teacher through which students can learn to write scientifically and incorporate multimodal resources into their writing through analyzing the schematic structures and grammatical patterns of sample texts and then reproducing these functions in their own writing.

The M3S project aims to bring together these two approaches to the development of scientific disciplinary literacies which, respectively, focus on (a) engaging students in the multimodal language practices of science through a guided inquiry process compared to (b) explicitly supporting students in interpreting and using the structural features of multimodal text. The challenge for the guided inquiry tradition, particularly in the context of the complex language practices of senior science, is how to effectively support teachers to guide students into an explicit understanding of these literacy practices. The challenge for the SFL tradition is how to scaffold these literacy practices in ways that make their purposes apparent. In the senior years particularly, the tension centres around the demands of meaningful engagement with purpose, linking this with students' use and refinement of multimodal language structures and the need for efficiency in introducing and consolidating disciplinary multimodal representational practices. In engaging with this challenge, one aim of the project is the identification of a metalanguage (or metalanguages) through which teachers and students can discuss multimodal textual structures in a form that is accessible and which can arise naturally in the context of explanation and problem-solving processes in science 
classrooms. The need for such a metalanguage is particularly important for students experiencing disadvantage through cultural, linguistic or socioeconomic circumstances or combinations of these (Bernstein \& Henderson, 2017; Delpit, 1988).

\subsection{Supporting multimodal literacies in the science classroom}

In this section, we draw on the science education literature to identify a range of discursive practices which are currently considered to be of critical importance, as part of the development of a functional multimodal scientific literacy. These include scientific argumentation, visualization practices, investigative processes and modelling. These are the multimodal discourses through which students interpret and work with science ideas. We argue the centrality of students appreciating the purpose of understanding how these multimodal genres make meaning as core to the duality of a developing multimodal disciplinary literacy and science learning.

\subsubsection{Argumentation}

Duschl (2008, p. 275) argued that learning in science should be conceptualized as a rich interplay of understanding and enacting epistemic and social practices, where students are expected to learn how and why to build theories and models, construct arguments, and to 'use the specialized ways of talking, writing and representing phenomena'. Argumentation has received considerable attention by researchers in science education as an important part of the wider discursive processes through which science ideas are established and validated through appeal to evidence (Erduran \& Jiménez-Aleixandre, 2008; Erduran, Simon \& Osborne, 2004; Osborne, Erduran \& Simon, 2004). Argument is built around claims, justifications and rebuttals on the basis of evidence and has particular grammatical and multimodal forms that are an important part of the explanatory discourse in science classrooms. Martin and Rose $(2008$, p. 211$)$ classify such argumentation processes as a distinctive scientific genre.

\subsubsection{Visualization}

Increasingly, in science, visual simulations, data displays, false colour photographs representing wavelengths imperceptible to the human eye or complex $3 \mathrm{D}$ representations are the material through which knowledge is generated and fixed in scientific papers and communications. Gooding (2006) notes that:

$[S]$ cientists use a variety of images that...combine visual and non-visual elements because scientific work requires representations that are hybrid (that combine verbal or symbolic expressions with visual and other sensory modalities) and plastic, enabling the meaning of an image, word or symbol to be negotiated and fixed 
and that accounts of the nature of science that are based only on verbal formulations (facts, laws, formulae) do not capture the nature of new knowledge production.

In school science, the role of visualization has been increasingly appreciated as a key aspect of learning in science, driven substantially by the writings of John Gilbert (2005a). Gilbert (2005b) argues that corresponding to its central role in science, visualization should play a correspondingly important role in science education. He further argues that "students -science students especially - must become metacognitive in respect of visualization, that they must show what I term 'metavisual capability"' (p. 9).

This call for such a capability is consistent with our concern to develop a metalanguage through which teachers and students can negotiate and refine visuo-spatial representations (see also Kress \& van Leeuwen, 2006; Tang, Won \& Treagust, 2019). Such a language would support the development of metarepresentational competence (diSessa, 2004; Kozma \& Russell, 2005).

\subsubsection{Modelling}

Modelling is a fundamental aspect of scientific epistemic processes, and models and model-based reasoning (Lehrer \& Schauble, 2003, 2006; Schwarz \& White, 2005) have been advocated as an important focus for science education. Models in science and science education vary widely, and classification schemes (Black, 1962; Gilbert, 2011; Harrison \& Treagust, 1996) have included scale models, analogue models, theoretical models and mathematical models, chemical formulae, maps and diagrams, simulations and concrete models.

Grosslight et al. (1991) found evidence that students may not understand the nature of models and process of modelling even when engaged in creating, testing, revising and using models, indicating the importance of students learning about the nature of models (Gobert \& Pallant, 2004; Prins, Bulte \& van Driel, 2009). Schwarz and White (2005, p. 167) argue,

A model-centered, meta-modeling approach, which emphasizes learning about the nature and purpose of models, also has the benefit of enabling students to develop accurate and productive epistemologies of science.

Again, then, we note the importance of the development of a metalanguage describing the literacy aspects of these central epistemic/discursive scientific practices, to support teachers and students to make explicit the semiotic resource forms underpinning thinking and working scientifically.

Added to this advocacy of metalanguages for describing argumentation, visualization and modelling, research has focussed also on metalanguages associated with investigative/inquiry practices, such as experimental design processes, the forms of productive questions (Lehrer, Kobiela \& Weinberg, 2013) and report writing practices (Honeycutt Swanson, Bianchini, Lee, 
2014; NRC, 2012). Genre pedagogies are designed to address this question by explicating the semiotic features through which such processes and reports structure and communicate knowledge in the discipline.

\subsection{In summary}

Students need to appreciate the variety of genres that construct and communicate scientific knowledge (such as are represented in scientific journals, reports, papers, textbooks and other public online and paper media communications) as a repository of culturally construed knowledge and values, with rich and complex language and other representational forms that they need to apprehend and flexibly use. This requires building student understandings of how meanings are made through the sophisticated language and multimodal representational work of constructing and interpreting such texts. A strong basis for this has developed through science education and social semiotic research, explicating the meaning-making resources of the structural multimodal discursive features of these texts and how the linguistic, visual and symbolic modes in these texts can be coordinated with material experience to support quality science learning (Gilbert, 2005b; Halliday \& Martin, 1993; Lemke, 1990; Martin \& Rose, 2008; Martin \& Veel, 1998; Osborne, Erduran \& Simon, 2004; Talanquer, 2011). While various metalanguages describing these multiple modes of meaning making have been developed, the work of deriving consensual classroom applicable versions to foster students' improved metarepresentational competence (diSessa, 2004; Kozma \& Russell, 2005) continues, as discussed further in Chapter 3. Finally, we argue the value of students being strategically supported to actively participate in multimodal material and textual practices if they are to appreciate their disciplinary centrality (Ainsworth, Tytler \& Prain, 2020; Lehrer, 2009; Manz, 2012; Tytler, Prain, Hubber \& Waldrip, 2013; Tytler et al., 2020).

\section{References}

Ainsworth, S., Prain, V., \& Tytler, R. (2011). Drawing to learn in science. Science, 333(6046), 1096-1097.

Ainsworth, S., Tytler, R., \& Prain, V. (2020). Learning by construction of multiple representations. In P. Van Meter, A. List, D. Lombardi, \& P. Kendeou (Eds.), Handbook of learning from multiple representations and perspectives (pp. 92-106). New York: Routledge.

Airey, J., \& Linder, C. (2009). A disciplinary discourse perspective on university science learning: Achieving fluency in a critical constellation of modes. Journal of Research in Science Teaching, 46(1), 27-49.

Bernstein, B. (1996). Pedagogy, symbolic control and identity: Theory, research and critique. London: Taylor and Francis.

Bernstein, B. (1975). Class and pedagogies: Visible and invisible. Educational Studies, 1(1), 23-41. 


\section{Language, image and multimodal mediation}

Bernstein, B., \& Henderson, D. (2017). Social-class differences in the relevance of language to socialization. In M. Argyle (Ed.), Social encounters: Contributions to social interaction (pp. 47-62). New York: Routledge.

Black, M. (1962). Models and metaphors. Ithaca: Cornell University Press.

Brown, J. S., Collins, A., \& Duguid, P. (1989). Situated cognition and the culture of learning. Educational Researcher, 18(1), 32-42.

Bybee, R. W. (1997). Achieving scientific literacy: From purposes to practical action. Portsmouth, NH: Heinemann.

Cazden, C., Cope, B., Fairclough, N., Gee, J., Kalantzis, M., Kress, G., ...\& Nakata, M. (1996). A pedagogy of multiliteracies: Designing social futures. Harvard Educational Review, 66(1), 60-92.

Delpit, L. D.(1988). The silenced dialogue: Power and pedagogy in educating other people's children. Harvard Educational Review, 58(3), 280-299.

diSessa, A. (2004). Metarepresentation: Native competence and targets for instruction. Cognition and Instruction, 22(3), 293-331.

Duschl, R. (2008). Science education in three-part harmony: Balancing conceptual, epistemic, and social learning goals. Review of Research in Education, 32, 268-291.

Elkins, J. (2011). Visual practices across the University: A report. In O. Grau (Ed.), Imagery in the 21st century. Cambridge, MA: MIT Press.

Erduran, S., \& Jiménez-Aleixandre, M. P. (2008). Argumentation in science education: Perspectives from classroom-based research. Dordrecht: Springer.

Erduran, S., Simon, S., \& Osborne, J. (2004). TAPping into argumentation: Developments in the application of Toulmin's argument pattern for studying science discourse. Science Education, 88(6), 915-933.

Ford, M., \& Forman, E. A. (2006). Refining disciplinary learning in classroom contexts. Review of Research in Education, 30, 1-33.

Gee, J. P. (2004). Language in the science classroom: Academic social languages as the heart of school-based literacy. In E. W. Saul (Ed.), Crossing borders in literacy and science instruction perspectives in theory and practice (pp. 13-32). Newark, DE: International Reading Association/National Science Teachers Association.

Gilbert, S. (2011). Models-based science teaching. Arlington, Virginia: NSTA Press.

Gilbert, J. K. (2005b). Visualization: A metacognitive skill in science and science education. In J. K. Gilbert (Ed.), Visualization in science education (pp. 9-27). Dordrecht: Springer.

Gilbert, J. K. (2005a). Visualization in science education. New York: SpringerVerlag Inc.

Gobert, J., \& Pallant, A. (2004). Fostering students' epistemologies of models via authentic model-based tasks. Journal of Science Education \& Technology, 13(1), $7-22$.

Gooding, D. (2004). Visualization, inference and explanation in the sciences. In G. Malcolm (Ed.), Studies in multidisciplinarity (Vol. 2, pp. 1-25). New York, New York: Elsevier.

Gooding, D. (2006). From phenomenology to Field theory: Faraday's visual reasoning. Perspectives on Science, 14(1), 40-65.

Goodrum, D., Hackling, M., \& Rennie, L. (2001). Research report: The status and quality of teaching and learning of science in Australian schools. Canberra, Australia: Department of Education, Training and Youth Affairs.

Grosslight, L., Unger, C., Jay, E., \& Smith, C. (1991). Understanding models and their use in science: Conceptions of middle and high school students and experts. Journal of Research in Science Teaching, 28 (9), 799-822. 
Halliday, M. A. K. (1978). Language as a social semiotic: The social interpretation of language and meaning. London: Edward Arnold.

Halliday, M. A. K., \& Martin, J. R. (Eds.). (1993). Writing science: Literacy and discursive power. London: Falmer Press.

Halliday, M. A. K., \& Matthiessen, C. M. I. M. (1999). Construing experience through meaning: A language-based approach to cognition. London: Cassell.

Harrison, A. G., \& Treagust, D. F. (1996). Secondary students' mental models of atoms and molecules: Implications for teaching chemistry. Science Education, $80(5), 509-534$.

Honeycutt Swanson, L., Bianchini, J. A., \& Lee, J. S. (2014). Engaging in argument and communicating information: A case study of English language learners and their science teacher in an urban high school. Journal of Research in Science Teaching, 51(1), 31-64.

Hubber, P., Tytler, R., \& Chittleborough, G. (2017). Representation construction: A guided inquiry approach for science education. In R. Jorgensen \& K. Larkin (Eds.), STEM education in the junior secondary school (pp. 57-87). Dordrecht, The Netherlands: Springer.

Hubber, P., Tytler, R., \& Haslam, F. (2010). Teaching and learning about force with a representational focus: Pedagogy and teacher change. Research in Science Education, 40(1), 5-28.

Hurd, P. D. (1998). Scientific literacy: New minds for a changing world. Science Education, 82, 407-416.

Keys, C., Hand, B., Prain, V., \& Collins, S. (1999). Using the science writing heuristic as a tool for learning from laboratory investigations in secondary school. Journal of Research in Science Teaching, 36(10), 1065-1084.

Klein, P. (2006). The challenges of scientific literacy: From the viewpoint of second-generation cognitive science. International Journal of Science Education, $28(2-3), 143-178$.

Klein, U. (2001). Introduction. In U. Klein (Ed.), Tools and modes of representation in the laboratory sciences. Boston: Kluwer Academic Publishers.

Kozma, R., \& Russell, J. (2005). Students becoming chemists: Developing representational competence. In J. Gilbert (Ed.), Visualization in science education (pp. 121-145). Dordrecht: Springer.

Kress, G. (2003). Genres and the multimodal production of 'scientificness'. In C. Jewitt \& G. Kress (Eds.), Multimodal Literacy (pp. 173-186). New York: Peter Lang.

Kress, G., Jewitt, C., Ogborn, J., \& Tsatsarelis, C. (2001). Multimodal teaching and learning: Rhetorics of the science classroom. London: Continuum.

Kress, G., \& van Leeuwen, T. (2006). Reading images: The grammar of visual design (2nd ed.). London; New York: Routledge.

Latour, B. (1986). Visualization and cognition: Drawing things together. Knowledge and Society, 6(6), 1-40.

Latour, B. (1999). Pandora's hope: Essays on the reality of science studies. Cambridge, MA: Harvard University Press.

Latour, B., \& Woolgar, S. (1979). Laboratory life: The construction of scientific facts. Princeton University Press: Princeton.

Lave, J., \& Wenger, E. (1991). Situated learning: Legitimate peripheral participation. Cambridge and New York: Cambridge University Press.

Lave, J., \& Wenger, E. (2002). Legitimate peripheral participation in communities of practice. In R. Harrison et al. (Eds.), Supporting lifelong learning: Perspectives on learning (Vol. 1, pp. 111-126). London: Routledge Falmer. 
Lehrer, R. (2009). Designing to develop disciplinary dispositions: Modeling natural systems. American Psychologist, 64(8), 759.

Lehrer, R., \& Schauble, L. (2003). Origins and evolution of models-based reasoning in mathematics and science. In R. Lesh \& H. Doerr (Eds.), Beyond constructivism: Models and modeling perspective on mathematics problem solving, learning, and teaching (pp. 59-70). Mahwah, NJ: Lawrence Erlbaum Associates.

Lehrer, R., \& Schauble, L. (2006). Cultivating model-based reasoning in science education. In K. Sawyer (Ed.), Cambridge handbook of the learning sciences (pp. 371-388). Cambridge, MA: Cambridge University Press.

Lehrer, R., Kobiela, M., \& Weinberg, P. J. (2013). Cultivating inquiry about space in a middle school mathematics classroom. ZDM, 45(3), 365-376.

Lehrer, R., Schauble, L., \& Lucas, D. (2008). Supporting development of the epistemology of inquiry. Cognitive development, 23(4), 512-529.

Lemke, J. (2004). The literacies of science. In E. W. Saul (Ed.), Crossing borders in literacy and science instruction: Perspectives on theory and practice (pp. 33-47). Newark DE: International Reading Association/National Science Teachers Association.

Lemke, J. L. (1990). Talking science: Language, learning and values. Norwood, NJ: Ablex.

Linder, C., Östman, L., \& Wickman, P. O. (2007). Promoting scientific literacy: Science education research in transaction. In Linnaeus Tercentenary Symposium, May 28-29, Uppsala, Sweden. Geotryckeriet Uppsala.

Manz, E. (2012). Understanding the codevelopment of modeling practice and ecological knowledge. Science Education, 96(6), 1071-1105.

Martin, J. R., \& Maton, K. (Eds). (2013). Making semantic waves: A key to cumulative knowledge-building. Linguistics and Education: Special issue on cumulative knowledge building in secondary schooling, 24(1), 1-74.

Martin, J. R., \& Rose, D. (2008). Genre relations: Mapping culture. London: Equinox Pub.

Martin, J. R., \& Veel, R. (Eds.). (1998). Reading science: Critical and functional perspectives on discourses of science. London: Routledge.

Moje, E. (2007). Developing socially just subject-matter instruction: A review of the literature on disciplinary literacy learning. Review of Research in Education, 31, $1-44$.

National Research Council (NRC). (2012). A framework for $\mathrm{K}-12$ science education: Practices, crosscutting concepts, and core ideas. Washington, DC: Committee on a Conceptual Framework for New K-12 Science Education Standards. Board on Science Education, Division of Behavioral and Social Sciences and Education.

Nersessian, N. (2008). Model-based reasoning in scientific practice. In R. Duschl \& R. Grandy (Eds.), Teaching scientific inquiry: Recommendations for research and implementation (pp. 57-79). Rotterdam: Sense Publishers.

Nersessian, N. J. (2010). Creating scientific concepts. A Bradford Book. Cambridge, Massachusetts London, England: MIT Press.

Norris, S. \& Phillips, L. (2003). How literacy in its fundamental sense is central to scientific literacy. Science Education, 87, 224-240.

Ogborn, J., Kress, G., Martins, I., \& McGillicuddy, K. (1996). Explaining science in the classroom. Buckingham: Open University Press.

Osborne, J., Erduran, S., \& Simon, S. (2004). Enhancing the quality of argumentation in school science. Journal of Research in Science Teaching, 41(10), 994-1020.

Painter, C. (2017). Multimodal analysis of picturebooks. In The Routledge companion to picture books (pp. 420-428). New York: Routledge. 
Park, J., Chang, J., Tang, K. S., Treagust, D. F., \& Won, M. (2020). Sequential patterns of students' drawing in constructing scientific explanations: focusing on the interplay among three levels of pictorial representation. International Journal of Science Education, 42(5), 677-702.

Peirce, C. S. (2010). Philosophy of mathematics: Selected writings. Bloomington, IN: Indiana University Press.

Peirce, Charles S. 1931-1959. Collected Papers, edited by C. Hartshorne, P. Weiss, and A. W. Burks. Cambridge: The Belknap Press. [C.P.]

Pickering, A. (1995). The mangle of practice: Time, agency and science. Chicago: University of Chicago Press.

Prain, V. (2006). Learning from writing in secondary science: Some theoretical and practical implications. International Journal of Science Education, 28(2-3), 179-201.

Prain, V., \& Tytler, R. (2013). Representing and learning in science. In Constructing representations to learn in science (pp. 1-14). Brill: Sense.

Prain, V., \& Tytler, R. (2012). Learning through constructing representations in science: A framework of representational construction affordances. International Journal of Science Education, 34(17), 2751-2773.

Prain, V., \& Waldrip, B. (2006). An exploratory study of teachers' and students' use of multi-modal representations of concepts in primary science. International Journal of Science Education, 28(15), 1843-1866.

Prain, V., Tytler, R., \& Peterson, S. (2009). Multiple representation in learning about evaporation. International Journal of Science Education, 31(6), 787-808.

Prins, G., Bulte, A. \& van Driel, J. (2009). Students' involvement in authentic modeling practices as contexts in chemistry education. Research in Science Education, $39,681-700$.

Rogoff, B. (2008). Observing sociocultural activity on three planes: Participatory appropriation, guided participation, and apprenticeship. In K. Hall, P. Murphy and J. Soler (Eds.), Pedagogy and practice: culture and identities, 58-74. Thousand Oaks, California: Sage Publications.

Schwarz, C. V., \& White, B. Y. (2005). Metamodeling knowledge: Developing students' understanding of scientific modeling. Cognition and Instruction, 23(2), $165-205$.

Shanahan, T., \& Shanahan, C. (2008). Teaching disciplinary literacy to adolescents: Rethinking content area literacy. Harvard Educational Review, 78, 40-61.

Talanquer, V. (2011). Macro, submicro, and symbolic: The many faces of the chemistry “triplet”. International Journal of Science Education, 33(2), 179-195.

Tang, K. S., \& Danielsson, K. (Eds.). (2018). Global developments in literacy research for science education. Cham, Switzerland: Springer.

Tang, K. S., Won, M., \& Treagust, D. (2019). Analytical framework for studentgenerated drawings. International Journal of Science Education, 41(16), 2296-2322.

Tytler, R., Prain, V., Hubber, P., \& Waldrip, B. (Eds.). (2013). Constructing representations to learn in science. Rotterdam, The Netherlands: Sense.

Tytler, R., Haslam, F., Prain, V., \& Hubber, P. (2009). An explicit representational focus for teaching and learning about animals in the environment. Teaching Science, 55(4), 21-27.

Tytler, R., Prain, V., \& Hubber, P. (2018). Representation construction as a core disciplinary literacy. In K-S. Tang \& K. Danielsson (Eds.), Global developments in literacy research for science education (pp. 301-317). Singapore: Springer. 


\section{Language, image and multimodal mediation}

Tytler, R., Prain, V., \& Peterson, S. (2007). Representational issues in students learning about evaporation. Research in Science Education, 37(3), 313-331.

Tytler, R., Prain, V., Aranda, G., Ferguson, J., \& Gorur, R. (2020). Drawing to reason and learn in science. Journal of Research in Science Teaching, 57, 209-231. https://doi.org/10.1002/tea.21590

Unsworth, L. (2001). Teaching multiliteracies across the curriculum. Buckingham: Open University Press.

Veel, R. (1997). Learning how to mean-scientically speaking: Apprenticeship into scientic discourse in the secondary school. In F. Christie, \& J. R. Martin (Eds.), Genre and institutions: Social processes in the workplace and school. London: Cassell.

Vygotsky, L. S. (1986). Thought and language, translated revised and edited by A. Kozulin. Cambridge, MA: MIT Press.

Vygotsky, L. S. (1978). Socio-cultural theory. Mind in society, 6, 52-58.

Wallace, C. S., Hand, B. B., \& Prain, V. (2004). Writing and learning in the science classroom. Dordrecht Netherlands: Kluwer Academic Publishers.

Waldrip, B., Prain, V., \& Carolan, J. (2010). Using multi-modal representations to improve learning in junior secondary science. Research in Science Education, 40(1), 65-80.

Wenger, E. (2011). Communities of practice: A brief introduction.

Wenger, E., McDermott, R. A., \& Snyder, W. (2002). Cultivating communities of practice: A guide to managing knowledge. Harvard Business Press.

Wittgenstein, L. (1972). Philosophical investigations( (1st ed.). Oxford: Basil Blackwell. 


\section{Distinguishing multimodal disciplinary literacy in school science}

\subsection{Introduction}

In chapter two we discussed the evidential basis for conceptualizing learning in science as a process of induction into the distinctive literacies of science as recontextualized in school curricula and pedagogy. This emphasizes the apprenticing of students into the distinctive uses of language and other representational resources routinely deployed by science professionals in carrying out their work. The meaning-making of these linguistic and other representations then is integrally related to their disciplinary-specific uses, so the literacies of science are infused into the construction and application of scientific knowledge. It follows that the discipline-specific literacies of science must be infused into science pedagogy, but, as argued in the earlier chapters, the nature of these infused discipline-specific literacies as recontextualized in school education needs to be made explicit so that all students are supported in accessing and creating the multimodal representations of scientific conceptualization.

Facilitating widespread engagement by science teachers in developing multimodal literacy infused into their pedagogy relies on greater understanding deriving from three areas of related research:

1. Delineating the nature and development of disciplinary literacy as distinguished from basic and intermediate literacy (Shanahan \& Shanahan, 2008, p. 44);

2. Investigating the commonalities and differences in multimodal literacy that characterize high school biology, chemistry and physics; and

3. Determining a consensual and accessible metalanguage for describing the meaning-making functions of the distinctive language and other representational forms of science.

In the following sections, we focus on developments in these three areas. We conclude the chapter by emphasizing the importance of both teachers and students being able to 'shunt' between the literate practices of multimodal disciplinary discourses and 'everyday' communication in negotiating knowledge building in classroom work and for students in demonstrating their learning in assessment contexts. 


\subsection{Disciplinary literacy}

A model of literacy progression proposed by Shanahan and Shanahan (2008, p. 44) takes the form of a pyramid with basic literacy as the foundational level which represents the most generalizable literacy competencies common to all or most contexts of literacy use, such as decoding and encoding text, recognition and use of commonly used vocabulary, comprehension and composition of simple narrative and expository texts and to a greater or lesser extent the accompanying pictorial and basic diagrammatic depictions. The middle level of the pyramid represents intermediate literacy where the literacy competencies become more sophisticated and less generally applicable as students experience emergent disciplinary literacy (Fang, Lamme \& Pringle, 2010; Fang \& Schleppegrell, 2010; Schleppegrell, 2013) involving the more differentiated deployment of language and image resources in their interpretation and composition of more complex information reports, explanations and argumentative texts. However, as students progress through junior and senior high school and the stronger classification and greater specialization of learning in subject areas, the literacy competencies required, while certainly maintaining those of basic and intermediate literacy, additionally include competencies that are much less generalizable and often highly specific to a particular subject area. These disciplinary literacy competencies are more challenging for students to develop because students' experience of them is confined to the particular subject area, and students are encountering very unfamiliar concepts and forms of language that are very different from those of everyday oral language - furthermore, those discipline-specific aspects of the literacy competencies students require are rarely explicitly taught.

Although there are certain commonalities in the use of academic language and other forms of representation across different disciplines, there are also discipline-specific discourse features and literacy practices. Disciplines differ extensively in how they create, disseminate and evaluate knowledge, and these differences are reflected in their specialized genres, distinctive symbolic artefacts and characteristic traditions of communication (Shanahan \& Shanahan, 2008, p. 48). Evidence for this derives from studies showing different characteristic literate practices within particular disciplines and from linguistic studies comparing their distinctive deployment of language resources (Eggins, Wignell \& Martin, 1993; Martin, 1993a, 2020; Unsworth, 1999; Wignell, Martin \& Eggins, 1993).

Evidence for discipline-specific literacy has been steadily accruing (Moje, 2008; Moje, Sutherland, Cleveland \& Heitzman, 2010; Shanahan \& Shanahan, 2017; Shanahan \& Shanahan, 2008, 2012). Shanahan and Shanahan (2008) worked with teams of researchers, teacher educators and teachers of chemistry, history and mathematics, as well as literacy experts in each team. The teams examined learning materials such as textbooks, web pages and articles indicating how they approached the reading, the literacy challenges they envisaged for students and the strategies they believed would assist students. Think aloud data was also obtained from team members on 
their literacy practices in interpreting two samples of high school and professional literature texts in the discipline area. The data analysis demonstrated deeply different literacy practices across the disciplines. For example, mathematicians emphasized precision reading, with even function words like 'the' being potentially of particular significance, while chemists drew attention to the transformation of information from one form to another relating diagrams and charts to the main text, and historians focussed particularly on the provenance of the source material.

Further evidence of discipline-specific literacies emerged from a study by Goldman, Britt, Brown, Cribb, George and Greenleaf (2016) that resulted in a conceptual framework for reading to learn based on distinguishing the literacies of literature, science and history. Additionally, a study by Spires, Kerkhoff, Graham, Thompson and Lee (2018) used factor analysis of questionnaire responses from about 800 US subject area teachers of English, science, history and mathematics to identify source literacy (attending to issues such as author reliability through institutional affiliation, corroboration of evidence from multiple authors), analytic literacy (analyzing technical terminology, graphs, data to support a model) and expressive literacy (deconstructing rhetorical devices, figurative language, style and voice). The three factors varied significantly by the four core disciplines. The stronger association of analytic literacy with science and mathematics, source literacy with history and expressive literacy with English aligns with the different orientations of the experts in mathematics (precision literacy) chemistry (relating diagrams, charts and text), and history experts (focussing on provenance) in the Shanahan and Shanahan (2008) study and the distinctive epistemic and literacy orientations in literature, science and history found by the Goldman et al. (2016) team.

Linguistic studies of high school textbooks and source materials in science and history have shown differences in the genres that are prominent (Martin \& Rose, 2008; Unsworth, 2001), as well as in the nature of the key vocabulary, classification and reasoning (Martin, 1993a, 2020; Unsworth, 1999). The principal genres found in high school science textbooks and source materials by Martin and Rose are indicated in the network in Figure 3.1 (see also (Unsworth, 2001, pp. 122-127)).

The genres in Figure 3.1 that are 'not time structured' are readily recognizable. Amongst those that are 'time structured', sequential explanations involve a series of events in which an obligatory causal relation is implied between each event and the next (e.g. the formation of wetlands, the formation of DNA in cell nuclei and how sound travels). Factorial explanations deal with events that may be explained by two or more contributing factors, such as how the Acacia tree species, Mulga, survives long droughts by reference to its shape, colour, and the food source in its own leaves. In consequential explanations a single event may have two or more consequences, each following independently from the causal event. For example, three independent consequences of the clearing of the woodlands of southern Australia are: death of remaining trees, erosion of land and destruction of habitat. 


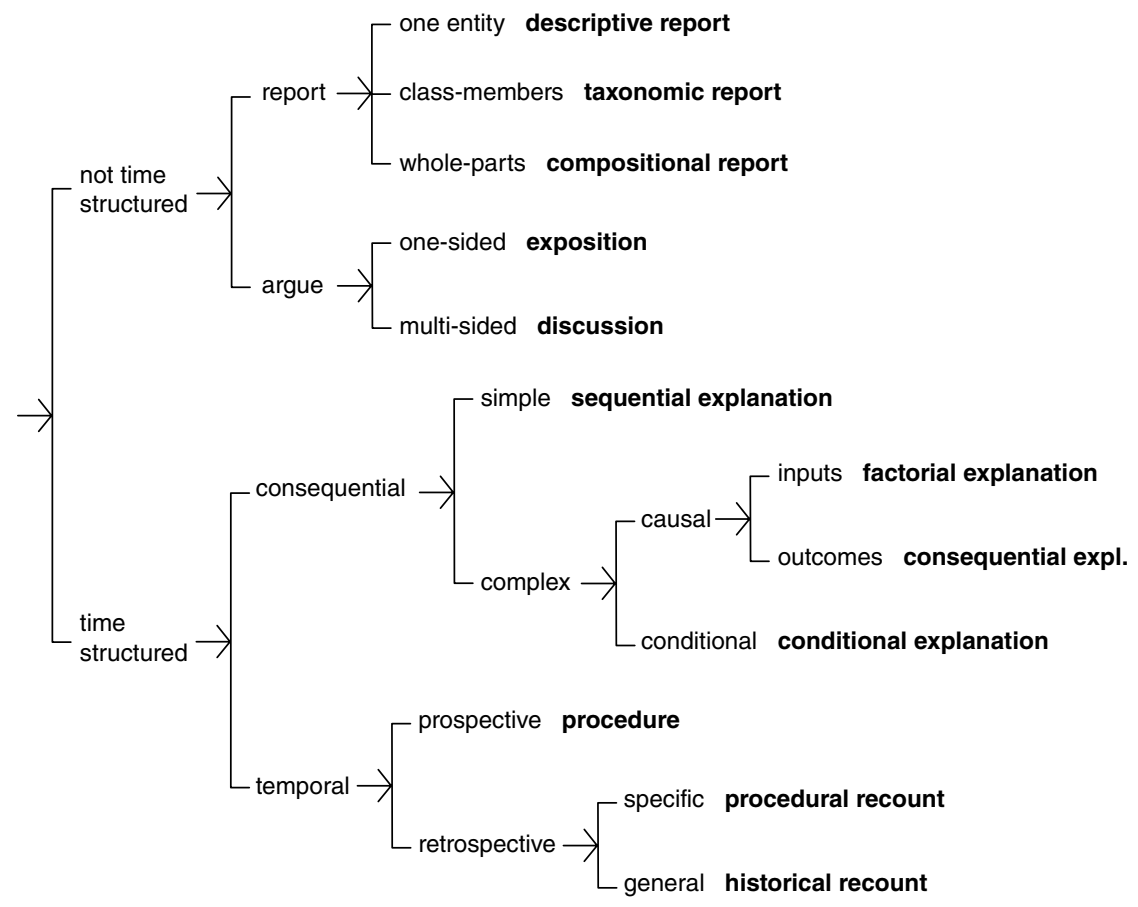

Figure 3.1 Principal genres in school science textbooks (Martin \& Rose, 2008, p. 167).

Conditional explanations construe effects as contingent on variable factors, such as the effects on animal populations under three conditions: if predators are absent, if prey are too few, and if numbers of both predator or prey fall and build up again. The procedure genre details the steps in conducting an experiment or investigation, while a procedural recount records the experiment or investigation and its outcomes.

If we compare the principal school science genres in Figure 3.1 with those identified by Martin and Rose in school history texts (Figure 3.2), we will notice some common genres and some that are distinctive to either science or history.

Both consequential and factorial explanations are common to science and history. Genres like procedure and procedural recount are prominent in science but don't appear to be so relevant in history. Similarly, the recount genres do not seem to be so significant in science. This is not to say that such genres never occur in science texts and, in fact, historical recounts also appear in maths texts. The principal genres of different school subject areas are distinguished by the relative frequency of their occurrence, as well as by their differential valuing within the discipline area. For example, although historical recounts occur in science, much more prominence tends to be given to scientific report and explanation genres. It appears that the use of particular genres also tends to vary across fields within subject areas. Genres 


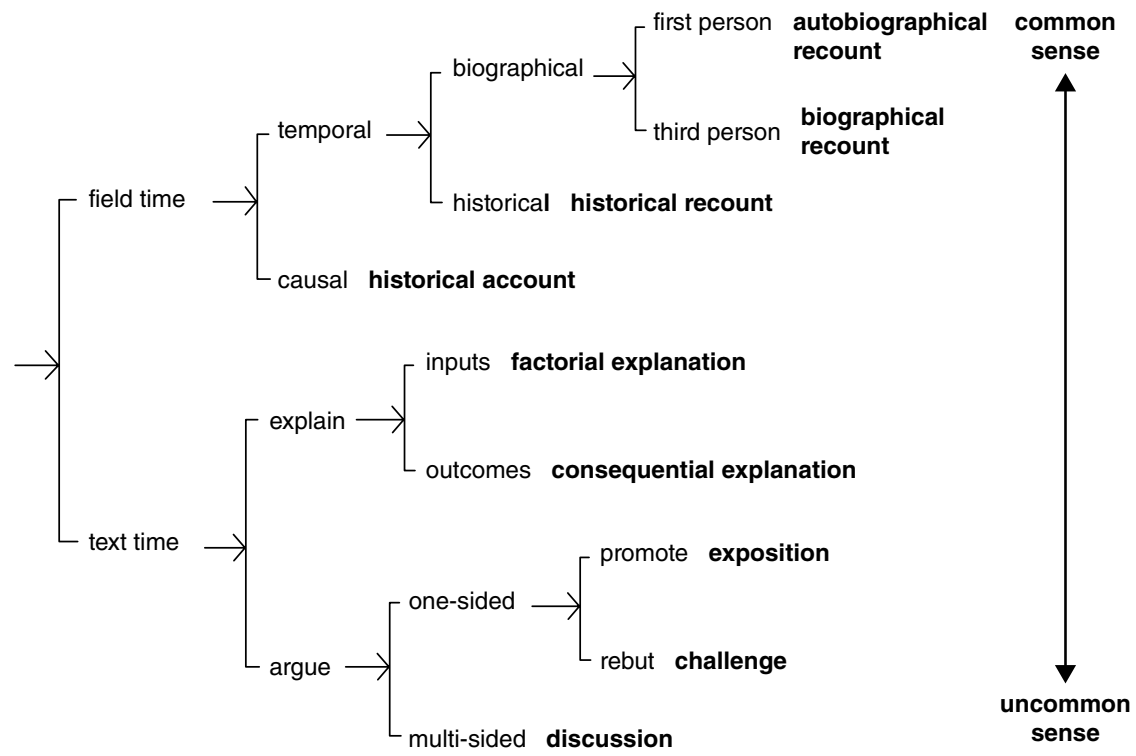

Figure 3.2 Principal genres in school history textbooks (Martin \& Rose, 2008, p. 130).

like exposition and discussion that challenge science, for example, are less commonly found than other genres and tend to occur more frequently in less well-established areas of the discipline like eco-science (Martin \& Rose, 2008, p. 223; Veel, 1998), nanotechnology (e.g. Lofts \& Evergreen, 2015, p. 360) or issues such as those around ongoing biological evolution, such as the emergence of antibiotic-resistant bacteria and pesticide-resistant insects (e.g. Chidrawi et al., 2013, pp 76-77). It does seem that there are some genres that occur in some subject areas but would be highly unlikely to occur in others. Furthermore, genres of science such as taxonomic and compositional reports, conditional explanations and procedural recounts are highly unlikely to be encountered with anything but minimal frequency in the English classroom. Clearly, building student competence in interpreting the genres of science cannot be relegated to the English teacher. The genres charted here are not exhaustive of those found in school science and history, and sometimes mixing or embedding of one genre inside another occurs (Martin, 1994), but they are one important dimension of both the commonalities and differences in the literacies of the various school subject areas.

The ways in which the grammatical and discursive resources of language are deployed in genres also distinguish the literacies of different disciplines. The language of science is characterized by the development of technicality. That is, science reinterprets experience technically by defining elements of experience using technical terms (e.g. ecosystem, biome, genome, mitosis, cytokinesis, electrolysis). These technical terms are ordered taxonomically and can define activities (e.g. cytokinesis, electrolysis) or participants (e.g. biome, genome) in activities. The activities are inter-connected through 
logical relations amongst them (like temporal sequence, causality, condition, comparison, etc.) to explain how things happen to come or be. The language of history, on the other hand, is characterized by a shift to what is referred to as abstraction. Martin (1993a, p. 226) points out that the discourse of history is not essentially one of technicality apart from a small set of terms referring to periods of time (e.g. the Middle Ages, the Dark Ages, the Renaissance) and possibly some distinctive -isms (e.g. colonialism, imperialism, jingoism). Martin also shows that the language of reasoning is typically used very differently in science and history. Reasoning is communicated through various means of expressing logical relations of temporality, causality, condition, etc. In science, these relations predominantly concern material happenings that are connected causally, conditionally, etc. Usually in science, these relations amongst activities are expressed explicitly through direct use of conjunctions, such as 'after', 'before', 'so', 'because' or 'if' However, in history, while such relations do occur, they are often implicit and can be realized by verbs, such as 'led to' or 'owed', or nouns, such as 'consequence' or 'precursor'. Rhetorical conjunctive relations are also more prominent. These refer to the kind of 'internal' reasoning that links propositions in discourse and are typified by conjunctive relations, such as 'that is', 'therefore' and 'hence'. These differences in technicality, abstraction and reasoning are indexical of the distinctive orientations to knowledge building in the disciplines. For example, Martin shows that science defines, classifies and exemplifies in order to construct new technical taxonomies whereas history classifies and describes in order to generalize across classes of participants so that science, in a sense, invents by constructing new knowledge and history interprets through generalizing and rearranging what is known (Martin, 1993a, p. 233).

Explication of the distinctive linguistic features of texts in different curriculum areas and empirical studies of the distinctive literacy practices of experts in different disciplines clearly indicate that the premise of 'language across the curriculum' or 'content area literacy' approaches (Antonacci, O'Callaghan \& Berkowitz, 2014; Bean, 2011; Berry, 2013), which are based on students developing a defined repertoire literacy strategies that have common application to different discipline areas, is not adequate to facilitate effective learning in the different subject areas.

\subsection{Distinctions amongst the disciplinary literacies of biology, chemistry and physics}

There has been very limited investigation of the commonalities and distinctions amongst the literacies of the science sub-disciplines. Some evidence of variation was found in a study of 231 chapters of science textbooks dealing with topics in biology, chemistry and physics and sampled from five series for junior high school (Freebody \& Muspratt, 2007; Muspratt \& Freebody, 2013). The greatest contrast was between biology and physics. Descriptive accounts in biology chapters were based on taxonomic criteria that were readily observable via the senses, whereas in physics, many of the entities 
do not have experiential real-world equivalents. The researchers found that vocabulary diversity was low in physics and high in biology with chemistry positioned mid-way along this cline. High-frequency function words in physics mainly established correct procedures and arrangements, in chemistry, they established classification, and in biology, they elaborated on classified entities. Grammatical organization was claimed to establish knowledge in physics on the basis of conditional rules, in chemistry through sets of statements and in biology through elaboration and persuasion. A few other studies have provided indications of sub-discipline-specific literacies through analysis of the treatment of the same topic in texbooks for biology, chemistry or physics. Here we will outline two studies of university textbooks and one of senior high school textbooks (Goddiksen, 2014; Hartley, Momsen, Maskiewicz \& D'Avanzo, 2012; Wahlberg \& Gericke, 2018). In each study, it can be seen that the epistemic orientation of the sub-discipline is reflected in the distinctive uses of linguistic and other representational resources, hence implicating sub-discipline-specific literacies.

Hartley and her colleagues (2012) investigated the representation of energy and matter in introductory university textbooks in the three science sub-disciplines and interviewed university teachers about how they explained these concepts. The treatment of energy was very different in each subject. All addressed the various forms of energy, but biology focussed on movement such as energy flow through ecosystems, while the emphasis in chemistry and physics was on conservation of energy. Matter was less clearly delineated and only specifically defined in half of the textbooks studied. The teacher interviews showed that in biology, discussions of energy and matter were bounded by the particular systems being dealt with at the time (e.g. body, ecosystem), whereas physicists' range of focus extended from the subatomic scale to the universe, and while chemists' defined boundaries in terms of chemical reactions at the molecular scale, they did refer to energy transfer from very small to very large scales. An interesting effect of this is on the ways that terminology is used differently in the three sub-disciplines. For example, when talking about rainforests, biologists would not discuss energy as being 'recycled' since, once transformed into heat, it can no longer be used by living systems for metabolic processes. On the other hand, the physicists equated transfer and recyling, and chemists indicated they would not use the term 'recycled' at all in discussing energy or matter. The different conceptual emphases in the topic across the sub-disciplines are reflected in the differences in the deployment of language and hence in the literacies of text interpretation and text composition.

The nature of explanations concerning polymers in university textbooks in biology and physics was investigated by Goddiksen (2014). She described the biology explanations as 'mechanistic'. They describe the mechanisms that occur as biological entities encounter other biological entities and engage in activities of transformation. These explanations explicate changes in the distribution, composition and interaction amongst material objects (e.g. how the series of bases in the DNA directs the production of RNAs and proteins). 
Explanations concerning polymers in physics are not so concerned with these mechanisms. Goddiksen refers to these explanations as derivations (cf conditional explanations in Martin and Rose, 2008). They show how the manipulation of the value of one variable produces a change in the value or probability distribution of another variable (e.g. an explanation of the elasticity of rubber would relate this variable quantitatively to the entropy of the rubber without considering the interactions amongst the polymers). The different conceptual foci of the sub-disciplines entail different forms of explanation with different linguistic and visual representational realizations and hence differences in the literacy practices of interpretation and composition.

Explanations of protein synthesis in senior high school chemistry and biology textbooks were compared by analyzing the technical terms for frequency of occurrence, distribution across text segments and interrelationships amongst terms (Wahlberg \& Gericke, 2018). The core technical terms had similar frequencies in biology and chemistry but different distributions for core and peripheral terms. Core terms were more central in biology because they were more strongly related to each other and peripheral terms. The results were interpreted as reflecting the 'conceptual' explanation of protein synthesis in biology and a 'mechanistic' explanation in chemistry. Mechanistic explanations provide descriptions of cellular entities and activities showing the way mechanisms work from beginning to end (cf. Goddiksen, 2014). Conceptual explanations are described as showing the relationships between such concepts in a causal rather than a mechanistic way. The lexical focus of the language analysis obviates access to any direct linguistic evidence about the relative extent of the expression of causality in these explanations; nevertheless, it is clear that very different types of explanations of the same phenomenon occur in biology and chemistry entailing different literacy practices.

\subsection{Differentiating multimodality in the literacies of biology, chemistry and physics}

There is a paucity of research into the commonality and variation of multimodal representation across biology, chemistry and physics. At the university level, Goddiksen (2014) described the different types of diagrams used in relation to the topic of polymers in biology and physics. Both subjects included composition images showing the structure of the various entities involved and the biology text also included what Goddiksen (2014) called 'mechanism schemas' which depict activity, showing how polymers with different structures interact to perform a particular function. These 'mechanism' schema diagrams were absent from the physics texts where the most prominent forms of depiction were graphs. In addition, the biology diagrams were richly colourful, while this was not the case in the physics texts. Parodi (2012) analyzed the relative frequency across biotechnology, chemistry, physics, linguistics, literature and history of graphs, tables, diagrams, geometrical figures, icons, maps, formulae, illustrations (photographs) and 
Table 3.1 Visualizations in different science sub-disciplines on the 2012 New York State Regents Examination (derived from LaDue et al., 2015)

\begin{tabular}{llll}
\hline & $\begin{array}{l}\text { Visualizations/ } \\
\text { Question }\end{array}$ & $\begin{array}{l}\text { Diagrams/ } \\
\text { Visualizations }\end{array}$ & $\begin{array}{l}\text { Graphs/ } \\
\text { Visualizations }\end{array}$ \\
\hline Earth science & $98 \%$ & $46 \%$ & $13 \%$ \\
Living environment & $44 \%$ & $54 \%$ & $5 \%$ \\
Chemistry & $27 \%$ & $78 \%$ & $8 \%$ \\
Physics & $53 \%$ & $56 \%$ & $44 \%$ \\
\hline
\end{tabular}

compositional webs (such as screenshots of websites that include verbal, graphic, mathematical and typographic modalities). Due to the inclusion of formulae, physics had the greatest aggregation of artefacts per page. Parodi did not explicitly discuss the relative occurrence of other multimodal artefacts across physics and chemistry, but it appears from his graphical information that chemistry included more graphs, diagrams, tables, illustrations and geometrical figures than was the case with physics. At the high school level, there is a dearth of literature examining visual representations across the science disciplines. A study of the end of high school 2012 New York State Regents examinations in chemistry, earth science, living environment (biology) and physics showed substantial differences in the proportion of questions, including visualizations and the proportion of different kinds of visualizations across the subjects (LaDue, Libarkin \& Thomas, 2015). Diagrams were the highest proportion with graphs also prominent in some subjects, but the proportions of both varied substantially across subjects (Table 3.1). Maps, cartograms and time charts appeared only in earth science and networks only in the living environment. These results implicate the differences in multimodal literacy demands in the science sub-disciplines.

\subsection{Metalanguage: describing the meaning-making resources of language and image}

Arguably the most educationally influential delineation of the semiotics of the discourse of science has emerged in the last few decades from systemic functional linguistics (SFL) through research on language led by Halliday (Halliday \& Martin, 1993, Martin 2017; Martin \& Veel, 1998), Lemke $(1990,2004)$ and more recently Doran (2017) and Hao (2020), and from related systemic functional semiotic research focussing more on images led by Kress (Kress, Jewitt, Ogborn \& Tsatsarelis, 2001; Kress \& Ogborn, 1998; Kress, Ogborn \& Martins, 1998; Kress \& van Leeuwen, 2006), Bateman (2008), O'Halloran (2003) and more recently Martin and Unsworth (Martin, Unsworth \& Rose, in press; Unsworth, 2020) and Doran $(2017,2019)$. An extensive international literature has reported the application of SFL in addressing literacy development in science learning (Dreyfus, Humphrey, Mahboob \& Martin, 2015; Fang \& Schleppegrell, 2010; Forey, 2020; He \& Forey, 2018; Humphrey, 2017; O'Hallaron, 
Palincsar \& Schleppegrell, 2015; Polias, 2015; Rose \& Martin, 2012; Schleppegrell, 2011, 2013). In recent years, influential edited volumes have brought together science education and SFL researchers with a common focus on the role of the language and multimodal representations of science in deepening student engagement and learning (Prain \& Hand, 2016; Tang \& Danielsson, 2018). To a greater or lesser extent, this work involved supporting teachers and students in using aspects of SFL-derived metalanguage as a shared means of discussing the deployment of the meaning-making affordances of language and image in their interpretation and creation of multimodal representations of science concepts.

A different orientation to the centrality of literacy in science learning, characterized as writing to learn, seemed less focussed on inducting students into the discourse forms of science and encouraged more diversified writing for different purposes and audiences, emphasizing personal meaning-making through everyday communicative contexts, although some programmes incorporated reiterative guidance toward scientific reasoning (Hand \& Keys, 1999; Levin \& Wagner, 2006; Rivard \& Straw, 2000). Somewhat aligned with this orientation, a representation construction approach (RCA) to pedagogies of knowledge building, while clearly informed by social semiotic perspectives, has not pursued an explicit or systematic role for metalanguage (Hubber \& Tytler, 2017; Hubber, Tytler \& Haslam, 2010; Prain \& Tytler, 2012; Tytler \& Hubber, 2010; Tytler, Prain \& Hubber, 2018; Tytler, Prain, Hubber \& Waldrip, 2013). Nevertheless, it appears that both the SFL and the writing to learn/representation construction orientations agree that to optimize students' learning, it is important that they understand the form/ function of the representational resources of language, image and mathematical scientific symbolisms (Prain \& Hand, 2016, p. 6; Tytler et al., 2013, p. 10), although RCA approaches have not documented their position as to the extent of students' acquiring conscious awareness of these form/ function relations. Both strands also appear to agree that students ultimately need to be able to interpret, critique and create canonical scientific representations (Prain \& Tytler, 2012, p. 2). In view of these convergences, and as an authoring team representing both strands, it seems to us productive to examine the possible bases for further agreement on the potential of a metalanguage shared by teachers and students for advancing these common goals. In this section, we examine the advantages and challenges surrounding the proposal of such a shared metalanguage, as well as outlining studies of the facilitative role of SFL-derived metalanguage in supporting students' development of multimodal disciplinary literacy.

The consensus on students developing an understanding of the form/ function of visual, verbal and symbolic/mathematical representations extends to 'macro conditions for quality science learning', including, importantly, teacher-guided consensus around representational adequacy (Prain \& Hand, 2016, p. 6).

However, Prain and Hand note that challenges remain at the 'micro level' of teaching/learning, including the timing and amount of explicit teaching 
of form/function relationships. Key to addressing these challenges is the issue of the semiotic knowledge base that underpins what students might be expected to learn about the form/function relationships. The substantial uptake of the SFL perspective by science education researchers suggests this as a possible consensual semiotic knowledge base (Airey \& Linder, 2017; Jones, Turney, Georgiou \& Nielsen, 2020; Liu \& Taber, 2016; Rappa \& Tang, 2018; Tang, 2013). SFL-oriented literacy researchers also recognize challenges concerning the nature, scope, optimal timing and mode of classroom implementation of an educationally accessible metalanguage 'good enough' to enhance student multimodal literacy development and learning (Macken-Horarik, Love, Sandiford \& Unsworth, 2018; Macken-Horarik, Love \& Unsworth, 2011; Rose, 2020b). The extent of common ground on this issue suggests that ongoing transdisciplinary collaboration amongst science education, social semiotics and literacy researchers will advance viable and productive approaches for classroom practice. In the following chapters, we develop a framework designed to encourage such transdisciplinary research and teaching initiatives. Here we outline advantages of an SFLoriented semiotic knowledge base for multimodal disciplinary literacy and issues of the derivation, adaptation and deployment of an accessible functional metalanguage for classroom work.

The prime advantage of SFL is its fundamental connection of form and meaning. It is also a theory that is at once extravagant and versatile. The extravagance resides in (a) comprehensiveness - accounting for the vast number of genres or types of texts that are used in a culture and the extensive and complex systems of meanings and their lexical, grammatical, phonological and graphological expressions (Halliday \& Matthiessen, 2004; Martin, 1992) and (b) the detail and delicacy with which these systems of meaning-making resources and the relationships amongst them are explicated. The versatility of SFL theory partly derives from its extravagance in that it is able to accommodate semiotic description of variation and novelty of expression at all levels from graphology/phonology to grammar to genre. The versatility is also due to the robustness of the underlying theoretical framework that accommodates the description of the meaning-making resources of other semiotic modes such as images (Caple, 2013; Kress \& van Leeuwen, 2006; Painter, Martin \& Unsworth, 2013). On the other hand, day to day use of such rich semiotic descriptions as an accessible shared metalanguage amongst teachers and students requires adaptation. This involves (a) selection of the extent and delicacy of the metalanguage to be used; (b) consideration of the non-technical modification of nomenclature and (c) determination of how and when the metalanguage would be deployed. A very substantial number of case studies have documented the take up of SFL metalanguage amongst teachers and students and have provided evidence through formative assessment of an associated improvement in students' interpretation and/or composition of text in different discipline areas. A number of such case studies have involved work in science classrooms (Forey, 2020; Gebhard, Chen \& Britton, 2014; Humphrey, 2017) and some 
have also documented associated improvement in student performance on summative external examinations (Forey, 2020; Humphrey, 2017). What is common amongst such studies is the need for adaptation of the SFL metalanguage. We will now outline some of these studies and examples of the adaptations and implementation strategies involving SFL metalanguage.

A project designed to improve students' written explanations was implemented with teachers and their 16-year-old students in a UK school with a large proportion of students whose first language was not English (Forey, 2020). The teachers had some prior training in SFL-based approaches to literacy, so Forey focussed this intervention on SFL concepts with which the teachers were most familiar. The relevant metalanguage was used by teachers and used with and by the students in relation to their writing in the science classroom. Typical of the outcomes of the overt use of metalanguage in scaffolding the students' writing was the student explanation of the sequence of processes in the nutrient cycle, where each clause represented one process in the cycle (but see Section 3.6 for the importance of students' learning how such meanings can be 'distilled' so that a sequence is represented by a single noun group). Another outcome in the Forey (2020) study on student writing was that the new information occurring at the end of each clause (Rheme) as a result of the process becomes the given information (Theme) at the beginning of the next clause, forming the typical zigzag thematic pattern across such explanations (Eggins, 2004, p. 324), demonstrating a coherent method of development in this student's text. Forey reports the science teachers' comments about feeling empowered by the metalanguage to talk with the students about language in a way that was not possible for them prior to the study. What is important to note is the constrained focus on a particular selection from the metalanguage apposite to the text creation goals of the topic of the classroom work. Similar adaptations are evident in a study with younger English language learners in the US in classroom work on global warming, where the metalanguage focus was on Theme/Rheme, nominalization, process and participant types and 'time words' (Gebhard et al., 2014). The nature of these kinds of classroom adaptations of SFL metalanguage is now a focus of systematic research by educational linguists (Fang, 2020; Macken-Horarik et al., 2018; Macken-Horarik et al., 201 l; Rose, 2020a, 2020b). Rose has pointed out that 'only a fraction of SFL's rich descriptions of grammar and discourse systems are essential for teachers' practice' (p. 274) and that the 'metalanguage they need is not the same as that designed for linguistics students in functional grammar textbooks. Rather its organization needs re-contextualizing for learning and application in classroom activities' (p. 291). This perspective together with the shared concern about students developing an understanding of the form/function of science representations amongst researchers with different orientations to literacy in science underlines the potential of collaborative, transdisciplinary research into how the use of an SFL-derived metalanguage can enhance multimodal disciplinary literacy development in science education. 


\subsection{Negotiating knowledge building: shunting between 'everyday' and disciplinary discourse}

The increasingly subject-specific literacies and technical discourses that characterize the sub-disciplines of senior high school science are much further removed from everyday discourse than the discourse forms encountered by students in their experience of basic and intermediate literacies. Notwithstanding some variation in pedagogic orientations, researchers and educators from different traditions in science education and those influenced by SFL concur that students need to come to understand the functional nature of the genre, grammar, discourse and multimodal forms of canonical representations of scientific knowledge. Achieving and demonstrating such understanding by students entails their being able to 'shunt' between the discourses of everyday experiences and technical discourses of scientific knowledge. The semiotic nature of this 'shunting' and the role of an SFLderived metalanguage in pedagogy designed to develop students' capacity for such bi-directional traversals are significant dimensions of the induction of students into the disciplinary representational practices of science. In this section, we emphasize teacher-student negotiated shunting between the communication norms of everyday experience and those of the discourse of science as being essential to building students' conceptual knowledge. We point to the value of teachers' explicit knowledge about how language and images make meanings and the advantage of a shared metalanguage between teachers and students in facilitating such learning. Finally, we indicate the alignment of these initiatives with the development of students' metarepresentational competence (MCA) and their potential compatibility with and enhancement of science pedagogies that include student representation interpretation and construction as core strategies.

More than three decades ago, the centrality to science pedagogy of shunting between more accessible, iconic representational forms and more abstract scientific discourse was outlined by Lemke (1989) who drew attention to the importance of moves in science classroom talk that 'continually restate the unfamiliar in more familiar terms and vice versa' (p. 138). More recently, Maton has theorized this notion more generally as what he has termed 'semantic waves' (Macnaught, Maton, Martin \& Matruglio, 2013; Maton, 2013). Maton characterizes discourse along parameters he calls 'semantic gravity' and 'semantic density'. Semantic gravity refers to context dependence: when semantic gravity is stronger, the represented meanings are closely related to particular contexts of use; when it is weaker, the meanings are less dependent on a particular context. Semantic density refers to degrees of condensation of meaning: when semantic density is stronger, more meanings are condensed within representations; when semantic density is weaker, fewer meanings are condensed. Semantic waves can describe discursive practices that 'unpack' scientific discourse with strong semantic density and weak semantic gravity and render this discourse in more iconic terms with weak semantic density and strong semantic gravity, as a downward wave, 


\section{Text 3.1 High-scoring student response}

(1) Mitosis is one of the two forms of cell division that occurs in our body, the other being meiosis.

(2) Mitosis is the process in which a cell divides into two cells identical to the original cell.

(3) Mitosis begins with DNA replication.

(4) This is when the cell's chromosomes replicate and split.

(5) The cell then divides into two cells each with 46 chromosomes, otherwise known as diploid cells.

(6) Mitosis is used for many processes in our body involving growth and repair.

and 'repack' such everyday representations in terms of highly condensed scientific discourse as an upward wave. Science learning necessarily entails students developing their capacity to manage this packing and unpacking. The symbiotic relationship between this representational competence and students' conceptual knowledge is succinctly demonstrated in a comparison of low-scoring and high-scoring responses to a year 11 biology examination short answer question requiring students to describe the process and role of mitosis (Macnaught et al., 2013). The high-scoring student response is shown in Text 3.1.

Macnaught et al. (2013) point out that the first sentence has high semantic density and low semantic gravity, but sentence two then decreases the density and increases the gravity. The same pattern occurs with the third sentence semantically dense and with low semantic gravity and then the fourth and fifth sentences again decrease the density and increase the gravity. Then the last sentence returns to high semantic density and low semantic gravity. Hence this short answer makes semantic waves that interrelate less dense, highly contextualized meanings with the distilled and decontextualized meanings of more technical representations. From an SFL perspective, this student uses 'nominalization' to distil into one noun group ('two forms of cell division') the complex series of actions in which multiple entities are engaged in this process. The same kind of distillation occurs in the noun group 'DNA replication', where a sequence of activities is represented as a single noun group. But the following sentence unpacks the distilled meaning in this nominalization and communicates the activities by specifying the entities concerned and the actions in which they engage. Hence, this student controls the linguistic tools to show how the more condensed, abstract meanings of complex scientific knowledge are constructed through language.

The response by the low-scoring student is shown in Text 3.2. 


\section{Text 3.2 Low-scoring student response}

(1) Mitosis is when the two parent cells come together, their DNA replicates and all these cells then replicate again, which go on to form two diploid cells.

(2) The 23 pairs of chromosomes combine to make it all up.

(3) All chromosomes contain the same genetic material that helps generate the body.

(4) The mitosis replicates the chromosomes which create enzymes.

There is no semantic wave in Text 3.2 - no distillation of meaning - no condensing of a sequence of activities and entities involved in them into a single noun group. Text 3.2 simply represents dynamically a series of events in which particular entities participate, whereas Text 3.1 not only does this (e.g. 'a cell divides into two') but also represents the same event in a single nominal group (e.g. 'two forms of cell division'). Macnaught et al point out that this is not simply to 'dress up' the meanings contained in Text 3.2. Rather, the two texts construct different kinds of meanings. Unlike Text 3.2, the nominalization ('two forms of cell division') in Text 3.1 also enables classification, and the cell compositional relations and definition of entities are represented clearly and efficiently. Text 3.1 reflects the knowledge-building practices of the discourse of biology in creating relationships of classification and composition and precise chains of logical relations.

The challenge for the writer of Text 3.2 is 'learning to handle text as technology' (Martin, 1993b) as a key dimension of apprenticeship into the disciplinary discourse of biology. The challenge for teachers is how to support the student to do this, especially in the context of the highly directed and assessment-driven curricula of senior high school science. Designing pathways of response to these challenges will be explored in more detail in the subsequent chapters. Here it is important to decouple the perception of the pedagogic use of SFL-related metalanguage from a necessarily 'highly directed, explicit teacher-focused pedagogy' (Prain \& Hand, 2016, p. 3). This decoupling is made clear by Macnaught et al. (2013) in discussing the 'joint construction' phase of the genre-based literacy TeachingLearning Cycle (TLC). The genre-based approach and TLC do not regard disciplinary literacy development as simply an individual responsibility of the student that may be gradually acquired through exposure to curriculum resources and peer and teacher feedback to student exploratory text creation. Rather it emphasizes anticipatory guidance from the teacher, hence the role of contextualizing, deconstructing and annotating recognized authoritative texts to develop students' understanding about the variety of ways in which linguistic choices construct disciplinary meanings and how such choices can be deployed to achieve students' purposes in creating their own texts. 


\section{Distinguishing multimodal literacy}

This is the context in which functional SFL adapted metalanguage is introduced to provide an efficient shared means of the teacher and students discussing the textual choices. The teacher-orchestrated collaborative text creation, known as 'joint construction', draws on what is learned through text deconstruction and may make use of metalanguage in discussing and deciding on mutually agreed text constructions. In this way, the collaborative composition process is seen as preparing students to undertake their subsequent independent text creation. Macnaught et al. emphasize that this interactive guidance is 'an opportunity to discuss and debate decisions about how knowledge is created through language and other media' and 'where variation from model texts can be creatively, yet discerningly explored' $(2013$, p. 55). There are several studies by SFL-oriented researchers that illustrate the shared teacher and student use of SFL-based metalanguage in contexts such as those described by Macnaught et al. (e.g. Fang \& Schleppegrell, 2010; Forey \& Cheung, 2019; Gebhard et al., 2014; He \& Forey, 2018).

The benefits of a shared metalanguage to discuss the meaning-making options of different linguistic and visual semiotic choices in text interpretation and creation are also compatible with research by diSessa (2004) concerning the significance of MCA in the efficacy of student interpretation and construction of visualizations in science learning. DiSessa (2004) indicates that

Lack of attention to how representations work, to their limits as well as capacities, and to alternatives to sanctioned representations may be limiting the sense students make of learning representations in school.

(diSessa, 2004, p. 300)

He also indicated that

[c] ertainly, it is implausible that students can learn these new representations one at a time and each completely from scratch. An obviously better approach is to teach general principles of representation.

(diSessa, 2004, p. 297)

DiSessa did not canvas the pedagogic use of a semiotic metalanguage, but the concerns he expressed warrant investigation of the potential of the SFLrelated description of the meaning-making resources of images by Kress and van Leeuwen (2006) in their 'grammar of visual design'.

The principles underpinning an RCA developed by Tytler and his colleagues include an interplay between teacher-introduced and studentconstructed representations where students are challenged and supported to refine, extend and coordinate their understandings' and an 'explicit focus on representational function and form, with timely clarification of parts and their purposes' (Tytler et al., 2013, pp 34-35). These principles from the RCA work on student multimodal text creation also suggest compatibility 
with the use of SFL-based metalanguages describing the function and form of the meaning-making resources of language and image.

\subsection{Conclusion}

A hallmark of effective teaching in science and of effective demonstration of learning is the capacity to articulate a mapping of interrelationships between more commonly accessible and iconic representations and the technical, abstracted scientific accounts of phenomena. Systematic metarepresentational knowledge may assist science teachers in enabling all students to engage in such mapping - and developing a shared metalanguage as a part of multimodal literacy-infused science pedagogy may facilitate this through enhancing students' MCA. In this chapter, we have indicated that exploring these possibilities rests upon appreciating the multimodal disciplinary literacy that is characteristic of science and the commonalities and distinctiveness of this disciplinary literacy in science sub-disciplines. We have further suggested that transdisciplinary research in collaboration with teachers may provide a new consensus on how infused multimodal disciplinary literacy can enhance teaching and learning in senior high school science. We now extend our transdisciplinary endeavours encompassing literacy, social semiotics and science education research to examining in Chapter 4 the contextual conditions of the senior high school for developing multimodal disciplinary literacy in science and then in Chapter 5 describing kinds of teaching/learning practices entailed as a basis for our proposed framework for infused multimodal disciplinary literacy in school science presented in Chapter 7.

\section{References}

Airey, J., \& Linder, C. (2017). Social semiotics in university physics education. In D. Treagust, R. Duit \& H. Fischer (Eds.), Multiple representations in physics education (pp. 95-122). Cham, Switzerland: Springer.

Antonacci, P. A., O'Callaghan, C. M., \& Berkowitz, E. (2014). Developing content area literacy: 40 strategies for middle and secondary classrooms. Thousand Oaks, CA: Sage Publications.

Bateman, J. (2008). Multimodality and genre: A foundation for analysis. London: Palgrave Macmillan.

Bean, T. (2011). Content-area literacy: Reaching and teaching the 21 st century adolescent. California: Shell Education.

Berry, E. D. (2013). Literacy for learning: A handbook of content-area strategies for middle and high school teachers. Lanham, MD: Rowman \& Littlefield.

Caple, H. (2013). Photojournalism: A social semiotic approach. Berlin, Germany: Springer.

Chidrawi, G., Davis, A., Farr, R., Lampman, K., Matchett, B., \& Young, P. (2013). Nelson iscience 10. Melbourne: Nelson Cengage.

diSessa, A. A. (2004). Metarepresentation: Native competence and targets for instruction. Cognition and Instruction, 22(3), 293-331.

Doran, Y. J. (2017). The discourse of physics: Building knowledge through language, mathematics and image. London: Routledge. 


\section{Distinguishing multimodal literacy}

Doran, Y. J. (2019). Building knowledge through images in physics. Visual Communication, 18(2), 251-277.

Dreyfus, S. J., Humphrey, S., Mahboob, A., \& Martin, J. R. (2015). Genre pedagogy in higher education: The SLATE project. London: Palgrave Macmillan.

Eggins, S. (2004). An introduction to systemic functional linguistics. London: Continuum.

Eggins, S., Wignell, P., \& Martin, J. R. (1993). The discourse of history: Distancing the recoverable past. In M. Ghadessy (Ed.), Register analysis: Theory and practice (pp. 75-109). London: Pinter.

Fang, Z. (2020). Toward a linguistically informed, responsive and embedded pedagogy in secondary literacy instruction. Journal of World Languages, 6(1-2), 70-91.

Fang, Z., Lamme, L. L., \& Pringle, R. M. (2010). Language and literacy in inquirybased science classrooms, grades 3-8. Thousand Oaks, CA: Corwin Press.

Fang, Z., \& Schleppegrell, M. (2010). Disciplinary literacies across content areas: supporting secondary reading through functional language analysis. Journal of Adolescent and Adult Literacy, 53(7), 587-597.

Forey, G. (2020). A whole school approach to SFL metalanguage and the explicit teaching of language for curriculum learning. Journal of English for Academic Purposes, 44, 100822.

Forey, G., \& Cheung, L. M. E. (2019). The benefits of explicit teaching of language for curriculum learning in the physical education classroom. English for Specific Purposes, 54, 91-109.

Freebody, P., \& Muspratt, S. (2007). Beyond generic knowledge in pedagogy and disciplinarity: The case of science textbooks. Pedagogies: An International Journal, 2(1), 35-48.

Gebhard, M., Chen, I.-A., \& Britton, L. (2014). "Miss, nominalization is a nominalization": English language learners' use of SFL metalanguage and their literacy practices. Linguistics and Education, 26, 106-125.

Goddiksen, M. (2014). Explanatory standards in biology and physics textbooks: The case of polymers. Retrieved 5 April 2020, from http://philsci-archive.pitt. edu/11150/

Goldman, S. R., Britt, M. A., Brown, W., Cribb, G., George, M., Greenleaf, C., ... Shanahan, C. (2016). Disciplinary literacies and learning to read for understanding: A conceptual framework for disciplinary literacy. Educational Psychologist, 51(2), 219-246.

Halliday, M. A. K., \& Martin, J. R. (Eds.). (1993). Writing science: Literacy and discursive power. London: Falmer Press.

Halliday, M. A. K., \& Matthiessen, C. (2004). An introduction to functional grammar (4th ed.). London: Arnold.

Hand, B., \& Keys, C. W. (1999). Inquiry investigation. The Science Teacher, 66(4), 27.

Hao, J. (2020). Analysing scientific discourse from a systemic functional linguistic perspective: A framework for exploring knowledge building in biology. London: Routledge.

Hartley, L. M., Momsen, J., Maskiewicz, A., \& D’Avanzo, C. (2012). Energy and matter: Differences in discourse in physical and biological sciences can be confusing for introductory biology students. BioScience, 62(5), 488-496.

He, Q., \& Forey, G. (2018). Meaning-making in a secondary science classroom: A systemic functional multimodal discourse analysis. In K.-S. Tang \& K. Danielsson (Eds.), Global developments in literacy research for science education (pp. 183-202). Cham, Switzerland: Springer. 
Hubber, P., \& Tytler, R. (2017). Enacting a representation construction approach to teaching and learning astronomy. In D. Treagust, R. Duit \& H. Fischer (Eds.), Multiple representations in physics education (pp. 139-161). Cham, Switzerland: Springer.

Hubber, P., Tytler, R., \& Haslam, F. (2010). Teaching and learning about force with a representational focus: Pedagogy and teacher change. Research in Science Education, 40(1), 5-28.

Humphrey, S. (2017). Academic literacies in the middle years: A framework for enhancing teacher knowledge and student achievement. New York: Taylor \& Francis.

Jones, P., Turney, A., Georgiou, H., \& Nielsen, W. (2020). Assessing multimodal literacies in science: Semiotic and practical insights from pre-service teacher education. Language and Education, 34, 1-20.

Kress, G., Jewitt, C., Ogborn, J., \& Tsatsarelis, C. (2001). Multimodal teaching and learning: Rhetorics of the science classroom. London: Continuum.

Kress, G., \& Ogborn, J. (1998). Modes of representation and local epistemologies: The presentation of science in education. SISC Working Papers, 2, 2-22.

Kress, G., Ogborn, J., \& Martins, I. (1998). A satellite view of language: Some lessons from science classrooms. Language Awareness, 7(2-3), 69-89.

Kress, G., \& van Leeuwen, T. (2006). Reading images: The grammar of visual design (2nd ed.). London: Routledge.

LaDue, N. D., Libarkin, J. C., \& Thomas, S. R. (2015). Visual representations on high school biology, chemistry, earth science, and physics assessments. Journal of Science Education and Technology, 24(6), 818-834.

Lemke, J. (1989). Making text talk. Theory into Practice, 28, 136-141.

Lemke, J. (1990). Talking science: Language, learning and values. Norwood, NJ: Ablex.

Lemke, J. (2004). The literacies of science. In E. W. Saul (Ed.), Crossing borders in literacy and science instruction: Perspectives on theory and practice (pp. 33-47). Newark, DE: International Reading Association.

Levin, T., \& Wagner, T. (2006). In their own words: Understanding student conceptions of writing through their spontaneous metaphors in the science classroom. Instructional Science, 34(3), 227.

Liu, Y., \& Taber, K. S. (2016). Analysing symbolic expressions in secondary school chemistry: Their functions and implications for pedagogy. Chemistry Education Research and Practice, 17(3), 439-451.

Lofts, G., \& Evergreen, M. J. (2015). Science quest 10: Australian curriculum (2nd ed.). Milton, Queensland: Jacaranda.

Macken-Horarik, M., Love, K., Sandiford, C., \& Unsworth, L. (2018). Functional grammatics: Reconceptualizing knowledge about language and image for school English. London: Routledge.

Macken-Horarik, M., Love, K., \& Unsworth, L. (2011). A grammatics 'good enough' for school English in the 2 lst century: Four challenges in realizing the potential. Australian Journal of Language and Literacy, 34(1), 9-23.

Macnaught, L., Maton, K., Martin, J. R., \& Matruglio, E. (2013). Jointly constructing semantic waves: Implications for teacher training. Linguistics and Education, 24(1), 50-63.

Martin, J. R. (1992). English text: System and structure. Amsterdam: Benjamins.

Martin, J. R. (1993a). Life as a noun: Arresting the universe in science and humanities. In M. A. K. Halliday \& J. R. Martin (Eds.), Writing science: Literacy and discursive power (pp. 221-267). London: Falmer. 


\section{Distinguishing multimodal literacy}

Martin, J. R. (1993b). Literacy in science: Learning to handle text as technology. In M. Halliday \& J. R. Martin (Eds.), Writing science: Literacy and discursive power (pp. 166-202). London: Falmer.

Martin, J. R. (1994). Macro-genres: The ecology of the page. Network, 21, 29-52.

Martin, J. R. (2017). Revisiting field: Specialized knowledge in secondary school science and humanities discourse. Onomazein, 111-148.

Martin, J. R. (2020). Revisiting field: Specialized knowledge in secondary school science and humanities discourse. In J. R. Martin, K. Maton \& Y. Doran (Eds.), Accessing academic discourse: Systemic functional linguistics and legitimation code theory (pp. 114-148). London: Routledge.

Martin, J. R., \& Rose, D. (2008). Genre relations: Mapping culture. London: Equinox Pub.

Martin, J. R., Unsworth, L., \& Rose, D. (in press). Condensing meaning: Imagic aggregations in secondary school science. In G. Parodi (Ed.), Multimodality: From corpus to cognition. London: Bloomsbury.

Martin, J. R., \& Veel, R. (Eds.). (1998). Reading science: Critical and functional perspectives on discourses of science. London: Routledge.

Maton, K. (2013). Knowledge and knowers: Towards a realist sociology of education. London: Routledge.

Moje, E. B. (2008). Foregrounding the disciplines in secondary literacy teaching and learning: A call for change. Journal of Adolescent \& Adult Literacy, 52(2), 96-107.

Moje, E. B., Sutherland, L., Cleveland, T., \& Heitzman, M. (2010). Integrating literacy instruction into secondary school science inquiry: The challenges of disciplinary literacy teaching and professional development. Ann Arbor, 1001, 48109-51259.

Muspratt, S., \& Freebody, P. (2013). Understanding the disciplines of science: Analysing the language of science textbooks. In M. Khine (Ed.), Critical analysis of science textbooks (pp. 33-59). Dordrecht: Springer.

O'Halloran, K. (2003). Intersemiosis in mathematics and science: Grammatical metaphor and semiotic metaphor. In A.-M. Simon-Vandenbergen, M. Taverniers \& L. Ravelli (Eds.), Grammatical metaphor (pp. 337-366). Amsterdam/Philadelphia: John Benjamins.

O’Hallaron, C. L., Palincsar, A. S., \& Schleppegrell, M. J. (2015). Reading science: Using systemic functional linguistics to support critical language awareness. Linguistics and Education, 32, 55-67.

Painter, C., Martin, J. R., \& Unsworth, L. (2013). Reading visual narratives: Image analysis of children's picture books. London: Equinox.

Parodi, G. (2012). University genres and multisemiotic features: Accessing specialized knowledge through disciplinarity. Fórum Lingurstico, 9(4), 259-282.

Polias, J. (2015). Apprenticing students into science: Doing, talking, writing and drawing scientifically. Stockholm: Hallgren and Fallgren.

Prain, V., \& Hand, B. (2016). Learning science through learning to use its languages. In B. Hand, M. McDermott \& V. Prain (Eds.), Using multimodal representations to support learning in the science classroom (pp. 1-10). Cham, Heidelberg, New York, Dordrecht, London: Springer.

Prain, V., \& Tytler, R. (2012). Learning through constructing representations in science: A framework of representational construction affordances. International Journal of Science Education, 34(17), 2751-2773. 
Rappa, N. A., \& Tang, K.-S. (2018). Integrating disciplinary-specific genre structure in discourse strategies to support disciplinary literacy. Linguistics and Education, $43,1-12$.

Rivard, L. P., \& Straw, S. B. (2000). The effect of talk and writing on learning science: An exploratory study. Science Education, 84(5), 566-593.

Rose, D. (2020a). Building a pedagogic metalanguage I: Curriculum genres. In J. R. Martin, K. Maton \& Y. J. Doran (Eds.), Studying science: Knowledge, language and pedagogy (pp. 236-267). London \& New York: Routledge/Taylor \& Francis.

Rose, D. (2020b). Building a pedagogic metalanguage II: Knowledge genres. In J. R. Martin, K. Maton \& Y. J. Doran (Eds.), Studying science: Knowledge, language and pedagogy (pp. 268-302). London \& New York: Routledge/Taylor \& Francis.

Rose, D., \& Martin, J. R. (2012). Learning to write, reading to learn: Genre, knowledge and pedagogy across the curriculum. London: Equinox.

Schleppegrell, M. (2011). Supporting disciplinary learning through language analysis: Developing historical literacy. In F. Christie \& K. Maton (Eds.), Disciplinarity: Functionallinguistic and sociological perspectives (pp. 197-216). London: Bloomsbury.

Schleppegrell, M. (2013). The role of metalanguage in supporting academic language development. Language Learning, 63(1), 153-170.

Shanahan, C., \& Shanahan, T. (2017). Disciplinary literacy Handbook of research on teaching the English language arts (pp. 281-308). New York: Routledge.

Shanahan, T., \& Shanahan, C. (2008). Teaching disciplinary literacy to adolescents: Rethinking content-area literacy. Harvard Educational Review, 78(1), 40-59.

Shanahan, T., \& Shanahan, C. (2012). What is disciplinary literacy and why does it matter? Topics in Language Disorders, 32(1), 7-18.

Spires, H. A., Kerkhoff, S. N., Graham, A. C., Thompson, I., \& Lee, J. K. (2018). Operationalizing and validating disciplinary literacy in secondary education. Reading and Writing, 31(6), 1401-1434.

Tang, K.-S. (2013). Instantiation of multimodal semiotic systems in science classroom discourse. Language Sciences, 37, 22-35.

Tang, K.-S., \& Danielsson, K. (2018). Global developments in literacy research for science education. Cham, Switzerland: Springer.

Tytler, R., \& Hubber, P. (2010). A representation-intensive signature pedagogy for school science. Paper presented at the Australian Association for Research in Education, Melbourne.

Tytler, R., Prain, V., \& Hubber, P. (2018). Representation construction as a core science disciplinary literacy. In K.-S. Tang \& K. Danielsson (Eds.), Global developments in literacy research for science education (pp. 301-318). Cham, Switzerland: Springer.

Tytler, R., Prain, V., Hubber, P., \& Waldrip, B. (2013). Constructing representations to learn in science. Rotterdam, Netherlands: Springer Science \& Business Media.

Unsworth, L. (1999). Developing critical understanding of the specialised language of school science and history: A functional grammatical perspective. Journal of Adolescent and Adult Literacy, 42(7), 508-527.

Unsworth, L. (2001). Teaching multiliteracies across the curriculum: Changing contexts of text and image in classroom practice. Buckingham, United Kingdom: Open University Press.

Unsworth, L. (2020). Intermodal relations, mass and presence in school science explanation genres. In Michele Zappavigna \& S. Dreyfus (Eds.), Discourses of hope and reconciliation: J. R. Martin's contributions to systemic functional linguistics (pp. 131-152). London: Bloomsbury Academic. 


\section{Distinguishing multimodal literacy}

Veel, R. (1998). The greening of school science: Ecogenesis in secondary classrooms. In J. R. Martin \& R. Veel (Eds.), Reading science: Functional and critical perspectives on the discourses of science (pp. 114-151). London: Routledge.

Wahlberg, S. J., \& Gericke, N. M. (2018). Conceptual demography in upper secondary chemistry and biology textbooks' descriptions of protein synthesis: A matter of context? CBE-Life Sciences Education, 17(3), ar51.

Wignell, P., Martin, J. R., \& Eggins, S. (1993). The discourse of geography: Ordering and explaining the experiential world. In M. A. K. Halliday \& J. R. Martin (Eds.), Writing science: Literacy and discursive power (pp. 136-165). London: Falmer Press. 


\section{Contextualizing the conditions for multimodal literacy practices in senior high school science}

\subsection{Introduction}

Despite a clear need for research into student learning in the increasingly demanding language environment represented by senior science, limited research has been carried out that focusses on the nature of these language demands (but see Maton, Martin \& Doran, forthcoming), student experience of this or pedagogies appropriate for supporting learning of this complexity, at this level. Part of the reason for this is the difficulty of researching in senior classrooms, given the many competing demands on teachers and students. The study that stimulated this book, the M3S project, has offered a unique opportunity to articulate the particular disciplinary literacies demanded of subjects at the senior secondary level, the contextual challenges these present for students and teachers and approaches to supporting student development of these literacies. The team consists of both linguists versed in semiotics and disciplinary experts with experience in teaching a range of science subjects at this level, allowing an in-depth accounting of the particular and distinctive semiotic forms demanded by these subjects and the contextual constraints on the development of these disciplinary literacies. This chapter explores the nature of these constraints, preparatory to an account in subsequent chapters of our research.

\subsection{The complexity of literacy practices at the senior level}

Previous chapters have highlighted the specific multimodal literacy demands of science texts and textual practices, positioning this within a perspective of learning as induction into the discipline-specific literacies of the sciences. Further, we have explored the relationship between these disciplinary literacies and literacy practices more generally, pointing to the very particular nature and forms of scientific disciplinary literacy and the distinctive genres represented in science textbooks. Further, we have reviewed research into the distinctive multimodality of literacies in biology, chemistry and physics, and opened an argument for the development of a metalanguage that can be shared between students and teachers to support the development of these distinctive disciplinary literacies. In this chapter, we examine the particular 
disciplinary literacy challenges associated with senior school science and the challenges for researching disciplinary literacies at these levels as a prelude to the research carried out within the multiliteracies (M3S) research within which this book is situated. Christie (2012) identifies the hierarchical nature of knowledge building in the sciences to establish procedures and principles underpinning an emerging body of ideas. At the senior school level, there is a condensation of meaning with an expansion of lexes of the different fields involving dense, often technically difficult language, a tendency to collapse independent clauses into large noun groups, grammatical forms that capture a variety of ways of expressing causal relations, and higher-order language forms such as grammatical metaphor (p. 188). In science, there is a flattening of attitudinal expression, the use of graphs, statistics and formulas and distinct genres associated with description, explanation and experimental procedures.

Much of the research into scientific disciplinary literacies, conducted by scholars versed in systemic functional linguistics and science educators with a multimodal semiotic perspective, has been conducted in the primary school and middle years (Christie \& Derewianka, 2008; Fang \& Schleppegrell, 2010; Fang, 2013; Veel, 1997), or in the tertiary context (Hao \& Hood, 2019) and workplaces (Rose, 1998). Within science education research with a literacy perspective, considerable work has been conducted at the primary school level (Lehrer, 2009; Lehrer \& Schauble, 2012; Prain, Tytler \& Peterson, 2009; Tytler, Haslam, Prain \& Hubber, 2009; Tytler, Murcia, Hsiung \& Ramseger, 2017) or the early years of secondary school (Hand \& Prain, 2002; Hubber, Tytler \& Haslam, 2010; Tytler, Haslam, Prain \& Hubber, 2009; Waldrip, Prain \& Carolan, 2010).

There are a number of issues that arise when transposing the findings and recommendations for approaches to disciplinary literacy development from the earlier years to senior secondary and tertiary environments.

- The first is the increasing complexity of the disciplinary literacy in terms of the semantic density of text and image and the complex interrelations between these (Airey \& Linder, 2009; Khine, 2013; Martin, Unsworth \& Rose, in press). In Australia, this increase in complexity of language and concepts is accompanied by the fact that classes now contain students who have actively chosen science subjects, many of whom therefore have developed a taste for, and some confidence with, scientific ways of knowing. Nevertheless, senior science classes can be quite diverse in terms of students' backgrounds and language capability, and this remains an issue for crafting effective pedagogies that can respond to such diversity. The technicality of the terms and processes and the complexity of textual demands that senior school students need to come to terms with mean that many of the pedagogical processes that aim at bridging between students' everyday languages to the languages of scientific concepts and reasoning processes need to be differently enacted, given the greater linguistic and representational complexity encountered 
in the senior years. Inquiry processes, whereby students conjecture, explore and negotiate explanatory ideas and problem-solving processes may have a different shape, involving a differing nature and degree of teacher guidance. The process of reconceptualizing scientific disciplinary practices for the classroom must always involve a conversation with the curriculum and with students' everyday language and interests and their learning needs. Increasingly, progressing into the senior years, the balance shifts towards a need to represent the mature literacies of scientific communities. Textbook representations place increasing demands on students' semiotic resources, with representations increasingly containing 'appresented' or hidden/assumed semiotic resources that require of students a certain level of disciplinary knowledge to discern and use (Eriksson, 2019; Eriksson, Linder, Airey \& Redfors, 2014; Linder, 2013).

- Second, the particular nature of the disciplinary literacy that is advocated will be shaped by the nature of curriculum content and the supporting assessment regimes, for instance, whether inquiry-based investigative work is valued and assessed, or whether the assessment regime includes extended explanatory work or project work or is limited to multiple-choice or short answer responses. These assessment regimes represent a position on the nature of the recontextualization of disciplinary epistemic practices and associated literacies that is developmentally appropriate for student induction into discursive practices. As such, they can significantly shape school teaching and learning cultures in ways that inevitably influence and potentially constrain pedagogical approaches focussed on literacy development that can be engaged with.

- Third, the imposition of high-stakes assessment around highly structured curriculum content means that teachers feel they have less time to develop the exploratory processes advocated by research into student representational work based on the alignment of classroom practices with disciplinary epistemic processes (Duschl, 2008; Prain \& Tytler, 2012). While senior science curricula often include investigative skills as a significant aim and problem-solving and critical thinking skills that would imply exploratory tasks as an important part of pedagogy, the pressures of time and restricted assessment regimes can offer significant constraints.

- Fourth, the pressures on teachers associated with these high-stakes assessment regimes make it difficult to enlist them in research that may require a time commitment and exploratory work around classroom activity, given that any change in practice is potentially high risk. Nevertheless, the reality is that curriculum content supported by competitive assessment regimes shapes the nature of the target disciplinary literacy and frames what is possible with regard to advocating for its development.

- Finally, in practical terms, the reality of teaching and learning in these high-stakes environments, including where teachers' reputations are 
dependent on student scores and their feelings of prime responsibility to students to maximize their life chances through these scores, creates a conservative environment that makes it difficult for researchers to collaboratively develop innovations in approach. This is possibly why there is a dearth of research at these levels, and why most of the innovation around disciplinary literacy development has occurred in the lower secondary and primary school environments, where the nature of learning is somewhat different.

The M3S project has operated in these conditions to explore, with teachers, ways of focussing on literacy development such that students' disciplinary understandings and practices can be improved. Within the M3S team are scholars who are familiar with the teaching and learning of the science disciplines at this level, as well as linguists familiar with the technicalities of the discursive features of text and practice. This unique constitution of the team has positioned it to effectively bridge the different disciplinary literacy traditions to explore a pedagogy that infuses multimodality through the teaching and learning process. In this chapter, we describe, firstly, the features of these literacies that students in each subject need to grapple with and master, before exploring the challenges to students mastering these, the role of assessment regimes in shaping literacy development and the contextual challenges involved in developing a responsive pedagogy.

\subsubsection{Complexity in learning biology}

Learning in each of the sciences, at the senior level, involves mastering the literacies involved in describing part-whole relations between entities at multiple levels of abstraction from molecular through macroscopic phenomena, creating explanations involving a variety of modelling processes and making sense of temporal processes involving material, energy and other transformations. Senior science textbooks contain multiple diagrams, photographs, equations and symbols and explanatory text which the reader needs to make sense of in order to establish a coherent account. As an example from biology, White, Tytler and Nielsen (2020) investigated year 11 biology students re-interpreting a biology text, in a topic they were familiar with, to construct a stopmotion (slowmation) animation of digestive processes (Hoban \& Nielsen, 2013). Tracking their construction of the animation showed clearly the struggle they had in interpreting and visually representing the different elements of the process. The challenge for two year 11 students, Marcia and Marley, in constructing their slowmation of digestive processes occurred at a number of different points in the sequence:

- Representing the part-whole relations and scale, in the breaking down of macroscopic food into sub-microscopic sugars 'Marcia: We'll show it as a big ball and then being separated ... together and then show them separating' (p. 218) 
- Visualizing the physical operation of the bolus's passage through the pyloric sphincter

- Representing visuo-spatially the sequence of events as chyme is broken down: 'Marcia: Hang on, we have got to show that it breaks down as a bolus, because that is what it does. Wait no, it breaks this down first and then it turns in the bolus' (p. 219)

- Dealing with the technical names of enzymes and their operations: 'Marcia: We should draw stuff inside so like what was it.... This should be bicarbonate, this one.... (Marley reads: "Pancreatic juice. Amylase, trypsin, lipase, and bicarbonate) ... Is it the same color as the amylase before? ... It was the green though, no it wasn't. There was no amylase in the stomach, okay. What was it at the start?"' (p. 221)

This 'cross-modal translation', from textbook images and text to constructing a 2D temporal account, involves transduction across modes. In this process, the meaning shifts according to the particular affordances of the mode to constrain attention on spatial, visual or temporal elements, for instance, of processes or relations. White et al. (2020) argue that this transduction can be modelled using a Peircian triad, with the book acting as an object that is now freshly reinterpreted/represented by the transduction across to the slowmation construction, with the meaning of the digestion process enriched through the spatial and visual affordances offered by the slowmation construction process (Prain \& Tytler, 2012). Figure 4.1 illustrates this process of semiosis. Arguably, without the demands of the slowmation to force fresh attention on the digestion narrative, students need to do exactly this sort of work mentally in interpreting the complex literacy demands of the text.

Reading such text is challenging, involving the imaginative construction of multiple terms and elements, much more so than for lower grade level texts where the meanings are less technical, less dense and closer to everyday discourse.

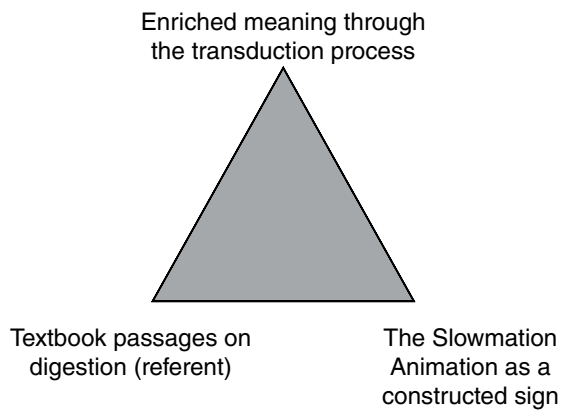

Figure 4.1 The process of semiosis in transducting from textbook to slowmation construction. 


\subsubsection{Complexity in learning physics and astronomy}

Physics texts contain similar complexity but with a different balance of modal challenges, involving more mathematical equations and symbols, for instance, and abstracted entities. These disciplinary differences will be teased out in later chapters, but to illustrate the challenges, three figures from the same page of a physics textbook (Moran et al., 2016) are shown in Figure 4.2 as part of a section on voltage, current and resistance relations in an electric circuit. The text includes definitions of EMF; description of the operation of a battery using a pump analogy; a mapping of voltage levels around the circuit; a gravitational analogy of this circuit and current; an annotated, formalized circuit diagram; and equations relating voltage, current, to prove the rule for adding resistances in the circuit. These are highly interrelated but distinct aspects of these 'simple' circuit phenomena, with transduction across modes requiring the juxtaposition of abstracted voltage concepts and variation in graphical form and across spatial arrangements, gravitational analogies and technicalities of symbols and annotations, as well as an indirect argument about the relationship between total and individual resistances that involves

There are a number of ways to visualise the energy changes in this circuit. One common analogy is to think of the charges as water being pumped around an elevated water course. The water gains potential energy as it is pumped higher, and as it flows back down the potential energy is converted into other forms. The diagram in Figure 4.1.5 shows how the analogy works with the energy changes that occur in a circuit. The battery acts as a 'pump' that pushes electrons up to a higher energy level and the electrons gain potential energy. As the electrons pass down through components in the circuit, their energy is transformed into other forms.

The change in electrical energy available to electrons can also be represented graphically, as shown in Figure 4.1.6.
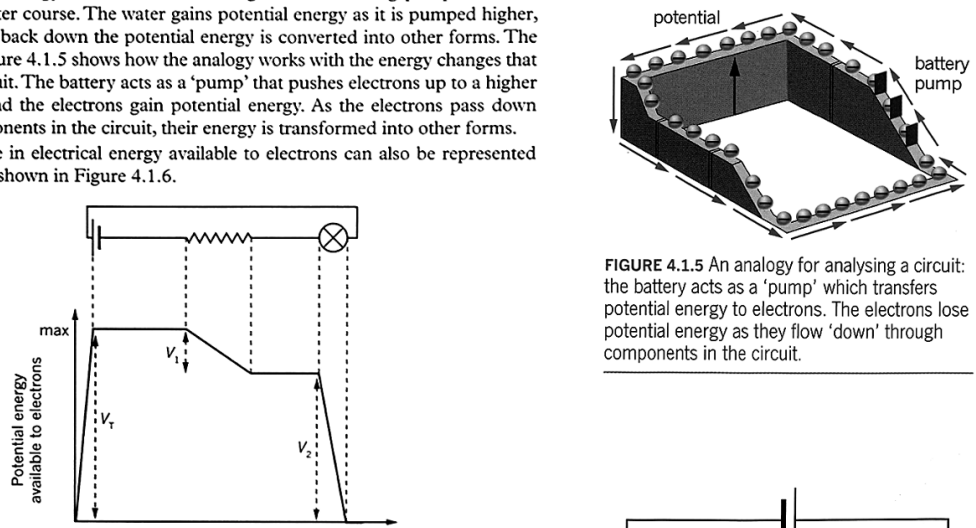

FIGURE 4.1.5 An analogy for analysing a circuit: the battery acts as a 'pump' which transfers potential energy to electrons. The electrons lose potential energy as they flow 'down' through components in the circuit.

FIGURE 4.1.6 The electric potential energy of an electron changes as it moves around the circuit. the electrons pass through the bulb. In this circuit, the bulb has more resistance than the resistor.

\section{Equivalent series resistance}

Consider the circuit in Figure 4.1.7. If the resistance of the fixed resistor is $R_{1}$, the resistance of the lamp is $R_{2}$ and the current flowing through both of them is $I$, then Ohm's law gives:

$V_{1}=I \times R_{1}$

and

$V_{2}=I \times R_{2}$

The total voltage drop across the two components is:

$V_{\text {Total }}=V_{1}+V_{2}=I R_{1}+I R_{2}=I \times\left(R_{1}+R_{2}\right)$

This equation shows the relationship between the potential difference supplied by the cell and the potential differences of the lamp and resistor. The last part of the equation also shows that the lamp and resistor can be replaced with a single resistor, without changing the current in the circuit. The single resistor needs to have a total resistance of $R_{1}+R_{2}$.

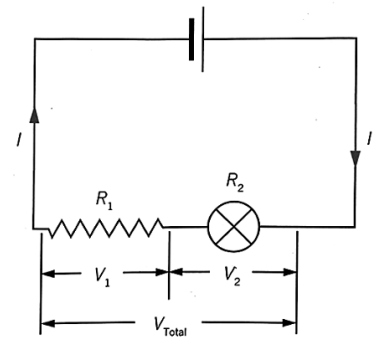

FIGURE 4.1.7 Using Ohm's law, it is possible to show the relationship between the potential difference supplied by the cell, $V_{\text {Total }}$, the current flowing in the circuit, $l$, and the resistances of the two components $R_{1}$ and $R_{2}$

Figure 4.2 Figures and text on one page of a year 11 physics textbook (Moran \& Fry, 2016, p. 125). 
coordinating mathematical and conceptual ideas and processes. These represent what Airey and Linder (2009) and Linder (2013) refer to as a 'critical constellation of modes' that must be coordinated to achieve understanding and operate with fluency to solve problems (Kozma \& Russell, 2005).

In the textbook chapter, further diagrams deal with a variety of electric circuit analogies, realistic circuit images to construct the logic of arguments establishing circuit relations, sub-microscopic modelling of current flow to establish Kirchoff's laws, an inset describing Kirchoff's historical achievements and more complex circuits and worked examples of their analysis. The textbook section is structured as an argument establishing the nature of voltage and its relationship round a circuit, and its relation to current and resistance. The text is strongly multimodal, introduces numerous technical terms and uses analogies and arguments to establish circuit relations. In each image, there is much that is 'appresented', and the student must infer meaning by working across these semiotic resources. The question the M3S project asks is: How might we devise pedagogical principles, including the use of a metalanguage, to support teachers and students to effectively deal with this density of text and image, and the conceptual relations between these semiotic entities in a situation of high content load and high-stakes assessment? The ways that Paulo, a physics teacher, introduces students to this same proof is analyzed in Chapter 8 of this book to show the complex orchestration of symbols, images, analogies and gestures involved in unpacking this for students.

Eriksson and colleagues (Eriksson, 2019; Eriksson, Linder, Airey \& Redfors, 2014) introduce the construct of 'disciplinary discernment' to denote the capacity of experts in the field to notice and read into representations key 'disciplinary affordances' that might escape the attention of or be misinterpreted by novices. Using examples from astronomy, in particular the Hertzsprung-Russell (HR) diagram characterizing stellar evolution, these authors develop a hierarchy of disciplinary discernment of semiotic resources in the field based on a comparison of interpretations of these by university students and academics. The levels are as follows:

1. Disciplinary identification - the recognition and naming of salient disciplinary objects

2. Disciplinary explanation - connecting and assigning disciplinary meaning to discerned objects, beginning to recognize their specific affordances (what they show and attend to)

3. Disciplinary appreciation - the ability to discern and analyze the disciplinary affordances of different representations and how they work together in a more holistic view of the discourse

4. Disciplinary evaluation - analyzing and critiquing the representations used, including their particular affordances

Airey and Eriksson (2019), in unpacking the HR diagram of stellar evolution, distinguish between the 'disciplinary affordance' of a semiotic resource, 
being its agreed function for the disciplinary community, and its 'pedagogical affordance', which is 'the aptness of a semiotic resource for teaching some educational content' (p. 99). They analyzed the complex meanings embodied in the HR diagram, which have been developed over a long period of time, to propose a simplified version for educational use that will not be so confusing to students. In their analysis, they identify four types of problem students can encounter when they meet disciplinary-specific semiotic resources for the first time: "the history of the resource, the omission of key information, the overloading that occurs due to the sheer amount of disciplinary knowledge on display and the students' own expectations about the knowledge and how it will be presented" (p. 106). From their analysis, it is clear that to unpack complex semiotic resources to help students 'read' them, teachers need an understanding of the complexities of representations, of assumed knowledge, of their sometimes-idiosyncratic histories and of students' own resources they bring to the reading.

We see in the aforementioned four-level hierarchy of disciplinary discernment increasing levels of interpretation and use of single representations, but also from level 3, how different representations work together within an explanatory discourse. Thus, reading the particular diagrams or symbols in Figure 4.2 is a matter of developing discernment at levels 1 and 2, but being able to coordinate those to develop a coherent explanatory discourse, as the text does, requires level 3 appreciation of their particular affordances graph, compared to diagram, analogy and mathematical symbolic relations. This is also what the physics teacher Paulo (referred to earlier) models in developing a proof of the relation between resistance, voltage and current in a series circuit. We argue that supporting students to achieve the evaluation level of disciplinary discernment requires access to a metalanguage with which to analyze and critique representational work, a programme that the M3S research has been engaging with.

This shift of attention from discernment of individual representations to an appreciation and use of multiple representations in developing explanations involves achieving fluency in a 'critical constellation of modes' (Airey \& Linder, 2009, 2017). It is also the focus of attention of Prain and Tytler (2012) who describe the construction of meaning as involving the coordination of multiple representations, each contributing an affordance that can be understood as a 'productive constraint' on perceiving and reasoning. We will introduce next the construct of representational competence that focusses explicitly on students' capacity to interpret, coordinate and effectively use representations.

\subsubsection{Complexity in learning chemistry}

For chemistry, similar to the biology and physics examples, concepts and explanations involve transduction across a range of modes involving, at senior school levels, increasingly complex models, arguments and temporal processes. The Johnstone triangle (Figure 4.3) is often referred to in describing 


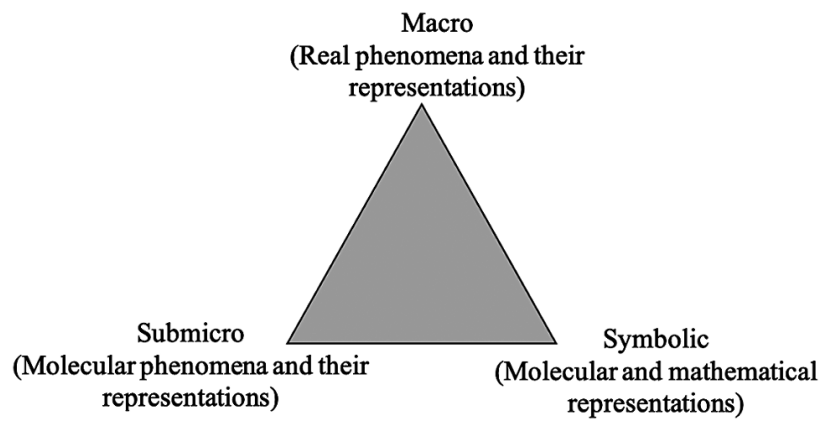

Figure 4.3 The three representational dimensions core to chemistry conceptions (Johnstone, 1991).

the challenges of visualization of chemical processes involving the need to transduct across macro, sub-micro and symbolic modes in order to construct explanations or solve problems in chemistry. This process of transduction is core to constructing the multimodal literacies and associated conceptual meanings through which chemical phenomena are understood.

In terms of the increasing semantic density in textbooks dealing with sub-microscopic models in chemistry and symbolic expressions, Figure 4.4 shows examples of molecular representations from early to later year 11 in a textbook published by Jacaranda. Note the sharp increase in semantic density across year 11 , which continues apace into year 12 , in which features of molecules become more abstracted and symbolic, with an increase in the represented elements to contain the representation of angles, bond types, re-organization of elements, 3D arrangement, bonding mechanisms and abstracted representations of groups.

Increasingly, over the secondary school years, these representations, and expectations of their use in explanatory and problem-solving tasks, become more abstracted, complex and involve coordination of representations across the sub-micro and symbolic domains. In inducting students into the discernment of these abstracted features, educators use a range of strategies including analogies or representations with pedagogical affordances to act as 'bridging models'. Figure 4.5 shows year 11 students coordinating a 'bridging model' (Pham, 2019) to help students read and solve problems involving molar concentration. The model uses crosses to represent moles and boxes to represent litres of solute to coordinate with mathematical calculations of concentration. This 'cross and portion' model is used by these students to underpin the symbolic mathematical calculations predicting the concentration of a solution formed by mixing $4 \mathrm{l}$ of $1 \mathrm{M}$ with $4 \mathrm{l}$ of $3 \mathrm{M}$ solution. Note how, in the transduction process, the visual model acts to anchor the quantities represented in the mathematical representation.

In further work with this notion of constructing bridging models to support the transduction from sub-micro to symbolic domains of the Johnstone triangle, students represented macroscopic properties of substances and 


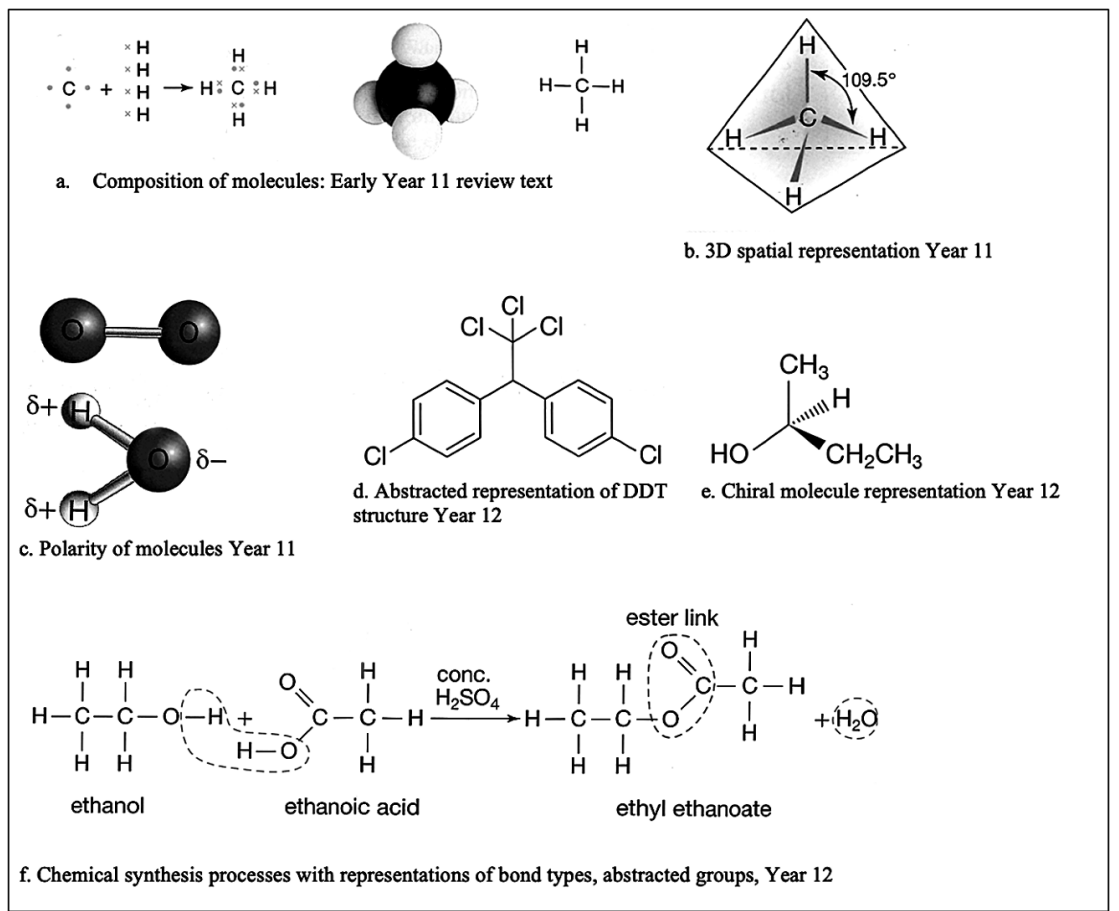

Figure 4.4 Increasing semantic density of representations of molecules across year 11: Jacaranda text Chemistry VCE Units 1 and 2 (Taylor, Stubbs \& Stokes, 2020).

Solution A

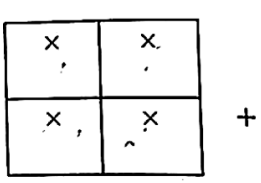

$1 \mathrm{~m} /$

\section{Solution B}

\begin{tabular}{|l|l|}
\hline$x \times x$ & $x \times x$ \\
\hline$x \times x$ & $x x x$ \\
\hline $\sin / 1$ & $4 / 8$
\end{tabular}

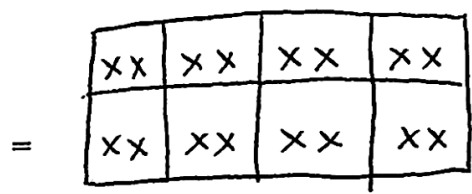

Solution $\mathbf{C}$

- calculared the number of mol in each solution $\rightarrow$ added them together.

- Divided that by the number of Litres: ratio: $M / L$

$$
\frac{\left(1_{M} \times 4\right)+(3 M \times 4)}{4_{L}+4_{L}}=\frac{4+12}{8}=\frac{16}{8}=\frac{2}{1}=2 M \operatorname{per} 1_{L}
$$

Figure 4.5 Year 11 students using a bridging 'cross and portion' model to calculate concentration when mixing two solutions (from Pham, 2019, p. 95). 
worked with molecular models and simulations to transduct across these representational modes. Pham argues that competent problem-solvers in chemistry have at their disposal mental models that correspond to these bridging models/analogies, but without the explicit support offered by these, unpacked by the teachers, the literacy demands of the transduction across macro, sub-micro and symbolic domains are considerable. Chapters 5 and 6 will explore in some detail the supporting role of the teacher in unpacking these literacy processes.

\subsubsection{Developing representational competence}

As flagged earlier in this review of the challenges of interpreting and using multiple multimodal representations in senior science, the question of disciplinary discernment, or representational competence, involves not only the interpretation and use of individual representations but also recognition of their particular affordances and their coordination in the literacy practices relating to explanation, reporting and problem-solving. Research into the construct of representational competence has gained pace recently, as a focus for developing disciplinary literacy in the sciences. Volkwyn, Airey, Gregorcic and Linder (2020), drawing on the work of Kozma and Russell (2005), De Cock (2012) and Linder et al. (2014) define representational competence $(\mathrm{R})$ as 'the ability to appropriately interpret and produce a set of disciplinary-accepted representations of real-world phenomena and link these to formalised scientific concepts' (p. 9l). They argue that R is made up of a set of discrete representational competencies (e.g. competencies in graphical interpretation and use, in diagram interpretation and use or mathematics) and also the ability to move fluently within (transformation) and across (transduction) representational systems. Gilbert (2008) offers listings of the component competencies of what he terms 'metavisualization' for each of the macro, sub-micro and symbolic domains for chemistry problem-solving, including graphical, gestural and diagram interpretation competency.

Kozma and Russell (2005) produced some of the seminal work relating to representational competence based on comparisons between novice and expert problem-solving in chemistry. Nitz and Tippett 2012 , quoted in Volkwyn et al., 2020, p. 91) summarize the main elements of the Kozma and Russell framing of representational competence as the ability to

(a) use representations for describing scientific concepts;

(b) construct and/or select a representation and explain its appropriateness for a specific purpose;

(c) use words to identify, describe and analyze features of representations;

(d) compare and contrast different representations and their information content;

(e) connect across different representations and explain the relationship between them; 
(f) realize that representations correspond to phenomena but are distinct from them; and

(g) use representations in discourse to support claims, draw inferences and make predictions.

This list has features in common with Eriksson's (2019) levels of disciplinary discernment, with the highest level involving the coordination and flexible use of representations in a critical capacity.

While these studies range across the senior school and tertiary levels, they identify a fundamental relationship between disciplinary knowledge, the capacity to interrogate and coordinate multimodal representations and explanatory and problem-solving capabilities. The rapidly growing sophistication of the representational work across the years arguably alters the balance between students' capacity to invent, explore and refine representations based on their everyday experience, and the need for teachers to explicitly introduce and interpret the abstracted and often counterintuitive representations that constitute disciplinary expertise. We nevertheless argue that while the balance between student invention and teacher framing may change as disciplinary constructs and representational systems become more abstract and complex, the fundamentals of semiosis remain the same. Students must in some sense construct/invent representations and engage with evaluation of these inventive approximations if they are to learn beyond mere reproduction of procedures.

\subsection{The contextual challenges for developing multimodal disciplinary literacies in senior science classes}

Separate from the challenges offered by the complex literacy demands of senior science conceptual content, there is a range of contextual challenges at this level of schooling that inhibit serious attention to literacy practices that would support quality learning. In this, we draw on literature and also our experience of working with teachers at this level to support the planning and implementing of literacy-informed lesson sequences and pedagogical practices.

\subsubsection{Working with teachers in the M3S project}

In the M3S project, we worked with groups of senior school science teachers in each of the biology, physics and chemistry disciplines, across four schools, to collaborate in developing teaching and learning approaches that focussed on disciplinary literacy development. As part of this study, we observed and documented classes, held planning meetings to generate and discuss pedagogy, interviewed teachers and students, constructed assessment items and analyzed student responses to these. The project used a design-based methodology to collaboratively plan and refine teaching and learning approaches to topics in each of the sciences at year levels 10,11 and 12. We will describe, in 
later chapters (6-9), the pedagogical approach developed within the project and provide examples of teaching and learning focussed on literacy development in each of the subject areas. For now, however, we draw on our experience of working with teachers, and on the literature, to describe the particular contextual challenges in developing multimodal disciplinary literacies at this level. These challenges relate to

- the prior knowledge and skills of students;

- the language issues experienced with special groups of students;

- the influence of the high-stakes assessment regimes operating at senior school level; and

- traditions of constrained pedagogical practices that are part of the culture of teaching senior science.

\subsubsection{Prior knowledge and disciplinary literacy skills of students}

The first of these challenges concerns the prior knowledge and literacy skills of students. In being confronted with the increased literacy demands of these senior years, students are often unprepared, not having been explicitly schooled in the interpretation and production of multimodal textual forms. There are a number of reasons this is the case.

First, traditions of teaching science tend not to include the explicit unpacking of representational conventions or explicit support for students through modelling of disciplinary discernment and explanatory practices. Teachers, if they are experts in the field, often do not appreciate the difficulties involved for students in interpreting text and diagrams, or mathematical representations, and classroom practices tend to focus on delivery of information and worked examples of standard problems. From a disciplinary literacy perspective, the curriculum should be framed to support progression in scientific disciplinary literacies, which includes, as described earlier, the development of disciplinary discernment involving the interpretation, appreciation and evaluation of the semiotic resources constituting knowledge in the disciplines. Allied with this, the development of representational competence involves the flexible use and coordination, as well as critical appreciation, of multiple representations. This involves explicit focus by teachers in unpacking the form and function of different representations and representational conventions for text (Maton, Martin \& Doran, in press) and a range of visual representations (Airey \& Eriksson, 2019; Gilbert, 2008; Prain \& Tytler, 2012; Tytler, Prain, Hubber \& Waldrip, 2013).

Second, there is a tendency for science textbooks, teachers and students to treat given representations as 'true' representations of phenomena rather than models that can be subject to critical analysis (Volkwyn et al., 2020). An important principle in the 'Role of Representation in Learning Science' (RiLS) project (Tytler et al., 2013) was that students should construct, critique and refine representations, including the critique of textbook images, and that the teacher should lead explicit and critical discussion of the form 


\section{Contextualizing the conditions}

and function of representations such that students come to appreciate their specific affordances. Teachers working in the project reported, as students transitioned from primary to secondary school, that these students were much more sophisticated than their peers in critiquing textual representations and discussing the efficacy of different models. The RiLS project, in advocating this critical analysis of representations, worked with teachers to refine their understandings of the affordances of particular semiotic resources and unpack students' representational work. RiLS did not develop generalized accounts of representational form related to function but worked with individual teachers to help them make their own judgments concerning critical feedback on student work. RiLS involved middle school students, age 10-13 years, which allowed curriculum flexibility for semiotic exploration. Arguably, in the highly structured environment of senior science classes, with an increase in semantic density (illustrated in Figure 4.4) and gravity (representing the increasing abstraction, for instance, of bonding configurations, also evident in Figure 4.4) and complex interrelations between representational modes that were described earlier, there is a need for more explicit guidance for students, and for teachers, concerning the particular disciplinary affordances of representational systems and how students might be supported to become critically aware of these and their use. For this, we need a language with which to work with teachers, to support their meta-awareness of these disciplinary literacy forms and how to support the induction of students into disciplinary representational competence. This issue was discussed in Chapter 3 and is further developed in Chapter 6.

An example of a metarepresentational approach to learning the disciplinary language forms of science can be found in the work of Tang (2016) in relation to experimenting with a grammar of explanation for middle years students. Tang worked with teachers of science to develop a 'premisereasoning-outcome (PRO)' framework as an instruction tool to scaffold year 9-10 students' written explanations. The framework was based on the structure of scientific explanations, consistent with but simpler than argumentation frameworks (Erduran \& Jiménez-Aleixandre, 2008). Students reported the PRO strategy provided a useful organizational structure for writing explanations, and explanations with this structure were graded better by teachers. Challenges for students included the difficulty of identifying the different stages in developing explanations and some indication that students found the structure restrictive of flexibility in explaining. In fact, analyses of explanations in science textbooks (Martin \& Rose, 2008; see also the analyses in Chapter 3 ) have shown the complexity and variety of explanatory forms, making it difficult to generate a 'one-size-fits-all' schema. These findings demonstrate the challenges involved in developing such meta approaches to literacy, with tension between the need to develop a consistent language, yet one that is sufficiently flexible for practical support of students and teachers and accommodates the variety that exists within the particular genre. This point applies equally to support for students to work flexibly with written text as it does with other modes. 


\subsubsection{Teachers' disciplinary literacy knowledge and perspectives}

In order to support students to engage explicitly with the literacies of the specific science disciplines, teachers need to have command of the multimodal representations through which meaning is generated. These may involve generic processes, such as explanation, modelling, argumentation and reporting of scientific investigative work, but may involve quite specific disciplinary representational processes, such as chemistry explanations involving transduction across the Johnstone triangle, unpacking biological processes involving relations between entities and temporal sequences that have detailed spatial features (White et al., 2020) or unpacking the HR diagram of stellar evolution for its form-function relations (Airey \& Eriksson, 2019). Neither the preparation of science teachers nor traditions in schools include explicit attention to the knowledge of semiotic structures they could draw on in discussing how the resources of language and image and other semiotic modes are deployed in different science education contexts. Part of the agenda of the M3S project, alongside investigating pedagogies attending explicitly to disciplinary discourse, has been to explore the possibility of developing a metalanguage that will help teachers to engage students knowingly with these semiotic processes central to disciplinary learning in the senior years.

Teachers of science, from primary through middle years secondary school, are often not themselves schooled in the specific disciplinary forms attending to the different sciences. In primary school, teachers are generalists. In secondary schools, many science classes are taught by teachers without formal qualifications in science or science pedagogy (Hobbs, 2020; Marginson, Tytler, Freeman \& Roberts, 2013) again with the consequence that they are not in a position to engage in the increasingly specific and technical literacy demands that enable flexible problem-solving and explanatory work in the sciences. Even for trained science teachers, they will have strong knowledge of their major discipline, but as we have seen, there are different explanatory forms in the different scientific disciplines such that command of disciplinary literacy forms in biology, for instance, does not completely or automatically translate across to physics. In any of these circumstances, teachers without strong disciplinary background may be limited in their confidence and competence to engage with and unpack with students the explicit multimodal representational literacy forms that would progressively build flexible knowledge across the primary and secondary years leading to senior school science where they meet, sometimes for the first time, a teacher in command of these disciplinary literacy forms.

Finally, there is an epistemological issue that arises for teachers being introduced to the role of multimodal representations as the basis for disciplinary literacy and for meaningful engagement with the concepts of the discipline. Teachers can traditionally view concepts as expressed by verbal definitions, as they are in curricula and often in textbooks, and representations as simply illustrations and communication devices associated with these. Treating 
diagrams, simulations and symbolic expressions as an explicit focus for literacy development does not come naturally, and science education researchers working with teachers (Hubber et al., 2010; Tytler et al., 2013) have identified both epistemological and pedagogical challenges for teachers in focussing on student representational work and orchestrating critical evaluation of student productions to support refinement and consensus around productive explanatory work.

\subsubsection{Language issues with special groups}

This prior knowledge of disciplinary language forms is particularly a problem with students from low socio-economic status (SES) backgrounds and English language learners (ELL; Bernstein, 1990, 2000). As discussed in Chapter 1, findings of significant gaps in achievement of higher and lower SES students in science and literacy is a major motivation for the study informing this volume. As a significant proportion of students in schools serving low SES populations are also designated as ELL, findings of similar disadvantage amongst these students are also highly relevant.

While there has been considerable debate as to the reasons for these unequal distributions of achievement, research from the perspective of the sociology of education has attributed the link to students' inexperience in engaging with the increasing complexities of language and with the simultaneous processing of meanings that must occur to engage in interpreting and composing texts (Bernstein, 2000; Rose, 2011). Further research from both sociological and critical literacies perspectives has investigated the relationship of educational discourses in perpetrating unequal distributions of power (Comber \& Nixon, 2009; Rose, 2010).

Such findings are strongly linked to pedagogic practices that provide little targeted attention to the literacies of science (Faller, 2017; Nunes, Bryant Strand, Hillier, Barros \& Miller-Friedmann, 2017) and particularly to the links that need to be made across modes for knowledge development (He \& Forey, 2018; Tang et al., 2014).

Rose (2011) argues that teaching practices that separate elements of learning tasks and modes of meaning are ineffective in supporting low SES students to engage successfully with texts for learning as they may not 'intuitively recognise relations between the dislocated elements, to synthesise them as meaningful wholes, and so develop the skills they need for learning at each stage' (p. 5). This point concerning coordination is further elaborated in Chapter 5. High-stakes testing regimes, it is argued, increasingly influence curricula that focus on the development of decontextualized basic skills (Comber \& Nixon, 2009).

\subsubsection{The influence of high-stakes assessment regimes}

Further challenges relate to the nature of the high-stakes assessment which drives teaching and learning in these years, the constrained curriculum 
environment resulting from this and the distortions this can cause in the development of literacy-focussed pedagogies that enable deeper learning.

The content of senior science courses is driven by the requirements of external assessment regimes that enforce content coverage that can place tight restrictions on the time available for any topic to be explored and concepts mastered. This places demands on the efficiency of coverage that can make it difficult for teachers to adequately engage with the diversity of students' literacy needs or indeed to work with researchers on pedagogical innovation. Working with teachers in the M3S project raised awareness of the team of the time constraints teachers were under to institute reform. To briefly summarize here what will be discussed in more detail in later chapters, the following observations make clear the issue of time related to content, and assessment, that teachers feel keenly and that constrain innovation:

- The pace and structure of the curriculum mean that teachers are very aware of how many lessons or weeks can be devoted to particular topics. In conversations with teachers from different schools, a common discussion point concerned their progress through textbook chapters, with traditions having developed around time organization and topic order. Pedagogy was not a natural subject of discussion or comparison.

- In terms of pedagogy, teachers had developed strategies for making the literacies represented in the texts available to students:

- Often teachers prepared PowerPoints that covered content efficiently but that tended to distract from pedagogies involving student production or targeted feedback, or extended unpacking of images. These PowerPoint productions often drew on textbook images and interpreted the texts through summary statements and dot points, circumventing the need for students to themselves read the denser text.

- Physics teachers in particular enjoyed comparing favourite analogies and visualization prompts to help students picture spatio-temporal arrangements.

- Teachers sometimes provided students with procedures for solving particular types of calculations, not having time to ensure all students had the deeper understandings of the concepts underpinning mathematical relations.

- The pace of content meant that teachers found it difficult to elicit and engage with student ideas and provide feedback on their ideas and their productions.

These traditions of re-interpreting and embellishing textbooks, while efficient and in many cases strategically delivered, ultimately removed the opportunity for students to engage critically with text or with problem-solving processes and for teachers to engage critically with student productions. 


\subsubsection{The role of assessment in shaping disciplinary literacy practices}

In most senior science courses there are distinct literacy demands associated with assessments and assessment types. A brief survey of international senior science assessment structures was carried out, including papers in biology, chemistry and physics from Victoria, New South Wales, New Zealand, the UK (Cambridge A level) and Singapore. The analyses reveal a variety of question types and knowledge expectations. These inevitably frame the particular literacy demands that are focussed on by teachers, distinct from considerations of disciplinary literacies that are focussed on in the research literature. These assessment structures define the particular forms of knowledge and practice that are privileged within the senior school system. As we argued earlier, the disciplinary literacy focus must inevitably involve a conversation between disciplinary practices in the field, curriculum and student conceptual resources and learning needs. To summarize some of these assessment regimes, we can identify some distinct types of questions, and tasks, that are in the assessment mix. In this list, tasks that are relevant to the State of Victoria in Australia, where the M3S study was conducted, are identified thus: *.

- Multiple-choice questions (most assessment regimes include such questions)*

- Short answer questions where students offer brief explanations or interpretations*

- Short answer questions requiring students to construct a sequence of events*

- Short answer questions encouraging or requiring the production of diagrams and annotations (rare in Victoria but more common in other jurisdictions)

- Free response and longer structured questions (Singapore)

- Qualitative and quantitative interpretations of extended multimodal text (Singapore, 2017-2019)

- Questions requiring extended answers requiring candidates to integrate knowledge from different parts of the syllabus (e.g. Cambridge, New Zealand)

- Questions requiring planning, analysis and evaluation (Cambridge)

- Practical papers requiring students to demonstrate practical inquiry skills (Cambridge)

- School-based assessments that require structured multiple-choice and short answer responses, and could include practical tasks*

- Posters or reports based on practical investigation*

- Individually selected and planned investigation*

Assessment at senior level, across various syllabi and jurisdictions, is aimed at (a) core knowledge and understanding; (b) handling, applying and evaluating information (Cambridge, Program for International Student Assessment (PISA)); or (c) experimental or investigative skills (Cambridge, PISA, 
school-based assessment in a number of jurisdictions). In Victoria, as elsewhere, there have been long-standing debates and tensions between the need to develop (a) core content knowledge in the sciences, implying facility with abstracted concepts and representational systems in solving standardized problems distinct from (b) context-based, situated knowledge, implying the flexible demonstration of disciplinary literacies in authentic contexts and distinct from (c) inquiry competences involving knowledge and application of investigative procedures and data modelling competence. Reconceptualizing disciplinary practices for representation in schools involves matters of principle, and politics, with traditions of examinations built around standard problem-solving using a tight set of abstracted concepts difficult to shift (Hart, 2001, 2002). What is at stake are the particular versions of the reconceptualization of disciplinary knowledge and practices that are considered appropriate for a senior science system that both prepares students for further study and provides a filter for entry into tertiary courses of differing status.

The point of this brief analysis of a few assessment regimes is to emphasize the variation in assessment approaches, which implies a different focus on types of literacy assessed and therefore emphasized in examination preparation. In Victoria, some variety of literacies, such as scientific report writing and investigative planning, is assessed at the school level. For the external assessment, however, common forms of required response are multiple-choice or short answers. Examples were found in the 2017-2019 Singapore examination of questions asking for interpretation (explanations, calculations) of extended textual accounts of an unfamiliar phenomenon. In New Zealand, questions require quite extended responses that demonstrate broad understandings of a topic. In New Zealand also there has been an opening up of curricula at the senior level to encourage personalization of learning and the development of skills for 21 st-century learning involving quite distinct literacy demands and associated pedagogies (Trask, 2019). In working with teachers in the M3S project, it was clear that the forms of examination questions were a significant driver in what teachers focussed on during class, and teachers had developed ways of dealing with material that matched expectations of these pared-back assessment types - for instance, in focussing on distinctions between the electric motor and generator configurations which were held to be traps for students in responding to patterns of electromagnetism questions in the assessment. Some types of questions asked students to construct a reasoned argument to explain a phenomenon, describe a process or evaluate the distinction between theories, and the literacy moves associated with these were one focus for the project, as will be described in subsequent chapters.

This is not to say that because assessment is largely multiple-choice or short answers that a wider set of literacies is not involved in learning the material. The development of understandings required to answer such questions will involve a range of multimodal literacies. Nevertheless, such assessment regimes must be recognized as offering a restricted range of possibilities to display the variety of scientific literacies that constitute developing 
disciplinary expertise and to this extent do not necessarily encourage rich literacy practices in senior school classrooms.

\subsubsection{Developing pedagogies to support multimodal disciplinary literacy}

The pressure from the challenges to teaching and learning science at the senior level, described earlier, inevitably leads to a number of issues representing constrained pedagogic practices. In working with groups of science teachers of years 10-12, we gained considerable insights into prevailing practices in the schools, including teaching and learning strategies, assessment approaches, and the construction and use of resources. We also gained insights into the commitments and concerns of these teachers, and the pressures on them and their students.

The first thing to be said is that these teachers were uniformly dedicated to the learning of their students and very aware of the challenges different students faced in mastering content at this level. In particular, with the four schools in the M3S project drawing on a low SES population, teachers were very aware of, but challenged to accommodate, the wide range of language skills in their classrooms, particularly with immigrant populations included in the mix. Teachers, in working with the team to plan approaches, had many stories to share about practical activities they had developed, analogies and metaphors they regularly used to introduce topics or strategies to help students with particular problem-solving moves. With some exceptions, however, these strategies did not explicitly focus on supporting students to develop literacy skills. The exceptions included teachers who

- unpacked examination questions by helping students systematically cross out contextual text to focus in on what the question was really asking or workshopping responses to extended explanation questions;

- developed a template for the construction of poster reports of an investigation (see Chapter 10);

- structured an electric motor simulation to systematically develop a narrative account of the process;

- supported redescription of text based on detailed reading (Hao \& Humphrey, 2019); and

- engaged in joint construction using written and visual text unpacking osmosis in biology.

Generally, however, in conversation with teachers, and observing classes, it was clear that there were a number of common problems associated with the pressures of content coverage and focus on examination techniques, including

- a predominance of direct teaching involving IRF discourse patterns (Sinclair \& Coulthard, 1975), with little opportunity provided to unpack text and support students to engage in producing and refining text; and 
- a lack of consistency in the use of textbooks, with a common default to PowerPoint presentations and resources offering simplified versions of the text, offering little opportunity for students to be supported to learn to read and interpret the major literacy forms exemplified in these.

In the M3S project, we worked with teachers across the four schools, offering regular meetings to present literacy principles and ideas for strategic disciplinary literacy development, and jointly planning activities and activity sequences. The methodology was design-based research which offered the opportunity to articulate and re-negotiate the constraints described earlier and explore the conditions under which pedagogical innovation could occur. Data that guided the ongoing development of approaches included field notes of meetings, video capture of classes, interviews with teachers and students, surveys and analysis of student responses to assessment tasks. The types of intervention that were developed, which are described in more detail in subsequent chapters, included

- developing support strategies for articulating textual forms - for instance, the grammars of explanation;

- developing approaches where modelling was foregrounded, involving student production of representations and transduction across modes with explicit unpacking of this process; and

- developed templates for reporting genres - for instance, poster work reporting on investigations.

In Chapter 5, we track traditions in science education and linguistics to identify the major through lines in pedagogies based around language strategies. Chapter 6 describes the development of a framework based on the project's work with teachers, describing pedagogical options through which these challenges might be addressed. In the following chapters, we describe in some detail the response of teachers in the M3S project to the challenge of engaging with language in supporting disciplinary learning in the different subjects.

\section{References}

Airey, J., \& Eriksson, U. (2019). Unpacking the Hertzsprung-Russell diagram: A social semiotic analysis of the disciplinary and pedagogical affordances of a central resource in astronomy. Designs for Learning, 11(1), 99-107.

Airey, J., \& Linder, C. (2009). A disciplinary discourse perspective on university science learning: Achieving fluency in a critical constellation of modes. Journal of Research in Science Teaching, 46(1), 27-49. https://doi.org/10.1002/tea.20265

Airey, J., \& Linder, C. (2017). Social semiotics in university physics education. In D. F. Treagust, R. Duit \& H. E. Fischer (Eds.), Multiple representations in physics education (pp. 95-122). Cham, Switzerland: Springer International Publishing. https://doi. org/10.1007/978-3-319-58914-5_5

Bernstein, B., (1990). Class, codes and control Vol. 4: The structuring of pedagogic discourse. London: Routledge. 
Bernstein, B., (2000). Pedagogy, symbolic control and identity: Theory, research, critique. London: Rowman \& Littlefield.

Christie, F. (2012). Language education throughout the school years: A functional perspective. Language Learning, 62(Supplement 1), 1-247.

Christie, F., \& Derewianka, B. (2008). Learning to write across the years of schooling. London \& New York: Continuum?

Comber, B., \& Nixon, H. (2009). Teachers' work and pedagogy in an era of accountability. Discourse: Studies in the Cultural Politics of Education, 30(3), 333-345.

De Cock, M. (2012). Representation use and strategy choice in physics problem solving. Physical Review Special Topics - Physics Education Research, 8(2), 020117. https://doi.org/10.1103/PhysRevSTPER.8.020117

Duschl, R. (2008). Science education in three-part harmony: Balancing conceptual, epistemic, and social learning goals. Review of Research in Education. 32, 268-291.

Erduran, S., \& Jiménez-Aleixandre, M. P. (Eds). (2008). Argumentation in science education. Perspectives from classroom-based research. Dordrecht: Springer.

Eriksson, U. (2019). Disciplinary discernment: Reading the sky in astronomy education. Physical Review Physics Education Research, 15(1), 010133.

Eriksson, U., Linder, C., Airey, J., \& Redfors, A. (2014). Introducing the anatomy of disciplinary discernment - an example for astronomy. European Journal of Science and Mathematics Education, 2(3), 167-182.

Faller, E. (2017). Reading and writing as scientists? Text genres and literacy practices in girls' middle-grade science. Journal of Adolescent \& Adult Literacy, 61(5). https://doi.org/10.1002/jaal.698

Fang, Z. (2013). Disciplinary literacy in science: Developing science literacy through trade books. Journal of Adolescent es Adult Literacy, 57(4), 274-278.

Fang, Z., \& Schleppegrell, M. J. (2010). Disciplinary literacies across content areas: Supporting secondary reading through functional language analysis. Journal of Adolescent \& Adult Literacy, 53(7), 587-597.

Gilbert, J. (2008). Visualization: An emergent field of practice and enquiry in science education. In J. K. Gilbert, M. Reiner \& M. Nakhleh (Eds.), Visualization: Theory and practice in science education (pp. 3-24). Dordrecht: Springer.

Hand, B., \& Prain, V. (2002). Teachers implementing writing-to-learn strategies in junior secondary science: A case study. Science Education, 86(6), 737-755.

Hao, J., \& Hood, S. (2019). Valuing science: The role of language and body language in a health science lecture. Journal of Pragmatics, 139, 200-215.

Hao, J., \& Humphrey, S. L. (2019). Reading nominalizations in senior science. Journal of English for Academic Purposes, 42, 100793.

Hart, C. (2001). Examining relations of power in a process of curriculum change: The case of VCE physics. Research in Science Education, 31(4), 525-551.

Hart, C. (2002). Framing curriculum discursively: Theoretical perspectives on the experience of VCE physics. International Journal of Science Education, 24(10), 1055-1077.

He, Q., \& Forey, G. (2018). Meaning-making in a secondary science classroom: A systemic functional multimodal discourse analysis. In K.-S. Tang \& K. Danielsson (Eds.), Global developments in literacy research for science education (pp. 183-202). Cham, Switzerland: Springer.

Hoban, G., \& Nielsen, W. (2013). Learning Science through Creating a 'slowmation': A case study of preservice primary teachers. International Journal of Science Education, 35(1), 119-146. 
Hobbs, L. (2020). Learning to teach science out-of-field: A spatial-temporal experience. Journal of Science Teacher Education, 31(7), 725-745, https://doi.org/10. 1080/1046560X.2020.1718315

Hubber, P, Tytler, R., \& Haslam, F. (2010). Teaching and learning about force with a representational focus: Pedagogy and teacher change. Research in Science Education, 40(1), 5-28.

Johnstone, A. H. (1991). Why is science difficult to learn? Things are seldom what they seem. Journal of Computer Assisted Learning, 7, 75-83.

Khine, M. (2013). Critical analysis of science textbooks. Evaluating instructional effectiveness. Perth: Springer.

Kozma, R., \& Russell, J. (2005). Students becoming chemists: Developing representational competence. In J. K. Gilbert (Ed.), Visualization in science education (pp. 121-145). Dordrecht, Netherlands: Springer. https://doi.org/10.1007/ 1-4020-3613-2_8

Lehrer, R. (2009). Designing to develop disciplinary dispositions: Modeling natural systems. American Psychologist, 64(8), 759-771.

Lehrer, R., \& Schauble, L. (2012). Seeding evolutionary thinking by engaging children in modeling its foundations. Science Education, 96(4), 701-724.

Linder, A., Airey, J., Mayaba, N., \& Webb, P. (2014). Fostering disciplinary literacy? South African physics lecturers' educational responses to their students' lack of representational competence. African Journal of Research in Mathematics, Science and Technology Education, 18(3), 242-252. https://doi.org/10.1080/10288457. 2014.953294

Linder, C. (2013). Disciplinary discourse, representation, and appresentation in the teaching and learning of science. European Journal of Science and Mathematics Education, 1(2), 43-49.

Marginson, S., Tytler, R., Freeman, B., \& Roberts, K. (2013). STEM: Country comparisons. Melbourne: The Australian Council of Learned Academies. Retrieved from www.acola.org.au

Martin, J. R., \& Rose, D. (2008). Genre relations: Mapping culture. London: Equinox Pub.

Martin, J. R., Unsworth, L., \& Rose, D. (in press). Condensing meaning: Imagic aggregations in secondary school science. In G. Parodi (Ed.), Multimodality: From corpus to cognition. London: Bloomsbury.

Maton, K., Martin, J. R., \& Doran, Y. (Eds.). (in press). Teaching science: Knowledge, language and pedagogy. London: Routledge.

Moran, G., \& Fry, C. (2016). Heinemann physics 11: VCE units 1 \& 2 (4th Ed.). Melbourne, Victoria: Pearson Australia.

Moran, G. et al. (2016). Heinemann Physics 11 (4th Ed). Melbourne Victoria: Pearson Australia.

Nitz, S., \& Tippett, C. D. (2012). Measuring representational competence in science. In E. De Vries \& K. Scheiter (Eds.), Staging knowledge and experience: How to take advantage of representational technologies in education and training? EARLI SIG 2 meeting, August 28-31, Laboratoire des Sciences de l'Education, Université PierreMendès-France (pp. 163-165). Grenoble: Université Pierre-Mendès-France.

Nunes, T., Bryant, P., Strand, S., Hillier, J., Barros, R. and Miller-Friedmann, J. (2017). Review of SES and science learning in formal educational settings. A report prepared for the EEF and the Royal Society. Retrieved from https:// educationendowmentfoundation.org.uk/public/files/Review_of_SES_and_ Science_Learning_in_Formal_Educational_Settings.pdf 
Pham, L. P. (2019). Students constructing representations to problem-solve and learn in senior chemistry. Melbourne: $\mathrm{PhD}$ thesis, Deakin University.

Prain, V., \& Tytler, R. (2012). Learning through constructing representations in science: A framework of representational construction affordances. International Journal of Science Education, 34(17), 2751-2773.

Prain, V., Tytler, R., \& Peterson, S. (2009). Multiple representation in learning about evaporation. International Journal of Science Education, 31(6), 787-808.

Rose, D. (1998). Science discourse \& industrial hierarchy. In J. R. Martin \& R. Veel (Eds.) Reading Science: Critical and functional perspectives on discourses of science (pp. 236-265). London: Routledge.

Rose, D. (2010). Beating educational inequality with an integrated reading pedagogy. In F. Christie \& A. Simpson (Eds.), Literacy and social responsibility: Multiple perspectives. London: Equinox.

Rose, D. (2011). Meaning beyond the margins: Learning to interact with books. In S. Dreyfus, S. Hood \& M. Stenglin (Eds.), Semiotic margins: Meaning in multimodalities (pp. 177-209). London: A\&C Black.

Sinclair, J. M., \& Coulthard, M. (1975). Towards an analysis of discourse: The English used by teachers and pupils. New York: Oxford University Press.

Tang, K. S. (2016). Constructing scientific explanations through premise-reasoningoutcome (PRO): An exploratory study to scaffold students in structuring written explanations. International Journal of Science Education, 38(9), 1415-1440.

Tang, K. S., Delgado, C., \& Moje, E. B. (2014). An integrative framework for the analysis of multiple and multimodal representations for meaning-making in science education. Science Education, 98(2), 305-326.

Tytler, R., Murcia, K., Hsiung, C.-T., \& Ramseger, J. (2017). Reasoning through representations. M. Hackling, J. Ramseger, \& H. Chen (Eds.), Quality teaching in primary science education (pp. 149-179). Cham: Springer. DOI: 10.1007/978-3-319-44383-6

Taylor, N., Stubbs, A., \& Stokes, R. (2020). Jacaranda chemistry 1. Melbourne: Jacaranda.

Trask, S. A. (2019). Repositioning teachers and learners in senior science for 21 st century learning [Doctoral dissertation, The University of Waikato].

Tytler, R., Haslam, F., Prain, V., \& Hubber, P. (2009). An explicit representational focus for teaching and learning about animals in the environment. Teaching Science, 55(4), 21-27.

Tytler, R., Prain, V., Hubber, P., \& Waldrip, B. (Eds.). (2013). Constructing representations to learn in science. Rotterdam, The Netherlands: Sense Publishers.

Veel, R. (1997). Learning how to mean—scientifically speaking: Apprenticeship into scientific discourse in the secondary school. Genre and Institutions: Social Processes in the Workplace and School, 161, 195.

Volkwyn, T. S., Airey, J., Gregorcic, B., \& Linder, C. (2020). Developing representational competence: Linking real-world motion to physics concepts through graphs. Learning: Research and Practice, 6(1), 88-107. https://doi.org/10.1080/ 23735082.2020.1750670

Waldrip, B., Prain, V., \& Carolan, J. (2010). Using multi-modal representations to improve learning in junior secondary science. Research in Science Education, 40(1), 65-80.

White, P. J., Tytler, R., \& Nielsen, W. (2020). Animation construction as cross-modal translation in senior biology. In L. Unsworth (Ed.), Learning from animations in science education (pp. 209-228). Dordrecht, Netherlands: Springer. 


\section{$5 \quad$ Teaching and learning practices for multimodal literacy in science education}

\subsection{Introduction}

The integral role of multimodal representations as mediating tools for knowledge building requires attention to the pedagogic practices and strategies that support senior students' equitable participation in multimodal disciplinary literacy. Recognition that many students have not been supported in the interconnected learning of science and multimodal disciplinary literacy has led to productive collaboration across diverse science education and literacy research communities to design professional learning strategies with the dual aim of enhancing science conceptual and literacy learning (Yore, 2018).

In earlier chapters, we discussed motivations for designing pedagogies that provide support for culturally and linguistically diverse learners to develop the more abstract scientific discourse needed for senior secondary school learning. We presented a rationale for a multimodal literacy infused science pedagogy (MLISP) and highlighted challenges of negotiating consensus amongst different research traditions and of researching student learning in senior school science. In this chapter, we extend discussion of pedagogic approaches that recognize the constitutive role of language and other modes of disciplinary discourse in science to highlight examples of practice that can be co-opted as illustrative of these approaches. Firstly, however, we revisit discussion of foundational approaches begun in Chapter 1 and refine the conceptual map we designed to relate key dimensions of practice.

\subsection{Mapping pedagogies in science education and literacy research}

In Chapter 1, we argued broadly for a sociocultural perspective that 'presupposes that students' learning is social and therefore highly influenced by their interactions with others (Vygotsky, 1978) but noted significant challenges in synthesizing models influenced by these perspectives. These include well recognized issues identified by Tang $(2019$, p. 83$)$ as 'a lack of theoretical development in bridging science education and literacy research', as well as divergent categorizations and emphases in accounts of pedagogic practice. Elision of some aspects of the semiotic mediation is inevitable, given the 
complex 'translation steps' involved in publishing research and the need to respond to curriculum and wider social contexts (Yore, 2018). However, the result is that areas of potential consensus amongst approaches are not always evident, and models tend to be characterized in terms that foreground extremes of practice. For example, the focus of literate practice has been represented as either 'process' or 'product' (Matruglio, 2019), the teacher's role in scaffolding as either a 'guide on the side' or a 'sage on the stage' (Morrison, 2014) and models of guidance as those which 'prepare' or 'repair' (Dreyfus, Humphrey, Mahboob \& Martin, 2015). The topographical perspective we adopted to map influential cognitive and sociocultural approaches in Chapter 1 allowed us to reveal more nuanced relationships to enhance productive dialogue towards a MLISP.

While recognizing the continuing relevance of cognitive strategies (Fang, 2020; Hand, Yore, Jagger \& Prain, 2010; Yore, 2018), our focus in this chapter is on relationships between loosely bounded situated approaches that are represented in the science education literature as inquiry (Tytler, Prain, Hubber \& Waldrip, 2013) or practice-based (Tang, 2019) and functional linguistic or genre-based models that emphasize the 'expert guidance' and a shared metalanguage for discussion of semiotic choices (Fang, 2020; Macnaught, Maton, Martin \& Matruglio, 2013; O'Halloran, Palinscar \& Schleppegrell, 2015; Rose \& Martin, 2012). These relationships are represented along the horizontal axis of Figure 5.1. The vertical axis allows us to relate foundational models that focus on oral and written language to those that have been developed to support students to interpret and create multimodal representations. Significant blurring of boundaries across all dimensions can be related to concerns within pedagogic approaches to introduce students to the underpinning disciplinary epistemic practices of science

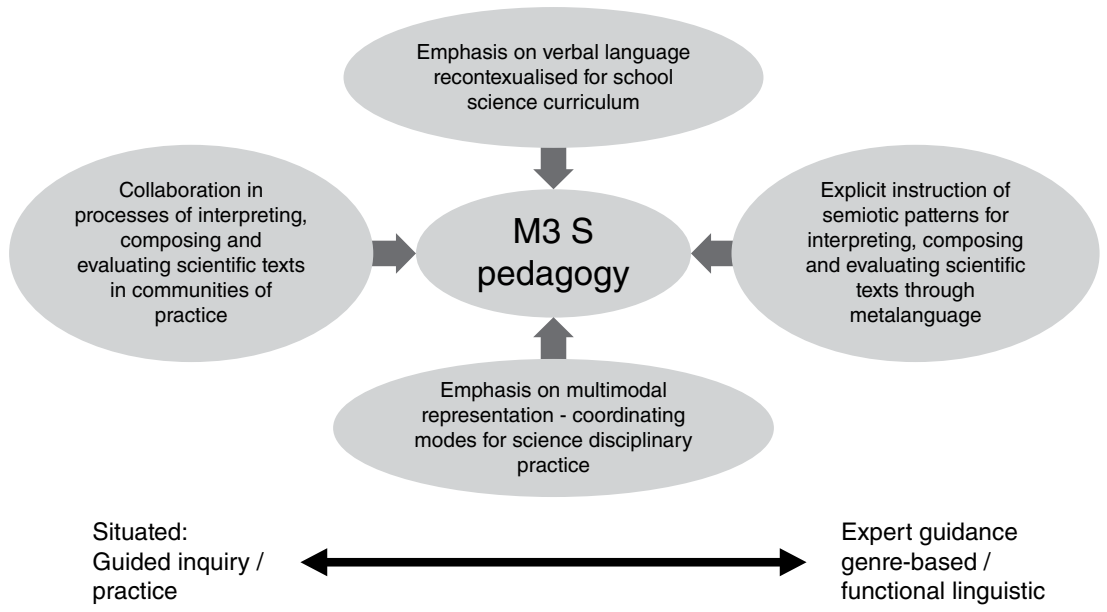

Figure 5.1 A conceptual map for reviewing pedagogies informed by sociocultural approaches to literacy and learning. 
(Lehrer \& Schauble, 2012; Tytler et al., 2013) and to refinements to meet the needs of culturally and linguistically diverse learners (Feez \& Quinn, 2017; Palinscar \& Schleppegrell, 2014).

The review that follows focusses on the potential contribution of strategies from situated and expert guidance perspectives to a MLISP framework. Within each section, we trace developments from verbal literacy models to those which foreground multimodal sense making in science (Hand et al., 2010; Tang, 2019).

\subsection{Situated perspectives: foundational models of guided inquiry}

Situated perspectives emphasize the role of interaction and cooperation with peers in awakening internal developmental processes (Lave \& Wenger, 1991; Vygotsky, 1978). In science education, these perspectives have informed a range of guided inquiry models, which seek to align school knowledge and practices, including interaction with texts, with those represented in the scientific world (Brown, Collins \& Duguid, 1989; Chen, Park \& Hand, 2016; Hand, 2008; Mortimer \& Scott, 2003; Palinscar \& Brown, 1984; Tytler et al., 2013). Despite lack of clarity as to the extent of this alignment (Tang, 2019), guided inquiry models that integrate literacy have been found to have a positive impact on the achievement of diverse learner groups (Hand et al., 2010; Nunes et al., 2017) and have informed approaches that emphasize multimodal representation (Tytler et al., 2013). In the models shown in Table 5.1, semiotic mediation is evident in descriptions of 'learning tools' that teachers design and orchestrate to assist students' engagement in literate practice (Chen et al., 2016). These include oral interaction, writing and reading, as well as semiotic representations that combine modes.

Guided inquiry models have varying emphases in relation to the scope and timing of literacy guidance. Although the nature of the guidance is not always made explicit in published descriptions (Tytler, Ferguson \& White, 2020), the teacher's role is most evident in designing collaborative learning

Table 5.1 An overview of foundational guided inquiry models integrating literacy

\begin{tabular}{|c|c|c|c|}
\hline & $\begin{array}{l}\text { Guidance through } \\
\text { Exploration }\end{array}$ & & Anticipatory Guidance \\
\hline $\begin{array}{l}\text { NAME OF } \\
\text { MODEL }\end{array}$ & $\begin{array}{l}\text { Argument Based } \\
\text { (e.g. Science Writing } \\
\text { Heuristic) }\end{array}$ & $\begin{array}{l}\text { Communicative } \\
\text { Approach }\end{array}$ & $\begin{array}{l}\text { Cognitive } \\
\text { Apprenticeship }\end{array}$ \\
\hline $\begin{array}{l}\text { Key } \\
\text { designers }\end{array}$ & $\begin{array}{l}\text { Chen et al. (2016); } \\
\text { Hand }(2008)\end{array}$ & $\begin{array}{l}\text { Mortimer and } \\
\text { Scott }(2003)\end{array}$ & $\begin{array}{l}\text { Brown et al. (1989), } \\
\text { Palinscar and Brown } \\
\text { (1984) }\end{array}$ \\
\hline $\begin{array}{l}\text { Learning } \\
\text { tools }\end{array}$ & $\begin{array}{l}\text { Talk and writing } \\
\text { (e.g. learning map) }\end{array}$ & $\begin{array}{l}\text { Talk, classroom } \\
\text { interaction }\end{array}$ & Reading processes \\
\hline
\end{tabular}


activities and in eliciting student responses through questioning. Activities include the following:

- Exploration - Students explore beginning ideas, build understandings of scientific context. Teacher probes students' views, sets up a task or challenge

- Investigation/challenge - Students collaborate to generate inquiry question/s, record and organize data with learning tool. Teacher designs test/observation and provides probes

- Negotiation/debate - Students' problem-solving processes and representations are compared with those of experts in groups/whole class. Teacher questions to articulate and refine 'proto-theories'

- Reflection/revision - Students articulate change of ideas during the inquiry and respond individually with fading support. Teacher pushes students into independent problem-solving

As shown in Table 5.1, argument-based inquiry models are situated closer to the exploratory end of the guidance continuum due to their focus on promoting immersion in a literacy context before proceeding through steps of the inquiry process (Hand, 2008). Cognitive apprenticeship models (Brown et al., 1989) foreground anticipatory guidance of processes and strategies that are used by expert scientists through steps such as the following:

- Modelling: Teacher externalizes the cognitive processes that experts use

- Coaching: Teacher offers hints to direct students' attention, etc.

- Presentation: Teacher/text presents an authoritative case for scientific view

- Scaffolding: Teacher provides Physical or procedural support that is gradually removed

As discussed in Chapter 1, models that focus on one literate mode (e.g. reading, writing, oral argumentation) may elide or background other dimensions that are essential to the inscriptions of professional scientific practice and their recontextualizations in senior science classrooms. These models do however offer important understandings for supporting students' successful engagement with multimodal disciplinary literacy.

\subsubsection{Classroom interaction strategies in guided inquiry}

A focus on classroom interactions has enabled researchers to develop models of the productive discussion and dialogic talk that move students towards a scientific view (Mortimer \& Scott, 2003; Tytler et al., 2020). To explore the teacher's discursive role in working with students' ideas, Mortimer and Scott developed a framework which has been influential in examining the degree to which talk is authoritative or dialogic and the degree to which it is interactive. Authoritative discourse is understood to refer to patterns of talk where the teacher leads students towards disciplinary recognized knowledge 
forms, while dialogic discourse encourages the opening up of ideas by canvassing more than one point of view. Dialogic discourse is characterized through a range of prompts provided by the teacher following students' initial responses to a question on a topic.

While Tytler and Aranda (2015) argue that teachers respond to the opportunities and constraints of their contexts in a range of ways that cannot be explained in terms of dichotomies, descriptions of discursive moves have by and large focussed on guidance following students' initial contribution. Moves such as recasting students' responses in a scientific register and introducing them back into the discourse align with those identified in disciplinary literacy research (Sharpe, 2008) and with the joint construction strategies discussed in Chapter 3. However, little attention in guided inquiry models has been given to supporting culturally and linguistically diverse students, whose prior experience may not have set them up for active participation in classroom or group interactions. Excerpts of teacher-student interactions in the research literature rarely include information about which groups of learners are active in responding to questions; however, science teachers have been found to be reluctant to call on students who do not self-nominate to answer questions (Archer \& DeWitt, 2016). Extending interactions only after a student's initial contribution limits teachers' ability to monitor all students' progress, which is crucial in high-stakes assessment regimes discussed in Chapter 4.

Strategies proposed to support students' equitable participation include 'cued elicitation', where the teacher pauses in an oral explanation for a student to complete a word (Edwards \& Mercer, 1987), thus allowing the teacher to monitor that a student is following a line of reasoning. Guided inquiry models also promote the continuation of everyday terms; however, such activity presupposes that sufficient time is available to make the shift to scientific language. Stimulus materials provided prior to oral discussion have also been recommended as strategies to promote students' equitable participation in discussion (Morin, Simonneaux, Simonneaux, Tytler \& Barraza, 2014); however, as discussed in Chapter 4, hidden and assumed semiotic resources in written materials and textbook representations in senior school science present particular challenges that need to be considered in scaffolding oral interactions.

\subsubsection{Reading strategies in guided inquiry}

Models of guided inquiry that focus on reading as a foundational literacy have been influenced greatly by a research tradition in science education known as cognitive apprenticeship (Brown et al., 1989; Palinscar \& Brown, 1984). Because these models focus on reading capacities that are believed to be shared across subject areas, they have greatly influenced language across the curriculum (LAC) rather than disciplinary literacy approaches. Strategies of modelling in these approaches focus on generic processes and procedural aspects of reading, rather than on the distinctive ways in which texts build 
knowledge (de Oliveira \& Dodds, 2010; Freebody, Maton \& Martin, 2008). Nevertheless, the inclusion of semiotic activity for students to demonstrate learning through multiple modes and artefacts and the promotion of learning tools such as graphic organizers provides a basis for the cross-mode semiotic activity that is integral to multimodal disciplinary literacy pedagogies.

Reading strategies are also centralized in more recently developed models of disciplinary literacy and multiliteracies models, which aim to support students from culturally and linguistically diverse communities in mainstream science classrooms (Moje, 2015). Unlike strategies in LAC models, disciplinary literacy strategies emphasize the importance of understanding how texts work in navigating towards specialized disciplinary discourse. Applications in elementary and middle years classrooms make space for anticipatory guidance, as well as collaborative activity, exploring target discourse features firstly in talk about everyday concepts and then to more complex understandings (Palinscar \& Schleppegrell, 2014). Such considerations align to some extent with strategies we have described in Chapter 3, involving shunting between more accessible, iconic representational forms and more abstract scientific discourse (Lemke, 1990). However, application of situated reading strategies in senior classrooms requires careful attention to the selection and sequencing of texts which can support conceptual knowledge building, as well as consideration to the linguistic challenges of using texts from diverse domains for curriculum learning. As we have argued in relation to material provided as stimulus for oral discussion, linguistic challenges involved in comprehending and interpreting texts are often overlooked in pedagogic models. An example of such a challenge in senior school science is illustrated in an excerpt from a year 11 biology textbook shown as Text 5.1, which is the opening section of an account about the work of professional scientists (Chidrawi, Robson \& Hollis, 2010), which functions to make connections between the particular scientific concept and its development through

\section{Text 5.1 Excerpt from year 11 biology textbook}

In the second half of the nineteenth century there was a revolution in microbiology, primarily due to the research of Louis Pasteur and Robert Koch. Working separately, they were able to make an invaluable contribution to our understanding of infectious disease. Although they each used aspects of the other's work in their own research, the degree of collaboration and communication was minimal as they did not get on with each other. Prior to the work of Pasteur, Koch and others, the explanation for the cause of disease and decay was the theory of SPONTANEOUS GENERATION. This involved the idea that life, such as the maggots that were present in rotting flesh, arose spontaneously from non-living things... Subsequently, Pasteur was able to disprove this theory.

(Chidrawi et al., 2010, p. 256) 
professional science research. In this excerpt, the capitalized term SPONTANEOUS GENERATION names the concept. Linguistically, the concept is presented as a 'technical' noun group that distils a sequence of activities and entities using a grammatical process called nominalization. Other nominalizations and 'abstract terms' that occur in this excerpt are highlighted.

Excerpts such as this are often judged by teachers to be easy to read because of the temporal unfolding of events and the focus on the 'doings' of people. Nominalizations that distil a technical concept, such as 'spontaneous generation' or 'pasteurization', are often highlighted when first introduced in textbooks and those most relevant are carefully 'stepped out' and defined in classroom conversation. However, other nominalizations, such as 'collaboration', 'revolution', 'communication' in this excerpt are typically not attended to in classroom discourse or in guided reading activity (Martin \& Matruglio, 2013). Recent social semiotic studies have built on Halliday's concept of grammatical metaphor to explore the role of these kinds of nominalizations in integrating the multiple fields which occur in texts from diverse domains, such as those used to contextualize scientific phenomena in textbooks, professional research and popular science reports (Hao \& Humphrey, 2019). Glossed as 'text-making' nominalizations, they work with other abstract nouns called semiotic nouns (e.g. words such as 'research' and 'idea') in this excerpt to condense significant activities of the scientific research practice involved.

Researchers from across the science education and literacy research community (Norris \& Phillips, 2003; Snow, 2010) argue that attention only to 'technical terms', without acknowledging their relationship to these other academic terms limits opportunities for students to use texts in knowledge building. As discussed in Chapter 4, students electing science subjects for senior study may be differently prepared through the pathways offered at the schools, as well as their diverse experiences related to linguistic and socioeconomic backgrounds. In Section 5.5, we provide elaboration of how explicit attention to language features such as those illustrated earlier can augment situated approaches in authentic inquiry (Palinscar \& Schleppegrell, 2014).

\subsubsection{Writing strategies in guided inquiry}

Guided inquiry models focussing on writing outlined in Figure 5.2 differ significantly in terms of the learning tools and activities that are emphasized. One foundational learning tool, the Science Writing Heuristic (SWH) integrates writing with oral language but recognizes that written and oral language have different roles in enabling the development of conceptual knowledge and concepts (Chen et al., 2016; Hand, 2008; Wallace, Hand \& Prain, 2004). Learning tools promote the distribution of literate activity across modes, with talk used while conducting investigations in particular contexts and writing used to create more abstract and condensed representations of meaning. To support students to coordinate talk and writing within an inquiry process, the SWH includes written outlines, called learning 


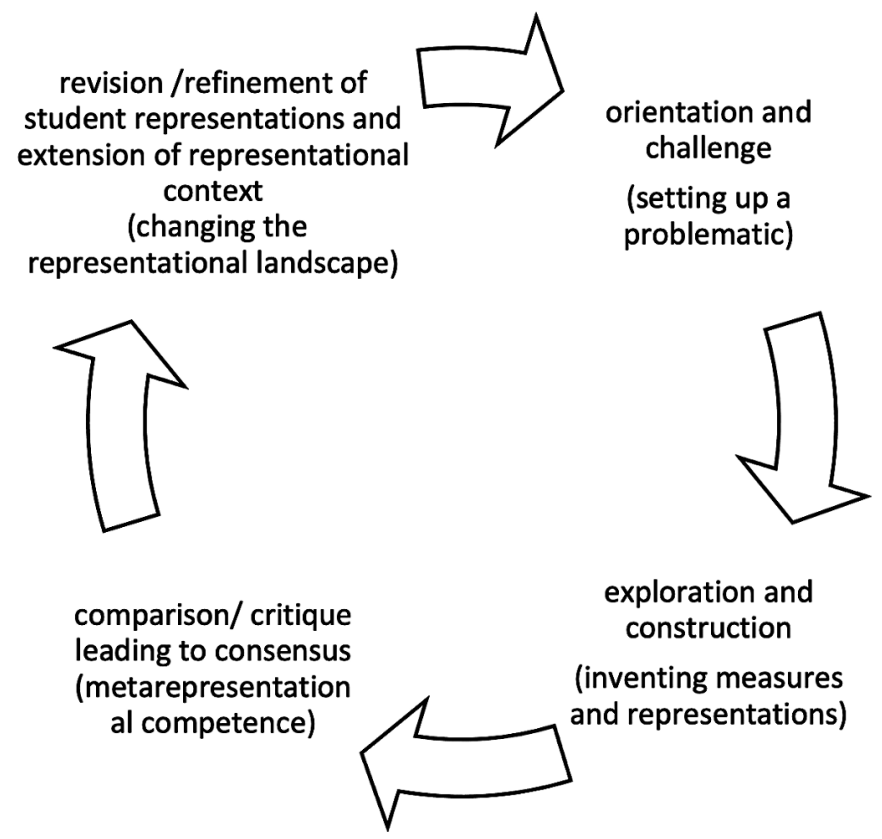

Figure 5.2 Sequence of processes in guided inquiry pedagogies.

placemats, with prompts to support students to consolidate and integrate ideas they are negotiating and sharing through talk and experience (Wallace et al., 2004). As students deploy the different modalities, there is an expectation that they will shunt between everyday and technical discourses that are essential in building conceptual knowledge. While the discourse resources that enable this shunting are not made explicit in descriptions of SWH practice, learning placemats, like graphic outlines discussed previously, need to be considered in supporting more active engagement in 'writing to learn' in senior science classrooms.

\subsection{Towards multimodal disciplinary literacy: representational construction}

In recent years, science education scholars have expanded models such as the SWH to design pedagogies which have come to be known as representation construction approaches or RCA (Lehrer \& Schauble, 2012; Olander, Wickman, Tytler \& Ingerman, 2018; Tang \& Danielsson, 2018; Tytler et al., 2013; Tytler et al., 2020). From a pedagogic perspective, scaffolding theories are drawn on to investigate differentiated opportunities offered by material and symbolic tools in 'constraining' and enabling students' attention to be directed to particular meanings inherent in interpreting phenomena (Prain \& Tytler, 2012). In Figure 5.2, we outline a sequence of processes proposed by RCA researchers to induct students into disciplinary epistemic practices 
through responding to authentic purposes. Matching principles outlined by Lehrer, Konold and Kim (2006) are shown in brackets.

RCA research has offered a significant contribution to explicating the mediating role of semiotic tools in curriculum learning (Lehrer \& Schauble, 2012; Olander et al., 2018). Situated perspectives on learning are drawn on in RCA models to design activities that allow explanations to be created progressively in response to authentic purposes for inquiry and initiated by students' drawing on their own experience, prior knowledge and everyday language. While early descriptions of RCA emphasized teachers' input in clarifying the representational resources and identifying big ideas in preparation for student led activity (Tytler et al., 2013), more recent descriptions articulate the teachers' mediating role in terms of 'tinkering' and joint assessment, directed to ensure that students' work is focussed and productive and to orchestrate shared discussion/evaluation of students' representation work (Olander et al., 2018).

RCA models recognize the affordances and capacities of written text but argue that truncated abstractions and other complexities of the written mode can allow differences in conceptions to go unnoticed. However, RCA researchers argue that the meaning attached to any one mode, or representation, is inevitably partial and draw explicitly on social semiotic theories (Halliday \& Martin, 1993; Kress \& van Leeuwen, 2006; Lemke, 1990) to attend to the different roles of different modes in opening up new meanings in science. Their concern with the messy 'practice' of science differentiates these models from skills-based inquiry models. Processes which involve students working across modes, which are identified by Kress (2010) as 'transduction', have been developed to open opportunities for students to create representations that reveal meanings that may be concealed in truncated abstractions. As we will discuss in Section 5.6, these processes have informed strategies designed for senior science classrooms in the Multiliteracies in Senior School Science (M3S) project.

While RCA theorists (Tytler \& Aranda, 2015; Tytler et al., 2020) acknowledge the need for further explication of the teacher's discursive role in pedagogic activities, a range of material and symbolic tools are conscripted throughout pedagogic processes to build students' understandings. Unlike situated approaches that privilege students' existing linguistic repertoire, RCA studies conducted in secondary contexts (Olander et al., 2018) draw attention to shifts in register along the continuum from more everyday to specialized scientific language. Teacher-led strategies include revoicing of students' contributions in more scientifically precise language and recording more scientific language from oral discussion in written form on the board. In whole-class discussion, teacher questioning aims to externalize students' current reasoning, with continued teaching strategies conceptualized as 'tinkering' and 'joint assessment' deployed to revise representations. Nevertheless, the acceptance, at least initially, of students' everyday representations and approximations of genres and terminology, which is a key element of RCA pedagogy, may not be effective in supporting students to build technicality in senior school science subjects. 


\section{Teaching and learning practices}

Reviews of pedagogic models have found that representational practice, when supported by strategic intervention of the teacher, plays a central role in inducting diverse learners into science discourse (Hand, Norton-Meier, Gunel \& Akkus, 2016; Tang, Delgado \& Moje, 2014). RCA theorists recognize the need to further explicate the nature of the strategic intervention to ensure that processes observed in student interactions are made visible to all students. In a study of an elementary classroom, Tytler and Aranda (2015) identified a range of moves used by expert teachers to guide and shape students' understandings in classroom discourse, including eliciting and acknowledging, clarifying and extending. These moves were found to be drawn upon flexibly to coordinate a range of verbal, imagic and gestural modes in response to the opportunities and constraints of the contexts. While explication of the moves involved in scaffolding interactions is crucial to understanding the nature of strategic intervention in RCA models, attention to building students' understandings of the form and function of representational resources is not emphasized in applications, nor is metalanguage discussed as a resource for integrated literacy practice.

In summary, the review of RCA approaches highlights significant areas of actual and potential consensus around the role of literacy in building scientific understandings. In their explicit attention to how multiple modes work together to open up meanings for students and their concern to promote the role of the teacher in coordinating and orchestrating students' composition and refinement of representations, RCA approaches offer significant contributions for the development of a multimodal disciplinary pedagogy for senior science students. In the next section, we review foundational literacy pedagogies informed by systemic functional linguistics (SFL) and related visual semiotics outlined in Chapter 3. Although the development of these models has occurred primarily in the context of verbal language use, investigation of genre-based models allow us to further explore synergies and challenges related to quality science teaching and learning.

\subsection{Expert guidance perspectives: integrating explicit instruction through metalanguage}

Genre-based models have been developed largely in response to evidence that appropriate scaffolding for learners from diverse socio-economic and linguistic backgrounds depends on teachers' knowledge of the semiotic challenges students face, as well as strategies to address them (Freebody et al., 2008). Two models, the Teaching Learning Cycle (TLC), focussing on writing, and Reading to Learn (R2L), which largely focuses on reading, have been developed by language and literacy researchers (Rose \& Martin, 2012; Rothery, 1994) and applied in science education (de Oliveira \& Lan, 2014; Feez \& Quinn, 2017; Palinscar \& Schleppegrell, 2014). Social semiotic theories have also informed integrated multiliteracies approaches (Cope \& Kalantzis, 2015; Unsworth, 2001), which have been applied to support 
students in science to engage with, interpret and compose multimodal print and digital texts (Brisk, 2016; He \& Forey, 2018; Humphrey, 2020). However, pedagogic strategies for developing understandings of how multimodal texts work have to date depended upon understandings developed in verbal language contexts (Unsworth, 2004).

\subsubsection{The TLC}

As argued in Chapter 3, genre-based approaches provide anticipatory guidance in learning through and learning about the texts that are valued for disciplinary learning and assessment. The representation of the TLC, which is strongly influenced by sociocultural theories of Vygotsky and research in early childhood learning, is shown in Figure 5.3.

Significant synergies with RCA and other guided inquiry models are evident throughout the TLC model. For example, the stage of 'setting the context' aligns with 'orientation' steps of guided inquiry models in providing exploratory and interactive activity to ensure shared knowledge of a topic or social activity (field) and to build understanding of the significance

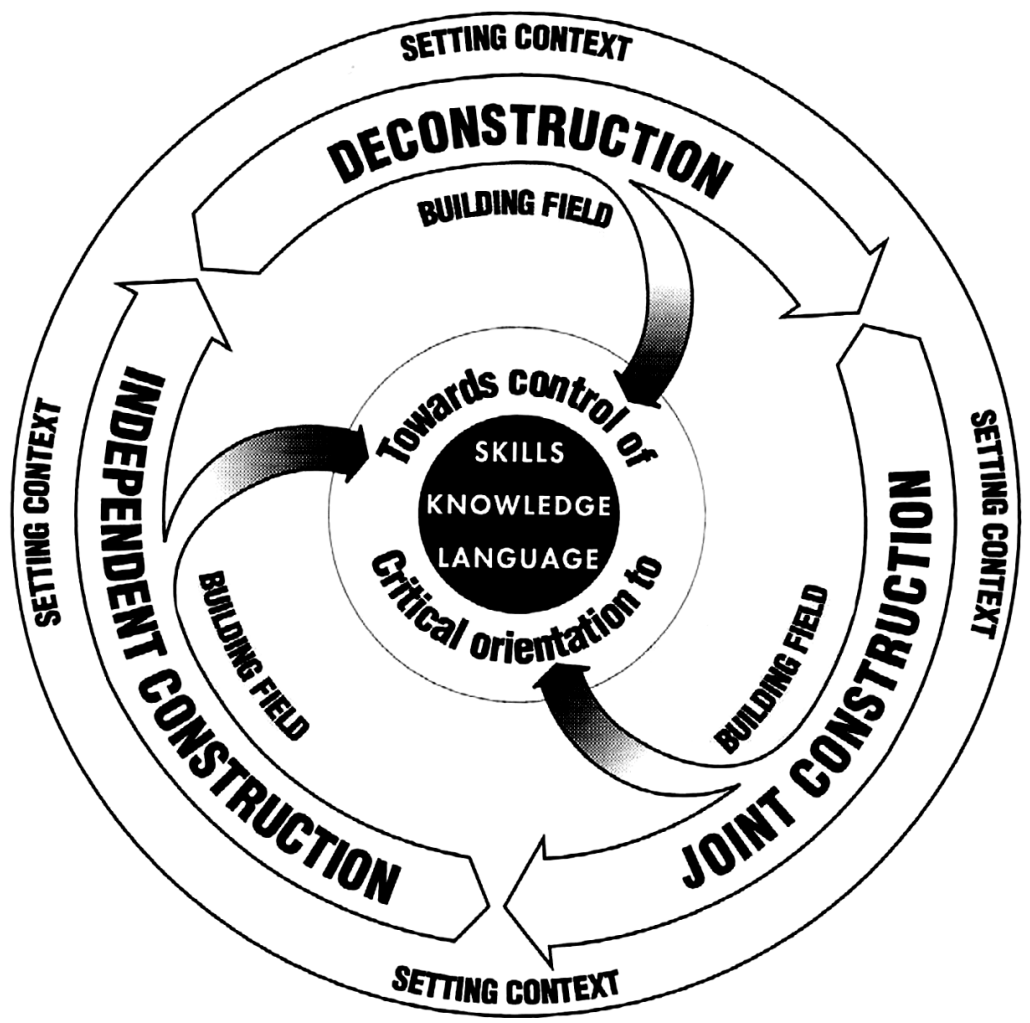

Figure 5.3 The teaching and learning cycle (Rothery, 1994). 
and purpose of the target text type in relation to learning intentions. Joint construction may involve peer-peer construction of parts of texts however, in common with strategies advocated in undergraduate science education (Airey \& Linder, 2009), guidance toward standard disciplinary discourse is crucial at this stage. Independent construction may be individual with consultation and feedback cycles that align with RCA's revision/refinement stage and may also involve peer collaboration. Recent explications of the semiotic mediation that occur in the TLC have drawn attention to the multiple modes that are coordinated and orchestrated by the teacher, whether the target genre is written or multimodal (Macnaught, 2018). For example, students are frequently provided with diagrammatic note-taking outlines to constrain attention towards structural features of the target genre or to field relationships in written and or multimodal sources (Brisk, 2016; Humphrey, 2017). Synergies of these 'cross-mode' strategies with the transduction strategies we have discussed in relation to RCA pedagogies will be further discussed in Section 5.6.

Some alignment with guided inquiry approaches is also evident in descriptions of micro-level teaching and learning strategies within the TLC. In common with studies of classroom interactions modelled in broader sociocultural research, descriptions of joint construction move in tertiary settings have drawn from research in early childhood settings (Painter, 1986) to focus on the role of dialogic and exploratory talk and on the scaffolding provided by the teacher following the contribution of a learner (Macnaught, 2018). Likewise, theories of appropriation (Leont'ev, 1981) have been drawn on to model strategies of 'revoicing' and 'recycling' technical language that has been introduced into the classroom conversation so that it is available for all students to use in knowledge building conversations (Sharpe, 2008).

Despite these synergies with guided inquiry approaches, critical aspects of 'expert guided practice' distinguish the TLC from models towards the 'situated' end of the continuum presented in Figure 5.1. Firstly, while the stage of deconstruction shares characteristics of 'modelling' and 'coaching' represented in some situated models (Brown et al., 1989), modelling in the TLC is understood as explicit teacher-led analysis of one or more texts representing a target genre. Unlike RCA models that initially honour student approximations of genres, such modelling occurs early in the TLC, typically following a diagnostic task to ascertain learners' literacy needs in relation to the target genre. As we have noted in Chapter 1 , it is the prior modelling of texts in the same genre that enables expectations of tasks to be made visible to diverse learners. Including this anticipatory guidance must also involve deconstruction strategies to ensure that the investigation of genres in not limited to their role in the reproduction of knowledge and to ensure that target texts are represented as 'always sites for contestation' (Luke, 1996, p. 318).

A related distinction of the TLC model, which we discussed in Chapter 3 , is the nature and use of metalanguage that is developed over time through iterations across pedagogic stages. From an equity perspective it is the 
sharing of a language for talking about language that empowers diverse learners to participate in the metadiscussion that is valued in socially oriented approaches, however an effective classroom metalanguage can be built with relatively few resources from SFL's rich descriptions (Rose, 2020). In the TLC, metalanguage is first introduced by the teacher in discussion of how semiotic patterns influence and are influenced by contextual variations such as purpose, audience, subject matter and mode. In joint construction, the teacher draws on previously introduced metalanguage to affirm students' contributions to the creation of a new text or to negotiate rewordings. Throughout this process and in consultation that occurs in independent construction, metalanguage augments process-oriented strategies, for example, to model the register shifts involved in refining, editing and proofreading the draft.

While the metalanguage applied in elementary and middle years science applications of the TLC has focussed primarily on the purposes and stages of genres, or on grammatical features (de Oliveira \& Lan, 2014), some applications have also focussed on discourse-level features (Macnaught et al., 2013; Palinscar \& Schleppegrell, 2014). In the M3S project, a metalanguage at the discourse level has allowed the technical and text-making role of nominalization to be distinguished in senior science textbooks (Hao \& Humphrey, 2019 ) and for reasoning to be made visible in reports of science investigations (Humphrey, Hao \& Rose, 2020). These dimensions are crucial in apprenticing students into handling scientific language in the senior school years. While SFL also offers great potential for developing a robust metalanguage for talking about multimodal representations, descriptions of how modes interact within representations have only recently emerged in disciplinary literacy contexts (Martin, Unsworth \& Rose, in press; Unsworth, 2020).

In the next section, we turn our attention to descriptions of the R2L model to reveal further distinctions of expert guidance, particularly within micro-level classroom interactions (Rose \& Martin, 2012).

\subsubsection{The R2L model}

While features such as the anticipatory timing of modelling and to some extent the use of metalanguage are shared across genre-based approaches, close analysis of interactions within the $\mathrm{R} 2 \mathrm{~L}$ model has brought to light features of micro-level teaching and learning that are also of relevance to the design of a multimodal disciplinary literacy pedagogy (Rose, 2020; Rose \& Martin, 2012). Explicit interaction moves in the R2L model are oriented towards the successful completion of a task and include

\section{Prepare Focus Task Evaluate Elaborate.}

These moves ensure that all students have sufficient understandings of the field prior to undertaking compositional challenges. As with guided inquiry interactions, elaborating moves characterized as Evaluate and Elaborate steps 
attend to the teachers scaffolding role following a students' initial response to the challenge. However, a distinctive feature of R2L cycles is the explicit attention given to the micro-level interactions that occur prior to students' engagement with an initial task, through moves called 'Prepare'.

The anticipatory support in the 'Prepare' move aims to set students up for successful comprehension of the field or subject matter of representations. The semiotic choices that realize that field are explicated in interaction cycles at different scales: in relation to whole text, phase, sentence and word meanings. Of particular interest are descriptions of this move in detailed reading at sentence level. Following shared reading and discussion of the selected phase and the target sentence, the teacher provides cues for a nominated student to locate a selected word or phrase within that sentence. Cues include an approximate meaning using everyday language to facilitate the nominated student's comprehension and if needed, guidance as to the location of the word/phrase. It can be argued that questions that are typically asked of students when reading, such as 'Who can tell me what 'ampicillan' means?', lead students out of the text and require students to already have prior knowledge to provide an answer. As prior knowledge is likely to be inequitably distributed amongst students in diverse classrooms, not all students will be able to successfully respond and the question is thus an assessment of reading. In contrast R2L anticipatory cues, such as, 'Can you tell me the word in the middle of the sentence that names a type of antibiotic?', lead the student into the challenging text to find the more technical and precise wordings. Although the Prepare move is teacher-led, it is the nominated student who successfully makes the interpretative step and the shift to the technical, scientific register, thus enabling discursive activity to move quickly beyond approximation. Following this move, the interaction can be extended in ways similar to those found by Tytler and Aranda (2015) and opened up to all students, including those who have been prepared through their prior experience to be active participants in knowledge construction.

Through careful selection of text phases, detailed reading activity has been found to be an effective way to support students to tune in to key meanings, both in the technical field that is under investigation and, crucially in fields related to research activity and text making that are not typically attended to in guided text inquiry. Multiple cycles of such interactions, involving interactions of modalities are typically followed by whole-class joint construction, where students are guided to draw on their highlighted text to appropriate the expert voice of scientific research in reporting their own research findings. From the perspective of equity, the Prepare move enables the teacher to nominate any student to respond to the initial question with confidence that location and meaning cues have set them up for successful response.

As with research in RCA approaches, genre pedagogies have been found to be effective in supporting the literacy and disciplinary learning achievement of students in schools serving students from low SES, Aboriginal and Torres Strait Islander Communities and English Language Learners (de Oliveira \& Lan, 2014; Palinscar \& Schleppegrell, 2014). Pedagogic strategies from 
both R2L and the TLC are increasingly embedded within guided inquirybased approaches in a range of science education contexts (Fang, 2020; Feez \& Quinn, 2017; Hao \& Humphrey, 2019) and productive dialogue with researchers from situated traditions have resulted in further articulation of practices that promote attention to disciplinary meaning making and critical perspectives (O'Halloran et al., 2015). There is no doubt that a concern to make SFL's multilayered theory accessible to teachers has led to oversimplified accounts of genre-based practices that elide complex orchestration of the enactment of expert guidance. However, greater attention to practices that encourage learners' active contribution to the production of knowledge (e.g. Macnaught et al., 2013) have helped to dissociate genre-based pedagogies with from reductive practices.

In summary, there is significant consensus amongst researchers from guided inquiry and genre-based traditions that high-level scientific reasoning and argument requires an inter-play between everyday forms of communication and the disciplinary representations of science. These shared understandings have provided a crucial foundation for developing pedagogies for integrating multimodal disciplinary literacy and exploring the role of multimodal metalanguage (Martin et al., in press; Unsworth, 2020)

\subsection{Going forward: transdisciplinary research and pedagogic development}

The emergence of transdisciplinary collaborations amongst researchers informed by social semiotic perspectives (Feez \& Quinn, 2017; Jones, Turney, Georgiou \& Nielsen, 2020; Maton, Martin \& Doran, in press; Nielsen, Jones, Georgiou, Turney \& Macken-Horarik, 2019; Tang et al., 2014; Tang, Wong, Mocerino, Treagust \& Tasker, in press), including the M3S study reported on in this volume, have contributed significantly to understandings of how disciplinary multimodal literacy practices and strategies can be infused within guided inquiry and practice. These studies bring together expert guided and situated perspectives on pedagogy to better understand how literacy activity and broader representation construction can effectively mirror the practices of professional science, which, as argued in previous chapters, are recontextualized to accommodate the realities of schooling and the science curriculum. The guided inquiry settings of strategies described in these applications recognize the active role of students and their engagement in informal literacy practices, as well as the anticipatory guidance required to support diverse learner groups.

One major area of alignment recognized by M3S researchers relates to the use of transduction strategies. As discussed in previous sections, applications of both RCA and to some extent genre-based pedagogies have drawn on this concept to integrate activities that require students to re-describe meanings of one mode to another. Conversations amongst science education and literacy researchers have enriched understandings of the semiotic mediation provided through such activities, particularly in supporting senior 
students to engage in independent reading of challenging multimodal texts. In a recent application of genre pedagogy, Tang and Putra (2018) provide students with flowcharts to visualize the 'goings on' of procedures in experiments in ways that facilitated the conduct of the experiment. Initial deconstruction of written experimental procedures provided anticipatory guidance to support students to engage with these learning tools. In the M3S project, transduction strategies such as the (completed) note-taking flow chart shown in Figure 5.4 were designed to constrain biology students' attention to the relations amongst the items and activities, in this case, by stepping out the required number of activities to be included in an explanation of the mitosis phase, prophase. The use of such multimodal representations lends themselves to differentiation for diverse learner groups; for example, more or less information from the source text may be included in the diagram and explicit modelling of the discourse and/or grammatical patterns that realize these activities in the written mode may also be provided, depending upon the needs of learners.

A crucial contribution of recent transdisciplinary research is the further development of a bridging metalanguage (Macnaught, 2018) that is accessible and recognizable to science teachers. In the activity shown above, the term 'momenting', which is derived from recent SFL descriptions of field (Martin \& Doran, in press) was used with M3S biology teachers to refer to the way activities can be indefinitely detailed by breaking down the 'moments' that are involved. In our data of secondary school science textbooks, the same field activity was found to be represented as both momented and unmomented activity, reflecting the particular level of detail expected in senior school biology. In Figure 5.4, the key stage of the cell cycle, prophase, is not named as an unmomented activity but momented by being broken down into activities. Unmomented activities frequently occur in the captions and headings accompanying such images. Teachers recognized the value of this terminology to share with students how far they were expected to break down activities in response to assessment questions and to guide them in recognizing 'moments' of most significance.

The explanatory power of SFL metalanguage is also increasingly recognized by rhetorical scholars in applying research to pedagogy (Hyland, 2012). In science education, Tang \& Putra (2018) have used SFL descriptions of written explanation genres to reveal causal relations of rhetorical moves, expressed as Premise, Reasoning, Outcome and to inform a metalanguage for writing templates. Similarly, collaborative studies in undergraduate science contexts and within the M3S project have drawn on Hao's (2020) linguistically principled unpacking of reasoning in research reports to reveal discursive moves for generalizing and reasoning. Ongoing developments within SFL and multimodal discourse analysis have also been recognized by rhetorical theorists (Oddo, 2013) as offering a powerful metalanguage for revealing recontextualizations of verbal discourse in multimodal and digital environments and indicate potential areas of future collaboration with rhetorical scholars. However, the lack of tools available for understanding 


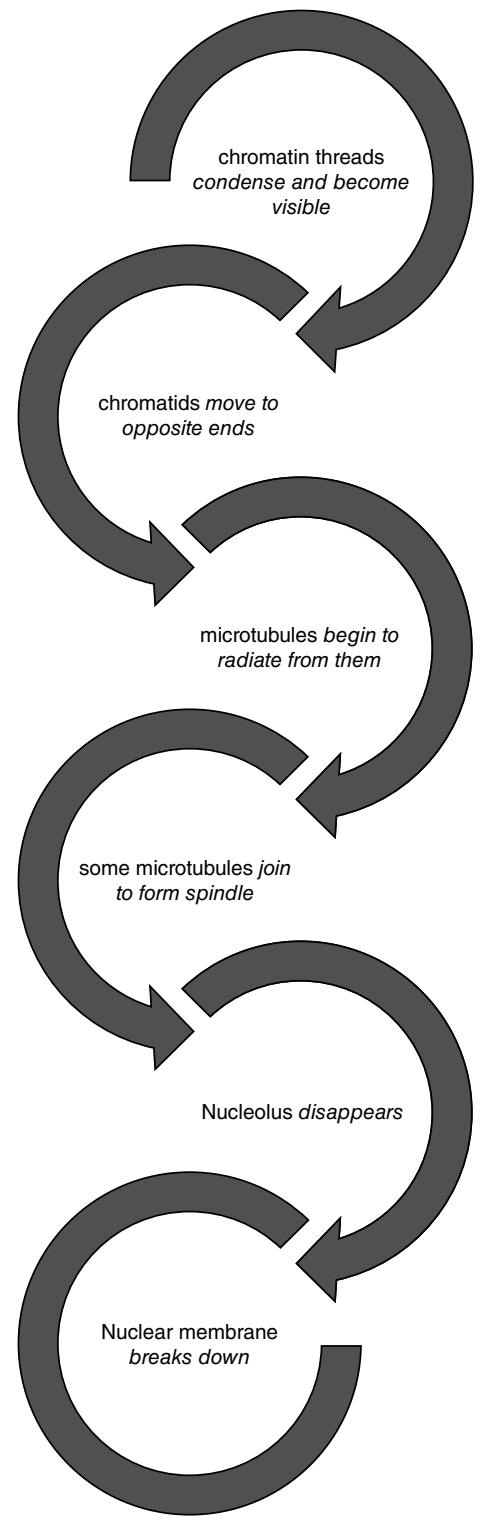

Figure 5.4 Image redescription of 'prophase'.

interactions in multimodal texts have so far limited the capacity of researchers to provide an '[e]xplicit focus on representational function and form' (Tytler et al., 2013, p. 35). For example, descriptions provided by Kress and van Leeuwen (2006) do not provide a metalanguage for talking about verbiage in relation to image.

More recent investigations of the scope of modalities that are coordinated within the R2L interaction cycles to scaffold interpretation of infographics 
(Unsworth, in press), as well as investigations of the multiple modes at work within joint constructions and lecture presentations (Hao \& Hood, 2019) have significantly progressed teachers' understandings of how oral language may be augmented as a form that metalanguage may take. Similarly, findings as to the multimodal affordances of target representations reported on in Chapter 3 (e.g. Doran, 2017, 2019) have contributed greatly to teachers' capacity to design and implement integrated learning tasks and in knowing what needs to be unpacked in particular disciplinary contexts.

In Chapters 7-12, we discuss further how metalanguage at the level of grammar and discourse was used to scaffold students' multimodal literate activity in physics, chemistry and biology in the M3S project. However, while it is clear that SFL theory has provided a basis for a metalanguage for talking about meanings across modes, further transdisciplinary research is needed to explore the robustness of this theory in supporting teachers and students to move between representations.

\subsection{Conclusion}

The review of pedagogic approaches provided in this chapter has enabled us to tease out important synergies amongst pedagogic approaches which have a sociocultural orientation as well as to highlight potential issues that need to be addressed in developing a multimodal disciplinary pedagogy. Most essential are issues related to how learners may be engaged in active construction of knowledge and provided with the anticipatory support that may be needed to succeed in high-stakes school assessment contexts. To be applicable to all learners, a pedagogic design must spell out the how and when of teacher intervention, as well as the mediating affordances of the representations themselves. In both cases, attention must be given to the essential metalanguage that enables explicit talk about meanings and their contexts. In Chapter 6, we propose a framework that has been developed in response to considerations raised in this and earlier chapters.

\section{References}

Airey, J., \& Linder, C. (2009). A disciplinary discourse perspective on university science learning: Achieving fluency in a critical constellation of modes. Journal of Research in Science Teaching, 46(1), 27-49.

Archer, L., \& DeWitt, J. (2016). Understanding young people's science aspirations. London, UK: Routledge.

Brisk, M. E. (2016). Multimodal reports in elementary school classrooms. In M. F. Alexandre \& C. A. M. Gouveia (Eds.), Theory, application, analysis: Studies in systemic functional linguistics (pp. 281-304). Lisbon, Portugal: CELGA-ILTEC.

Brown, J. S., Collins, A., \& Duguid, P. (1989). Situated cognition and the culture of learning. Educational Researcher, 18(1), 32-42.

Chen, Y.-C., Park, S., \& Hand, B. (2016). Examining the use of talk and writing for students' development of scientific conceptual knowledge through constructing and critiquing arguments. Cognition and Instruction, 34(2), 100-147. 
Chidrawi, G., Robson, M., \& Hollis, S. (2010). Biology in focus: HSC course. Melbourne, Australia: Cengage Learning Australia.

Cope, B., \& Kalantzis, M. (Eds.). (2015). A pedagogy of multiliteracies: Learning by design. Basingstoke, UK: Palgrave Macmillan.

de Oliveira, L. C., \& Dodds, K. N. (2010). Beyond general strategies for English language learners: Language dissection in science. Electronic Journal of Literacy Through Science, 9(1), 1-14.

de Oliveira, L. C., \& Lan, S. W. (2014). Writing science in an upper elementary classroom: A genre-based approach to teaching English language learners. Journal of Second Language Writing, 25, 23-39.

Doran, Y. J. (2017). The discourse of physics: Building knowledge through language, mathematics and image. London, UK: Routledge.

Doran, Y. J. (2019). Building knowledge through images in physics. Visual Communication, 18(2), 251-277.

Dreyfus, S. J., Humphrey, S., Mahboob, A., \& Martin, J. R. (2015). Genre pedagogy in higher education: The SLATE project. Basingstoke, UK: Palgrave Macmillan.

Edwards, D., \& Mercer, N. (1987). Common knowledge: The development of understanding in the classroom. London, UK: Routledge.

Fang, Z. (2020). Toward a linguistically informed, responsive and embedded pedagogy in secondary literacy instruction. Journal of World Languages, 6(1-2), 70-91.

Feez, S., \& Quinn, F. (2017). Teaching the distinctive language of science: An integrated and scaffolded approach for pre-service teachers. Teaching and Teacher Education, 65, 192-204.

Freebody, P., Maton, K., \& Martin, J. R. (2008). Talk, text, and knowledge in cumulative, integrated learning: A response to 'intellectual challenge'. Australian Journal of Language and Literacy, 31(2), 188-201.

Halliday, M. A. K., \& Martin, J. R. (1993). Writing science: Literacy and discursive power. Pittsburgh, PA: University of Pittsburgh Press.

Hand, B. (Ed.). (2008). Science inquiry, argument, and language: A case for the science writing heuristic. Rotterdam, Netherlands: Sense Publishers.

Hand, B., Norton-Meier, L. A., Gunel, M., \& Akkus, R. (2016). Aligning teaching to learning: A 3-year study examining the embedding of language and argumentation into elementary science classrooms. International Journal of Science and Mathematics Education, 14(5), 847-863.

Hand, B., Yore, L., Jagger, S., \& Prain, V. (2010). Connecting research in science literacy and classroom practice: A review of science teaching journals in Australia, the UK and the United States, 1998-2008. Studies in Science Education, 46(1), 45-68.

Hao, J. (2020). Analysing scientific discourse from a systemic functional linguistic perspective: A framework for exploring knowledge building in biology. London, UK: Routledge.

Hao, J., \& Hood, S. (2019). Valuing science: The role of language and body language in a health science lecture. Journal of Pragmatics, 139, 200-215.

Hao, J., \& Humphrey, S. (2019). Reading nominalisations in senior science. Journal of English for Academic Purposes, 42, 100793.

He, Q., \& Forey, G. (2018). Meaning-making in a secondary science classroom: A systemic functional multimodal discourse analysis. In K.-S. Tang \& K. Danielsson (Eds.), Global developments in literacy research for science education (pp. 183-202). Cham, Switzerland: Springer International Publishing.

Humphrey, S. (2017). Academic literacies in the middle years: A framework for enhancing teacher knowledge and student achievement. New York: Routledge. 


\section{Teaching and learning practices}

Humphrey, S. (2020). The role of teachers' disciplinary semiotic knowledge in supporting young bi/multilingual learners' academic and reflexive multiliteracies. Language and Education. https://doi.org/10.1080/09500782.2020.1772282

Humphrey, S., Hao, J., \& Rose, D. (2020). Launching research: A Martinian perspective on science pedagogy. In M. Zappavigna \& S. J. Dreyfus (Eds.), Discourses of hope and reconciliation: J. R. Martin's contributions to systemic functional linguistics. London: Bloomsbury Academic.

Hyland, K. (2012). Genre and discourse analysis in language for specific purposes. In C. Chapelle (Ed.), The concise encyclopedia of applied linguistics (pp. 1-8). Hoboken, NJ: Wiley Blackwell.

Jones, P., Turney, A., Georgiou, H., \& Nielsen, W. (2020). Assessing multimodal literacies in science: Semiotic and practical insights from pre-service teacher education. Language and Education, 34(2), 153-172.

Kress, G. (2010). Multimodality: A social semiotic approach to contemporary communication. London: Routledge.

Kress, G., \& van Leeuwen, T. (2006). Reading images: The grammar of visual design (2nd ed.). London: Routledge.

Lave, J., \& Wenger, E. (1991). Situated learning: Legitimate peripheral participation. Cambridge: Cambridge University Press.

Lehrer, R., Konold, C., \& Kim, M.-J. (2006). Constructing data, modeling chance in the middle school. Paper presented at the Annual Meeting of the American Educational Research Association, San Francisco, CA. http://citeseerx.ist.psu. edu/viewdoc/download?doi=10.1.1.578.4577\&rep=repl\&type=pdf

Lehrer, R., \& Schauble, L. (2012). Seeding evolutionary thinking by engaging children in modeling its foundations. Science Education, 96(4), 701-724.

Lemke, J. (1990). Talking science: Language, learning and values. Norwood, NJ: Ablex.

Leont'ev, A. N. (1981). The problem of activity in psychology. In J. V. Wertsch \& L. Vygotsky (Eds.), The concept of activity in Soviet psychology (pp. 37-71). Armonk, NY: Sharpe.

Luke, A. (1996). Genres of power? Literacy education and the production of capital. In R. Hasan \& G. Williams (Eds.), Literacy in society (pp. 302-338). London, UK: Longman.

Macnaught, L. (2018). Multimodal metalanguage. In H. de Silva Joyce \& S. Feez (Eds.), Multimodality across classrooms: Learning about and through different modalities. Newcastle upon Tyne, UK: Cambridge Scholars Publishing.

Macnaught, L., Maton, K., Martin, J. R., \& Matruglio, E. (2013). Jointly constructing semantic waves: Implications for teacher training. Linguistics and Education, 24(1), 50-63.

Martin, J. R., \& Doran, Y. J. (in press). Seeing knowledge through field: Understanding scientific explanations. In K. Maton, J. R. Martin \& Y. J. Doran (Eds.), Studying science: Knowledge, language, pedagogy. London, UK: Routledge.

Martin, J. R., \& Matruglio, E. (2013). Revisiting mode: Context in/dependency in ancient history classroom discourse. In H. Guowen, Y. Zhu, Z. Delu \& Y. Xinzhang (Eds.), Studies in functional linguistics and discourse analysis (pp. 7295). Beijing, China: Higher Education Press.

Martin, J. R., Unsworth, L., \& Rose, D. (in press). Condensing meaning: Imagic aggregations in secondary school science. In G. Parodi (Ed.), Multimodality: From corpus to cognition. London, UK: Bloomsbury. 
Maton, K., Martin, J. R., \& Doran, Y. J. (in press). Studying science: Knowledge, language, pedagogy. London, UK: Routledge.

Matruglio, E. (2019). Beating the bamboozle: Literacy pedagogy design and the technicality of SFL. Australian Journal of Teacher Education, 44(4), 1-13 Article 1.

Moje, E. B. (2015). Doing and teaching disciplinary literacy with adolescent learners: A social and cultural enterprise. Harvard Educational Review, 85(2), 254-278.

Morin, O., Simonneaux, L., Simonneaux, J., Tytler, R., \& Barraza, L. (2014). Developing and using an S3R model to analyze reasoning in web-based crossnational exchanges on sustainability. Science Education, 98(3), 517-542.

Morrison, C. D. (2014). From 'sage on the stage' to 'guide on the side': A good start. International Journal for the Scholarship of Teaching and Learning, 8(1), 1-15, Article 4.

Mortimer, E., \& Scott, P. (2003). Meaning making in secondary science classrooms. Maidenhead, UK: Open University Press.

Nielsen, W., Jones, P., Georgiou, H., Turney, A., \& Macken-Horarik, M. (2019). Learning science through generating multimodal digital explanations: Contributions to multimodality in educational practice. In J. P. Wildfeuer, J. Bateman, O. Seizov \& C.-I. Tseng (Eds.), Multimodality: Disciplinary thoughts and the challenge of diversity (pp. 247-276). Berlin, Germany: de Gruyter.

Norris, S. P., \& Phillips, L. M. (2003). How literacy in its fundamental sense is central to scientific literacy. Science Education, 87(2), 224-240.

Nunes, T., Bryant, P., Strand, S., Hillier, J., Barros, R., \& Miller-Friedmann, J. (2017). Review of SES and science learning in formal educational settings: A report prepared for the EEF and the Royal Society.

O'Halloran, C. L., Palinscar, A. S., \& Schleppegrell, M. J. (2015). Reading science: Using systemic functional linguistics to support critical language awareness. Linguistics and Education, 32, 55-67.

Oddo, J. (2013). Discourse-based methods across texts and semiotic modes: Three tools for micro-rhetorical analysis. Written Communication, 30(3), 236-275.

Olander, C., Wickman, P. O., Tytler, R., \& Ingerman, Å. (2018). Representations as mediation between purposes as junior secondary science students learn about the human body. International Journal of Science Education, 40(2), 204-226.

Painter, C. (1986). Writing to mean: Teaching genres across the curriculum. Applied Linguistics Association of Australia (Occasional Papers), 9, 62-97.

Palinscar, A. S., \& Brown, A. (1984). Reciprocal teaching of comprehension-fostering and monitoring activities. Cognition and Instruction, 1(2), 117-175.

Palinscar, A. S., \& Schleppegrell, M. J. (2014). Focusing on language and meaning while learning with text. TESOL Quarterly, 48(3), 616-623.

Prain, V., \& Tytler, R. (2012). Learning through constructing representations in science: A framework of representational construction affordances. International Journal of Science Education, 34(17), 2751-2773.

Rose, D. (2020). Building a pedagogic metalanguage I: Curriculum genres. In J. R. Martin, K. Maton \& Y. J. Doran (Eds.), Studying science: Knowledge, language and pedagogy (pp. 236-267). London, UK: Routledge.

Rose, D., \& Martin, J. R. (2012). Learning to write, reading to learn: Genre, knowledge and pedagogy in the Sydney school. Sheffield, UK: Equinox.

Rothery, J. (1994). Exploring literacy in school English. Sydney, Australia: Metropolitan East Disadvantaged Schools Program.

Sharpe, T. (2008). How can teacher talk support learning? Linguistics and Education, $19(2), 132-148$. 
Snow, C. E. (2010). Academic language and the challenge of reading for learning about science. Science, 328(5977), 450-452.

Tang, K.-S. (2019). Scientific practices as an actor-network of literacy events: Forging a convergence between disciplinary literacy and scientific practices. In V. Prain \& B. Hand (Eds.), Theorizing the future of science education research (pp. 83-98). Cham, Switzerland: Springer Nature Switzerland.

Tang, K.-S., \& Danielsson, K. (2018). Global developments in literacy research for science education. Cham, Switzerland: Springer International Publishing.

Tang, K.-S., Delgado, C., \& Moje, E. B. (2014). An integrative framework for the analysis of multiple and multimodal representations for meaning-making in science education. Science Education, 98(2), 305-326.

Tang, K.-S., \& Putra, G. B. S. (2018). Infusing literacy into an inquiry instructional model to sup- port students' construction of scientific explanations. In K. S. Tang \& K. Danielsson (Eds.), Global developments in literacy research for science education (pp. 281-300). Cham, Switzerland: Springer International Publishing.

Tang, K.-S., Wong, M., Mocerino, M., Treagust, D. F., \& Tasker, R. (in press). Multimodal affordances of immersive virtual reality for visualising and learning molecular interactions. In L. Unsworth (Ed.), Learning from viewing and creating animations in science education: Innovative developments in semiotic and educational research. Cham, Switzerland: Springer International Publishing.

Tytler, R., \& Aranda, G. (2015). Expert teachers' discursive moves in science classroom interactive talk. International Journal of Science and Mathematics Education, 13(2), 425-446.

Tytler, R., Ferguson, J., \& White, P. (2020). A pedagogy for learning data modelling through constructing, evaluating and orchestrating representational systems. Learning: Research and Practice, 6(1), 5-18.

Tytler, R., Prain, V., Hubber, P., \& Waldrip, B. (2013). Constructing representations to learn in science. Rotterdam, Netherlands: Sense Publishers.

Unsworth, L. (2001). Teaching multiliteracies across the curriculum: Changing contexts of text and image in classroom practice. Buckingham, UK: Open University Press.

Unsworth, L. (2004). Comparing school science explanations in books and computer-based formats: The role of images, image/text relations and hyperlinks. International Journal of Instructional Media, 31(3), 283-301.

Unsworth, L. (2020). Intermodal relations, mass and presence in school science explanation genres. In M. Zappavigna \& S. J. Dreyfus (Eds.), Discourses of hope and reconciliation: J. R. Martin's contributions to systemic functional linguistics (pp. 131-152). London, UK: Bloomsbury Academic.

Unsworth, L. (Ed.). (in press). Learning from viewing and creating animations in science education: Innovative developments in semiotic and educational research. Cham, Switzerland: Springer International Publishing.

Vygotsky, L. (1978). Mind in society: The development of higher psychological processes. Cambridge, MA: Harvard University Press.

Wallace, C. S., Hand, B., \& Prain, V. (2004). Writing and learning in the science classroom. Dordrecht, Netherlands: Springer Netherlands.

Yore, L. (2018). Commentary on the expanding development of literacy research in science education. In K.-S. Tang \& K. Danielsson (Eds.), Global developments in literacy research for science education (pp. 379-397). Cham, Switzerland: Springer International Publishing. 


\section{A framework for infused multimodal disciplinary literacy in school science}

\subsection{Introduction}

In this chapter, we propose a framework for the permeation of multimodal disciplinary literacy development throughout all phases of science teaching and learning sequences. Our framework negotiates areas of actual and potential consensus amongst the different traditions in science education research that commit to the centrality of multimodal literacy in the construction and communication of scientific understanding while differing in the nature and extent of this commitment in their pedagogic orientations.

These situated approaches of guided inquiry and guided practice in science education and genre-based/functional linguistic approaches and the main continua along which they vary are introduced in Chapter 1 and summarized in Figure 1.1, and further discussed in Chapter 5 and highlighted in Figure 5.1. We propose a framework to strategically navigate the topological space around these continua. Our framework involves guided inquiry and collaborative exploration in communities of practice nuanced with timely targeted explicit instruction to make visible semiotic affordances and patterns of disciplinary use of verbal text, as well as multiple modes of representation through an accessible metalanguage. Our framework seeks to facilitate the apprenticing of students into the epistemology of science, as well as acknowledging and addressing the complexity of the senior high school curriculum and contextual challenges as discussed in Chapter 4 . These challenges include the increasing sophistication and complexity of the language and images through which science concepts at this level are expressed, educational disadvantage arising from students' socio-economic background and/or their use of English as an additional language, the influence of high-stakes assessment regimes in the final years of high school and traditions of constrained pedagogical practices that are part of the culture of teaching senior high school science.

In the next section of this chapter, we progressively build our framework for multimodal literacy infused science pedagogy (MLISP), drawing on our previous chapters to highlight commonalities amongst the different research perspectives and the bases on which we believe divergences might 
be reconciled. In so doing we refer to illustrative interventions in the literature that support the efficacy of the various pedagogic dimensions which we have adopted/adapted and brought into a distinctive, principled but flexible synthesis in our framework (Chen, Park \& Hand, 2016; Forey, 2020; Macnaught, Maton, Martin \& Matruglio, 2013; Nam, Choi \& Hand, 2011; Tang, 2019; Tytler, Prain, Hubber \& Waldrip, 2013). In the third section of the chapter, we briefly sketch the potential significance of our MLISP framework for improving the achievement of low socio-economic status (SES) students. We compare responses to short-answer examination questions by high- and mid-level achieving year 12 physics students and outline examples of pedagogic practice informed by various dimensions of our framework that address the limitations in multimodal disciplinary literacy evident in the response of the mid-level achieving students. More detailed examples of classroom practices informed by our framework in biology, physics and chemistry are discussed in Chapters 7,8 and 9, respectively.

\subsection{A framework for MLISP}

\subsubsection{Semiotic mediation as core to the construction and communication of scientific knowledge}

In Chapter 2, we established that central to science reasoning and knowledge building is an understanding of the various modes of representation as intrinsic to the construction and communication of conceptual understanding. This seminal understanding of multimodal representations as mediating tools is at the core of our MLISP framework, hence we have represented this at the centre or nucleus of our cyclic model in Figure 6.1. We showed in Chapter 4 that as students move through the grades to senior high school and the science concepts that they encounter become more complex, the representational forms in the various modes become concomitantly more technical and discipline specific. Hence the progression of students' learning in science and their induction into the representational forms of scientific discourse are inextricably linked. This duality is the key premise underlying our pedagogic proposals for the integrative development of students' scientific conceptualization and multimodal disciplinary literacy through strategic adaptations of guided inquiry pedagogy. As we argued in Chapter 4, inquiry-based approaches need to be in conversation with the nature of the curriculum and contextual constraints that characterize the senior high school, necessitating flexibly deployed re-configurations of the nature and extent of teacher guidance. The complete fusion of such adapted guided inquiry and induction into the representational practices of science flows through all of the interconnected pedagogic relationships amongst the teacher, the student and the classroom community. These fundamental postulations deriving from the centrality of multimodal representations as mediating tools form the base of our framework, which is represented in Figure 6.1. 


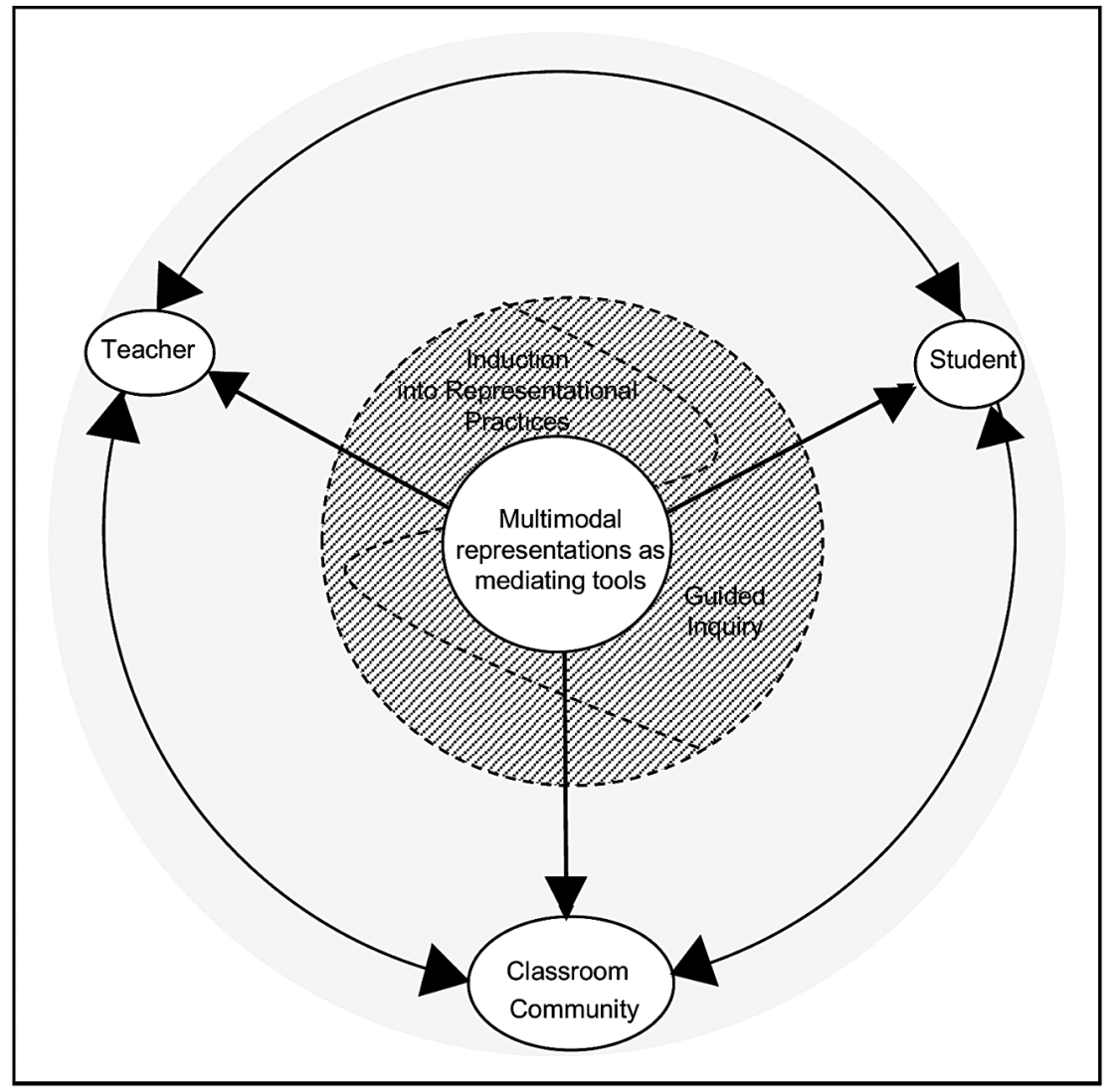

Figure 6.1 Fundamental bases for multiliteracies infused science education.

\subsubsection{Guided inquiry}

Amongst the traditions characterized as situated approaches represented by guided inquiry and guided practice in Chapter 5 , there is a fairly common underlying pedagogic sequence. The main stages in this sequence are discussed in Chapter 5 as involving exploration, investigation/challenge, negotiation/debate and reflection/revision and summarized in Figure 5.2. For our framework, we have incorporated a similar sequence, glossing the stages as Challenge, Investigation, Negotiation, Consensus/Confirmation, Learning Consolidation. While the genre-based/functional linguistic pedagogy does not specify such a sequence, the 'negotiating field' phase of the genre-based Teaching-Learning Cycle (TLC) involves identifying what part of the field is being explored, what the students already know about it, what experiences and activities will be part of the exploration and how information from the activities will be recorded (Rose \& Martin, 2012, p. 65). An example of the application of the TLC incorporating this phase involves students investigating issues in global warming (Unsworth, 2001, p. 240). 


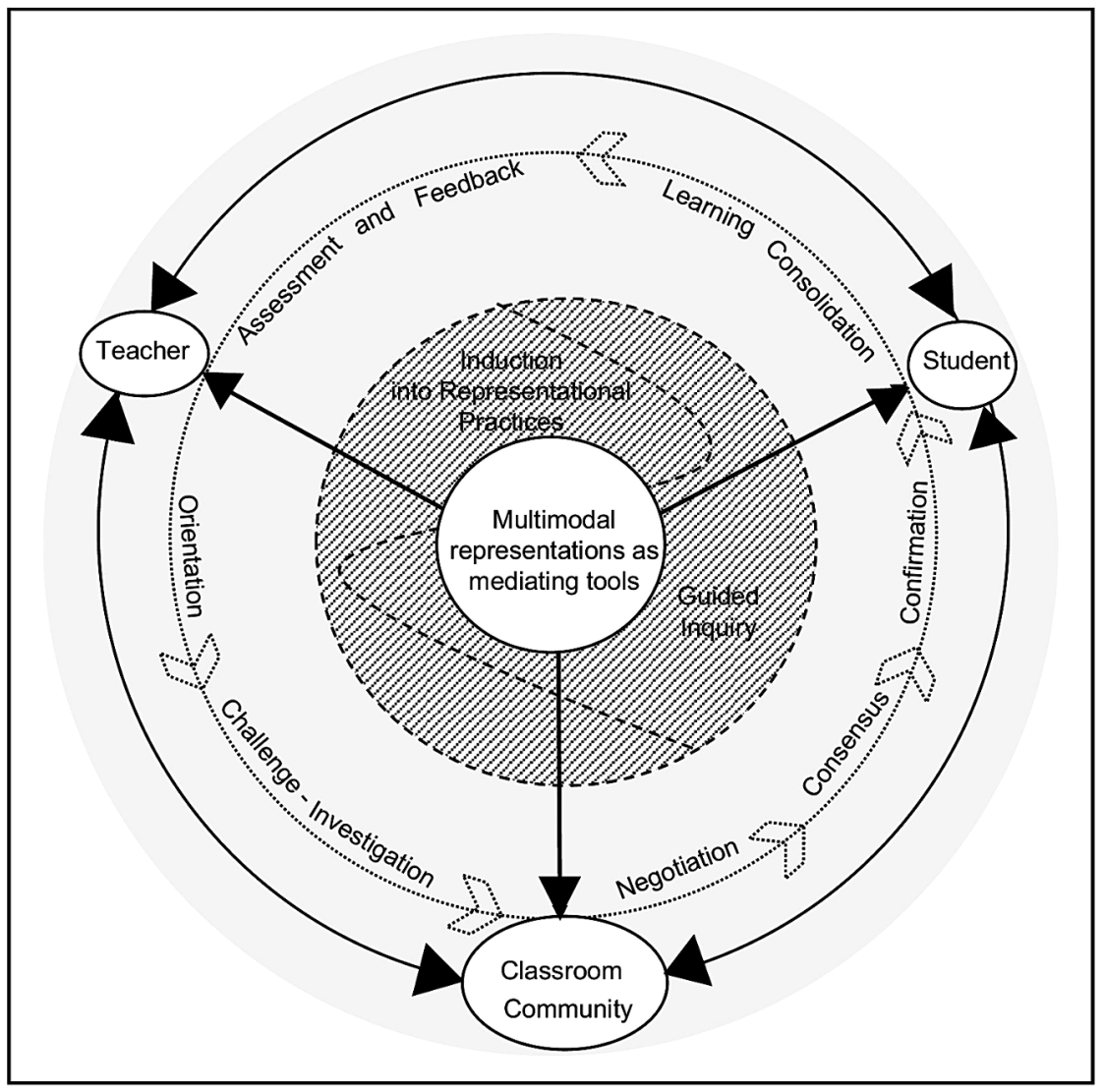

Figure 6.2 Teaching/learning sequences for guided inquiry pedagogy.

The convergence across different research orientations emphasizes the importance of this pedagogic dimension, which is incorporated into our framework, as shown in Figure 6.2.

In the orientation, the teacher interacts with the students in the classroom community to introduce the scientific context in which the phenomena to be addressed are located, engaging the students' interest and eliciting from them relevant prior knowledge arising from previous work or from the contextualizing of the new topic. From this orientation, the challenge(s) or inquiry question(s) are derived. In the representation construction approach, the posing of these challenges about problematic aspects of phenomena that require explanation necessarily entails representational challenges (Tytler, Prain \& Hubber, 2018). The investigation to address these challenges or inquiry questions is typically undertaken by small groups of students with guidance from the teacher, the extent of which varies depending on the nature of the investigation and the learning needs of the students. Investigations most frequently involve the use of concrete materials and sometimes 
apparatus but could also occur through the exploration of digital and/or paper media verbal and/or multimodal representations. Students' material investigations may also be linked to representational challenges. Once the students have formulated what they consider viable responses, these are shared and compared amongst the entire classroom community and a consensual response is negotiated, which may, as appropriate, be confirmed through critical consultation of canonical accounts. In the representation construction approach, the challenge, investigation and negotiation phases are frequently iterative, as the negotiation of tentative responses raises further challenges until a consensual response is achieved (Tytler et al., 2013). The approach emphasizes the learning processes that occur through these progressive student responses to the representational challenges (Tytler, Prain, Aranda, Ferguson \& Gorur, 2020). Although sometimes not made explicit, an important phase is the consolidation of learning, which frequently involves further student representation construction to communicate what was learned in a refined, more precise and polished form.

While, following the orientation, the challenge initiates the investigation, this dimension of guided inquiry is not confined to a discrete phase but rather imbues all phases with critical questioning of investigative methodology, the nature of consensus and the potential tentativeness of confirmation and consolidation, as well as the assumptions inherent in the design of the teaching/learning experiences and hence the teacher's evaluation of the teaching. Similarly, assessment and feedback should occur throughout and not only at the end of the cycle. While productive evaluative feedback amongst peers can occur within the classroom community work, it is crucial, albeit logistically difficult, that all students receive individual feedback on their work from the teacher. Although students can consolidate their learning within collaborative group work activities, it is crucial that the pedagogy ensures that all students demonstrate individually their consolidation of the relevant learning outcomes. The location of learning consolidation with assessment and feedback at the top of the cycle spanning the connection between the teacher and the individual student in Figure 6.2 emphasizes the importance of teacher assessment and feedback on each individual student's contribution so that each student's learning and concomitant development of representational competence is monitored.

The broad approach described here is largely reflected across the traditions of science pedagogy research described in Chapter 5 as guided inquiry and guided practice within the science education literature. While the phases such as Orientation, Challenge, Investigation, Negotiation, Consensus/ Confirmation and Consolidation are seen within inquiry-based approaches as reflective of the epistemic processes of scientists, and hence inculcating epistemological understanding amongst students, Tang (2019) has drawn on several studies to emphasize the 'messier' reality of scientists' practices (Erduran, 2015). He refers to the depiction by Mody (2015) of scientists working like bricoleurs generating tools and literacy devices for provisional use as they proceed with their work, rather than simply following defined 


\section{2}

protocols throughout the research process. Like Tang, we see the enactment of these science practices as recontextualized within senior high school pedagogy as 'messier' adaptations of guided inquiry protocols. Such adaptations might include, for example, interpolations of teacher-directed student activity, teacher orchestrated input and, as Tang (2019) illustrates, student rehearsals of learning from previously completed worksheets to facilitate progress in their current undertaking.

\subsubsection{A pedagogy of synthesis between multimodal disciplinary literacy and scientific practices}

While literacy is ostensibly accorded a key role in the guided inquiry pedagogies, the nature and conduct of literate practice is frequently only minimally mentioned or completely elided in reports of the intervention studies. For example, the representation construction approach indicates the importance of '[e]xplicit focus on representational function and form, with timely clarification of parts and their purposes' (Tytler et al., 2013, p. 35), but this is not explicated in reports of the work. Similarly, Chen, Park and Hand indicate that students are involved in '[c]omparing science ideas to textbooks or other printed resources' (2016, p. 110), but there is no mention of how this occurs in the report of this study. Much of the research in these traditions seems to background or elide reading to learn in science, whereas intensive reading is an integral aspect of scientists' investigations and knowledge building (Wellington \& Osborne, 2001, p. 42). Our framework aims to make visible these literate dimensions of the pedagogy.

We emphasize the permeation of many different types of multimodal literate practice throughout the adapted recontextualized scientific practices comprising the pedagogic sequences. Tang (2019) reminds us of the work of Latour and Woolgar (2013) and more recently of Mody (2015), showing how scientists incessantly make use of 'inscriptions' throughout the stages of their work and that these can include a wide range of literate activities such as informal lab notes, as well as graphs and various forms of reading and multimodal text formulation. Tang (2019) exemplifies the reflection of this permeation of literate practice in a year nine chemistry class, showing, for example, how student reading and translating text to tabular expression functions in the early challenge phase of the pedagogy, far from the occurrence of close reading being confined to later phases of comparing student representations with canonical versions. He further notes how the teacher refers the students to reading and learning from previously constructed notes to enable them to progress their current investigation. Exposure of these kinds of facilitative literate learning experiences emphasizes the importance of study and revision in augmenting learning through investigation. In an account of university undergraduate students' science learning from a disciplinary discourse perspective, Airey and Linder (2009) explained the significance of students achieving discursive fluency in a critical constellation of representational modes. Since the meaning conveyed by any one representational mode is 
always only partial, the experiences of several different modes of representation of particular phenomena are required to be holistically representative of a disciplinary way of knowing. In discussing the various learning experiences through which students gradually progress towards this discursive fluency, Airey and Linder drew attention to the role of ongoing formative literate activities which they referred to as 'repetitive practice' such as 'the reading and re-reading of lecture notes and prescribed textbooks' $(2009$, p. 35). They emphasized that repetitive practice was equally important in receptive and productive modes.

While oral language interaction, talking science (Lemke, 1990), between the teacher and students and amongst students is central to teaching and learning, the spoken mode is also ephemeral and needs to be productively augmented through functional interpolation of multimodal text interpretation and creation throughout the pedagogic sequence. As well as 'journal writing' or 'creating a presentation or poster' (Nam et al., 2011), Chen, Park and Hand (2016, p. 110) refer to 'informal writing' in generating an inquiry question. Other informal representation construction can be readily incorporated into classroom work. For example, initial speculations about potential explanations by students in response to teachers' questions may also at times be usefully committed to brief written and/or multimodal 'inscriptions' that students are then invited to share, encouraging cognitive engagement of all students. Similarly, reading and representation interpretation may involve quite brief or rather more extended verbal and/or multimodal representations at various stages in the pedagogic sequence, incorporating study, revision and practice. As part of our framework, in Figure 6.3, we show this encompassing integration of representation interpretation, construction and critique within the multimodal interactive classroom discourse.

\subsubsection{Teacher demonstration and guidance within the network of classroom interaction}

While the widely supported approach of guided inquiry to inculcating scientific practices in classroom pedagogy may be committed to the centrality of multimodal representation interpretation and creation, there remains a lack of clarity as to precisely how such approaches facilitate students' learning to use the multimodal literacies of science to reason about and critically communicate scientific interpretations of phenomena (Prain \& Hand, 2016 , p. 2). This may be partly due to science teachers' implicit operational knowledge rather than explicit descriptive knowledge of how the meaning-making resources of language and various kinds of visualizations and symbols are effectively deployed in scientific discourse and hence their constrained capacity to explain such usage to students. However, it also seems that there is a fairly steadfast adherence to the role of the teacher as exclusively that of facilitator or guide to student learning and an apparent reluctance to also incorporate a more direct instructional role. As we noted in Chapter 3, the consensus on students developing an understanding of the 


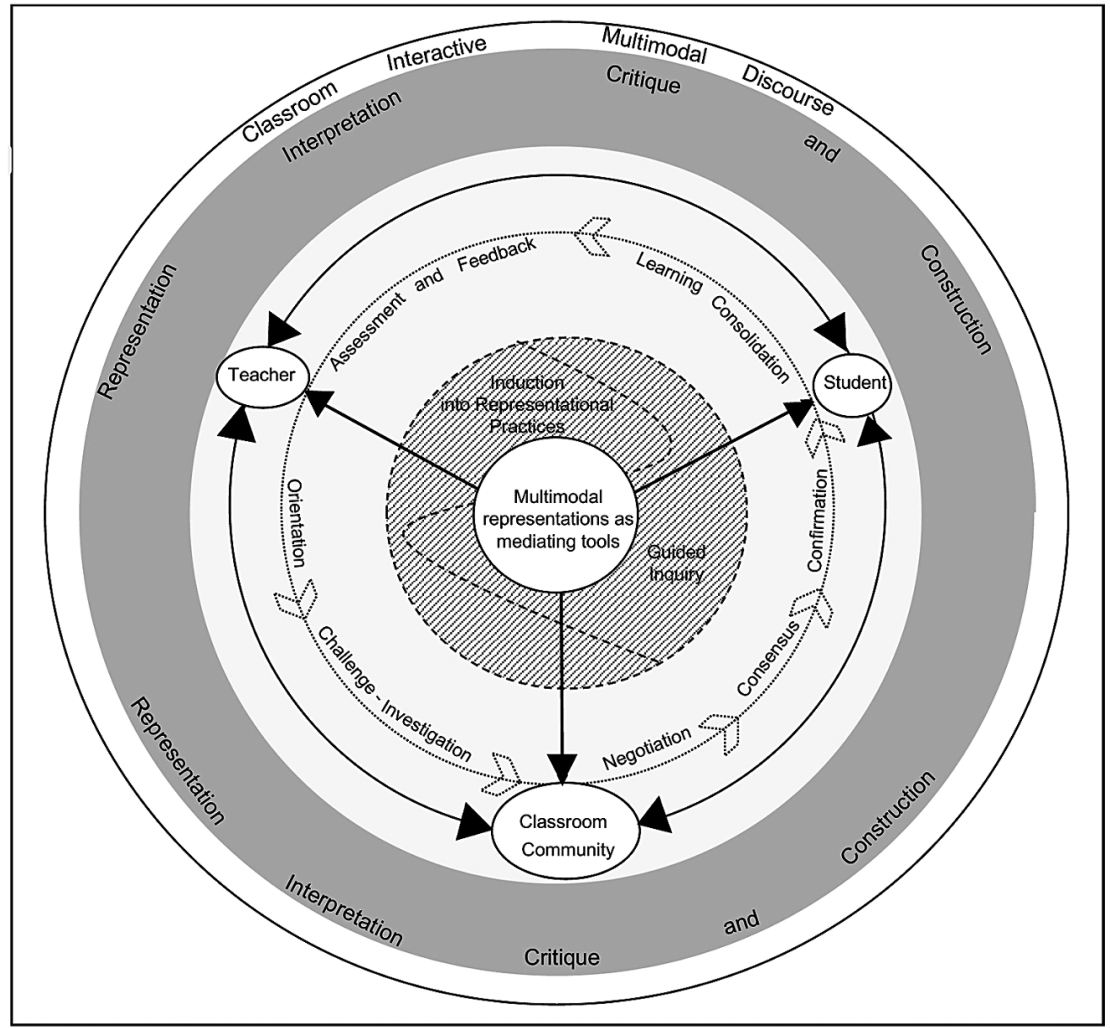

Figure 6.3 Pedagogic synthesis of multimodal disciplinary literacy and scientific practices.

form/function of visual, verbal and symbolic/mathematical representations extends to 'macro conditions for quality science learning', including, importantly, teacher-guided consensus around representational adequacy (Prain \& Hand, 2016, p. 6). However, Prain and Hand note that challenges remain at the 'micro-level' of teaching/learning, including the timing and amount of explicit teaching of form/function relationships.

The strategic incorporation of teacher-directed learning and/or direct teacher input into an adapted guided inquiry approach to science pedagogy certainly does not obviate the sustainability of active learning by students. Concern about the timing and amount of explicit teaching of form/function relationships by some researchers associated with guided inquiry approaches who advocate the centrality of multimodal literacy in science learning may stem from a concern with over-reliance on traditional teacher-directed approaches or from simplistic characterizations of SFL genre-based pedagogy as 'highly directed, explicit teacher-focused pedagogy' (Prain \& Hand, 2016, p. 3). However, as Macnaught et al. (2013) pointed out, the joint construction phase of this pedagogy is 'an opportunity to discuss and debate 
decisions about how knowledge is created through language and other media' and 'where variation from model texts can be creatively, yet discerningly explored' (p. 55). But clarifying the potential for consensus amongst those working in the tradition of guided inquiry and those working from an SFL genre-based pedagogic perspective is also constrained by the lack of any precise account in the guided inquiry literature about the pedagogy that enables students to come to understand 'the form/function of different visual, verbal and mathematical representations' and use these to interpret and create convincing textual claims (Prain \& Hand, 2016, p. 6). In our framework, we seek to provide a basis for a viable resolution of the challenges to consensus amongst guided inquiry and SFL genre-based approaches around how students can be gradually effectively inducted into confident use of the canonical multimodal representational forms of science discourse.

A key issue in working towards this consensus is to clarify the potential of flexible deployment of a range of teacher and student pedagogic roles within the interactive contexts of the teacher with the whole class or the teacher with small groups or individual students and students collaborating with peers in small groups. In Figure 6.3, we established multimodal representations as mediating tools as core to these interconnected interactive contexts (represented by the double-headed arrows) of the teacher, individual students and the classroom community as they negotiate the duality of guided inquiry induction into science practices and multimodal disciplinary literacy. This dynamic weaves throughout the lesson and sequences the different kinds of representation interpretation, construction and critique that pervade the classroom activity. But the question is what is the repertoire of pedagogic practice that orchestrates the weaving so that the infusion of multimodal disciplinary literacy development throughout the induction into science practices optimizes learning for all students, including those from socio-economically disadvantaged backgrounds and those for whom English is an additional language, who have been shown to struggle with the disciplinary literacies of school science (Nunes et al., 2017; Teese, 2013). As we have shown in Chapter 4, this pedagogic repertoire needs to address additional contextual pressures such as the vastly greater complexity of the discourse of senior high school biology, chemistry and physics than that experienced by students in junior high school science, as well as the impact of the high-stakes external matriculation level examination that students face at the end of their senior high school years.

What might be regarded as augmentation, adaptation or customizing of guided inquiry was briefly noted in the previous two sections. The study of a junior high school science class by Tang noted the incorporation of students' learning through their study of previously constructed notes to facilitate the progression of their current project. This points to the utility of learning through interpolated literate practices such as study and revision within an adapted pedagogy flexibly framed around guided inquiry. Similarly, we noted the study by Airey and Linder (2009) which reported the strategies of university science students in progressively developing increased 


\section{Infused multimodal disciplinary literacy}

discursive fluency in multimodal disciplinary literacy as including reading and re-reading lecture notes and prescribed textbooks. In view of the paucity of research into multimodal disciplinary literacy taking into account the contextual pressures in senior high school science, it is useful to further consider this study with university science students. Airey and Linder (2009, p. 42) emphasize the importance of learning the discourse of science by doing science with scientists, holistically experiencing disciplinary ways of knowing, but they also point out that in guiding students towards standard disciplinary discourse, teachers should not only scaffold student meaning making but also model disciplinary discourse and actively engage students in their attempts to make meaning with such discourse for themselves.

This orientation of Airey and Linder (2009) is consistent with the SFL genre-based pedagogy, which we introduced as the TLC in Chapter 3 (Section 3.6) and revisited briefly earlier in this section (Macnaught et al., 2013). The basic progression within the TLC inclusive of multimodal representations involves:

- building the field - this can involve empirical investigation and/or vicarious exploration of phenomena through simulation, viewing animations/movies, reading paper media and/or online texts, as well as excursions, etc.

- modelling by the teacher of the creation of the target representation(s) for the programme of study and deconstructing target representations to explicate the visual and verbal meaning-making resources deployed.

- joint construction where the teacher and students draft a representation together.

- independent individual student construction of the target representation.

Of course, these stages can be elaborated, telescoped or selectively collapsed according to the needs of the student group. For example, the progression from joint construction by the teacher and the class group towards independent individual student representation construction can involve intermediate phases of students collaborating in pairs or small groups, and the modelling and deconstruction can be elaborated to critical interpretation and explication of the relative affordances of different meaning-making resources in committing different kinds of meanings. The TLC practices of modelling/ deconstruction and joint construction can also be implemented on a microscale involving very brief classroom interactions. For example, in calling for responses from the class for possible interpretations of data observations, the teacher may model oral and multimodal representational responses for one situation, drawing attention to the visual and verbal resources used to communicate the responses. Students might be asked to respond to different but related instances of data observation; the teacher might record several responses on the board and work with the students to edit/reformulate their responses, explaining why any representational changes were made. The teacher modelling could occur before or after the student responses - to 
potentially equivalent efficacy in optimizing all students' dual development of scientific conceptualization and multimodal disciplinary representation.

Being alert to the subtleties and potential nuancing of the ways in which multimodal disciplinary literacy development is pursued in accounts of guided inquiry and genre-based pedagogies affords the kind of pragmatic but principled synthesizing of approaches that can assist in addressing the complexities and distinctive challenges of science education in the senior high school. With this in mind, in Figure 6.4, we elaborate our framework with a range of broad categories of teacher and student pedagogic roles fused into the encompassing cycle of different kinds of representation interpretation, construction and critique. As indicated in the bottom half of Figure 6.4, these include joint teacher-student engagement in these representation practices and teacher-scaffolded student engagement with them, as well as student collaborative learning, but we have also given emphasis to teacher demonstration, modelling or explication of the various multimodal literate practices.

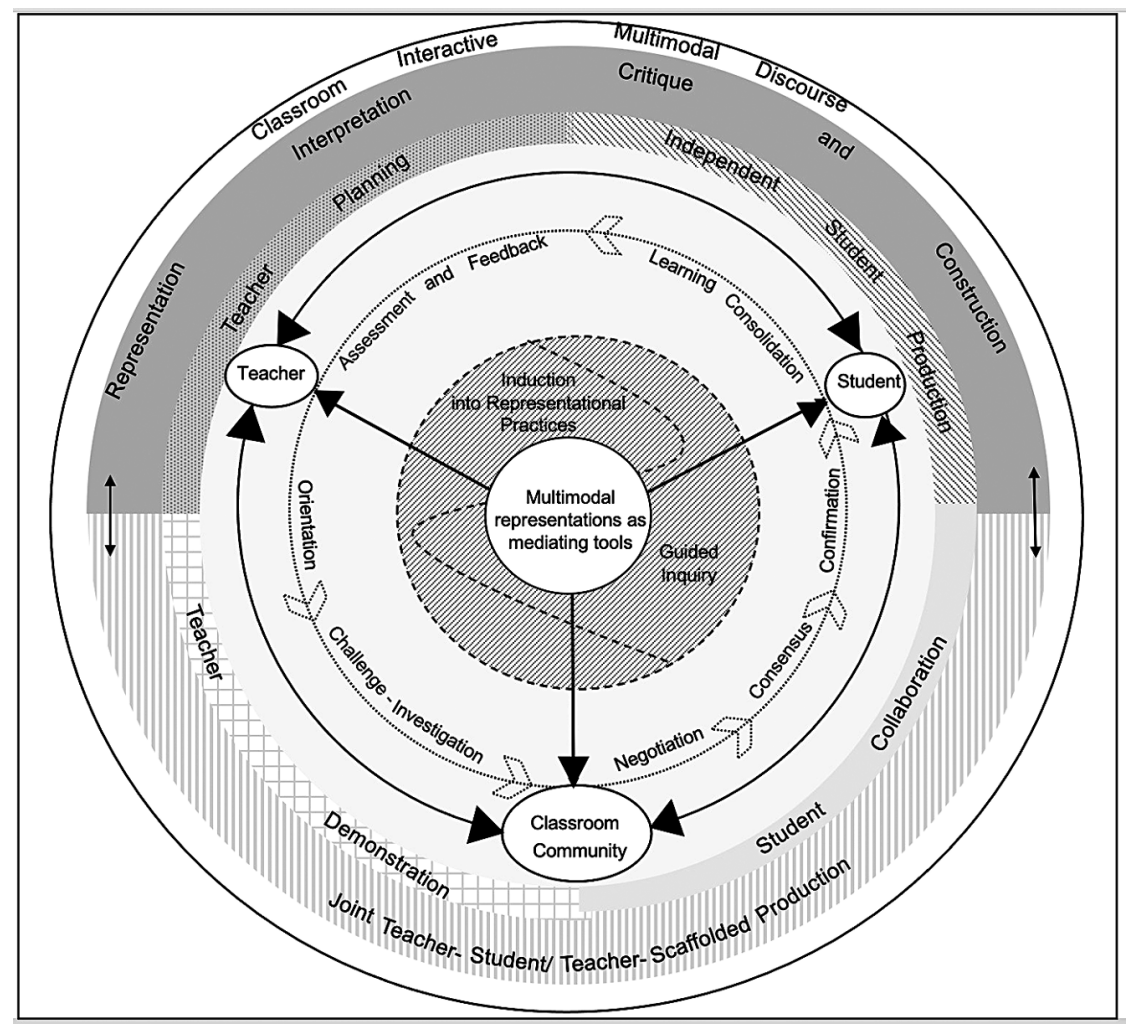

Figure 6.4 Interweaving directed teaching with scaffolded and student collaborative and independent learning in a pedagogic synthesis of multimodal disciplinary literacy and scientific practices. 
Important further inclusions in these teacher and student pedagogic roles are the close attention to the independent endeavours of the individual student and the crucial teacher preparation required to orchestrate this pedagogic repertoire in the classroom, as indicated in the top half of Figure 6.4. In the Multiliteracies in Senior School Science (M3S) project, we observed that in ostensibly productive student peer collaboration, there were frequently students whose contributions did not evidence their personal representation interpretation capacities nor their individual multimodal formulation of responses to their collaborative investigations. It is important to ensure that the range of guided and peer collaborative learning experiences are managed towards optimizing an outcome of individual student competence building. Given the significance for students of external final examinations where individual demonstration of scientific understanding and reasoning is what counts, preparation via their ongoing active individual engagement in the multimodal discursive practices that realize recontextualized scientific practices in this context and direct targeted feedback on their individual responses is essential.

Our framework for infused multimodal literacy in science pedagogy entails challenges for teachers in preparing classroom programmes designed to attend explicitly to multimodal disciplinary literacy in recognition that disciplinary ways of knowing are inseparable from their discursive representations. However, an additional major barrier may be, as Airey and Linder (2009, p. 7) have noted in the literature for university teachers, that the thinking of specialist science teachers is so rooted in their disciplinary discourse that they are unaware that the discursive construction of meaning they take for granted is not immediately accessible to students who are relative disciplinary novices. Constructive disruption of this understandably taken-for-granted orientation to disciplinary discourse is crucial to developing an enhanced pedagogy that deliberatively attends to the complete interconnectedness of student induction to scientific practices and their discursive representations. For this to occur, we need to be building teachers' awareness of the distinctiveness of their disciplinary discourse and its inaccessibility to relative discipline novices, as well as providing teachers with a means to develop students' competence in the interpretation and deployment of that disciplinary discourse. The key to doing this is the use of a metalanguage that describes the meaning-making resources of the various representational modes that can be shared amongst teachers and students to enable direct discussion about how multimodal representations mediate scientific conceptualization.

\subsubsection{Metalanguage and developing metarepresentational competence}

The professional training of science teachers has not usually included the study of linguistics or semiotics applied to provide systematic descriptions of how language and other representational modes construct meaning in the discourse of science. It is nevertheless clear that it is science teachers who need to develop their students' discipline-specific multimodal literacy competencies, which are inseparable from their science learning. In Chapter 3 
we indicated the prodigious amount of research from systemic functional linguistics and related visual semiotics that has produced extensive accounts of the linguistic nature of scientific discourse and a growing literature on the semiotics of science visualizations (Doran, 2017, 2019; Halliday \& Martin, 1993; Hao, 2020; Kress \& van Leeuwen, 2006; Lemke, 1990; Martin \& Veel, 1998). We also outlined examples from an increasing amount of educational research reporting the productive use by science teachers of the metalanguage derived from this research in developing their students' disciplinary literacy (Forey, 2020; Forey \& Cheung, 2019; Gebhard, Chen \& Britton, 2014). While the scope of this book does not permit the inclusion of extended descriptions of the systems of linguistic and visual semiotic resources that construct meanings in science discourse, our approach is to illustrate how the use of selected aspects of the linguistic and visual semiotic metalanguage can facilitate the development of multimodal disciplinary literacy for all students. In addition to the exemplification we provide, we acknowledge the teacher-oriented publications that introduce science teachers to the role of systemic functional semiotic metalanguage in disciplinary literacy development (Knain, 2015; Polias, 2015; Unsworth, 2001) in the hope that our work will bridge into increased provision of professional learning in this area for teachers by universities and government and non-government school education authorities.

Notwithstanding the well-established linguistic and visual semiotic descriptions of multimodal science discourse, as we indicated in Chapter 3, the recontextualization of these descriptions for pedagogic use remains a collaborative teacher-researcher work in progress. The quest is to derive a consensual, functional and educationally accessible metalanguage that describes meaning in the multiple realms of language, various forms of visualizations, symbolic representations and multimodal interactions that is 'good-enough' to meet the needs of disciplinary multimodal literacy development in classroom teaching (Macken-Horarik, Love \& Unsworth, 2011; New London Group, 2000). Such a metalanguage is potentially instrumental in advancing students' metarepresentational competence as we indicated in Chapter 3 and further discussed in Chapter 4. We argued that supporting students to be able to move to the higher levels of disciplinary representational discernment such as analyzing the affordances of different types of representations and comparing, contrasting and critiquing them in terms of the nature and extent of the meanings they realize, requires a shared, consistent, functional and educationally accessible metalanguage. Evidence to date of teachers' positive perceptions of the pedagogic viability of aspects of systemic functional semiotic metalanguage that have been introduced into classroom work provides a grounding for wider implementation and a foothold into ongoing collaborative professional learning and research to refine and extend such initiatives (Forey, 2020). On this basis, we complete our overall framework for guiding the infusing multimodal disciplinary literacy in science pedagogy as Figure 6.5, integrating the deployment of a shared functional semiotic metalanguage to support the explication of representational affordances and 


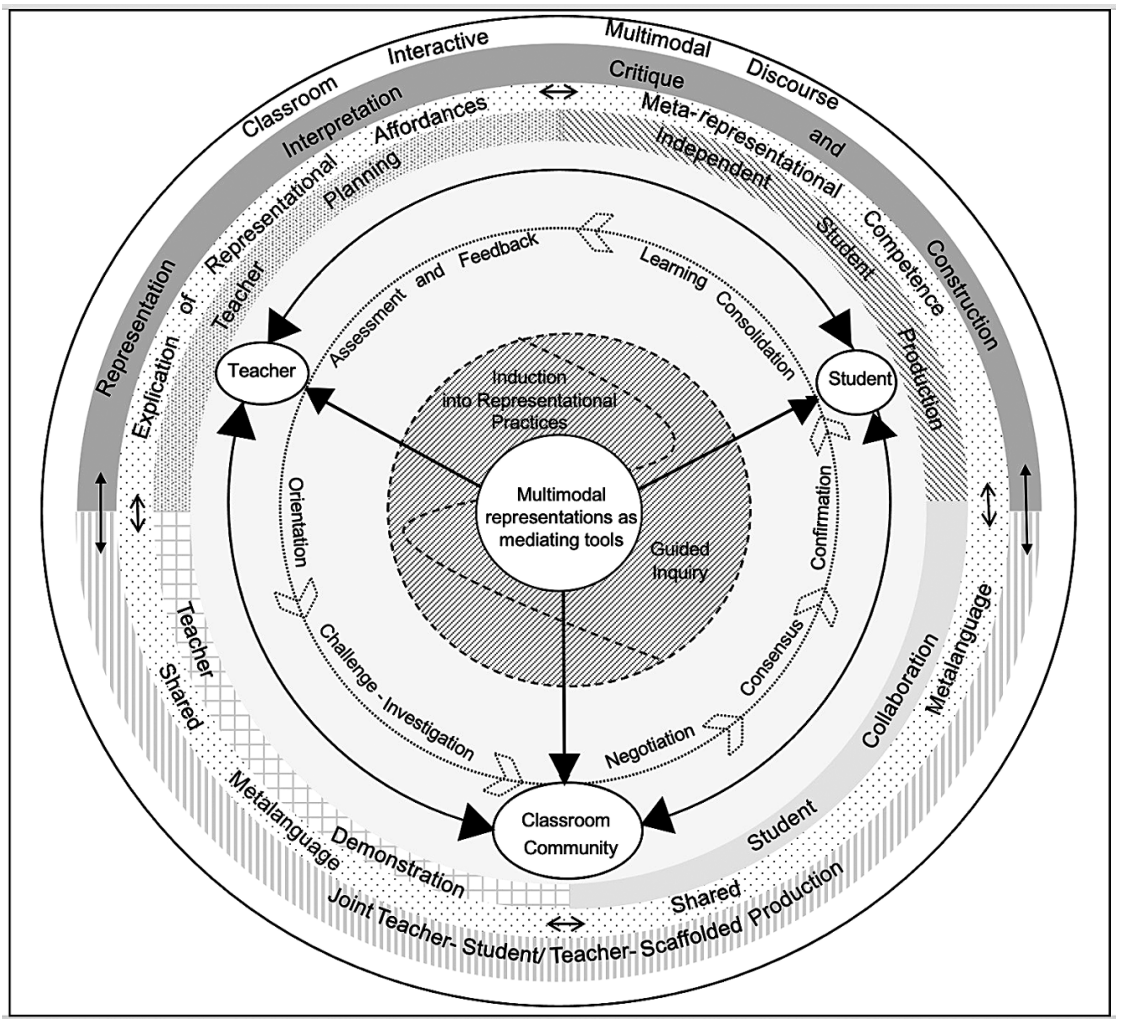

Figure 6.5 A framework for multimodal disciplinary infused science pedagogy.

the development of students' metarepresentational competence. The development and use of this metalanguage are completely integrated throughout the various forms of representation interpretation, construction and critique as they are modelled, directed or scaffolded through learning experiences by the teacher. The metalanguage is also increasingly used by students as they collaboratively and independently engage in these representational processes. In the next section, we suggest practical ways in which the pedagogic integration of metalanguage and development of metarepresentational competence may enhance the learning and achievement of students through their deliberative induction into the multimodal disciplinary discourse of science.

\subsection{Multimodal representational proficiency and student achievement in summative science assessments}

\subsubsection{Student responses to short-answer examination questions}

A variety of complex factors contribute to the underachievement of many low SES students in senior high school science as indicated in final-year high 
school examinations conducted by state or national education authorities. We noted research indicating that for these students one such factor is the precision and dexterity with the technical expression required in short-answer examination questions, which exceed their literacy capacities (Teese, 2013). We were interested to examine how this might distinguish the higher achieving students from mid-level achieving year 12 students in the schools in low SES areas in the M3S project. In the initial stage of the study, we collected student responses to short-answer assessment items similar to those included in final-year external examinations. These were culminating tasks completed by students at the conclusion of classroom units of work of about two to three weeks duration. Here we compare the responses to one short-answer question by the highest achieving and a mid-level achieving student in one of the year 12 physics classes. We then discuss how the multimodal disciplinary literacy features that distinguish the students' responses might be addressed through pedagogy informed by various dimensions of our MLISP framework.

The year 12 physics students completed the assessment task about a direct current electric motor shown in Figure 6.6.

The students' responses were rated by their teacher on a five-point scale (Excellent, Very Good, Good, Moderate, Minimal). In the class of eleven students, no student was rated as Excellent. Alex was the only student in

Below is a representation of the principle of the electric motor.

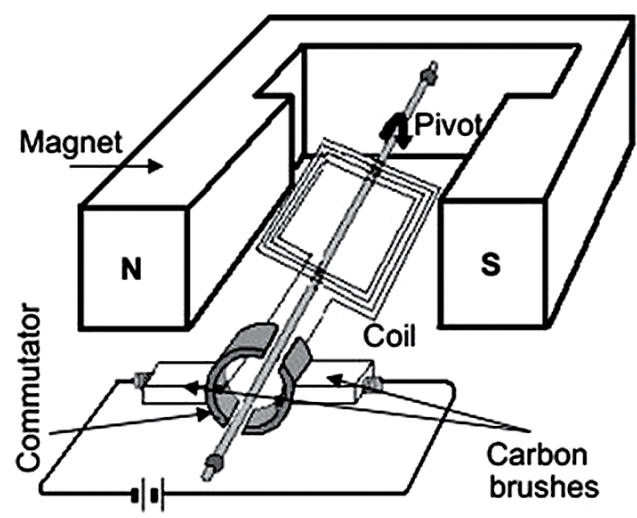

Explain the sequence of events that occur with the commutator, and the current and force, to keep the motor spinning. Draw simple diagrams to illustrate your explanation.

Figure 6.6 Year 12 physics electric motors task. 


\section{Infused multimodal disciplinary literacy}

the class whose work was rated as Very Good and Kim was the only student whose work was rated as Good. The work of the other nine students in the class was rated either Moderate or Minimal. Copies of the responses by Alex and Kim are shown in Figures 6.7 and 6.8, respectively (the typed versions of the students' texts were inserted by the researchers).

1

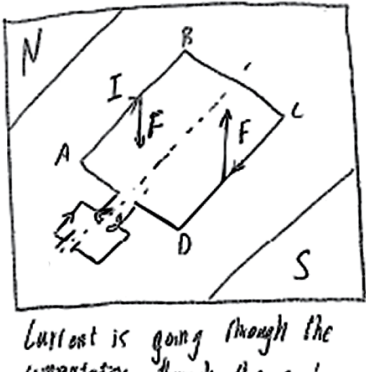

cortantator though the con frow $A$ ov $B$. The fore according to the Rights-hond-Stapl rile will le dows on sille $A B$ and of as side $P C$. This cesees a nef lique cand iobation ant i- clockwise,

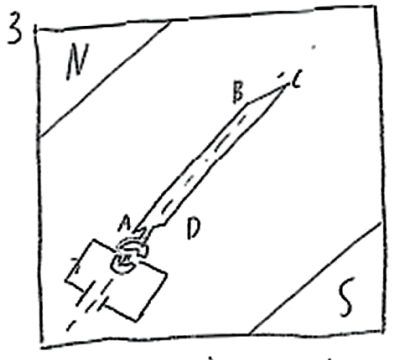

The carcont has now been cut of frove the coil hae is the cossinulater thes the is no furce on the coils.

3. The current has now been cut off from the coil due to the commutator thus there is no force on the coils.

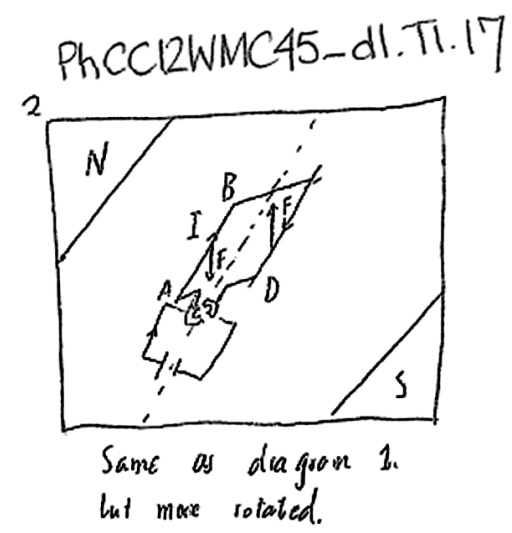

1.Current is going through the commutator through the coil from $\mathrm{A}$ to $\mathrm{B}$. The force according to the Right-hand-Slope rule will be down on side $A B$ and up on side $D C$. This causes a net torque and rotation anti-clockwise.

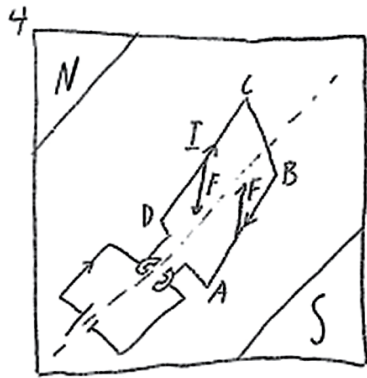

The mosutern has hought

the coil into the position shoun

and now the curreni has been

revared with it now goring from

D Io $L$ and $B$ to A. Thes allowing

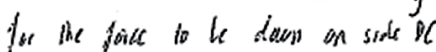

and up on sole $A B$ keqtieg the net

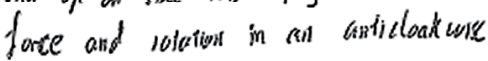
direction.

4.The momentum has brought the coil into the position shown and now the current has been reversed with it now going from $D$ to $C$ and $B$ to $A$. Thus allowing for the force to be down on side $D C$ and up on side $A B$ keeping the net force and rotation in an anticlockwise direction.

Figure 6.7 Alex's explanation of the electric motor. 


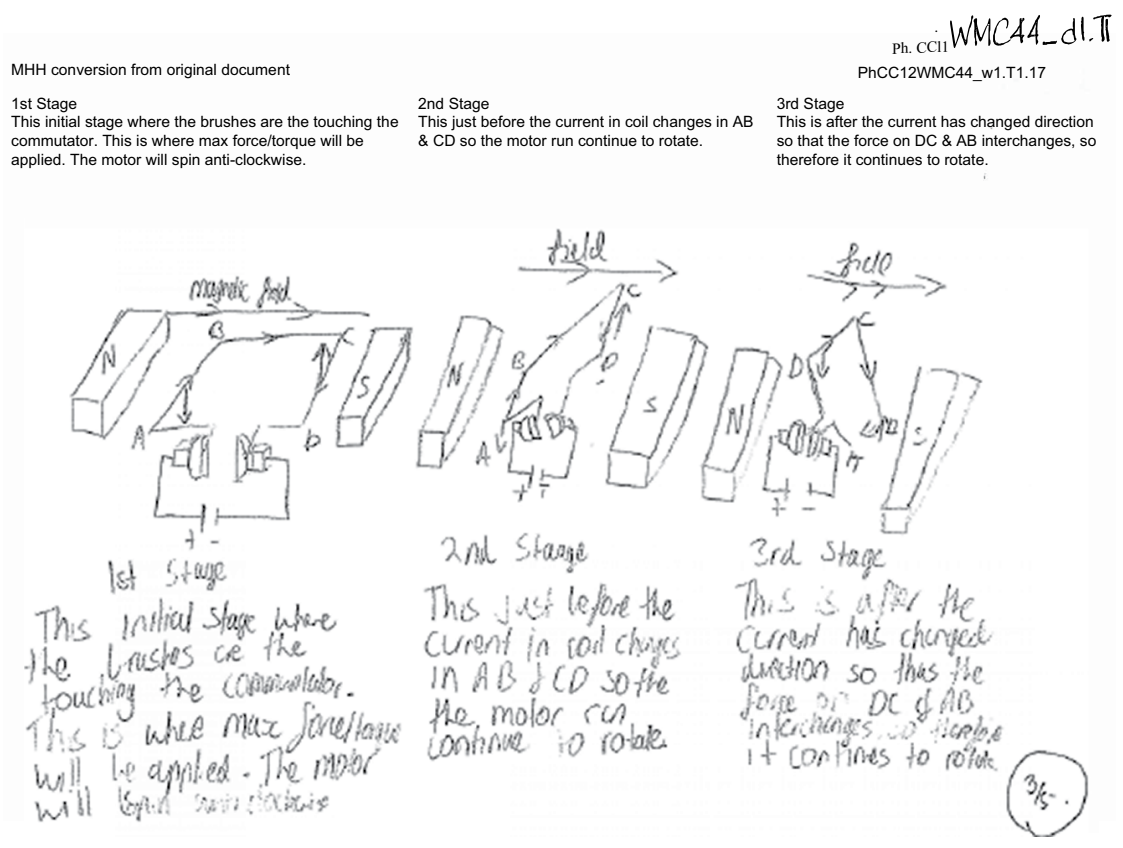

Figure 6.8 Kim's explanation of the electric motor.

\subsubsection{Comparing the short-answer examination responses by high and mid-achieving students}

The meanings committed in the language and/or images in the responses by Alex and Kim were mapped against a composite list of the meanings included in explanations of the functioning of a simple direct current electric motor in year 12 textbooks and related websites, as shown in Table 6.1.

The most obvious difference between the two responses is that Kim (Figure 6.8) includes only three images. Table 6.1 confirms that this difference is due to Kim's not addressing, in language or image, the situation when the coil is in the vertical position and the current is cut off, and related to this, Kim does not mention the momentum that carries the coil past this current break point in the commutator. These may be the principal reasons for Kim's receiving a lower grade since, apart from these omissions, Table 6.1 shows that the meanings included in the responses of both students largely correspond.

However, there are other less obvious differences in the representation strategies of the two students that reflect Kim's more limited representational dexterity and precision and perhaps inhibit the demonstration of this student's understanding of the detailed functioning of the electric motor. As indicated in the first four rows of Table 6.1, Alex indicates the direction of the current and the forces in his language and his image, whereas Kim commits these meanings only in the images. The consequence of this is that Kim does not explicate verbally what causes the torque. 


\section{Infused multimodal disciplinary literacy}

Table 6.1 Comparison of student responses with a composite of textbook and website explanations of the functioning of an electric motor

\section{Main points in an explanation of the functioning of a DC motor as derived from year 12 textbooks and related websites}

$\frac{\text { Alex }}{\text { verbiage image }} \frac{\text { Kim }}{\text { verbiage image }}$

1. The direction of current in the coil is specified.

2. The forces exerted on the sides of the coil $\mathrm{Y}$ are perpendicular to the magnetic field when the plane of the coil is horizontal.

3 . The right-hand rule.

4. indicates the direction of the forces.

5. The resultant torque (and its direction).

6 . The consequent rotation of the coil.

7. and direction of rotation.

8 . When the plane of the coil is vertical there is no torque.

9. and no current flowing through the coil - Y

10. because of the commutator. $\mathrm{Y}$

11. The momentum will make the coil turn past the current break point in the commutator.

12. and current will flow again but in the opposite direction.

13. The forces will now be reversed.

14. The coil will continue to rotate.

15. in the same direction.

16. This reversal of the current and the forces will happen each time the plane of the coil is in the vertical position.

17. The coil will keep spinning as long and the current flows.
Y

Y

Y Y

Y

Y

Y

Y

$\mathrm{Y}$

Y

Y

Y

Y

Y

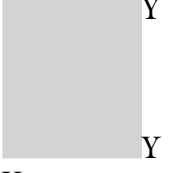

Y

Y

Y

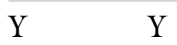

Y

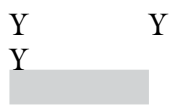

This initial stage where the brushes are touching the commutator.

This is where the max torque/force will be applied.

(Figure 6.8 Kim's explanation of the electric motor)

On the other hand, since Alex indicates the direction of the current and the forces acting on the coil in both image and text, the cause of the torque can be communicated through language using the text reference 'This' and the realization of causality through the verb 'cause'.

The force according to the right-hand slap rule will be down on the side $\mathrm{AB}$ and up on the side DC.

This causes a net torque and rotation anti-clockwise.

(Figure 6.7 Alex's explanation of the electric motor)

In the previous text, Alex uses 'this' to condense the meanings of the entire prior clause and then realizes cause explicitly through the verb. In Kim's case, 
however, there is no such meaning condensation because the direction of the current and consequent direction of the forces are not verbalized and hence the cause of the torque could not be verbalized. Kim's use of 'this' simply identifies the diagram. Kim may well know why the torque is at the maximum in this position of the coil, but not expressing this through both language and image, and perhaps not being accustomed to using 'this' to function as demonstrative text reference, meant that this knowledge of the cause of the torque could not be demonstrated. While perhaps less impactful on the clarity of the explanation, further examples indicate Kim's greater use of informal language such as 'spin' rather than Alex's 'rotation' and Kim's somewhat imprecise:

' $[t]$ his is after the current has changed so the force on $D C \& A B$ interchanges'

compared with Alex's

'the current has been reversed with it now going from $\mathrm{D}$ to $\mathrm{C}$ and $\mathrm{B}$ to $\mathrm{A}$. Thus, allowing for the force to be down on side DC and up on side AB.'

What we can begin to see as suggestive from this comparative analysis to this point is that the difference between what was regarded as a passable response to the question by Kim and a very good response by Alex may be at least partially due to Kim's limited repertoire and lack of deftness in the deployment of visual and verbal representational strategies. The contrast in this representational deftness of the two students becomes more apparent as we examine their responses more closely.

From the perspective of the strategic use of visual literacy, there is a noticeable difference in the type of image selected by the students. Parts of Kim's diagram (Figure 6.8) are depicted from a more naturalistic coding orientation as indicated by the 3D representation of the magnets and the commutator (Kress \& van Leeuwen, 2006, p. 172). On the other hand, Alex's diagram (Figure 6.7) is highly schematic rather than realistic, depicting only those elements of composition and activity that are essential to the explanation, which typifies the technological coding orientation of multimodal disciplinary discourse (Kress \& van Leeuwen, 2006, p. 172). Composition is treated very differently in the drawings of these students. Alex uses a minimalist representation of the electric motor components, showing only a very truncated view of the magnet sufficient to indicate the poles and a highly economic, schematic indication of the commutator. On the other hand, Kim provides a full drawing of both poles of the magnet and a more detailed drawing of the commutator, including the carbon brushes. This difference is also evident in the compositional labelling, again only the minimal necessity in Alex's drawings, whereas Kim somewhat redundantly labels the direction of the magnetic field and also quite redundantly uses symbols to label the positive and negative poles of the power source. 
There are also clear differences in the depictive dexterity demonstrated in the two responses. For example, Kim's drawing of force arrows is problematic. In the second image in Figure 6.8, force arrows appear to be positioned parallel rather than perpendicular to the sides of the coil, and while force arrows on the third image may appear more accurate, they are not drawn to show the direction clearly. Alex's drawing of force arrows is much clearer and image three in Figure 6.7 shows no force arrows - consistent with the text and consistent with no arrows indicating current flow. In Kim's depiction of images two and three in Figure 6.8, it is difficult to envision the direction of the rotation of the coil between images. This is partly because side DC in the third drawing should be parallel with side DC in the second drawing. On the other hand, the proficiency of Alex's drawing of the sequence of images two, three and four in Figure 6.7 readily conveys the anti-clockwise rotation of the coil. There is a clear difference in the visual literacy competence of the two students such that Alex's strategic choices and dexterous deployment of image resources align with the functional role of the diagram in the explanation.

Overall, the higher achieving student, Alex, demonstrates inscriptional practices that are far more strategically focused on the explanatory purpose of the diagram. The choice of image depiction is essentialized showing only what is necessary to the explanation and the dexterous execution of the drawing achieves clear communication of the detailed image elements. The use of annotation is economical and includes only what is essential to the explanation, while the concurrent representation of meaning in the text block and the image facilitates the inclusion of causal relations, which can only be constructed through language.

\subsubsection{Enbancing students' multimodal demonstration of scientific knowledge through developing metarepresentational competence}

Our proposal with our MLISP framework is that by infusing multimodal disciplinary literacy development throughout science pedagogy, incorporating functional educationally accessible metalanguage shared amongst teachers and students, with strategic integration of teacher-directed, teacherscaffolded and student exploratory learning experiences, science learning and assessment outcomes for all students can be enhanced and more students like Kim will be enabled to demonstrate more effective learning through their improved discursive fluency in the multimodal literacy of their discipline. Here we draw on our comparison of the responses by Alex and Kim to provide a brief illustrative indication of the ways in which selected aspects of our framework can inform pedagogy that would address the learning needed by students like Kim to improve their answers to such assessment items.

We begin by considering two important discrepancies between the responses of Alex and Kim in the choice of images and use of accompanying text. These are Kim's omission of any representation of the situation when the coil is in the vertical position and the current is cut off, and the 
absence of an explicit statement of the cause of the torque due to Kim's representation of the direction of the current and forces in the image only. Decisions about how to depict the continuous activity of the electric motor in the form of static image(s) can be informed by systemic functional semiotic accounts of the representation of activity (Hao, 2020, p. 28; Doran \& Martin, 2021; Unsworth, 2020). While the movement of the coil in a simplified electric motor can be construed verbally as if it were a single undivided activity by the nominalization 'rotation', this phenomenon is actually composed of many interconnected activities. Changes in these activities such as the direction of the current and the forces on the coil, produce the different phases of the rotation, such as when the plane of the coil is perpendicular to the magnetic field and the torque is maximized or when the plane of the coil is vertical and there is no torque. In explaining a continuous activity, it's reconstrual as a series of phases is referred to by SFL theorists as 'momenting', so the rotation of the coil consists of a series of moments. Now each of these moments can be further momented, so the moment when the coil is perpendicular to the magnetic field can also be described in terms of the activity and direction of the current and direction of the forces acting on the coil. This reconstrual of particular moments of an activity as composed of further activities is referred to as 'tiering'. This theorizing applies to the representation of all activity such as mitosis in biology for example, which can be momented as prophase, metaphase, anaphase and telophase, and each of those phases can be further momented into a series of activities. For example, the prophase can be further momented - as chromosomes condense, the nucleolus breaks down, two centriole pairs move apart, microtubules radiate from the centrioles, the microtubules attach to the centromere of the chromosomes and so on. Hence, we have a tiered representation of mitosis. Now once this metalanguage of momenting and tiering of activity is shared by the teacher and the students, it can be used to describe the different visual and verbal representations of activity and to guide the choice of image(s) and language to represent one or more tiers of the momented activity in explanations of phenomena such as the functioning of an electric motor or mitosis.

Once teachers are aware of the utility of this kind of metalanguage and incorporate it in their planning, it can be introduced and sustained throughout the pedagogy. In the MLISP framework, we have suggested this in the circular representation of shared metalanguage encompassing the various dimensions of the pedagogy (Figure 6.5). Teachers can introduce the metalanguage through guided inquiry as they scaffold student investigations such as the assembly of an electric motor kit and observation, oral explanation and subsequent multimodal representation of what occurs when students swap the wires connecting the power supply to the electromagnet and the loop. The metalanguage can then be used in discussing the students' representations in terms of the suitability and sufficiency of the moments selected to be depicted and how the further tiered momenting is depicted as movement and direction of current and forces. Alternatively, the teacher may introduce 


\section{8}

the metalanguage through explication of the functioning of the motor while presenting an animated simulation and then further consolidate this metalanguage in discussing with students their representations following their assembly and investigation of an actual electric motor kit. The metalanguage could be further sustained and consolidated as a tool for comparison and critique of various textbook and website representations, and clearly, the metalanguage becomes a tool for an important part of the feedback to students on their responses to assessment items. This kind of pedagogic focus on the relationship between representational strategy and demonstrating knowledge of the field may assist in obviating the less than optimal selection of moments for depiction in Kim's response to the electric motor question. Using the notion of tiering to draw attention to the recursive momenting of activity required to explain the particular phenomenon may also assist students like Kim to ensure that they actually account for the cause of observed effects, such as the torque in this case, and that they are alert to the need to use language to make this causal relation explicit.

Improving Kim's representational strategy also entails choosing the type of image that is optimal to the representational purpose and eliminating unnecessary visual and verbal detail so that the representational focus is on only that which is required for the explanation. This involves students learning about the gradation of types of images from realistic to schematic, how to relate different forms of schematic images to their more realistic counterparts, determining which types of images are apposite to what needs to be explained and learning how to actually construct such images. As we indicated in Section 2.4, in the context of the greater conceptual complexity of senior high school science, the requirements of curriculum coverage, the pressure of impending external examinations, and the inexperience of many students in interpreting and creating multimodal representations at this level of sophistication, it is important on occasions for the teacher to lead in deconstructing a variety of such models, explicating their affordances and their deployment of visual and verbal resources and then modelling and jointly constructing such representations with students in preparation for the students' scaffolded and then independent interpretation and creation of these texts. The teacher needs to lead the introduction of relevant metalanguage integrated with the learning experiences, but this teacher-led aspect of the learning can be deployed flexibly. For example, after student assembly of a simple electric motor kit, investigation and explanation of the functioning of the motor, the teacher might display and explicate the affordances and deployment of the semiotic resources of one or more realistic diagrams and then demonstrate how one or more forms of schematic diagram can be derived from the more realistic versions, critically relating all of these to the materiality of the electric motor itself. Another option would be to jointly construct one or more schematic diagrams with the students, which could then be critically compared with related textbook or website diagrams or the student-created diagrams. This approach would similarly attend to the verbiage associated with the diagrams. Through teacher deconstruction, demonstration and/or 
joint construction, for example, using metalanguage such as 'text reference', 'causal verb', 'conjunction' and 'nominalized cause', students could be familiarized with various verbal realizations of causality as alternatives to that used by Alex, providing experience to students like Kim for whom such expressions may not be so readily deployed in their own writing.

The force according to the right-hand-slap rule will be down on the side $\mathrm{AB}$ and up on the side DC. This causes a net torque and rotation anti-clockwise (text reference and causal verb).

The force according to the right-hand-slap rule will be down on the side $\mathrm{AB}$ and up on the side $\mathrm{DC}, \underline{\mathrm{so}}$ there is a net torque and the coil will rotate anti-clockwise (conjunction).

The force according to the right-hand-slap rule will be down on the side $\mathrm{AB}$ and up on the side DC. For this reason, there is a net torque and the coil will rotate anti-clockwise (nominalized cause).

Through this kind of deliberative pedagogic attention to the interface between visual and verbal representational strategy and the demonstration of scientific understanding, the visual and verbal representational repertoires, as well as the precision and dexterity of expression of students like Kim, can be enhanced through the routine processes of learning and teaching in science classrooms. In Chapters 7, 8 and 9 we provide more detailed accounts of examples of learning experiences in physics, chemistry and biology respectively, indicating a variety of ways in which the MLISP framework has informed classroom practice.

\section{References}

Airey, J., \& Linder, C. (2009). A disciplinary discourse perspective on university science learning: Achieving fluency in a critical constellation of modes. Journal of Research in Science Teaching, 46(1), 27-49.

Chen, Y.-C., Park, S., \& Hand, B. (2016). Examining the use of talk and writing for students' development of scientific conceptual knowledge through constructing and critiquing arguments. Cognition and Instruction, 34(2), 100-147.

Doran, Y. J. (2017). The discourse of physics: Building knowledge through language, mathematics and image. London: Routledge.

Doran, Y. J. (2019). Building knowledge through images in physics. Visual Communication, 18(2), 251-277.

Doran, Y. J., \& Martin, J. R. (2021). Field relations: Understanding scientific explanations. In K. Maton, J. R. Martin, \& Y. J. Doran (Eds.), Teaching science: Knowledge, language, pedagogy (pp. 105-133). London: Routledge.

Erduran, S. (2015). Introduction to the focus on...scientific practices. Science Education, 99(6), 1023-1025.

Forey, G. (2020). A whole school approach to SFL metalanguage and the explicit teaching of language for curriculum learning. Journal of English for Academic Purposes, 44, 100822. 


\section{0}

Infused multimodal disciplinary literacy

Forey, G., \& Cheung, L. M. E. (2019). The benefits of explicit teaching of language for curriculum learning in the physical education classroom. English for Specific Purposes, 54, 91-109.

Gebhard, M., Chen, I.-A., \& Britton, L. (2014). "Miss, nominalization is a nominalization:” English language learners' use of SFL metalanguage and their literacy practices. Linguistics and Education, 26, 106-125.

Halliday, M. A. K., \& Martin, J. R. (Eds.). (1993). Writing science: Literacy and discursive power. London: Falmer Press.

Hao, J. (2020). Analysing scientific discourse from a systemic functional linguistic perspective: A framework for exploring knowledge building in biology. London: Routledge.

Knain, E. (2015). Scientific literacy for participation: A systemic functional approach to analysis of school science discourses. Rotterdam: Sense Publishers.

Kress, G., \& van Leeuwen, T. (2006). Reading images: The grammar of visual design (2th ed.). London: Routledge.

Latour, B., \& Woolgar, S. (2013). Laboratory life: The construction of scientific facts. Princeton: Princeton University Press.

Lemke, J. (1990). Talking science: Language, learning and values. Norwood, NJ: Ablex.

Macken-Horarik, M., Love, K., \& Unsworth, L. (2011). A grammatics 'good enough' for school English in the 21st century: Four challenges in realizing the potential. Australian Journal of Language and Literacy, 34(1), 9-23.

Macnaught, L., Maton, K., Martin, J. R., \& Matruglio, E. (2013). Jointly constructing semantic waves: Implications for teacher training. Linguistics and Education, 24(1), 50-63.

Martin, J. R., \& Veel, R. (Eds.). (1998). Reading Science: Critical and functional perspectives on discourses of science. London: Routledge.

Mody, C. C. (2015). Scientific practice and science education. Science Education, 99(6), 1026-1032.

Nam, J., Choi, A., \& Hand, B. (2011). Implementation of the science writing heuristic (SWH) approach in 8th grade science classrooms. International Journal of Science and Mathematics Education, 9(5), 1111-1133.

NewLondonGroup. (2000). A pedagogy of multiliteracies: Designing social futures. In B. Cope \& M. Kalantzis (Eds.), Multiliteracies: Literacy learning and the design of social futures (pp. 9-37). Melbourne: Macmillan.

Nunes, T., Bryant, P., Strand, S., Hillier, J., Barros, R., \& Miller-Friedmann, J. (2017). Review of SES and science learning in formal educational settings. London: University of Oxford/Education Endowment Foundation.

Polias, J. (2015). Apprenticing students into science: Doing, talking, writing and drawing scientifically. Stockholm: Hallgren and Fallgren.

Prain, V., \& Hand, B. (2016). Learning science through learning to use its languages. In B. Hand, M. McDermott \& V. Prain (Eds.), Using multimodal representations to support learning in the science classroom (pp. 1-10). Cham, Heidelberg, New York, Dordrecht, London: Springer.

Rose, D., \& Martin, J. R. (2012). Learning to write, reading to learn: Genre, knowledge and pedagogy across the curriculum. London: Equinox.

Tang, K.-S. (2019). Scientific practices as an actor-network of literacy events: Forging a convergence between disciplinary literacy and scientific practices. In V. Prain \& B. Hand (Eds.), Theorizing the future of science education research (pp. 83-98). Cham, Switzerland: Springer. 
Teese, R. (2013). Academic success and social power: Examinations and inequality. North Melbourne: Australian Scholarly Publishing.

Tytler, R., Prain, V., Aranda, G., Ferguson, J., \& Gorur, R. (2020). Drawing to reason and learn in science. Journal of Research in Science Teaching, 57(2), 209-231.

Tytler, R., Prain, V., \& Hubber, P. (2018). Representation construction as a core science disciplinary literacy. In K.-S. Tang \& K. Danielsson (Eds.), Global developments in literacy research for science education (pp. 301-318). Cham, Switzerland: Springer.

Tytler, R., Prain, V., Hubber, P., \& Waldrip, B. (2013). Constructing representations to learn in science. Rotterdam, The Netherlands: Sense.

Unsworth, L. (2001). Teaching multiliteracies across the curriculum: Changing contexts of text and image in classroom practice. Buckingham, UK: Open University Press.

Unsworth, L. (2020). Intermodal relations, mass and presence in school science explanation genres. In M. Zappavigna \& S. Dreyfus (Eds.), Discourses of hope and reconciliation: J. R. Martin's contributions to systemic functional linguistics (pp. 131-152). London: Bloomsbury Academic.

Wellington, J., \& Osborne, J. (2001). Language and literacy in science education. Buckingham: Open University Press. 


\section{Multimodal disciplinary literacy in the senior biology classroom}

\subsection{Introduction}

Placing multiliteracies at the centre of pedagogy in biology in the Multiliteracies in Senior School Science (M3S) project resulted in representations being used at certain points of time within learning sequences for specific purposes. The focus on multiliteracies also saw biology teachers use more varied modes of representations and spend more time deconstructing representations with students. When working with students to produce representations, the movement between different modes of representation was central to the pedagogy used. The examples presented here from biology demonstrate that infusing pedagogy with multiliteracies involves using multimodal representations as mediating tools. Through engagement with constructions of concepts in disciplinary contexts, students are supported to develop disciplinary-specific knowledge (Moje, 2015; Shanahan \& Shanahan, 2008; Tytler, 2007).

Research into genre pedagogy has emphasized how representations of knowledge can be used at certain times within a sequence of learning for specific purposes. The genre teaching and learning cycle, as introduced in Chapter 3, first emphasizes the use of representations to orient students to the field of knowledge being studied (Christie, 2012; Dreyfus, Humphrey, Mahbob \& Martin, 2016; Rose \& Martin, 2012). In Chapter 6, we identified orientation as a key element of pedagogy when placing representation at the heart of science teaching and learning. Biology teachers in the M3S project used multimodal representations in extended ways to orient students initially to key concepts, as well as key grammatical features that construct their realization in language. The learning opportunities generated, and the ways in which these could have been extended even further, are discussed in this chapter.

Students continue to develop an understanding of the field of knowledge as they are guided by the teacher to analyze and deconstruct various representations as a topic of study progresses (Christie, 2012; Macnaught, Maton, Martin \& Matruglio, 2013; Rose \& Martin, 2012). They are supported to develop an understanding of content knowledge when they are provided with representations of different modes, as well as single representations that contain multiple modes (Lemke, 1998; Moje, 2008; Prain \& Tytler, 2013; 
Tytler, 2007), and these representations are deconstructed (Christie, 2012; Dreyfus et al., 2016; Macnaught et al., 2013; Rose \& Martin, 2012). During deconstruction, the ways of making meaning are explored, their affordances discussed (Dreyfus et al., 2016; Prain \& Tytler, 2013; Rose \& Martin, 2012) and limitations considered (Prain \& Tytler, 2013; Tytler, Hubber, Prain \& Waldrip, 2013b). Biology teachers in the M3S project significantly altered their pedagogy through the inclusion of more than one representation when presenting part of the field for a topic and engaging students in the deconstruction of these representations. Examples of teachers' evolving pedagogies are described, along with a discussion of ways in which the deconstruction of representations of various modes could be extended.

Building understanding of a field of knowledge continues as students are supported to construct their own representations (Dreyfus et al., 2016; Prain \& Tytler, 2013). As indicated within our framework set out in Chapter 6, representation construction may occur jointly, with the teacher providing expert guidance or when the students are working more independently in small groups or individually (Dreyfus et al., 2016; Macnaught et al., 2013; Rose \& Martin, 2012). During such activities, students will continue to develop their familiarity with the discipline area if they discuss the conventions, affordances and limitations of various representations they have made (Moje, 2007; Prain \& Tytler, 2013). Both joint and independent construction of representations occurred within the biology classrooms participating in the M3S project. The extent to which students engaged in discussions about the conventions, affordances and limitations of their representations is considered, along with ways in which this pedagogy could be enhanced.

The pedagogy that emerged for the biology teachers paid attention to the nature of representations of various modes and the ways in which these representations can be used to mediate knowledge of the field. As a result, a metalanguage for talking about representation began to emerge. As discussed in Chapter 6, the development of a metalanguage is essential for extending discussion of the ways in which meanings are being made within a specific disciplinary context (Christie, 2012; Rose \& Martin, 2012). A discussion of how the pedagogies generated for biology in the M3S project could be extended to include more metalanguage is considered at the end of this chapter.

\subsection{Using representations to introduce the field of knowledge}

The biology teachers within the M3S project were used to using representations of various modes to introduce students to a topic. Often, a YouTube clip would be used. For example, one teacher in the project typically used a video on the creation of spider silk to introduce the topic of transcription and translation at a year 12 level. Another teacher typically used a short video on lactose intolerance to introduce the year 12 topic of natural selection. Short videos were not the only modes used to introduce topics for the students. For example, one teacher used a text that included more than 


\section{Multimodal disciplinary literacy in biology}

one kind of genre, a macrogenre, that included a narrative about an athlete who overheated to introduce the topic of homeostasis in year 11. When talking about their introductions to topics with the researcher, the teachers explained that they looked for initial representations that used everyday language to introduce senior secondary biology topics. Involvement in the M3S project exposed the biology teachers to further ideas about building a field of knowledge through representations, which resulted in extended practices when introducing a topic to students.

Students will be supported to understand the nature of a topic from the perspective of a particular field of science if the teacher emphasizes discipline-specific terminology and semiotic patterns as initial representations are shared (Christie, 2012; Macnaught et al., 2013; Tytler et al., 2013b). This kind of semiotic approach to science learning places representation of knowledge at the centre of building conceptual understanding of a topic for students. It is through the strategic use of representations that the teacher can share key concepts of a topic and develop an understanding (Christie, 2012; Rose \& Martin, 2012; Tytler, 2007). One of the most effective ways to do this work in classrooms is for the teacher to make connections between everyday language and the language of 'academic registers' (Gibbons, 2018, p. 1). Through the use of everyday language initially, the teacher can begin to engage students in concepts. Gradually, the teacher can support the students to move from the language typical of language that is spoken-like within a conversation about a topic to the language required for academic written text (Gibbons, 2018).

\subsubsection{Moving from everyday to discipline-specific language during orientation to the field}

Initially, the biology teachers understood the need to build field knowledge through representations in various modes, and they associated this practice with the importance of using everyday language to introduce complex topics. However, in the first stages of the project, the teachers made little use of the everyday language within the representations to build towards discipline-specific terminology and semiotic patterns. For example, one teacher in year 11 began a lesson on homeostasis with a YouTube clip. Following the YouTube clip, the teacher stated,

So he is a Dutch guy. So there is some, there's some English, some English documentaries as well because after, after he started to be able to do particular things he gained notoriety and all of a sudden the foreign press kind of got on to it and then they started umm, they started umm interviewing him in English and stuff. Umm so in terms of today anyway basically this is the introduction to just homeostasis and basically self-regulation.

Within this monologue by the teacher, there is little movement between everyday language and the academic technical language of the topic. The 
only example is when the teacher uses the term homeostasis and then provides the more everyday language of 'self-regulation'. The students were not invited into a dialogue that could have helped them to move towards the disciplinary-specific language of biology.

\subsubsection{Transitioning to discipline-specific language in an orientation to protein synthesis}

Work with the researcher in the second year of the project focussed on making more use of the representations selected to introduce topics to students to form explicit connections between everyday language and the disciplinary-specific language patterns of the discipline. The year 12 teachers worked with the researcher to use the short video on the production of spider silk to introduce the linguistic pattern of scientific definitions to the students. An activity was planned where the students would be asked to come up with two definitions individually as they watched the clip beginning with the following:

'Spider silk is...'

'A transgenic organism is...'

The two stems provided to the students introduced the linguistic pattern typically used for definitions in biology. Each contained a noun group followed by a relational process 'is'. The stem for definitions provided to the students also emphasized the linguistic pattern typical within noun groups in biology. Each of the two noun groups consisted of a thing (silk, organism) and a classifier (spider, transgenic). After watching the short video, the students shared their definitions with the whole class and discussed them. The definitions that they produced further highlighted the linguistic structure of definitions within biology. For example, the definition of spider silk, '[s]pider silk is a protein', followed the typical pattern in biology of a noun group connected to another noun group through the relational process 'is'.

As well as highlighting for the students the linguistic pattern for definitions, the language specific work supported the development of knowledge of the field. For example, by focussing on the definition '[s]pider silk is a protein' the teachers moved students towards the more abstract concept of making protein through the replication of DNA. The definition '[a] transgenic organism is an organism that has had a gene from another organism put into its chromosomes' asked students to begin to connect genes and chromosomes with the process of protein synthesis. Throughout the initial work on language, the concepts central to the field were built.

The short YouTube clip on spider silk was then used to support students with writing the genre dominant within the senior secondary topic on transcription and translation. In the final end-of-year examination, the students would be required to write sequential explanations about the topic. The 


\section{Multimodal disciplinary literacy in biology}

teachers planned with the researcher for the students to begin the topic by using the language of the YouTube video to write a short sequential explanation in small groups in response to the question, "What did the scientists do to make goats produce spider silk?' While the sequential explanations were expressing simplified concepts that used mostly everyday language from the video, the process also began to engage students in linguistic patterns essential for the more academic and technical sequential explanations that they would write later in the topic. For example, the explanation ' $t \mathrm{t}] \mathrm{hey}$ copied one of the two genes that spiders have for making silk and spliced it into the DNA of goats' included important discipline-specific use of action verbs 'copied' and 'spliced' that would be relevant in more technical explanations. The action verbs were also within sentences communicating events (e.g. 'they copied one of the two genes') that were placed within a sequence of activity.

The next step involved the students working in small groups to see if they could add more scientific content to their explanations from memory. The teachers had explained to the researcher that the students already had some prior knowledge of protein synthesis. By rewriting their initial explanations, the students had the opportunity to draw on prior knowledge of concepts and language to see how effectively they could incorporate the precise and technical language of biology within their explanations on spider silk. They could use the everyday language contained in the initial explanations as building blocks towards patterns of language more appropriate for the discipline of biology.

The planning completed by the researcher and the teachers turned the short video on spider silk from a brief look into the topic to a resource that scaffolded students from everyday spoken language to the more academic language patterns of the discipline. Through the video, the students would be given the opportunity to consider the linguistic patterns of definitions, noun groups and sequential explanations within the topic of protein synthesis. At the end of the topic on protein synthesis, the students who could use these linguistic patterns effectively did better within final assessments.

High-achieving students could use the disciplinary-specific language features that the sequence of learning had emphasized. At the end of the topic on protein synthesis, they could use noun groups in three different ways to present meanings about classification.

- They placed classifiers next to nouns to make meanings within their texts about types of entities (e.g. RNA nucleotides).

- They expanded the noun group to include a complementary reference, which provided additional information about type (e.g. complementary RNA nucleotides).

- They provided meaning about classification within the noun group by using the qualifying phrase after the noun (e.g. the order of amino acids). As a result, their noun groups were packed with precise and specific information about classification. 
The high-achieving students in the topic also used the noun group and the clause more broadly to provide important meanings about composition within sequential explanations on protein synthesis.

- They concisely provided information about composition by using a possessive qualifier beginning with 'of' in the noun group (e.g. the anticodon of the tRNA).

- They used the clause, a relational process, to depict composition (e.g. the tRNA has an anticodon).

- They used a clause, with a relational process and a circumstance of place (e.g. the promoter located on a gene).

Another way in which the high-achieving students used the noun group was to include epithets that gave information about how things appeared in the naturalistic world. These students included detailed descriptions within the noun group so that entities were clearly described throughout. One student who achieved excellent results for a written sequential explanation included noun groups such as 'single-stranded pre-mRNA' and 'fully developed polypeptide chain'. As a result, the ways in which things could be perceived at each stage of the explanation were included.

The sequential explanations of the high-achieving students in this topic also provided a detailed sequence of activities within their written texts. To do this, they used detailed clauses that included a broad range of material (action) processes and prepositional phrases to provide information about the circumstances in which the actions occurred. The material (action) processes that these students used were precise and carefully chosen so that the activity occurring was accurately presented. For example, one high-achieving student wrote of how 'RNA polymerase attaches to the promoter located on a gene in an anti-sense strand'. Within the clause, the material (action) process of 'attaches' is carefully selected. Information is also provided about the circumstance of where this action happens within a prepositional phrase: 'to the promoter'. The entity engaged in this action is also carefully defined through the classifying noun group 'RNA polymerase'. The work of the high-achieving students within the topic included multiple clauses such as this. Material (action) processes were chosen to suit the disciplinary context, as were the prepositional phrases to indicate where specific actions were happening throughout the explanation. At times, these students also used prepositional phrases to indicate from where activities were happening: 'from the nucleus'.

\subsubsection{Working with combined genres to build knowledge of disciplinary language patterns}

Within the topic of protein synthesis, a multimodal video clip introduced students to the field of the topic and began to develop their knowledge of language patterns and concepts. Within the year 11 topic on homeostasis, a written macrogenre became the focus of planning to begin to build the field 


\section{8}

for the students. The macrogenre included two genres: a narrative about an athlete who had overheated and a sequential explanation about homeostasis. It came from the textbook being used in year 11 and is representative of the kinds of macrogenres found in textbooks that attempt to engage students by placing more academic technical text types within real-life stories.

The teacher who used this genre to introduce the topic to the students explained to the researcher and her fellow teachers that she usually asked the students to read the story individually. There would then be some class discussion about what happened to the athlete prior to the teacher beginning some explicit teaching about homeostasis. The researcher supported the teachers to look for ways in which the representation could be used further to build student understanding of both concepts and language patterns.

The planning that was completed involved the teachers explaining the nature of the macrogenre first. The students were then invited to find the more technical consequential explanation that was embedded within the narrative. To do this, the teachers and the researcher designed an activity that asked the students to focus on the sequence of activities. In small groups, the students listed in order the steps that occurred as the athlete overheated. The students were also asked to indicate if two steps were occurring at the same time. Once the students had listed the activities that occurred when the body could no longer regulate temperature, the next step in the planning involved the teacher leading a discussion on how causation is expressed in consequential explanations. The teacher began with the point that causation is often implied by listing one activity after another; the first activity is a necessity for the next activity to occur. The teacher asked the students to look at their sequence of steps and to see where causation has been implied. The teacher then referred the students back to the written microgenre and asked them to look for words and groups of words that directly expressed causation. The students worked on this task in small groups and shared what they found with the whole class. The teacher then explained that some of the words and groups of words involve verbs within sentences (e.g. causing, resulted in) while others are working as conjunctions (e.g. [a]s a result).

Throughout the discussion on causation in the representation of homeostasis, there is field building occurring. The students are engaged in discussion about what causes what. As well as developing understanding of the ways in which scientists express causation in biology, the students are constantly engaged in the key concepts of the topic. From the beginning of the topic, the students are also building their knowledge of the ways in which ideas are sequenced and connected within consequential explanations in biology.

\subsection{Building field knowledge through deconstruction of representations}

The planning completed on the textbook macrogenre for homeostasis involved the deconstruction of a representation. The teacher and the students had begun to break the text down into parts. While the use of representations 
in various modes was already part of the pedagogy of the senior biology teachers, the deconstruction of the semiotic patterns of the representations was not part of their teaching practices at the beginning of the project. Often, the biology teachers' lessons consisted of rapid movement through a range of representations in different modes. For example, one biology teacher in year 11 within two minutes shared four representations of mitosis and meiosis with her students. During this time, the teacher moved rapidly through the images and made little movement beyond everyday language to more academic and technical language. As she pointed to parts of the four representations, she made statements like '[ $t$ ] here are three of these structures here', '[y]ou've got this elongated structure' and ' $[t]$ his is what it is like drawn'.

The careful deconstruction of representations supports students to further their conceptual understanding of topics, as well as to build understanding of the conventions used within disciplinary contexts to make meaning for specific purposes. By involving students in the deconstruction of representations, teachers are making explicit the conventions of representations and also continuing to build field knowledge of a topic (Christie, 2012; Macnaught et al., 2013; Tang \& Moje, 2010). Through the incorporation of such strategies into their pedagogy, teachers acknowledge that capacities for representing knowledge in disciplinary contexts are not innate and automatically known (Rose \& Martin, 2012). Rather, the practice of deconstructing representations stems from the belief that all students can learn about how representations are made (Moje, 2015; Rose \& Martin, 2012). Through deconstructing representations, the teacher involves students in a socio-cultural approach to knowledge building, where the conventions of meaning-making in specific representations are connected to social and cultural purposes (Dreyfus et al., 2016; Moje, 2015; Prain \& Tytler, 2013; Rose \& Martin, 2012). As a result, the affordances of specific ways of making meaning within a disciplinary context are made explicit (Prain \& Tytler, 2013).

\subsubsection{Knowledge building through deconstructing representations of mitosis and meiosis}

Over time, the biology teachers built more deconstruction of representations into their planning. For example, when teaching about mitosis and meiosis, a year 11 biology teacher included deconstruction of visual images that represented the stages of the processes. At one point, the teacher displayed an image with the heading 'Spindle Anatomy' and then deconstructed the image with the class:

T: So we've got these bits here. What are these things? (Teacher points to the centrosomes)

MULTIPLE STUDENTS: Centromere/centrosomes.

T: Centrosomes - so some of you have got like centromere or centrosome. Yeah, centrosomes. They attach to the centromeres via which things here? (Teacher points to the spindle fibres) 
MULTIPLE STUDENTS: Spindle fibres

T: Spindle fibres. Yeah so the centrosomes they give out spindle fibres and they attach themselves to these centromeres.

T: So they have used this word in this diagram called kinetochores. Kinetochore is another word for spindle fibre. It's an older word, I think. Umm still used sometimes.

During the dialogue, the teacher breaks the visual representation into parts and uses the process of deconstruction to move the students from everyday language to technical terms. The teacher prompts the students to search for more technical terms by using everyday language within questions, such as 'things'. At one stage, the teacher moves from the technical term 'spindle fibres' to the even more technical term of 'kinetochore'. The teacher also redirects when some students are using the term 'centromere' incorrectly.

\subsubsection{Knowledge building through deconstructing representations of genes and DNA}

The topic on DNA and genes in year 10 used text deconstruction to focus on how scientists write precisely about types of entities to present meaning about types and subtypes. The teachers worked with the researcher to help the students to deconstruct a short written extract from a year 10 textbook to investigate the ways in which scientists classify entities and produce taxonomies of type. The text extract used is provided below:

Genes are made of a chemical called deoxyribonucleic acid (DNA). DNA is the genetic material that is passed from one generation to another. It is found in the nucleus of almost every cell in your body. The DNA molecule consists of two long, thin strands of complementary nucleotides that are held together by hydrogen bonds. The double-helix shape of DNA is often compared to a twisted ladder.

(Silvester, 2016, p. 4)

Text deconstruction began by looking at the abbreviation DNA and finding within the text the full name of 'deoxyribonucleic acid'. The teacher spoke of this being a noun group consisting of the thing 'acid' and the classifier 'deoxyribonucleic' and then explained how the classifier carries the meaning about type. The teacher then asked the students to look through the text extract to find all the noun groups that include meaning about type. Once the students shared the other noun groups that they have found, there was a class discussion about the meanings being created about types of entities. The teacher then led further discussion about how taxonomies of types and subtypes of things are constantly being created in scientific writing.

Through this kind of text deconstruction, the students are building field knowledge within the topic, as well as knowledge about the ways in which scientists present meaning in written text. The students learn that noun 
groups consisting of classifiers will carry meanings about types of entities, which, in turn, consist of meanings about taxonomies of types of things. As a result, student understanding is extended. Instead of just rote learning the term 'DNA molecule', the students build an understanding that there are many molecules that make up the living world. One important molecule is the DNA molecule, and this molecule is an acid. It is also a specific subtype of acid (deoxyribonucleic).

Teachers of year 10 classes also worked with the researcher to include in their planning deconstruction of the same textbook extract to provide students with an understanding of composition and the ways in which scientific writers develop knowledge about wholes, parts and subparts. The teacher pointed out the cell as an entity within the written extract and then asked the students to work out from the text what is within the cell. From the information provided, the students found that the information within the cell is a nucleus and within the nucleus is DNA. The teacher then modelled a small part of the language from the extract: 'It is found in the nucleus' (Silvester, 2016, p. 4). The teacher asked what the pronoun '[i]t' refers back to. The students related this to the entity identified within the previous sentence 'DNA'. The teacher then talked about how the scientific writer has used a verb group 'is found' and the circumstance 'in the nucleus' to establish meaning about parts and subparts.

The teacher then drew students' attention to another part of the written extract: 'The DNA molecule consists of two long, thin strands of complementary nucleotides' (Silvester, 2016, p. 4). The teacher asked the students to identify the main entity in this clause and then to establish if information about composition is being given. The students worked in pairs and then offered responses. With the students' input, the teacher confirmed that the DNA molecule is made up of nucleotides and that these nucleotides are made up of strands. The teacher then pointed out that the science writer has provided meaning about composition by using the verb 'consists' followed by a circumstance 'of two long, thin strands of complementary nucleotides'.

Having built up an understanding of the cell and some of its key components, the teacher then asked the students to work in small groups to draw two visual representations with written annotations. The first is to represent the cell consisting of a nucleus and DNA, and the second is to represent a DNA molecule. In this activity, the students needed to use the information from the short, written extract to develop their visual representations with written annotations. Once the students have completed these in groups, they needed to compare and contrast their visual representations with other groups and debate why a certain form of representation more precisely and comprehensively provided information about composition. The teacher then drew on the groups to feedback into a whole-class discussion.

As the class discusses the merit of certain ways of representing the knowledge visually, the teacher pointed out certain conventions about the ways in which the cell and its parts and subparts are represented visually. For example, the nucleus is represented as a circle within the cell, and its size is small relative to the cell. 
Through this activity, the students learn important information about the ways in which biological scientists represent knowledge. They learn that both written and visual representations are valued and that scientists will often move between these modes of presentation to provide key meanings, such as the ways in which entities are composed of wholes, parts and subparts. As the students are building their topic knowledge, they are also creating understandings of how scientists make language and image work to express specific and precise meaning within a disciplinary context.

\subsubsection{Learning about the limitations of representations through deconstruction}

The process of deconstructing representations in disciplinary contexts should also involve students analyzing the limitations of specific meaning-making conventions (Moje, 2015; Tytler et al., 2013b). The deconstruction of representations can build understanding for students of why particular conventions exist to make meaning within specific cultural contexts, but the process can also be used to foster critical analysis, where students look at the limitations of certain ways of presenting complex disciplinary knowledge (Moje, 2015; Tytler et al., 2013b). Such an approach reinforces for students that knowledge is constructed by human beings within socio-cultural contexts and that no one representation will hold 'the truth' about a scientific domain (Tytler, Hubber \& Prain, 2013a, p. 52).

Within the M3S project, the biology teachers often asked the students to critique the images that they had created as a way to move the students towards conventions, but critiquing the conventions themselves was not apparent. For example, within a year 11 topic on mitosis and meiosis, the students engaged in activities that enabled them to critique their own visual creations and to move towards required conventions. At the beginning of the topic, the students were asked to represent visually a prokaryotic and eukaryotic cell. Instructions for the task asked that the organelles be drawn in their 'known positions within the cell', and they needed to be labelled. Once the students completed this task in small groups, the teacher provided them with examples of images of each, which the students used to modify their own visual representations.

Later in the same topic, the students worked in small groups to replicate a stage of mitosis using pipe cleaners, masking tape, string and two objects to represent the centrosomes. The students were also instructed to annotate their models by using paper labels. Once each group had completed their stage of the process, a photograph of their model was taken and uploaded to a collaborative site so that the class could analyze each one. The class discussion of each model focussed on whether or not everything had been included if the process at that stage was clearly depicted and if the cell structures were accurately labelled. Following the discussion, the students had to refine their models in small groups and then upload a new photograph to the collaborative site. 
By working in this way, the students critiqued their own visual representations and made modifications based on the conventions required in the disciplinary context. The learning that occurred could have been extended by the teacher prompting the students also to critique the conventions. The students could have been guided to consider the extent to which the conventions accurately represent the natural world. Through such discussion, the students could learn that all visual representations have affordances and limitations and that scientists constantly collaborate to decide on the best ways in which to represent knowledge in visual forms.

The focus within the biology classrooms on the critique of students' visual representations as a way to learn about conventions was likely to be a result of the context in which the senior secondary teachers were working. During planning sessions, the teachers often spoke about the need for students to represent knowledge in precise and specific ways. The teachers' emphasis on certain conventions was connected to their own understanding of the conventions required in the disciplinary context, as well as their perceptions of assessment requirements. For example, in one videoed classroom scenario for year 12 at the beginning of the project, the teacher focussed on a formula for writing short answer sequential explanation responses. She gave the students the acronym QAFMA and then asked the students what each letter stood for. The students knew the formula extremely well and were able to respond with the information: questioning word, area of study, focus on question, marks, allocation. The phrase 'questioning word' asked the students to focus on the word within the question that defined the kind of question being asked (e.g. explain). 'Area of study' required that the students focus on the parts of the question that guided them to the specific topic being covered in the question. 'Focus on the question' asked that the students identify the specific focus for the question within the topic of study. 'Marks' required that the students use the number of marks allocated to the question to determine the length of response required and the number of points that needed to be made. The final nominalized term 'allocation' asked the students to give marks to the different sections of the short answer response as a way to gauge the detail required in each section. For this teacher, at the beginning of the project, providing students with this kind of formula for the writing of short answer responses was literacy teaching.

\subsection{Extending field knowledge through joint and independent construction}

The biology teachers in the M3S project used both joint and independent construction to build further students' capacity to understand and represent knowledge. Both joint and independent construction have been introduced as important strategies in Chapter 6. Through the construction of representations, jointly and independently, students can continue to develop an understanding of a field of knowledge, as well as developing further their capacities for representing this knowledge in discipline-specific ways (Dreyfus et al., 2016; Prain \& Tytler, 2013). Joint construction involves the teacher being present to 


\section{Multimodal disciplinary literacy in biology}

offer expert guidance as the students work towards creating a representation (Dreyfus et al., 2016; Macnaught et al., 2013; Rose \& Martin, 2012). The biology teachers in the project approached joint construction in two main ways. At times, the teachers provided guidance for the construction of representations before, during and after the process of creation. However, on other occasions, the teachers chose to allow the students to explore possibilities for representing knowledge of a topic before they provided expert guidance.

\subsubsection{Joint and independent construction on mitosis and meiosis}

One example of when the teacher provided the students with expert guidance before, during and after the process of representing knowledge was during the year 11 topic on mitosis and meiosis. The teacher presented two visual representations on the smartboard. One represented the early prophase stage, while the other represented what happened later in the process. The students in the class also had copies of the two representations. While some key entities had been included in the visual images, others had been left out. The teacher worked with the students to complete the images. For example, joint construction occurred to include the centromeres:

T: Do we have centromeres by this stage?

MULTIPLE STUDENTS: Yes

T: Where would they be?

S1: Where the labels are.

S2: Is it the chromosomes?

T: Yeah so where the chromosomes sort of. Where the two chromatids in every chromosome seem to touch. That's where we have the centromeres yeah. [As the teacher says this, he draws the centromeres into the diagram for the late stage of prophase.] So label that into your diagrams also.

\subsubsection{Joint and independent construction on natural selection}

Another example of the teacher guiding joint construction throughout the process of students creating representations was during the year 12 topic on natural selection. The teachers planned to first provide the students with a definition of natural selection from their textbook: Natural selection is 'the process by which new heritable traits, whether morphological, physiological or behavioural, evolve and persist in a population' (Kinnear, 2016, p. 395). The teachers then planned to model for the students three stems of definitions using the common format of a noun group, containing classifiers, followed by a relational process:

A morphological heritable trait is

A physiological heritable trait is

A behavioural heritable trait is 
The students then worked in pairs to construct the last part of the definition using their own words. The pairs of students then shared their definitions with the whole class, and, as they did so, the teacher modelled how some of the everyday language used by the students could be recast to be more technical and academic. As a result, the teacher jointly constructed the three definitions with the students.

In both examples, the teacher was involved in the joint construction from the beginning. However, on other occasions, the teacher allowed the students more room to explore possibilities in the beginning before becoming involved as the expert user of disciplinary language. During the same topic, the teachers planned to provide the students with an extract from their textbook:

Populations have a pool of inherited (genetic) variation. A change in the environmental conditions in which a population lives can act as an agent of selection. The action of an agent of selection can produce differential survival and reproduction rates in the member of a population, depending on differences in their inherited physical, physiological or behavioural characteristics. Where members of a population, because of their particular genetic make-up or genotype, have a higher survival and reproductive rate compared to other members of the population, they are said to have a selective advantage.

(Kinnear, 2016, p. 382)

The students were asked to read through the extract and then work in small groups to represent the consequential explanation visually. The only instruction provided to the students was that they needed to complete a visual representation with some written annotations included as well. Once the students had completed the representation, they presented them to the whole class. During the presentations, the students were encouraged to consider what had worked well to represent the knowledge and where they had struggled to represent a particular concept. The students then worked with the teacher as a class to come up with one penultimate representation. During the joint construction, the teacher spoke about the affordances of certain symbols, such as arrows, to represent the required knowledge.

In both examples from the topic on natural selection, the teacher guides the students towards the conventions of representations and opens up opportunities for discussion about the affordances and limitations of language patterns or forms of symbolic representation. During the first example, the teacher provides guidance about language patterns from the beginning, while in the second example, the students work in small groups with little expert guidance until later in the process. Both ways of working enable the students to consider how certain linguistic or symbolic forms can be used to their full potential to represent knowledge. Within the first example, the students are guided to consider how more academic and technical language can be used within definitions. In the second example, the process of joint construction with the teacher involves making decisions about the best uses 


\section{Multimodal disciplinary literacy in biology}

of symbols to represent key concepts. As well as learning about forms of representation, the students also continue to build their conceptual understanding of natural selection.

\subsubsection{Peer joint construction}

Joint construction, where a more knowledgeable other guided work on the construction of representations, also occurred during the project within small group work when only students were present. The extent to which joint construction occurred in these situations depended on the make-up of the group. If a student member of the group held knowledge about how to construct a representation and took the lead, moments of joint construction occurred within student group work. For example, during the year 11 topic on mitosis and meiosis, one student in paired group work took the lead when producing a visual representation of metaphase.

S1: So you need the centrioles.

S2: Draws centriole.

S1: Then you draw these again at the top (referring to centrioles).

S2: Draws centriole.

S1: No, no like this (draws centriole at top of representation).

S1: So there is the equator like down the middle (draws line across middle of representation).

S1: So these need to be on line. So like they all need to be along the line (draws chromatids).

S2: Draws chromatids along the centre line as well.

S1: And these spindles like they go through the chromatid like that (draws one spindle fibre).

S1: And this side and you just follow them (draws spindle fibre on opposite side).

S2: Like each one?

S1: Yep.

S2: Draws in other spindle fibres.

In this example, one student takes the lead with both technical terminology and the construction of the visual representation. She names the key entities involved in metaphase throughout the dialogue and directs where the entities need to be placed within the cell in relation to each other. The other student is also involved in the construction of the visual representation, but it is under the direction of the more knowledgeable student.

\subsubsection{Independent construction}

All of the units of work planned by the biology teachers with the researchers ended with a form of independent construction. While the students were expected to produce representations independently at the end of the unit, 
the work on representation prior to this point provided extensive support for the final task. For example, the topic on natural selection ended with a task where the student had to represent a case study in both written and visual form. By the time the students came to do this task, they had already engaged in an activity that involved reading a written consequential explanation of natural selection and then using this to construct jointly a visual representation of natural selection. The joint construction of a visual representation had provided them with knowledge about symbolic representation for this topic.

To complete the independently constructed visual and written texts on natural selection, the students were provided with a case study about a subspecies of the Western Grey Kangaroo on Kangaroo Island. The students were required to present a consequential explanation on why the subspecies on Kangaroo Island had morphological and genetic differences from the Western Grey Kangaroo on the mainland of Australia. First, the students were asked to "[i]dentify the process involved and explain how the population of Kangaroo Island Kangaroos has evolved to have thicker coats than their mainland relatives'. In response, one student wrote the following consequential explanation:

This is known as natural selection where in the beginning the kangaroos on kangaroo island varied in size, colour and hair thickness. However due to the cold and windy climate of kangaroo island, many kangaroos would have died from the cold. Alleles for a smaller, darker and longerhaired kangaroo were favourable because it means the kangaroo could better resist the cold. This meant that kangaroos with these alleles and thereby phenotype were able to survive and pass on their alleles. This meant that there was a larger number of these alleles. This meant that there was a larger number of these alleles in their offspring. This led to an increase in the expressed phenotype and over time the entire population expressed this phenotype.

Within the independently constructed written text, the student is able to present meanings about causation and consequence through the use of conjunctions and logical metaphor. Conjunctions used to express causation include 'due to', '[ $t]$ his meant', 'thereby' and 'because'. Rather than using conjunctions to link ideas causally at times, the student also uses logical metaphor, where processes have been used in place of conjunctions (Martin \& Rose, 2008). For example, the student uses the verb 'led' ([t]his led to an increase) and verb group 'would have' (many kangaroos would have died from the cold).

The student then constructs the visual representation of the case study independently. The task requires that the student can work across modes and use appropriate meaning-making resources to present consequences in both written and visual text. The visual representation produced by the student is presented in Figure 7.1. 


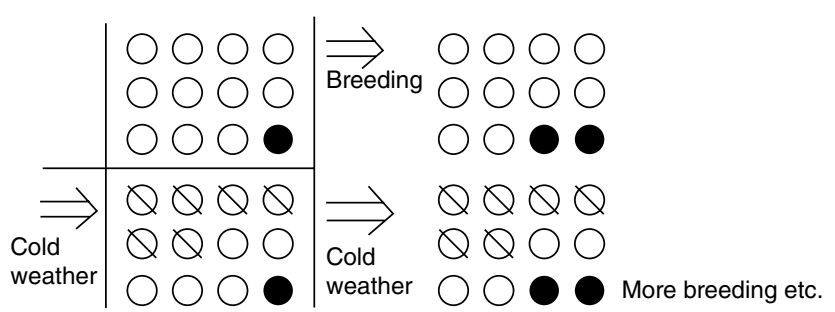

Figure 7.1 Student's visual representation of the case study on natural selection.

The student uses circles to symbolically represent the kangaroos. Circles that are not coloured in represent those in the Kangaroo Island population that do not carry the alleles for thicker fur, while the coloured in circles do represent this subtype. Arrows are used to represent symbolically the processes that are occurring. The first arrow represents the process of breeding amongst the population on Kangaroo Island. The arrow connects an initial population with few members having the thicker fur to a second population where more kangaroos with thicker fur begin to emerge. The second arrow represents the effects of cold weather where those in the population without thicker fur begin to die. The student represents this symbolically by drawing a circle with a line through it. A third arrow is used to suggest that the activity involving the cold weather continues over time and more kangaroos without thick coats begin to die, while more kangaroos with thick coats appear in the population.

Through the use of symbols in the visual representation and the use of conjunctions and processes in the written text, the student effectively presents notions of cause and consequence. The language patterns and symbols that the student employs had been modelled during the joint construction activity that occurred earlier in the unit. The student is able to draw on these understandings as they create final independent representations for the topic.

\subsection{Developing a metalanguage}

By infusing their pedagogy with a focus on representation, the biology teachers involved in the M3S project engaged students in thinking about how concepts are represented in written and visual forms. As discussed in Chapter 6, this kind of focus on representational thinking is required if students are to develop a metalanguage about representations. Through a shared language about representation, teachers and students can discuss the affordances and limitations of written and visual texts that carry key meanings about the field of study.

Biology teachers within the project developed pedagogies that focussed students' attention on language patterns in written texts. For example, the work conducted with a macrogenre on homeostasis supported students to consider how causation can be implied through the sequencing of clauses, or it can be included explicitly through causal verbs and conjunctions. 
The use of a YouTube clip to introduce the topic of protein synthesis provided opportunities to consider the language pattern involved in expressing definitions. Through these teaching moments, and others like these, the teachers effectively focussed on the language of written texts within the disciplinary field.

Every opportunity that was developed to include a focus on written language patterns could have been extended in some way. The moments when a focus on representation was created provided rich opportunities to extend student knowledge about language. For example, in the topic on natural selection, the teachers planned with the researchers to have a focus on the language pattern used for definitions in biology. Providing the beginning of the clause, such as 'A morphological heritable trait is', modelled for students the language pattern for writing definitions. The focus allowed students to learn about how the clause can be used to write clear and precise definitions in biology. Even this small example could then have been extended to include further learning about language patterns in biology. For example, the teacher could focus on the noun group 'morphological heritable trait' and discuss with the students the way in which two classifiers have been used to set up precise understandings of the type of trait within the noun group. By focussing on language within written text, the teachers provided students with opportunities to consider the language patterns essential for expressing meaning in the discipline. Each one of these opportunities could have been extended again to consider more patterns and to support student understanding of the grammar being used within the disciplinary context.

There were also times when the learning about visual representations could have been extended. For example, when the two students are engaged in peer joint construction of the phase of metaphase within the topic of mitosis and meiosis, multiple opportunities arise for further representational work. The students draw key entities within the cell, including the centrioles, the chromatids and the spindle fibres. The teacher could have initiated further discussion with the students about how they had represented each entity and whether they were represented appropriately for the disciplinary context. Discussion could also have been generated about the proximity of each entity in relation to each other, and in relation to the cell and whether these relationships were represented clearly in the visual image. Through this kind of conversation, the students could have engaged in further thinking about the conventions used to represent the cell and its components during metaphase and the limitations of these conventions when representing complex aspects of the natural world. The students are also supported to develop further a metalanguage about visual representation by discussing shape, size and proximity.

\subsection{Conclusion}

The biology teachers involved in the M3S project found opportunities to focus on representations throughout sequences of learning. Prior to the project beginning, they had often used multimodal texts to orient the students 
to a field of knowledge. Involvement in the project saw the teachers use these multimodal texts in much more comprehensive ways at the beginning of learning sequences. They worked with one of the researchers to ensure that the multimodal representations were used in ways that helped students to move from everyday language to the more academic disciplinary language of biology required in the senior years of schooling.

As learning sequences progressed, the teachers incorporated more varied modes of representations and they spent much more time than previously guiding students through the deconstruction of texts. Prior to the project, a number of the biology teachers indicated that they would often move quickly through multiple forms of representations to support the building of field knowledge, but they did not focus on the nature of the representations and how patterns of language and image conveyed key meanings. A key shift in pedagogy involved the teachers using fewer forms of representations for a concept and spending more time with students pulling apart written and visual texts and looking at their limitations. The process of deconstructing texts supported students to develop conceptual understanding, as well as knowledge of how representations are constructed to represent key meanings.

Another aspect of pedagogy that emerged for the biology teachers was an emphasis on the joint and independent creation of representations. The teachers created multiple learning opportunities within learning sequences for students to participate in jointly constructed texts. The teacher provided guidance as the students made contributions to the creation of written and visual representations. Often this teacher guidance occurred throughout the creation of the text. At times, joint construction occurred with only students involved. During these learning opportunities, a student with knowledge about the topic and the ways in which it could be represented could offer guidance to other students. Teacher guidance was also effective after the peer constructions of text. Learning sequences developed by the teachers and the researcher created opportunities for the teacher to lead students to critique their representations, to consider the conventions used and to think about how these conventions may be limited given the complexities of the natural world. Throughout the process of joint construction, learning opportunities occurred that involved both conceptual understanding and knowledge of how to represent key meanings.

Opportunities for students to engage in the independent construction of texts were also generated. Often, joint construction had occurred first, which provided students with the knowledge and understandings required to then undertake independent constructions. Some of the tasks designed by the biology teachers involved students constructing texts in one mode first before then representing the same concepts in another mode of representation.

A focus on representations within the biology classrooms generated dialogue and thinking about the grammatical patterns of written language and images. Through an emphasis on the ways in which texts had been created, 
the teachers engaged the students in thinking about the conventions used to represent the natural world and the meanings typically carried through these conventions. As a result, a metalanguage began to develop. While this metalanguage could have been extended at times, the biology teachers created learning opportunities that allowed for rich conversations about how elements of texts within biology carry key meanings.

\section{References}

Christie, F. (2012). Language education throughout the school years: A functional perspective. Chichester, West Sussex: Wiley-Blackwell.

Dreyfus, S. J., Humphrey, S., Mahbob, A., \& Martin, J. R. (2016). Genre pedagogy in higher education: The SLATE project. London: Palgrave Macmillan. https://doi. org/10.1007/978-1-137-31000-2

Gibbons, P. (2018). Bridging discourses in the ESL classroom: Students, teachers and researchers. London: Bloomsbury Academic.

Kinnear, J. (2016). Nature of biology 2. (5th ed.). Melbourne: Jacaranda.

Lemke, J. (1998). Multiplying meaning: Visual and verbal semiotics in scientific text. In J. R. Martin \& R. Veel (Eds.), Reading science: Critical and functional perspectives on discourses of science (pp. 87-113). London \& New York: Routledge.

Macnaught, L., Maton, K., Martin, J. R., \& Matruglio, E. (2013). Jointly constructing semantic waves: Implications for teacher training. Linguistics and Education, 24, 50-63. https://doi.org/10.1016/j.linged.2012.11.008

Martin, J. R., \& Rose, D. (2008). Procedures and procedural recounts, genre relations: Mapping culture. London: Equinox.

Moje, E. B. (2007). Chapter I developing socially just subject-matter instruction: A review of the literature on disciplinary literacy teaching. Review of Research in Education, 31(1), 1-44.

Moje, E. B. (2008). Foregrounding the disciplines in secondary literacy teaching and learning: A call for change. Journal of Adolescent and Adult Literacy, 52(2), 96-107. https://doi.org/10.1598/JAAL.52.2.1

Moje, E. B. (2015). Doing and teaching disciplinary literacy with adolescent learners: A social and cultural enterprise. Harvard Educational Review, 85(2), 254-278. https://doi.org/10.17763/0017-8055.85.2.254

Prain, V., \& Tytler, R. (2013). Representing and learning in science. In R. Tytler, V. Prain, P. Hubber \& B. Waldrip (Eds.), Constructing representations to learn in science (pp. 1-14). Rotterdam: Sense Publishers. https://doi. org/10.1007/978-94-6209-203-7

Rose, D., \& Martin, J. R. (2012). Learning to write, reading to learn: Genre, knowledge and pedagogy in the Sydney school. Sheffield: Equinox.

Shanahan, T., \& Shanahan, C. (2008). Teaching disciplinary literacy to adolescents: Rethinking content-area literacy. Harvard Educational Review, 78(1), 40-59. https://doi.org/10.17763/haer.78.1.v62444321p602101

Silvester, H. (2016). Oxford science 10. Melbourne: Oxford University Press.

Tang, K-S., \& Moje, E. B. (2010). Relating multimodal representations to the literacies of science. Research in Science Education, 40, 81-85.

Tytler, R. (2007). Re-imagining science education: Engaging students in science for Australia's future. Camberwell, Vic.: Australian Council for Educational Research. 


\section{Multimodal disciplinary literacy in biology}

Tytler, R., Hubber, P., \& Prain, V. (2013a). Structuring learning sequences. In R. Tytler, V. Prain, P. Hubber \& B. Waldrip (Eds.), Constructing representations to learn in science (pp. 51-66). Rotterdam: Sense Publishers. https://doi. org/10.1007/978-94-6209-203-7

Tytler, R., Hubber, P., Prain, V., \& Waldrip, B. (2013b). A representation construction approach. In R. Tytler, V. Prain, P. Hubber \& B. Waldrip (Eds.), Constructing representations to learn in science (pp. 31-50). Rotterdam: Sense Publishers. https://doi.org/10.1007/978-94-6209-203-7 


\section{Multimodal disciplinary literacy in the senior physics classroom}

\subsection{Introduction}

This chapter describes research into the infusion of multimodal disciplinary literacy into pedagogy in senior physics classrooms, in low socio-economic status school environments. The chapter begins by picking up and extending the discussion in Chapter 4 regarding the literacy demands of physics at this level, through analysis of textbooks, assessments and through evidence from teacher interviews and classroom observations. It then describes case studies of teachers working with new multimodal literacy practices, illustrative of the principles outlined in Chapter 6, in three areas: multimodal representational practices to explain electric circuits, joint construction of text and image in developing causal explanations of an electric motor and the building of graphical literacy resources in the topic of motion.

\subsection{Literacy demands of senior school physics}

As with other sciences, acquiring knowledge in physics requires the orchestration of representations across multiple modes (Airey \& Linder, 2009; Doran, 2017; Hubber \& Tytler, 2017; Tytler, Prain \& Hubber, 2018). In particular, the Multiliteracies in Senior School Science (M3S) team's analysis of physics texts, assessment items and field notes of teacher presentations show a balance towards abstracted mathematical (equations and graphs) and visual modes. Physics teachers' discussions of their approaches to topics contained frequent references to visualization; they described student difficulties with visualizing 3D situations using $2 \mathrm{D}$ representations, often including complex temporal changes involving cause and effect. For instance, the relation between force direction on a wire and current and magnetic fields is spatially complex, involving 3D conceptualization. Figure 8.1 illustrates the right-hand rule used to imagine these, rendered in the text in $2 \mathrm{D}$ but invariably demonstrated through embodied means in the class.

Challenges involving the multimodal nature of physics disciplinary literacies can be illustrated by the density of text and images in physics textbooks. Figure 8.2, showing an excerpt from a year 12 textbook, involves conceptualizing the magnetic flux through an idealized current coil at different 


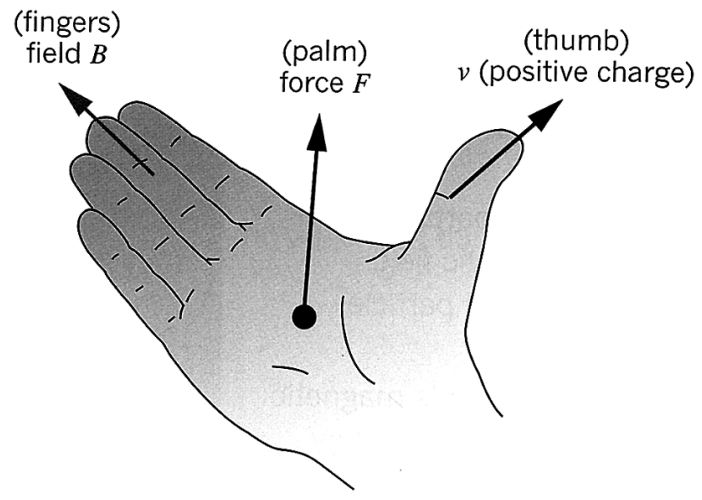

Figure 8.1 Embodied representation of the spatial relations between magnetic field and current direction, and force on a wire (Bail \& Moran, 2017, p. 55).

The direction of the induced current will reverse every time the plane of the loop reaches a point perpendicular to the field. The magnitude of the induced emf will be determined by the rate at which the loop is rotating. It will be a maximum when the rate of change of flux is a maximum. This is when the loop has moved to a position parallel to the magnetic field and the flux through the loop is zero, i.e., the gradient of the flux versus time graph shown in Figure 4.3.10 is a maximum.

(a)
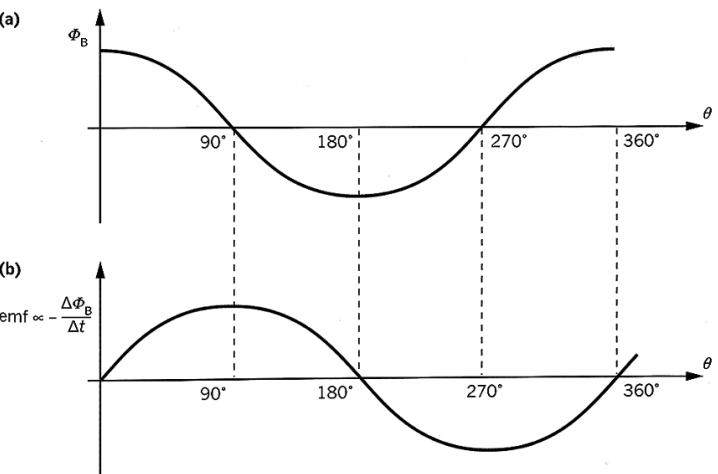

FIGURE 4.3.10 (a) The flux, $\Phi_{B}$, through the loop of Figure 4.3 .9 as a function of the angle between the field and the normal to the plane of the area, $\theta$. (b) The rate of change of flux and hence emf through the loop as a function of the angle between the field and the normal to the plane of the loop, $\theta$. The loop is rotating at a constant speed.
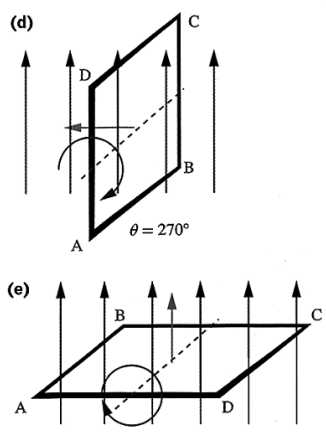

$\theta=360^{\circ}$

FIGURE 4.3.9 A single loop of a generator rotating in a magnetic field. (a) The plane of the area of the loop is perpendicular to the field $B$ and the amount of flux $\Phi=B A$ is at a maximum. (b) The loop has turned one quarter of a turn and is parallel to the field; $\Phi=0$. (c) As the loop continues to turn, the flux increases to a maximum but in the opposite sense relative to the loop in (a); $\Phi=-B A$. (d) The flux then to the loop in (a); $\Phi=-B A$. (d) The flux then
decreases to zero again as the loop is parallel to the field before repeating the cycle again from (e) onwards.

Figure 8.2 Multimodal orchestration of abstracted spatial relations of magnetic field to current loop, graphical representation and text (Bail \& Moran, 2017, p. 125).

angles. The flux itself is an abstracted quantity depending on field intensity and the angular projected coil area. This results in a sinusoidal graph of flux variation which is itself transformed into an induced emf, which is the negative rate of change, or slope, of the flux graph. Note how the text, in creating an account of flux and its representations, refers across the figures and incorporates mathematical expressions, developing an argument based on temporal and spatial relations between real (the loop) and imagined 
(the field, the orientation, the flux) entities. Teachers in the M3S meetings shared the different ways they supported students to conceptualize the flux concept $(\varnothing)$ using analogy (light falling on a surface at an angle or water from a hose on a surface) and embodied demonstrations with key questions.

Interpreting the text requires an advanced level of 'disciplinary discernment' (Eriksson, 2019; Eriksson, Linder, Airey \& Redfors, 2014) where students need to be able to read the conventions in the diagrams, and equations, and notice the key features of the relations between field and loop and the implications for flux for different loop angles. We note here also the appresentation or hidden/assumed nature of semiotic resources in the text (Linder, 2013), such as the arrow representing the planar direction of the loop or the notion of 'function' which is central to an understanding of the meaning of the graphs. Teaching this material requires attention to students coming to see these implicit semiotic resources, as well as to recognize the meaning of what is present, and understand the literacies involved in mounting explanations that coordinate the multiple, multimodal textual features.

Assessment items often involve students interpreting such diagrams in particular contexts and reconstituting relations to graphs, or mathematical expressions, in order to solve problems. Teachers also referred to students confusing diagrams with similar features, such as a diagram of a generator (Figure 8.3) with that of an electric motor. Note how in Figure 8.3 the detail needed to interpret the situation such as the field lines and rotation stages is now appresented.

Coordinating visual, symbolic and written language forms in causal explanations is a key literacy demand for students (Tang, 2016; Tang, Delgado \& Moje, 2014). This can be seen in the written text in Figure 8.1 and also Figure 4.2. In both cases, the text contains an argument for constructing the mathematical and graphical entities based on causal relations between real (wires, resistors) and abstracted (field lines, flux, voltage, current) entities. For other constructs, such as potential in an inverse square force field, the logical relations are between multiple abstract entities, gravitational force (conceptualized through considering the gravitational field) and energy

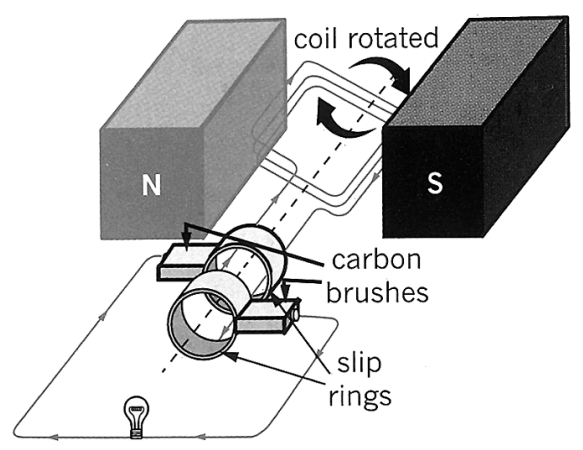

Figure 8.3 Schematic of an AC generator (Bail \& Moran, 2017, p. 126). 


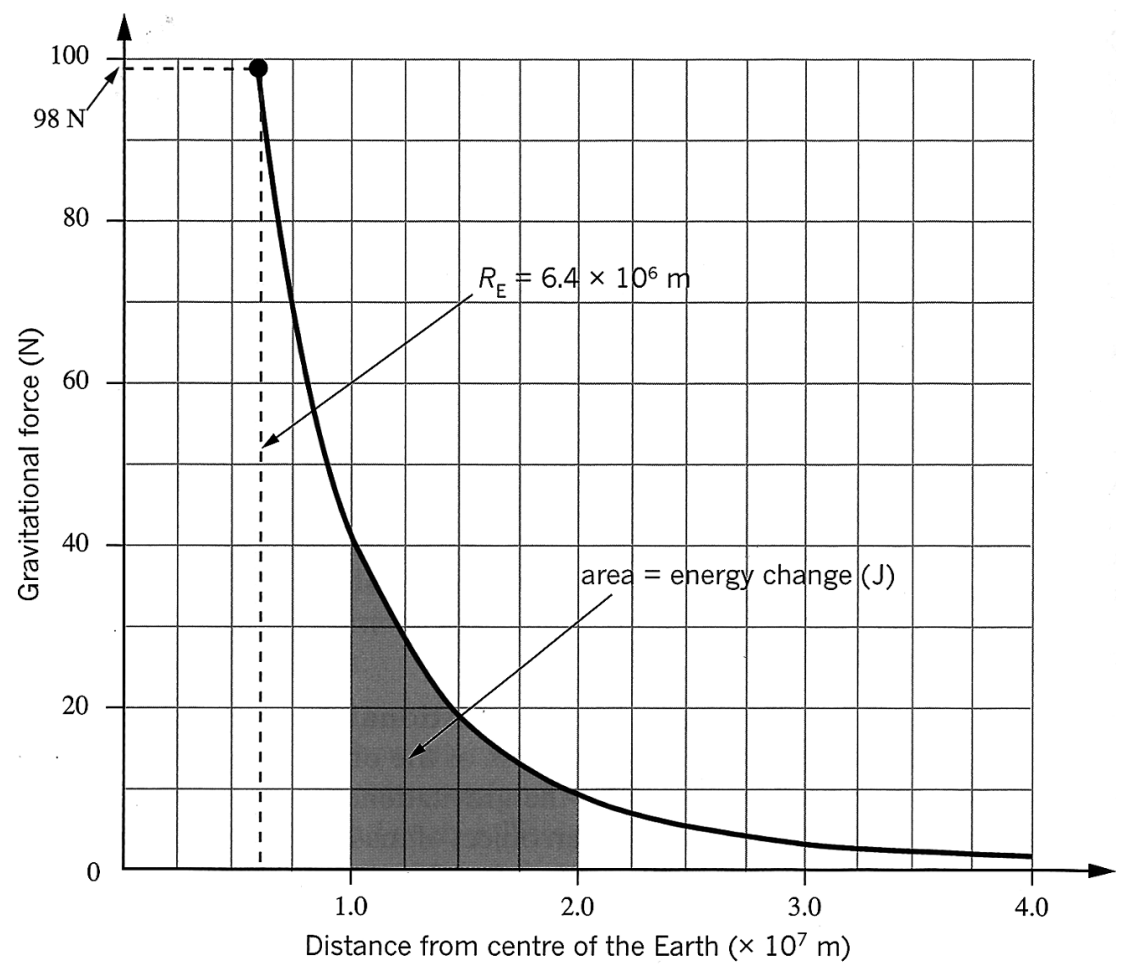

Figure 8.4 Conceptualizing gravitational energy as the area under a graph of gravitational force vs. distance (Bail \& Moran, 2017, p. 246).

change (conceptualized as work done in moving the body). Implicit in Figure 8.4 is the reading of force, or weight, at the surface of the earth.

Arguments for such abstracted entities often take the form of mathematical proof, often containing definitions, such as the derivation of Faraday's law shown in Figure 8.5. Note the appresented symbol for the component of magnetic field perpendicular to the plane of the current loop area, within the definition of flux, the recognition of which is part of disciplinary discernment.

Causal arguments expected as part of the disciplinary literacy of senior school physics also include the relation between theories and evidence. Figure 8.6 is an assessment item from the Victorian Certificate of Education, requiring students to identify the key evidence that distinguishes between a particle and wave interpretation of the photoelectric (PE) effect and explain why this evidence discounts the wave model. This is what Martin and Rose (2008) describe as a conditional explanation, requiring the recognition that the respective theories are supported, contingent on the energy of emitted electrons being dependent on the frequency or the intensity of the incident light. Analysis of student responses to this question demonstrated a lack of inclusion of key elements of the scientific account of the PE effect in most 
FARADAY'S LAW OF INDUCTION

Faraday's investigations led him to conclude that the average emf induced in a conducting loop, in which there is a changing magnetic flux, is proportional to the rate of change of flux.

This is now known as Faraday's law of induction and is one of the basic laws of electromagnetism.

Magnetic flux is defined as $\Phi_{\mathrm{B}}=B_{\perp} A$.

If the flux through $N$ turns (or loops) of a coil changes from $\Phi_{1}$ to $\Phi_{2}$ during a time $t$, then the average induced emf during this time will be:

$$
\varepsilon=-N \frac{\left(\Phi_{2}-\Phi_{1}\right)}{t}
$$

and if the change in magnetic flux $\Phi_{2}-\Phi_{1}=\Delta \Phi_{\mathrm{B}}$, then

$$
\text { (1) } \varepsilon=-N \frac{\Delta \Phi_{B}}{\Delta t}
$$

Figure 8.5 Establishing Faraday's law of electromagnetic induction (Bail \& Moran, 2017 , p. 115).

\section{Year 12 Physics \\ Independent Assessment Task: The Photoelectric Effect}

Instructions: Read the following information about the photoelectric effect and answer the questions below. Please use a dark pencil or pen to write your answer as your answer sheet needs to be scanned to be recorded.

You may want to include drawing(s) and formulae along with your written answer.

The photoelectric effect experiment supports the particle model of light rather than the wave model of light. The following are observed in a photoelectric effect experiment.

Observation 1: The number of emitted electrons (the photocurrent) depends on the intensity of the incident light.

Observation 2: The energy of emitted electrons depends only on the frequency of the incident light and is independent of the intensity.

Observation 3: The energy of the emitted electrons depends on the metal surface involved.

The particle model can account for all the above three observations.

The wave model can explain two of these observations but not a third.

Question

Select the observation that the wave model cannot explain and write the number in the 'Observation number' box below.

Explain how the particle model satisfactorily explains this observation.

Observation Number

Explanation:

Figure 8.6 Assessment item requiring a conditional explanation based on coordination of theory and evidence.

student explanations. Analysis of the top-scoring student's response compared to text generated by the researcher is shown in Figure 8.7. This student effectively used conjunctions appropriate to conditional language and successfully coordinated the main features of the argument. However, the 


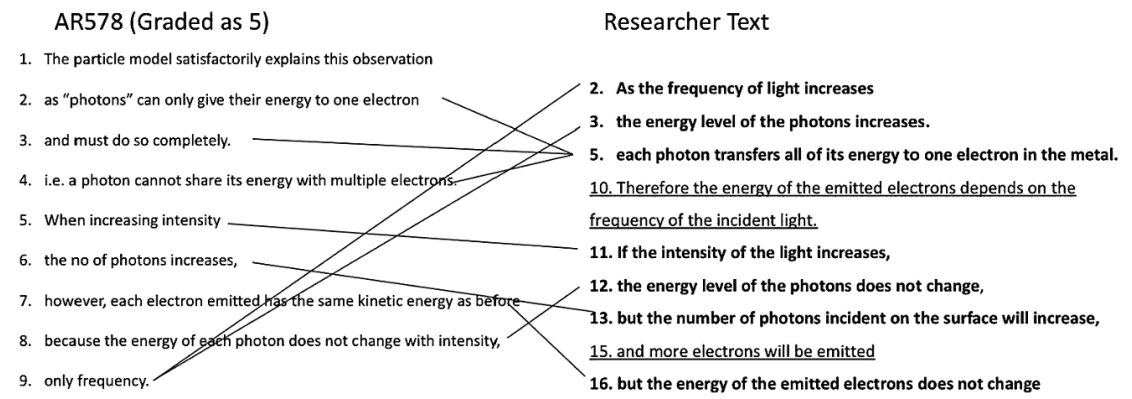

Figure 8.7 Comparison of the top-graded (by the teacher) student response with an M3S researcher-generated text. The underlined explanatory moves are not duplicated by this student.

bulk of responses fell well short of the level achieved by this student, leading to a conclusion that support for these literacies involving indirect explanation should be provided by teachers through structured practice.

In this brief overview, a number of features of what is entailed in the development of disciplinary literacies in physics have been identified through textbook illustration, through the experience of working with teachers in the project and through analysis of student productions. Key challenges identified that are particularly evident for physics are

- the significant presence of diagrams that contain detailed visual representations of abstracted concepts and their relations;

- complex spatial relations embedded in diagrams, alongside often complex temporal relations, such as for rotating coils or bodies moving in force fields;

- explanations that regularly involve transduction across visual, spatial, graphical and mathematical modes, with high levels of semantic density and low semantic gravity (see Maton, 2013a, and Chapter 3, this volume, Section 3.6); and

- definitions and explanations/arguments that involve a variety of forms of reasoning: deductive, inductive and model based, direct and conditional.

The disciplinary literacy complexities for physics involve not only the development of disciplinary discernment in regard to recognizing and interpreting a variety of features of representations but also being able to express the logic of these semiotic resources in the way they relate to phenomena. Students need to recognize the formal relations between force diagrams and Newton's laws, for instance, and be able to recognize how to use these conventions to distil the key elements of situations, which allows the appropriate force diagrams to be constructed. Students need to recognize 
and apply the mathematical and symbolic representational resources represented by circuit diagrams and to develop a facility in using these to distil the key arrangements of more complex circuits. In the case studies that we now present of working with teachers to focus on inducting students into mastering key multimodal semiotic resources of four topics, we attend not only to unpacking the formal semiotic forms but also to the logics underpinning these representational forms and their relation to practical problem-solving.

\subsection{Case studies of multimodal disciplinary literacy practices}

The M3S project involved working with groups of physics teachers to enact multimodal disciplinary literacy principles in a variety of topics. The experience is described through four case studies, dealing respectively with electric circuits, electric motor operation, describing motion and reporting experimental investigations. The broad features of the approaches can be explicated in terms of the pedagogical models developed in Chapter 6. In these cases, we draw particularly on the collaborative work, teaching moves and reflections of two 'pilot teachers', Paulo and Tanya, who were instrumental in learning sequence design and trialling for their year 11 and year 10 classes.

\subsubsection{Modelling electric circuits}

This case study describes a teaching and learning sequence on the topic of electric circuits, co-designed with a year 11 physics teacher. The sequence involves exploration of multiple models including role plays and activities supporting the flexible interpretation of abstracted circuit diagrams to establish an understanding of circuit concepts. The pedagogy involved increased focus on student generation of ideas and a slowing of the pace of topic coverage for deeper consideration of concepts.

The sequence was designed to develop the multimodal literacies associated with solving circuit problems. In the sequence, students construct written, diagrammatic and mathematical representations which the teacher can then use as the basis of discussion and joint construction of an agreed model. There is an emphasis on teacher questioning, monitoring and providing feedback on students' literacy moves. Students engage with material exploration. The overview of the sequence is described in Table 8.1. Explicit literacy moves are indicated by **.

Figures 8.8 and 8.9 show student work on circuit concepts, the first exploring written text accounts of the operation of the circuit, the second from a worksheet where students interpret a simple circuit using different models. Each presents an account of current flow, and potentially opens up opportunities for clarification and refinement, for instance unpacking what 'compressed' and 'friction' refer to in the second account. 
Table 8.1 Outline of the electric circuits sequence

Stage/activity type
Activity 1
Orienting - opening the field

- Exploring students' ideas

- Stimulus activity
Activity details

- Give each pair of students a battery, a globe and ONE wire. The task is to light the globe.

- Once the light goes on, ask each student to produce a drawing showing how it works. Draw also what they think goes on in the wire.

- Compare the drawings and use these to establish a scientifically valid representation of what happens in a circuit.

- Once the task is completed and it is established that you need a complete circuit, introduce representations of circuits and teach the ideas of current and voltage directly.

[This activity probes the common alternative conception of a battery as a source of energy that flows directly to the globe when connected - the source consumer model. The activity emphasizes the need for a complete circuit.]

\section{Language focus, forms of representation}

Teacher introduces circuit representation on the board, working from student drawings and with discussion concerning the important elements (complete circuit, battery and globe, arrow representation of current), to extend to formalisms $\left({ }^{* *}\right.$ joint construction). Then use 'PowerPoint' (ppt)images of circuits and deconstruct $\left({ }^{* *}\right)$ the essential elements of different types of diagrams.

On the board, summarize, using text and a drawing, what is happening with the current to make the globe light. 
Activity 2

A long circuit

Introducing voltage, current, resistance, energy:

Orientation/Building the field -

- Establishing language (current, voltage... without defining explicitly - voltage is the 'strength' of a battery, and it changes around a circuit).

- Introduce notions of resistance, current...
Set up a circuit around the room, with long wires, a battery, globe (or globes) and switch. Discuss. What do you predict? Will the wires heat up? Will there be a delay in the globe lighting up? What is happening in the wires? In the globe? What's happening with the energy? What does the switch do?

The teacher introduces formal circuit diagrams and labels this.

Questions to be addressed as discussion starters:

- Why do you need a complete circuit?

- What does it look like inside the wire?

- What happens at the switch?

- What is the role of the battery?

- How do you imagine what goes on in a resistor or a light globe?

[These questions drive the discussion. They could be formally dealt with but can play a powerful role as discussion starters. Get students to talk in pairs to discuss and then run a class discussion summarized in joint note construction. Through this process, the ideas of voltage and current are established.]
Ideas about what's happening in the circuit are introduced as a qualitative inquiry to establish key questions that need exploration.

At each point in the discussion, the teacher works on the board and unpacks ${ }^{* *}$ deconstructs the meaning of the symbols - resistance, voltage, battery, globe...

From the student pairs' input and discussion, the teacher runs joint construction ** activities to generate a series of statements in answer to these core questions.

Generate questions that lead to the next activity. How should we think about (visualize) what happens in the circuit? How do we think about current, voltage? 
Extend the model to explore the following questions:

- How do we model a series circuit with two lights?

- How do we model a parallel circuit with two lights?

- What if one light has twice the resistance of the other?

The important thing with the role play is that students are continually challenged to predict and interpret what is happening.
Language focus, forms of representation

Talk and reflect after each question before moving on to two lights.

Give students time to think.

Cross-mode work as role play is interpreted through talk.

At each point, go back to text language and deconstruct ** what this language means in terms of the model. For example, draw a circuit with a change with numbers to represent what we just did in those terms.

Explain and problem-solve with simple circuits perhaps set up a different condition and ask a student, or each student, to re-interpret with a circuit diagram. Perhaps draw a circuit on the board and then add an element and challenge students to modify the role play to illustrate what happens.

Introduce the notion of voltage as 'energy ticket per charge' leading to 'joule/coulomb'.

Have a continuous back and forth between diagrams on the board/in their books and the role play $(* *$ deconstruction/scaffolding comprehension of the links between the various models and role play using images on the board or ppt images).

Through questioning, make apparent the limitations of the role play. 
Activity 4

Exploring models: Comparing/

evaluating, cross-mode recasting

Activity 5

Ways of representing series and parallel circuits and combinations:

Guided exploration of relations between voltage, current, energy and resistance in series and parallel circuits.
Each group is assigned two models (hydraulic, mechanical, rope, pizza delivery, gravity models)

For each model, they discuss and report on:

- What analogies are used for current and voltage?

- Which other circuit components are represented in the model?

- What does each model show well, and what does it not show about circuit ideas?

Groups present their findings and ideas using text and images to compare. The teacher runs a class discussion using these ideas to focus on issues like:

- Does the model show a complete circuit?

- Could a switch be illustrated using this model?

- What are the strengths of the different models?

- Can any one model give a complete picture?

This can be done in a variety of ways using combinations of exercises and lab activities.
The teacher refers back to the links between the role play and circuit diagram to model this task so that students understand that each model has particular strengths and gaps in what it can explain ( ${ }^{* *}$ cross-mode recasting, comparing/ evaluating, scaffolding comprehension, relating to accepted scientific representation).

The key aspect of these analogies/models is that they have a particular, metaphorical way of representing the distinction between energy (pizzas, height...) and material flow (riders, water...)

These models are at different levels of abstraction, from concrete (pizza) to abstract. Some of the models have distracting elements e.g. the pizza shop in the pizza delivery model. Discuss the core elements of each model.

Establish a standard way of representing circuits. Students explore ways of visualizing/analyzing circuit resistance in terms of combinations of series and parallel resistance combinations.

A series of activities follows where students explore actual circuits, are challenged to represent their findings, use digital simulations to explore different circuit features and construct and share puzzle circuits. 
164 Multimodal disciplinary literacy in physics

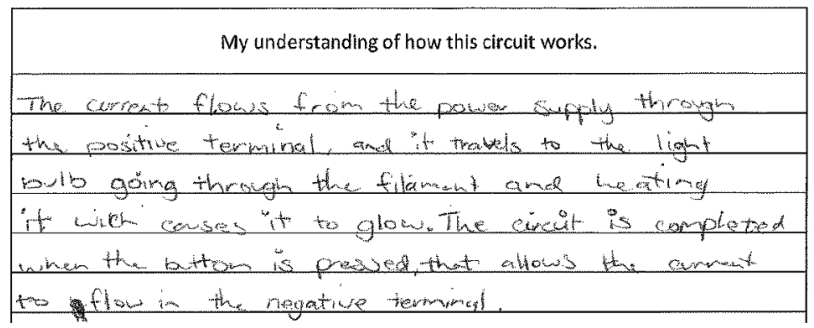

(a)

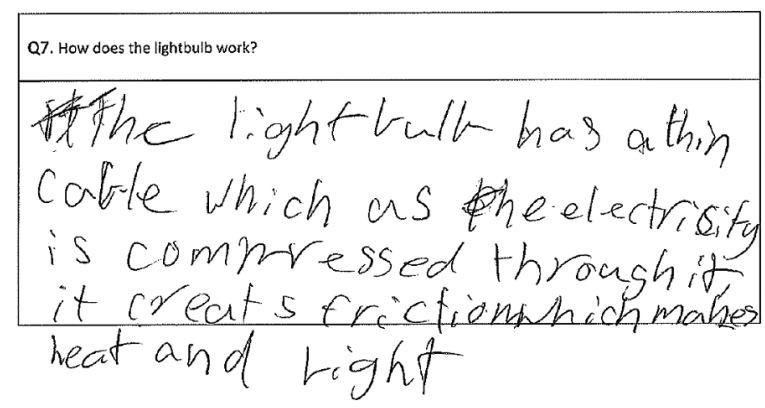

(b)

Figure 8.8 (a, b) Examples of student-written text where they express their ideas about features of circuits.

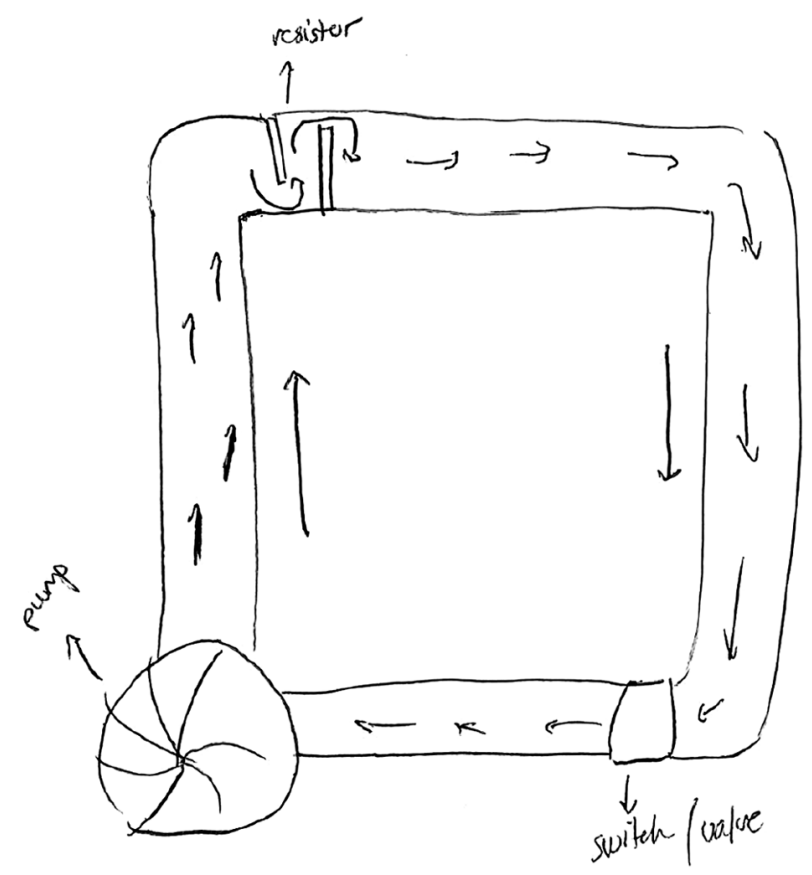

Figure 8.9 A student's interpretation of a simple circuit using a hydraulic model. 
Another teacher, Tanya, working together with another colleague to explore these role plays (Activity 3 in the sequence) and models (Activity 4 ) of electric circuits, expressed her view on the modelling approach in a presentation given to other teachers:

Critiquing the effectiveness of circuit models in supporting transduction processes across representational modes:

- Having just constructed and critiqued their own globe circuit prepared students to enter this task more completely.

- Students spoke with confidence; they found the task fun. They deconstructed the diagrams really thoroughly. They responded to the analogies embedded in the diagrams. The models bridged the gap between the visible world and the subatomic level.

- Students could easily modify the circuits to add a switch in the form of a tap, a gate or a traffic light. They had the background knowledge of how gravity, transport or water pressure worked, which made this more accessible.

On the role plays of different circuits involving tickets or vouchers for energy exchange (Activity 3), Tanya talks of students' growing confidence and of the ongoing value of establishment of these models to monitor and negotiate students' conceptions:

- Intervention exposes students' gaps in their knowledge. For example, students can't account for the transfer of energy. When I asked what the difference was between students with and without a Post-it note either side of the globe, they weren't able to explain.

- By the second and third cycles (circuits) students were responding much more quickly to teacher probe questions.

- Throughout the topic of electric circuits, students referred to the role play (they initiated references). Even weeks later, students were intrigued by the problems of representing very complex circuits through the role play.

- I could initiate reference to the role play throughout the topic to get students on track/connected to content. I could explain the workings of a complex circuit in terms of an adjustment to one of the role-play circuits, such as an extra globe in series with the parallel circuit.

Tanya referred to the opportunities these modelling activities opened up for monitoring students' ideas and orchestrating feedback

New misconceptions came up all the time, providing opportunity to address them

- S1: Do electrons lose all of their charge?

- S2: No, they use most of it in the globe. 
Formative assessment opportunities abounded. Typical of first round (incorrect expressions):

- energy is lost in the globe

- voltage is given up

- voltage is lost in the globe

Whereas third round was more like,

- electrons transfer energy, which is transformed into heat and light.

Tanya explained the effect of working in the M3S project on her practice:

- I have paid a great deal more attention to students' ability to represent their knowledge visually. I've given them more opportunities to critique other people's formal and informal visual representations.

- I am building students' mastery of physics language at all points in the teaching and learning process, not just at summative assessment.

In this account by Tanya of her experience, we can see the benefits of an explicit focus on models and unpacking through these the meanings underpinning circuit concepts of current, voltage, energy and charge. Students were able to import understandings from gravity, and fluid flow, to explicate these circuit ideas. The models 'bridged the gap' between the visible (macro) and sub-micro world of charged particles, a case of transduction across modes (Kress, 2010; Volkwyn et al., 2020). We will see in the next vignette the way Paulo orchestrated his board work to bridge the gap between macro, micro and symbolic representations of circuit concepts related to resistance. The other thing to note in Tanya's account was the way the focus on representational work allowed her to engage with student ideas, provide feedback, and lead them to more sophisticated language and conceptions. Multimodal languages, to her, achieved new significance for conceptualizing learning, and as a pedagogical focus.

In this next vignette, we describe the way that Paulo established, through carefully framed board work and demonstration, the formal expression for the sum of resistors in series. We describe one small part here, of a more extended analysis of the longer episode (Tytler, Pham \& Unsworth, in press). The argument involves orchestrating transduction across visual and symbolic modes, written text and analogic modelling. In the sequence, Paulo utilizes a whiteboard, PowerPoint slide, a demonstration and verbal and gestural linking of images.

In the sequence leading up to the particular transduction moves, we will focus on how Paulo does the following:

1. Uses talk and gesture to point to symbolic text and circuit images to describe how the current is the same along the series circuit and will only flow if the switch is closed. His gestures point out locations on the circuit, represent 'gaps' across the switch, and current movement (Figure 8.10a)

2. Points to a text reference 'total potential difference' and underlines the text on the board (Figure 8.11). He then establishes the meaning of 

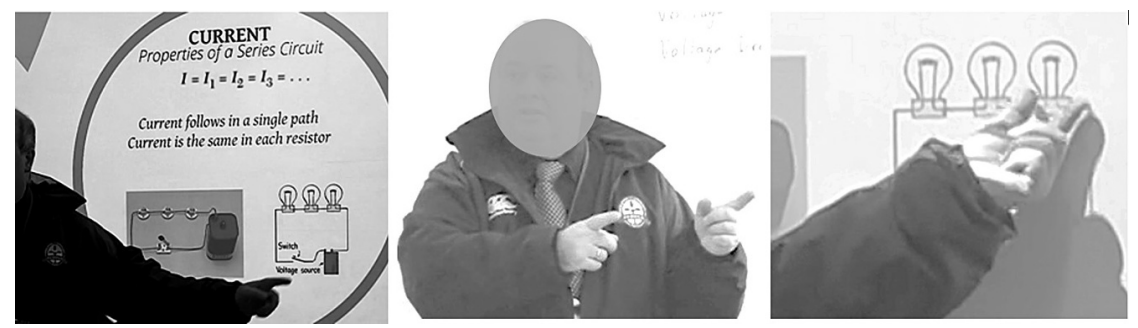

Figure 8.10 (a) The switch is open. There's a break in the path. (b) Paulo indicates spatially the separate voltage drops across three lamps. (c) Paulo indicates with a gesture the voltage drop across the lamp, between two points.

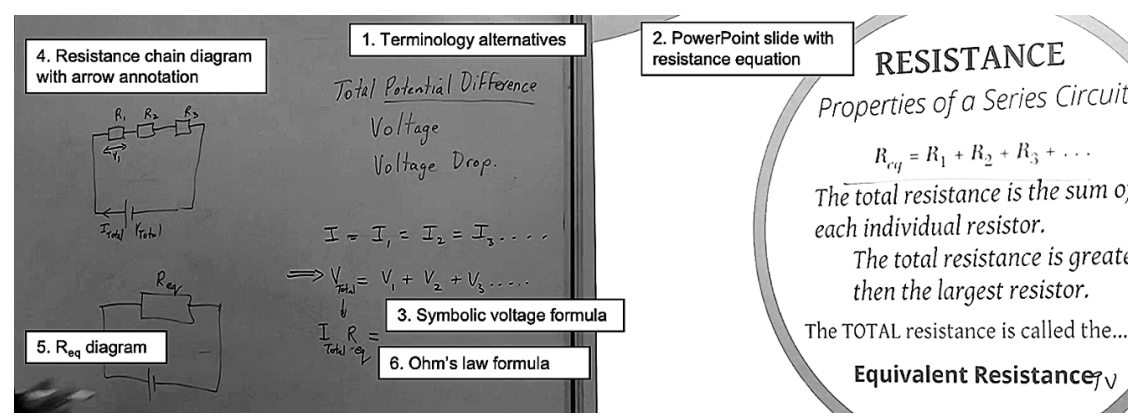

Figure 8.11 Paulo's board work in conjunction with text on PowerPoint. The representations include ( 1 ) the terminology relating to the potential difference, (2) the PowerPoint slide of textbook summary, (3) the formula for successive voltage drops across the resistors, (4) a circuit diagram showing resistor arrangement with resistance value annotations, (5) an equivalent circuit clarifying the meaning of $\mathrm{R}_{\mathrm{eq}}$ and (6) the beginnings of a recasting of the voltage relations using Ohm's law.

voltage drop by dropping a pen and linking gravitational and electrical potential energy drop using gesture to represent the movement of electrons across the resistors, analogous to the pen drop.

3. Focussing now on the voltage relations across the three lamps, he writes the formula ' $\mathrm{V}=\mathrm{V} 1+\mathrm{V} 2+\mathrm{V} 3+\ldots$ ' and then represents it in a circuit diagram to visually interpret what this means spatially (using spatial /pictorial gesture).

'Each resistor only gets a portion of total voltage. It is a portion of total voltage. That is what Thomas said before'. (The concept here is linked to text on the ppt, teacher's verbal language and student's previous talk.) Here Paulo uses a gesture with his two hands to represent spatially the carving of the voltage spatially across the three lamps (see Figure 8.10b).

4. Establishes that for the $9 \mathrm{~V}$ battery, there will be a drop of $3 \mathrm{~V}$ across each lamp 'Go back to the circuit diagram, this one has three lamps. This battery here has got $9 V$ and we got three lamps. Each lamp gets a portion of voltage $(3 \mathrm{~V})^{\prime}$ and indicates spatially the voltage drop across one lamp using a gesture (Figure $8.10 \mathrm{c}$ ). He then draws in a voltmeter to emphasize that voltage is across a lamp. 
To recap this process of establishing the voltage relations across the lamps, we can see that what Paulo has done is interpret for students the meaning of the ' + ' in the equation interpreted spatially as a successive drop across each lamp that can be added to sum to the total. Implicit in the gesture is the distinction, often confused by students, between current which flows through a circuit and voltage which is understood as being across a circuit element. These are spatial concepts that are implied in textbook accounts, often appresented, and underpin the nature of the transduction process by which symbolic and visual and material representations are coordinated.

Following the establishment of these voltage relations, Paulo continues his analysis to establish the resistance of the three lamps in the circuit, which involves coordinating across the visual, symbolic and written modes. $\mathrm{He}$ does this using a gesture that links the different elements of the argument, together with talk.

In the full analysis (Tytler, Pham \& Unsworth, under development), we argue that the coordination of these different representations requires transduction across modes that involve reinterpreting the symbolic expressions of the formulae to add a dimensionality to the entities involved (e.g. the interpretation of the ' + ' sign in the equation as representing successive voltage drops along the line of resistors or the ' $\mathrm{V}$ ' as referring to an energy difference 'across' a circuit element as a 'gap'). This transduction process often involves analogy, such as with Paulo's dropping of the pen, and emphasizing the equivalence of lifting it to the battery providing energy. This alignment across the different modal representations (achieved by Paulo through talk and gesture) needs to be understood in ways that enable flexibility in problem-solving. Achieving multimodal literacy in relation to circuit electricity involves learning to negotiate transductions across symbolic, sub-micro, visual, graphic and written textual modes. We argue, through this analysis of Paulo's presentation, that this 'disciplinary discernment' (Eriksson, 2019; Eriksson, Linder, Airey \& Redfors, 2014) (a) involves more than being able to recognize elements of any particular representation, (b) involves the capacity to relate particular features of these different modal representations and (c) can involve subtleties in temporal/spatial/symbolic relations and/or the importation of analogous systems that are difficult to duplicate on the page of a textbook. The teacher's task in this case is to help students navigate these links, using gestural and material supports to help 'stitch' the representations together in disciplinary recognizable ways. Paulo reported how his experience with M3S had alerted him to the need to approach concepts more carefully and slowly, to go deeper into supporting understandings. In this vignette, we have seen that the creative, flexible processes displayed by a teacher attuned to language can support students in these disciplinary transductive processes.

Following the introduction of circuit concepts of voltage, current, energy and resistance, the sequence aimed to build student flexibility in analyzing circuits with combinations of resistors in parallel and series. Figure 8.12 


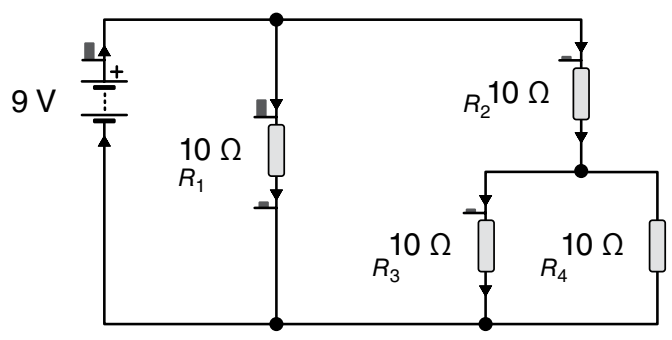

Figure 8.12 Worksheet designed to help students analyze resistance combinations.

shows a worksheet designed by Paulo to build fluency with series and parallel circuit voltage, current and resistance. The task focusses on the logic of circuit analysis and involves transduction across image, text and mathematics.

- What is the first step you would take to calculate the equivalent resistance $R_{T}$ of this circuit? Explain why?

- Which section of the circuit has the most current flowing through it? (Do not calculate anything.)

- Highlight/shade the section.

- Explain how you decided this.

- If the section with device $R_{1}$ was cut, find the equivalent resistance of the circuit, $R_{T}$.

- With $R_{1}$ back in use, sketch a short circuit across $R_{4}$ and find the new equivalent resistance, $R_{T}$.

- With all sections of the circuit and devices intact, find the equivalent resistance, $R_{T}$, of this circuit.

\subsubsection{Joint construction of a causal explanation}

As pointed out in the review of literacy demands in senior school physics (Section 8.2), a variety of types of causal arguments are a part of the disciplinary discourse, and indeed assessed in the external examinations. In that case, of the photoelectric effect, we found students' competence in constructing such arguments was disappointingly low. The example given of a high-scoring student demonstrates the sophistication in framing an argument that is expected and even then demonstrates that the student omitted some key parts of the logic. In M3S, we have been working with teachers on approaches to text construction of this sort, to support students to develop their literacy skills. This has generally involved working with students at the individual, small-group and whole-class level to achieve an understanding of how such text can be constructed, often using a 'joint construction' and deconstruction approach.

Gary, one of the participating teachers, became interested in unpacking the form of a quality explanatory answer. In a lesson focussed on this, he 
listed the criteria for a 'good explanatory answer' to an examination question, including

- Use linking words such as cause;

- Follow a logical sequence of dot points (e.g. start with cause then follow with effects);

- Be precise and concise; and

- Include formulae.

In this lesson, he had already had students produce answers to a question concerning why an electric motor rotates. He projected on the board the following statements:

- The commutator is in contact with the carbon brushes and conducts current in the coil.

- The communator rotates with the coil.

- The gap in the commutator is an insulator.

- The forces reverse according to the grip rule.

- At 90 degrees, it reverses the current.

- The motor rotates continuously in the same direction.

The transcript excerpts that follow illustrate how he helped students understand how to construct a response to the question:

G: So we're going to look at the sample answer. And you also look at your answer to see which things you may need to improve. Okay, first point is using linking words such as cause. What do we see about this answer, Tim?

TIM: They don't have any linking words?

G: They don't have any linking words. You need to use the 'cause' - what causes what? Can someone remind us? Alice?

ALICE: The commutator causes the currents to change...the forces to reverse and...

G: Okay that's pretty good. The commutator causes the current to reverse, which causes the force to reverse, which causes what final thing though? Yes?

STUDENT: $[\ldots]$ continuum $[\ldots]$

G: Motion... is it just?... rotation. Let's try and be as precise as we can. Rotation, okay, cause is a problem. Make sure you've got a cause word in there. Some of you do, some of you don't.

G: So dot points just help you organize it. Some of you've written continuous sentences which is good but dot points are also helping you make sure you've got enough. And follow a logical sequence, have a look at the sequence here. Have a look at the sequence. Is it okay? Is it okay? Why? Which order is wrong? 
STUDENT: 'The gap in the commutator' shouldn't that be at the top? G: Yeah - that's one thing. True. It could be. Another one, Arnold? ARNOLD: Where it says, 'The forces reverse' should be above [...

G: Yeah it should be - this is in the wrong place. This comes first. It reverses the current first then it reverses the forces. So the logical sequence is important. Any other things? Anything else? Yes, what's the problem?

G: Concise means - yes, reasonably concise. Don't fool yourself it's easy. To make it concise it's quite difficult. But don't try and write too many words. This is probably the hardest point of all - just a thing - just don't try and write too much. Okay. Next point - include one or more formulas.... What's a relevant formula? $\mathrm{F}=\mathrm{nBIL}$. Okay, so the formula we need is F = nBIL. A formula that's a super-duper answer that's got everything. It's an answer that's worth a lot - the best possible answer.

Here, Gary focusses on causal relations between different temporal events and ensuring the explanation represents the correct order of events. There are comments about precision and dot pointing for clarity. He also corrects common errors students made and during other parts of this discussion corrects students' misunderstandings about force direction and type.

The creation of explanatory, argumentation text can include clarity of description of temporal sequences involving causal chains. Explaining how an electric motor works, for instance, involves the coordination of visual/ spatial diagrams and symbolic mathematical expressions, in a causally related temporal sequence. Next, we describe Gary's approach to working between whole-class and small-group discussion and demonstration to jointly construct an explanatory account of the operation of the electric motor. In the case, we note the movement between small-group and whole-class construction of text, in concert with a simulation of the motor's operation.

In this lesson, Gary has student groups write a description of the operation of the commutator in the electric motor. While they work, and throughout the lesson, he has an animated simulation of the electric motor, with force and current reversals, playing on the board. After students have submitted their explanations, Gary does the following:

- Reads each explanation out to ask if they are broadly correct.

- Begins, on the board, to construct an idealized answer.

- Reads various groups' responses and asks, for each point, what is the next stage of the explanatory chain.

- Asks for other groups' comments on each group's contribution and workshops the creation of a series of ordered statements on the board.

- Discusses and corrects any misconceptions, questions students, comments on and adds detail to descriptions as needed, often referring to the simulation.

- Points out any simplification he introduces, emphasizes causal language and exemplifies the use of diagrams. 
At the end of this sequence, Gary has constructed a set of stages on the board which represents a coherent answer. He asks groups to compare this to their original productions. In the sequence, we note the attention to identifying the sequence of causal events, the workshopping of explanatory language, the use of diagrams and appeal to a visual simulation, monitoring and engaging with students' conceptions and consistent involvement of students in discussing appropriate explanatory forms.

\subsubsection{Building graphical literacy in a kinematics topic}

Graphs of motion in physics are customarily introduced as abstracted mathematical forms and interpreted through idealized motions. In this study, students were supported to develop understandings of graphical form and function by constructing graphs of motion with the purpose of interpreting real data. Their literacy development was driven by an authentic purpose in ways that reflect the 'mangling' (Pickering, 1995, 2012) between material and personal agency as they generated data and constructed graphs to make sense of a variety of motions. The study demonstrates ways in which teachers can productively engage students in the creation and negotiation of representations to interpret material measures, to support deeper learning.

This learning sequence was collaboratively constructed by the M3S team and a teacher of year 10 physics, Tanya. The aim was to introduce students to the graphical and mathematical representations of displacement, velocity and acceleration-time graphs that are a feature of studies of mechanics in the senior school. In this topic, students typically experience difficulty distinguishing between and interrelating these three types of graphs and using them to interpret everyday motion contexts. The sequence aimed to build students' graphical literacy by engaging them in grappling with the challenge of representing motion that was experienced as embodied and constructing sequences of representations, including spatial diagrams, tables of position vs. time and velocity-time graphs that could be linked to the experienced nature of the motion. To this end, the sequence reversed the traditional introductory sequence starting with definitions of displacement and abstracted graphs of displacement vs. time and then leading through analysis to abstracted velocity-time graphs, thence to acceleration. In this case, we started with a challenge for students to walk at a constant pace and verify this by marking their position at regular time intervals, with the focus on velocity considered to be a more tangible construct to build the ideas upon.

Table 8.2 describes the first two activities in the sequence, making clear the language focus that has students generating data, and data representations, in ways that the teacher can monitor students' processes and ideas and provide guidance and feedback. This pedagogical approach is consistent with the Chapter 6 framework (Figure 6.5) in a number of respects; student construction of multimodal representations to make sense of material 
Table 8.2 The first two activities of a year 10 kinematics sequence, with a focus on the literacies of data and graphical representations

\begin{tabular}{|c|c|c|c|c|}
\hline $\begin{array}{l}\text { Stage (orienting, } \\
\text { building meaning, } \\
\text { consolidation, } \\
\text { extension) and } \\
\text { purpose }\end{array}$ & Activities & $\begin{array}{l}\text { Form }(s) \text { of } \\
\text { representation } \\
\text { (key representational } \\
\text { focus- coordination/ } \\
\text { translation- source } \\
\text { and target text) }\end{array}$ & Language focus & $\begin{array}{l}\text { Form }(s) \text { of student } \\
\text { participation }\end{array}$ \\
\hline $\begin{array}{l}\text { Orienting to } \\
\text { the idea of } \\
\text { representing } \\
\text { motion } \\
\text { through data } \\
\text { construction and } \\
\text { representation. } \\
\text { Students create } \\
\text { data and } \\
\text { generate data } \\
\text { displays, as well } \\
\text { as consider } \\
\text { the features of } \\
\text { and relation } \\
\text { between distance } \\
\text { and speed vs. } \\
\text { time graphs for } \\
\text { constant speed. } \\
\text { Resources include } \\
\text { formalized } \\
\text { displacement } \\
\text { and velocity-time } \\
\text { graphs. }\end{array}$ & $\begin{array}{l}\text { Activity 2: Students construct data representing constant } \\
\text { speed. } \\
\text { - Students work in groups of five to six. Students are } \\
\text { challenged to walk at a constant speed over } 8 \mathrm{~m} \text { in } \\
\text { 8s. After a couple of trials, one student is chosen } \\
\text { to walk the constant pace and members mark their } \\
\text { position at } 2 \mathrm{sintervals} \mathrm{using} \mathrm{chalk} \mathrm{or} \mathrm{putting} \mathrm{down} \\
\text { a pen or block. (Students are each allocated a point } \\
\text { in time: } 2 \mathrm{~s}, 4 \mathrm{~s}, 6 \mathrm{~s} \text { ) One student is charged with } \\
\text { entering measures of position in a table. } \\
\text { Groups are then challenged to repeat the exercise } \\
\text { at twice the speed, this time recording position at } \\
\text { each second. }\end{array}$ & $\begin{array}{l}\text { Spoken, written, verbal } \\
\text { Movement from } \\
\text { material data } \\
\text { to tabular } \\
\text { representation }\end{array}$ & $\begin{array}{l}\text { Students } \\
\text { imaginatively } \\
\text { construct } \\
\text { data tables } \\
\text { of position } \\
\text { vs. time - } \\
\text { representation } \\
\text { challenge } \\
\text { and teacher } \\
\text { guidance in } \\
\text { groups. }\end{array}$ & $\begin{array}{l}\text { Verbal discussion } \\
\text { accompanied by jointly } \\
\text { constructed board } \\
\text { work consisting of } \\
\text { textual statements and } \\
\text { annotated diagrams } \\
\text { of position-time } \\
\text { relations associated } \\
\text { with constant speed. } \\
\text { Student note taking. } \\
\text { Student collaborative } \\
\text { construction of } \\
\text { measures. Invention } \\
\text { of tabular displays. } \\
\text { Interpretation of how } \\
\text { difference in speed } \\
\text { relates to the data } \\
\text { sets. }\end{array}$ \\
\hline
\end{tabular}




\section{Multimodal disciplinary literacy in physics}

experience, the careful framing by the teacher concerning what should be attended to (position, time), student group negotiation and teacher feedback and joint construction, transduction across modes as students make sense of different representational forms (marks on the ground, tables of data, diagrams and verbal identification of patterns). Subsequent activities in the sequence were

- Construction of data displays that included speed-time and position-time graphs;

- Investigating the relation between these graphs and generalizing these (joint construction);

- Exploring and representing more complex walking motions, including written accounts, and challenges where groups devise and swap complex motion instructions;

- Establishment of formal conventions of tables and graphs (teacher led);

- Extending to accelerated motion using video of a ball rolling down a slope;

- A representational challenge investigating motion under free fall, with graphical interpretation;

- More complex motions using carts with digital tracking; and

- Final assessment challenge requiring students to coordinate conditions for motion with representational work.

The sequence was designed to build the literacies of graphical and mathematical representation of constant and accelerating motion, drawing at each point on material investigation, emphasizing the affordances of the representational forms and monitoring and providing feedback on students' group and individual productions and ideas. There were multiple opportunities for the teacher to support students' negotiation of transduction across visuo-spatial, graphical and symbolic modes. Tanya, in interview, was clear about how the approach differed from her normal practice:

The key thing was not presenting the theory first, as board work, and notes. We started with practical work every lesson...it made a huge difference. It completely flipped it.

She talked about the opportunity for monitoring:

When the students were out doing the prac I went around to talk to each group...asking probing questions. Back in class, I asked questions that drew out the thinking of different kids. I teased out the sort of information I wanted from particular students and

(targeted my questions)

On the emphasis on refinement of graphical literacy and engagement with written accounts, she said, 
I liked that we were doing (graphing) for a lot of the lessons. I felt like students got better at graphing using a little bit, often...learning about graphs in small chunks. (They) had many opportunities to improve their graphing...it needs to be like that.

The output I got from students was a lot more than they usually write in a lot of classes. It was really effective in engaging students. Getting them interested in learning.

On joint construction:

I asked the students to write explanations of what happened and draw pictures and we workshopped what was happening together. I shared good responses on the board and we came up with our own.... We did explanations together...workshopped on the board and we did graphs together. I asked the students to tell me what to draw, and explain why.

In presenting to other teachers on her experience of the sequence, she referred to 'fundamental misconceptions' of students regarding interpretation of $\mathrm{x}-\mathrm{t}$ and $\mathrm{v}-\mathrm{t}$ graphs.

As a result of the project, and language \& literacy PD, I now realize that the precision of students' language often represents the level of their understanding, and I can use their language to diagnose misconceptions. I also realize that when I address the accuracy of their use of terms, I'm teaching them how to speak and think like a Physicist.

Overall, I believe I gained time as a result of this intervention.

There was evidence from Tanya's experience that the infusion of the multimodal literacy pedagogy, with its underlying focus on material exploration, was effective in increasing student engagement with learning, built on their everyday experience to develop abstract concepts, and encouraged improved monitoring and feedback processes. We can see the logic of the approach through the notion of cumulative knowledge building through successive 'semantic waves' 'where knowledge is transformed between relatively decontextualized, condensed meanings and context-dependent, simplified meanings (Maton, 2013b, p. 8). In this sequence, graphical and mathematical literacies underpinning kinematics knowledge begin with establishing representational practices with high semantic gravity, contextualized within everyday experiences of motion, and move towards practices of high semantic density that represent abstracted, decontextualized knowledge. As part of the design, Tanya discovered the benefits of working closely with students' ideas and representations, building them through whole-class board work that included joint construction and drew on her insights from working closely with students to monitor and offer feedback in their group work generating representations of their practical activities. 


\subsection{Discussion}

The analyses of these case studies generate insights into (a) the diverse yet distinctive ways physics knowledge involves transduction between and coordination of multimodal representations across a range of genres, (b) the key features of pedagogies, aligned with the M3S principles (Chapter 6) that support student learning and (c) the challenges and payoffs for teachers in enacting these pedagogies in the prevailing senior school science environment.

The cases described in this chapter illustrate many of the principles outlined in Chapters 5 and 6 with regard to pedagogical models that are applicable to the senior years. In the textbook illustrations, we can discern the modal complexity of disciplinary discursive practices in physics at this level, involving transduction across semantically dense representations and written text, often dealing with entities that are hidden (sub-micro representations, often analogies, of electron flow) or abstract (field lines, voltage, velocity). The velocity-time graphs, the role plays of circuits and the gestural enactments of current or embodied experience of different speeds are all devices that serve to render these abstract constructs concrete. In physics, this concretization of the abstract seems to be a particularly strong feature of disciplinary language practices.

In the cases, we can see that disciplinary discernment involves more than simply the interpretation of elements of representations. It involves competence in negotiating transduction across modes, and this involves the alignment of elements of each in deliberative ways, linking across spatial, symbolic and temporal features in ways that are not intuitive. The interpretation of the ' + ' in the voltage equation as the successive voltage drops along a line of resistors, for instance, is implied but needed gestural support as the teacher conducted the argument about equivalent resistance. The spatial reading of resistance networks is what is needed for and supported by the exercise sheet following Paulo's presentation. This 'discernment' of the order of successive analyses of parallel and series resistance elements requires flexible coordination of voltage drops, current flow and equivalent resistors.

Similarly, a flexible reading and use of velocity-time graphs require the understanding of how the points on the graph relate to position-time relations which can be represented in tables but also relate to spatial displays, and in the case in this chapter to embodied understandings of how these relate to fast or slow, or accelerating walking. Again, this involves being able to work across modes and being able to align particular features of each - for instance, the abstract velocity value in the graphical space with the actual distance between points that act to freeze time in tracking the motion. The mastery of equations of motion is a further transductive challenge.

In Paulo's presentation followed by the resistance worksheet, we see an example of direct teaching being followed by exploratory interpretation. In Tanya's motion sequence, the order is reversed, with students' material experience framed and channelled (an example of affordance as productive constraint; Prain \& Tytler, 2012) by the tracking of position over time and 
then transformed into data tables and graphs in a process of representation construction/invention closely monitored and shaped by the teacher. We see in Tanya's comments her use of joint construction, of the evaluation and refinement of students' work, of the building of competence over time and particularly of the advantages of working with groups of students as they grappled with the task, to monitor their thinking, and provide feedback and support. She claimed that through this structured process, student learning was improved, compared to her normal practice of directed teaching.

We see the strength of this approach through the representational challenge to support a close monitoring/feedback and negotiation/consolidation process in the electric circuit models, and in the role play, where students' ideas are refined over time as they interpret and re-interpret current and voltage and energy relations in a circuit through these transductive/modelling processes. These cases also illustrate the movement between individual, group and whole-class activity and discussion, and the responsive role of the teachers in expressing their own disciplinary judgements in supporting students.

These case studies demonstrate the nature and learning advantage conferred by the multimodal disciplinary literacy pedagogies developed during the M3S project, represented by Figure 6.5, and the central place of multimodal discursive practices in learning and allowing monitoring and support of learning. They also show how the pedagogy, while having distinct principles underpinning it, and a broad temporal pattern of investigation/ challenge, negotiation, refinement and consolidation of discourse practices, can vary in the order in which these occur. Here, teacher judgement premised on an understanding of the language processes at stake is critical.

\subsubsection{Establishing a metalanguage}

In these cases, the teachers were actively shaping the disciplinary discourse involving transduction across modes and links to material exploration, both in their direct teaching moves and in negotiating, evaluating and consolidating student representational work. During the M3S project, these teachers became more aware of the way these discourses worked as fundamental to the shaping of learning and knowing. Gary, in his work with the electric motor, developed an explicit language to help students understand the construction of explanatory text involving causal processes. We raise the question of whether, beyond strategically exemplifying and shaping the multimodal transductive processes in Cases 1 and 3, providing Tanya and Paulo with a comparable language that allowed them to explicitly refer to the nature of the link between graphical values and the underpinning data tables and spatial arrangement of position over time, or the spatial interpretation of the voltage equation, would have more powerfully supported student learning. Elucidating the nature of such a (meta) language that could be used to support students' understanding of the affordances of these multiple, multimodal representations and how they interrelate and are used in solving problems is an ongoing project. 


\section{References}

Airey, J., \& Linder, C. (2009). A disciplinary discourse perspective on university science learning: Achieving fluency in a critical constellation of modes. Journal of Research in Science Teaching, 46, 27-49.

Bail, D., \& Moran, G. (2017). Heinemann physics 12 (4th ed.). Melbourne: Pearson.

Doran, Y. J. (2017). The discourse of physics: Building knowledge through language, mathematics and image. New York: Routledge.

Eriksson, U. (2019). Disciplinary discernment: Reading the sky in astronomy education. Physical Review Physics Education Research, 15(1), 010133.

Eriksson, U., Linder, C., Airey, J., \& Redfors, A. (2014). Introducing the anatomy of disciplinary discernment - an example for astronomy. European Journal of Science and Mathematics Education, 2(3), 167-182.

Hubber, P., \& Tytler, R. (2017). Enacting a representation construction approach to teaching and learning astronomy. In D. Treagust, R. Duit \& H. Fischer (Eds.), Multiple representations in physics education (pp. 139-161). London: Springer.

Kress, G. (2010). Multimodality: A social semiotic approach to contemporary communication. London: Routledge.

Linder, C. (2013). Disciplinary discourse, representation, and appresentation in the teaching and learning of science. European Journal of Science and Mathematics Education, 1(2), 43-49.

Martin, J. R., \& Rose, D. (2008). Procedures and procedural recounts. Genre relations: Mapping culture. London: Equinox.

Maton, K. (2013a). Knowledge and knowers: Towards a realist sociology of education. London: Routledge.

Maton, K. (2013b). Making semantic waves: A key to cumulative knowledgebuilding. Linguistics and Education, 24(1), 8-22.

Pickering, A. (1995). The mangle of practice: Time, agency, and science. Chicago: University of Chicago Press.

Pickering, A. (2012). The robustness of science and the dance of agency. In L. Soler, E. Trizio, T. Nickles \& W. Wimsatt (Eds.), Characterizing the robustness of science (pp. 317-327). Dordrecht: Springer.

Prain, V., \& Tytler, R. (2012). Learning through constructing representations in science: A framework of representational construction affordances. International Journal of Science Education, 34(17), 2751-2773.

Tang, K. S. (2016). The interplay of representations and patterns of classroom discourse in science teaching sequences. International Journal of Science Education, 38(13), 2069-2095, https://doi.org/10.1080/09500693.2016.1218568

Tang, K. S., C. Delgado, \& E. B. Moje (2014). An integrative framework for the analysis of multiple and multimodal representations for meaning-making in science education. Science Education, 98(2), 305-326. https://doi.org/10.1002/sce.21099

Tytler, R., Prain, V., \& Hubber, P. (2018). Representation construction as a core disciplinary literacy. In K-S. Tang \& K. Danielsson (Eds.), Global developments in literacy research for science education (pp. 301-317). Singapore: Springer.

Tytler, R., Pham, L., \& Unsworth, L. (in press). Teacher modeling of transduction processes in senior physics.

Volkwyn, T. S., Airey, J., Gregorcic, B., \& Linder, C. (2020). Developing representational competence: Linking real-world motion to physics concepts through graphs. Learning: Research and Practice, 6(1), 88-107. https://doi.org/10.1080/2373 5082.2020.1750670 


\section{Multimodal disciplinary literacy in the senior chemistry classroom}

\subsection{Introduction}

This chapter describes the disciplinary literacy demands of senior school chemistry together with approaches to teaching the subject through a literacy lens. The case studies presented examine the multimodal literacies involved in understanding chemistry at this level through the lens of the Johnstone triangle. The work of Johnstone (e.g. 1982, 1991, 2010) - that learning in chemistry requires integrations of representations at three different 'levels' (macroscopic, submicroscopic and symbolic) - has 'become paradigmatic in chemistry and science education' (Talanquer, 2011). 'Macroscopic' refers to the concrete or sensorially apprehended world around us, sometimes as the result of experimental activity. 'Submicroscopic' refers to the abstract particulate level of matter (e.g. atoms, molecules, ions, etc.). The focus of much chemistry over the last century or more has been to provide explanations of macroscopic phenomena in terms of submicroscopic ones. Symbolic levels of chemical concepts (e.g. symbols of elements, chemical formulae and equations, mathematical equations, graphical representations) are used by scientifically literate people to communicate about the phenomena at an abstract level. Whilst Johnstone's original observations were not restricted to chemistry, it has become accepted that

the nature of chemistry as a subject is complex because it involves two distinct levels of formal concepts that need to be related to each other and to observed phenomena, and it is communicated not only through specialised technical vocabulary but also in terms of a whole range of other symbolic forms of representation.

(Taber, 2013, p. 165)

Johnstone's original thinking has been the subject of many adaptations and reinterpretations (Taber, 2013; Talanquer, 2011). He originally talked about 'multilevel thought', commenting on learners being often presented with explanations that involve being asked to think about very different types of things at once, and so the terminology 'level' has come to be used. He illustrated this point by using a triangle diagram from geology, and so 
'chemist's triangle' has become familiar terminology. The spirit of Johnstone's insight is arguably more important than the terminology that has grown up around it. If we accept that the macroscopic is about what we see and interact with, then the meaning at that level is straightforward (at least at face value), but some clarification is needed about the submicroscopic and symbolic. The submicroscopic arrives out of the chemist's interest in providing explanations, in which 'we invoke atoms, molecules, ions, structures, isomers, polymers etc. to give us a mental picture by which to direct our thinking and rationalize the descriptive level' (Taber, 2013, p. 157, emphasis added). It is not a 'level' in the sense of being about a particular degree of magnification. At one moment, a chemist might be thinking of a lattice structure comprising of something akin to miniature billiard balls; at another, they might consider the cross-section of the cloud of electrons around a nucleus. Both are mental pictures that direct the chemist's thinking, both are 'abstract particulate' because it does not matter whether the entities are available for direct inspection via suitably powered apparatus or not, but they exist in the mind's eye and direct the chemist's thinking.

Taber (2013) emphasizes that 'symbolic' is fundamentally about 'representation and communication'. He stresses that there is a specialist language of the subject (e.g. 'solution', 'element', 'orbital') and also special forms of representation (e.g. chemical symbols, chemical equations, graphs and diagrams) all of which need to be used in conjunction with a written/ spoken language (e.g. English) to communicate the meanings of chemistry. 'Symbolic' is a broader concern than, say, the symbols of the elements, chemical equations or manipulation of the various mathematical equations of chemistry. There is indeed a particular symbolic language and corpus of mathematical equations which are distinctive to chemistry. Some (e.g. Devetak, Vogrinc, \& Glažar 2009) seem to reserve 'symbolic' to refer to those, but we use 'symbolic' to mean all the various sketches, equations, graphs, etc., that a chemist may use to convey their 'mental picture', their operating model(s). These representations will include both those which may be regarded as canonical to the discipline and those more idiosyncratic and individual.

A scientific understanding of chemical phenomena comprises an ability to flexibly transition amongst the levels of Johnstone's triangle (Devetak, Vogrinc \& Glažar, 2009), and perhaps Johnstone's key insight is that working simultaneously with the descriptive, explanatory and representational is a significant cognitive load and needs to be worked towards, not expected all at once. For instance, formulae of the mole (e.g. $n=m / M$ ) and of calculating concentration (e.g. $c_{1} V_{1}=c_{2} V_{2}$ ) are lexically dense representations which to the trained chemist are indexical to certain submicroscopic arrangements, but that is not the case for beginner chemists. Learner-chemists need to be shown (and themselves encouraged to produce) a variety of different representations that relate to the theory. Drawing on Lemke's work, we can say that each such representation provides a 'language', in particular modal form, to model chemical phenomena, with each mode having particular 
affordances which open up distinct meanings; it is in this process of 'transduction' (Kress, 2000; Volkwyn, Airey, Gregorcic \& Heijkenskjöld, 2019) across these different modes, and meanings, that students represent the ways of knowing and acquire disciplinary knowledge (Lemke, 1998, p. 7). This is consistent with Kozma and Russell's (2005) claim that draws attention to how learners coordinate deliberatively across modes in the chemistry reasoning process. The flexibility across different modal forms that is fundamental to learning parallels the flexible transition amongst the levels of the triangle.

In this chapter, the relationship between the multimodal literacy infused science pedagogy (MLISP) model and the chemist's triangle is explored. The cases described in this exploration cover two topics: (a) the literacies involved in calculating concentrations in solutions chemistry and (b) the topic of the mole, and the explicit links with the notions of chemical equivalence, relative molar mass, stoichiometric combinations and the Law of Multiple Proportions. Both of these topics are explored through the introduction of a bridging model that exposes the nature of transduction across the triangle. We also link the construction and transduction of representations across modes with Kozma and Russell's (2005) framework of representation competence, with levels rising from the depiction of visible phenomena, to invisible entities, through to transduction across representations in different modes. Kozma and Russell's research showed that representational competence was central to expert chemists' problem-solving. Therefore it is considered a key competence to focus on as the disciplinary literacy of chemistry is developed.

\subsection{Solution chemistry}

In this case, the Multiliteracies in Senior School Science M3S team worked with one chemistry teacher to develop year 11 students' competence in the topic of solutions in a sequence described by Pham (2020). A series of representational activities were taught, focussing on developing the disciplinary literacies associated particularly with transduction across the submicroscopic and symbolic domains of Johnstone's triangle. According to research in this topic (Bucat \& Mocerino, 2009; Calik, 2005; de Berg, 2012; Devetak, Vogrinc \& Glažar, 2009), students frequently misunderstand the relationships between concentration and volume of solution and quantity of solutes (number of moles) in the solution (Calik, 2005; de Berg, 2012). These misunderstandings relate to difficulties students have in coordinating the symbolic mathematical representations of concentration calculations with the submicroscopic models and macroscopic phenomena they must relate to (Bucat \& Mocerino, 2009; Devetak, Vogrinc \& Glažar, 2009). Specifically, students can struggle to visualize the meaning of the numerators and denominators and their relations in standard concentration formulae.

The teaching sequence was designed to strategically support students to engage in different modal representations of the chemical phenomena. The teaching sequence started with a practical experiment that prompted students to coordinate the macroscopic and submicroscopic levels. The second 
activity then supported the development of mathematical representations of the submicroscopic using a bridging device, the drawn Cross-and-Portion (CPO) Model (Pham, 2020). In the CPO model, one cross represents one mole unit and one box represents a litre volume unit, enabling students to separately visualize the amount of substance, and the volume, in their symbolic equation work.

\subsubsection{Activity 1: practical demonstration and exploration (dilution and concentration)}

In Activity l, students were given instructions to successively dilute $\mathrm{KMnO}_{4}$ stock solution in water so they end up with four different solutions of discernibly different colour concentrations. The teacher conducted a demonstration of the experimental procedure. Students were challenged to 'summarise their observations and understanding about what happens to the four solutions' (Activity 1.1). Students then were given a representational challenge to 'draw what happens to the solutions at submicroscopic level' with an imagination that they 'can see at atomic level and are able to see what happens inside the solution in the beakers' (Activity 1.2).

At the macroscopic level, when responding to Activity 1.1, the students drew pictures and used written texts to depict and explain the observable phenomena. The students' written language and pictorial accounts show the colour-concentration relationship through the change of colour gradient (from dark purple to pale purple) and the reduction of potassium permanganate concentration. For example, many students in the class represented their observation by drawing a set of four solutions that show the decrease of colour gradient (Figure 9.1a). In addition, students also used the written word to describe the between the colour change through dilution of $\mathrm{KMnO}_{4}$ and concentration conceived of at the submicroscopic level: '[T]he more water we add, the more dilute the solution becomes. The more dilute the solution is, the more transparent the solution becomes. The particles are more spread when we add more solvent because liquid is in motion' (Figure 9.1b).

Activity 1 provided students with a material exploration as a way of introducing the visual languages of submicroscopic chemistry (particle representations) based on macroscopic level phenomena, with the $\mathrm{KMnO}_{4}$ colour as a visual marker that is modelled by the diagrams and texts noted earlier (Figure 9.1). At this point, in the MLISP model, the teacher is able to usefully intervene by unpacking and comparing students' representations and linking with scientific terms 'dilute/transparent', 'solvent'.

The systematic change of the $\mathrm{KMnO}_{4}$ colour was effective in engaging students in reasoning about the submicroscopic model of the solution dilution process. The change of colour could be seen as a trigger or indexical representation (Pham, 2020) that initiates students' conceptual thinking about the submicroscopic aspects of the dilution phenomena. It seems to assist student reasoning and facilitate flexibility of thinking between observation at the macroscopic level and explanation at the submicroscopic 

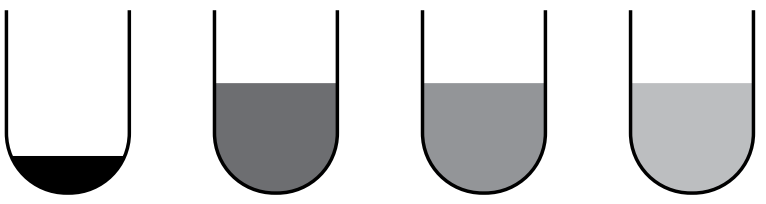

(a)

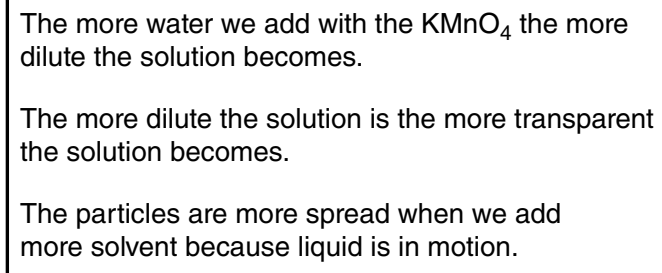

(b)

Figure 9.1 Examples of a students' drawings (a) and written texts (b) that depict the observational dilution phenomena.

level. For example, the students flexibly represented the change of colour through the dilution process using various representations such as lines/ squares to represent the beakers and circles/dots to illustrate the solute particles in diluted and concentrated solutions (Figure 9.2a). In addition, written language including scientific terminology was also used by students to further clarify their understandings of the dilution phenomena at the macroscopic, and submicroscopic levels. Figure 9.2 shows examples of two year 11 students' drawings that interpret their understandings of the observable phenomena and imagination of what they could see if they were able to view the potassium permanganate gradients at the submicroscopic level. The drawings indicate a decrease in the number of particles along the dilution steps.

The serial dilution process was illustrated in students' pictorial accounts and established through written language:

Solution one: 'Concentration is prominent in beaker as shown in dark purple. There are large number of particles per unit square in the solution'. Solution two and three: 'Taking a portion of solution into new beakers and diluting it in water caused particles to spread more throughout the solution. Taking a portion of the previous solutions lessened the number of particles per unit square as particles lessened'.

Solution four: 'Final solution consists of least number of particles spread throughout the solution. This is of the most dilute solution out of four solutions'. 


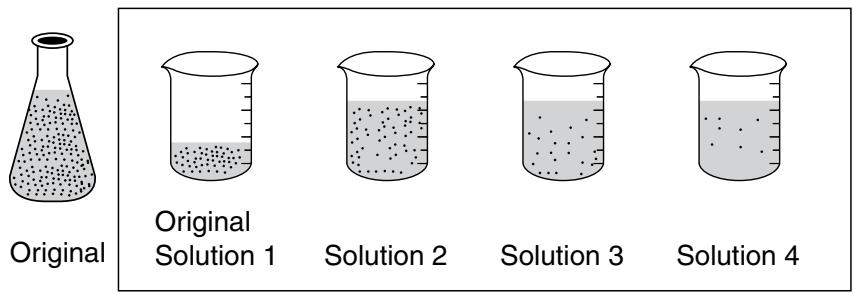

(a)

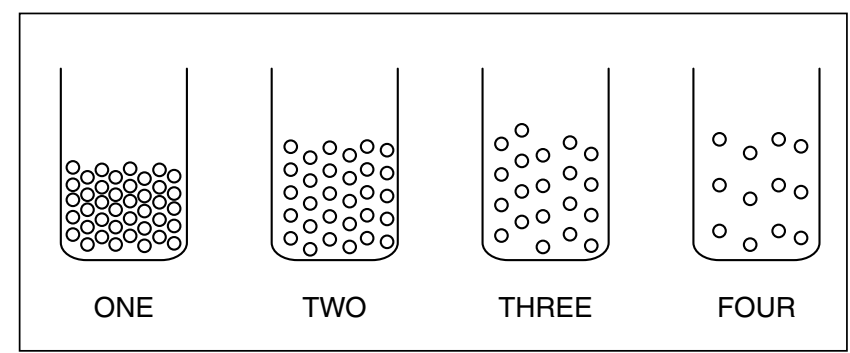

(b)

Figure 9.2 (a \& b) Examples of students' drawings that illustrate the submicroscopic scale of the dilution process.

Students used terminologies such as 'particles' and 'diluting', etc., to explain the mechanism of the serial dilution process at the molecular level. In this explanation, the solution is more diluted when more water is added. As a result, the number of particles in a given volume of the final solution is less compared to those of the previous solution. This justification is consistent with the different students' drawings as shown in Figures 9.2a and 9.2b.

The material exploration supported by the representational challenge thus supported students' multimodal literacy development in chemistry, in particular the ability to fluently link between the macroscopic and submicroscopic levels of the Johnstone triangle. This movement across levels is consistent with the early stages of Kozma and Russell's (2005) levels of representation competence. The beginning stage emphasizes learners' ability in generating 'representations of the phenomenon based only on its physical features, that is, the representation is an isomorphic, iconic depiction of the phenomenon at a point in time' (Kozma \& Russell, 2005, p. 133). The students in this study indeed shifted beyond the 'depiction' of the observable phenomena and represented the underlying chemical phenomenon using pictorial accounts (Figure 9.2). Students constructed representations 'based on unobserved, underlying entities or processes' (Kozma \& Russell, 2005, p. 133), with the 'language' of the submicroscopic representation including attention to concentration and even distribution of dots, with increased spacing with successive dilutions. This is indicative representational competence at Level 3 of Kozma and Russell's scheme. 
In relation to the MLISP principles, this first activity is a guided inquiry activity, with a focus on challenge and investigation. Our observation of classrooms was that the teacher should have focussed on negotiation and consensus/confirmation to a much greater extent. Moreover, the first activity provided the opportunity for teacher demonstration and guidance, and certainly, teachers welcome the window into students' thinking that the free construction of visual representations can bring. Negotiation and consensus are key to developing a metarepresentational competence - to have shared and understood representational systems in order to make possible a learning consolidation phase, which is the next activity.

\subsubsection{Activity 2: CPO model}

To achieve conceptual learning in chemistry, students need to link and coordinate representations. The challenge of teaching and learning is to find a way of linking these and making apparent the way meaning is coordinated across the Johnstone triad. Again, this can be seen as a language issue that involves making links between the 'grammars' of the different representations. For this topic, there is a need to find a mediating tool that enables 'amount of substance' (the mole) and volume to be appropriately visualized when using the mathematical expressions. This language issue requires the alignment of elements of each representational system. Details of students' transduction across the modal forms are presented next.

At the beginning of Activity 2, the teacher introduced the way the model works by unpacking how the crosses and portions related to the equation. For instance, the teacher explicitly explained the representational affordance of crosses and portions (one cross represents one mole, and one portion represents one litre). On the whiteboard, the teacher then demonstrated the manipulation of the CPO model to work out the concentration of the resulting Solution C, when $1 \mathrm{M}$ Solution A ( 1 cross in 1 portion) is mixed with $3 \mathrm{M}$ ( 3 crosses in 1 portion) Solution B (Figure 9.3).

The teacher's demonstration clarified the way that meaning is transferred and aligned across modes. Here, the elements of the visual model are explicitly aligned with the mathematical concentration expression featuring the amount of substance (crosses) as the numerator and volume (portions) as the denominator. This is not simply a matter of explicating the 'grammar' of one mode but rather drawing explicit attention to how the representations are related.

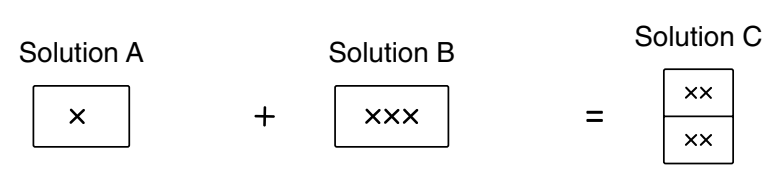

Figure 9.3 The CPO model that was used for the CPO demonstration activity. 
If we had a quantity of solution at a particular concentration and another solution at three times that concentration and then mixed them, then the resultant solution concentration would be at twice the first. With a colour as potent as $\mathrm{KMnO}_{4}$, it would be possible to observe this directly, using photometric techniques. The concentrations, before and after, are potentially directly observable, and they are related mathematically as a weighted average, but there is no implied explanation. The CPO model demonstrates how a particulate model can provide an explanation for what is observed and thus provides a 'bridge' between the macroscopic and symbolic/mathematical. In this way, the CPO model stimulated and supported students' quantitative reasoning. It has a numerical nature itself, in which the crosses and portions are able to be counted. This facilitates students' quantitative thinking and draws students' attention to the numbers of moles and volume. During the problem-solving process using the $\mathrm{CPO}$ model, students need to reason around these elements and the molar concentration. As such, the CPO model facilitates students' problem-solving by providing a supporting visualization to facilitate students to move from a submicroscopic to a symbolic/ mathematical representation.

Following this teacher presentation, students were provided with an example of their own to work on: a representational challenge. In responding to this challenge, the students used various forms of mathematical language such as written texts, algebraic ratios, fractions and equations to interpret their constructed CPO models. In this way, mathematics was successfully coordinated with the visual/drawn CPO models as another type of representation that supports students' problem-solving in learning the molar concentration concept. The figures that follow demonstrate the orchestration of the visual CPO model construction (Figure 9.4a) and mathematical languages to interpret abstract features of the $\mathrm{CPO}$ models. The logic of mathematics in the instance of establishing algebraic fractions is shown in Figure $9.4 b$.

As they coordinated across the visual CPO tool and mathematical languages, students were able to proceed to Level 4 of Kozma and Russell's representation competence framework, when they were able to make 'connections across two different representations or transform one representation to another based on the shared meaning of the different representations and their features' (Kozma \& Russell, 2005, p. 133). This level explicitly involves a transduction process.

The CPO model offers students visual diagrams that are more accessible than numbers and equations used in the conventional approach to learning the concentration concept. The students successfully utilized the CPO model as a quantitative/visual tool to allow material representation of the abstract concepts of mole and concentration. When learning the molar concepts in the traditional approach, students usually rely on only the mathematical equations that are at the symbolic levels of representations. The CPO model has been shown to enhance students' performance in problem-solving and establishment of abstract representations (e.g. numbers and mathematical 
Solution A

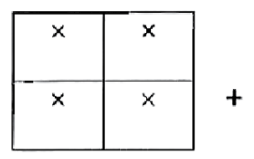

$4 L=1 M$

\section{Solution B}

\begin{tabular}{|l|l|}
\hline$x \times x$ & $\times \times \times$ \\
\hline$\times \times x$ & $\times \times x$ \\
\hline
\end{tabular}

$4 L=3 M$

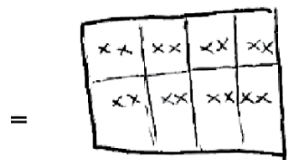

Solution C

$\frac{8 L}{16 m}=2 M$

$\times$ : Represent 1 mole in $1 \mathrm{~L}$

(a)

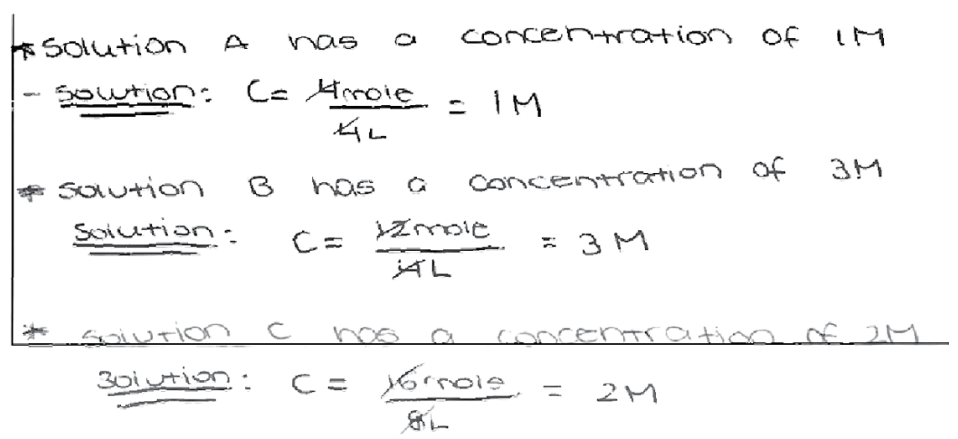

(b)

Figure 9.4 Examples of student's CPO model that represents Solution C as having 2 moles per litre (a) and mathematical fractions (b) that assist the CPO construction of Solution C $(2 \mathrm{~mol} / \mathrm{L})$.

equations) through its bridging functionality (the $\mathrm{CPO}$ analogue), in coordination with other representations (Pham, 2020), consistent with the qualitative observations noted in this case study.

The students' ability with constructing and coordinating representations was enriched through further elaborations of the CPO model. For example, students used the visual text of the CPO model to explicate the nature of Solution E (Figure 9.5), given Solutions D and F, using the following logic: '[L]ook at the final volume which is $12 \mathrm{~mL}$ and subtracted of the first one, getting 6 litters'. The 'expanded concentration' of $\mathrm{F}$ and $\mathrm{D}$ solutions were also 'looked at' by the student and 'subtracted F from D, getting 24 moles'. Then ' $I$ shared equally amongst 6 squares getting 4 cross per portion'.

As can be seen from the previous explanation, the mathematical equations (e.g. $12-6=6,36-12=24$ and $24 / 6=4$ ) were narratively formulated using visual texts. The $\mathrm{CPO}$ model essentially provided students with a visual tool to systematically and separately manipulate the volume and number of moles in the solution. It visually supported students in establishing symbolic 


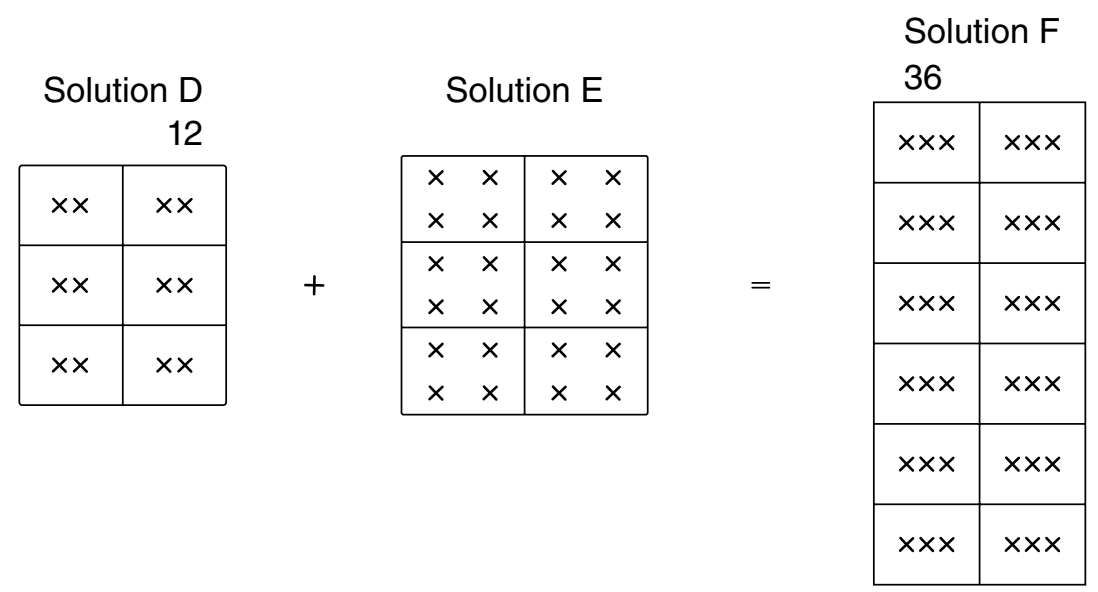

Figure 9.5 Examples of a student's CPO model that represents Solution E as having 4 moles per litre (A).

mathematical calculations to solve problems about the molar concentration concept. In other words, the CPO model serves as a bridge during students' meaning making/reasoning process that facilitates the transduction from submicroscopic to symbolic domains of the Johnstone triad.

\subsubsection{Multimodal representations as mediating tools for chemistry literacy}

As discussed earlier, the students were supported to solve molar concentration problems using a carefully designed semiotic resource that went beyond the conventional approach based simply on the application of mathematical formulae and manipulating numerical elements to calculate the number of moles or molar concentration. In a sense, the CPO model makes explicit the multimodal literacies involved in manipulating these formulae. The analysis of the student representation construction process reveals that students were able to read/interpret and coordinate macroscopic (chemical phenomena), submicroscopic (CPO model) and symbolic representations (symbolic mathematics) and use these to solve molar concentration problems.

The case illustrates two important aspects of the MLISP frame (as described in Chapter 6). First, is the clear illustration of the use of representations as mediating tools, in the operation of students' construction of a submicroscopic interpretation of concentration, and in the operation of the CPO model to bridge/transduct across Johnstone's levels. In this latter case, the semiotic load was mainly carried by the model, with the teacher involved in moving around the room to monitor students' work and provide advice. Second, is teacher planning, for the structure of the activity sequence specifically designed to support the development of multimodal disciplinary 
literacy interpreted through the Johnstone triangle. The teacher demonstration was strategically situated. Early in the teaching sequence, the students were provided with representational challenges that were undertaken independently. In the next stage of the sequence, the explication of representational affordances was part of the demonstration of the CPO model, and the model was aimed at developing metarepresentational competence to Level 2 of the Kozma and Russell (2005) framework.

\subsection{The mole}

The topic under consideration here is the teaching of the mole at year 10 level, and like the first topic considers students' competence in coordinating representations across Johnstone's domains as part of the multimodal disciplinary literacy involved in learning about the topic. The topic of 'the mole' has received considerable attention in the chemistry education literature (e.g. Fang et al., 2014, 2015, 2016; Furió et al., 2000, 2002; Giunta, 2015; Jensen, 2004; Padilla et al., 2008; Padilla \& Furió-Más, 2008; Pekdag \& Azizoglu, 2013; Staver \& Lumpe, 1993), but little explicit attention has been given to representational or explicitly multimodal approaches. That body of research has shown that teaching and learning the concept are challenging tasks for both teachers and students, and indeed that teachers may mean somewhat different things when they say they are teaching 'the mole'.

The mole, of course, is the SI unit for 'amount of substance', but curiously, this phrase is rarely used by teachers and virtually ignored by textbooks (Fang et al., 2015). Perhaps the essence of the difficulty with 'the mole' is that students are asked to engage with a unit which does not have any physical embodiment in terms of a measure of quantity unlike mass and volume (Ramful \& Narod, 2014). An understanding of 'chemical equivalence' and of the Law of Definite Proportions, at the macroscopic level, can point the way towards the need for a quantity such as the mole as part of an atomistic/particulate model of matter at the subatomic level. To that end, Fang, Hart and Clarke's (2016) discussion has been influential in our thinking. They emphasize the need for learners to have an understanding of what they call the 'number aspect' and the 'mass aspect' of the mole. The 'number aspect' is the mainstay of textbook presentations such as that used by M3S teachers (Commons et al., 2016), with the topic developed from a starting point of atomic mass, to relative mass, defining Avogadro's number, mole calculations and then molar mass. In terms of the 'mass aspect', the concept of the mole has also developed from an appreciation of 'chemical equivalence' and the relative masses involved at the macroscopic level, not in the definition of group size (i.e. Avogadro's number); De Bièvre and Peiser (1992) observe that before scientists started to use 'the mole' to describe an Avogadro's number of entities, most of chemistry would be able to develop, unconcerned with the exact magnitude of that number (p. 1538). (In the case that these two 'aspects' are unfamiliar to the reader, the two examples which follow are 
intended to elucidate the concepts, as well as illustrate multimodal representation practices in chemistry.)

Two teaching sequences are presented that can contribute to a teaching of 'the mole' that exemplifies the MLISP framework. The second of these, 'the mole is 6', was co-developed with M3S teachers as one part of an extended professional engagement with M3S teachers to help them understand the scope of what a unit of work on 'the mole' should encompass. Teaching of the mole is often strongly formula-based (i.e. learning to apply $n=m / M$ and its application to stoichiometry), and so, analogously to the molar concentration problem (as previously noted), students can struggle to visualize the meaning of the numerators and denominators. The teachers ultimately formed the view that, for the purpose of teaching the mole, a visual tool to allow the representation of 'chemical equivalence', consistency of group size, 'amount of substance' and stoichiometric combinations was necessary. 'The mole is 6' was directly inspired by the CPO model (Pham, 2020). That was, in a sense, the end-point of the journey with the teachers; along the way, we identified that a range of concepts, precursors to a sound understanding of the mole, were either presumed knowledge or typically glossed over. These included mass, counting-by-weighing, the Law of Definite Proportions and whether learners 'trust' it (cf. 'trusting the count' in mathematics learning, as described by Siemon et al., 2012). Most particularly, there is the idea of macroscopic 'chemical equivalence' central to the 'mass aspect' of the mole which can be represented by the same formula $(n=m / M)$ just as the 'number aspect' can. And so, we present a sequence which illuminates this idea of the 'mass aspect'.

\subsubsection{Demonstration and calculation of chemical equivalence}

The key idea here is that that most of chemistry would have been able to develop, unconcerned with the exact magnitude of the number of elementary entities in the group. Bucat (1984) takes such an approach to introduce the mole, the sequence of this is, briefly: the importance of counting-by-weighing; isotopes; relative atomic mass (strong development of the 'relative' notion and the arbitrariness of carbon-12); a mole as a counted-by-weighing quantity, only known relatively; exposition of 'amount of substance'; molar mass; and mole calculations.

The centrepiece of Bucat's presentation is a teacher demonstration: an electrolysis of copper, tin and lead is set up through serial wiring; in that way, it can be said that the quantity of electrons passing through each electrolytic cell of the experiment is the same. Following the parameters provided (including $0.4 \mathrm{~A}, 3,600 \mathrm{~s}$ ), one would expect that the copper electrode would lose approximately $0.47 \mathrm{~g}$, the tin electrode would lose approximately 0.87 and the lead electrode would lose approximately $1.55 \mathrm{~g}$. Through this, the point is made that these different substances are different in a range of their properties (e.g. colour, softness), but there is also a difference in 'chemical equivalence'. 
A sequence of calculations and provocations that follow the electrolysis example develops the ratio concept of equivalence. Students are asked to complete the following:

1. Calculate the ratios:

- mass of lead oxidized/mass of copper oxidized

- mass of lead oxidized/mass of tin oxidized

- mass of tin oxidized/mass of copper oxidized

The teacher then explains that with a variety of other experiments, chemists have been able to calculate the ratios of the average masses of all of the elements. And then the student is invited to complete the following:

2. Suppose that we make a scale of relative masses which lists the ratio of the average mass of an element to the average mass of copper:

- What is the relative average mass of tin on this scale?

- What is the relative average mass of lead on this scale?

3. Suppose that we make a scale of relative masses which lists the ratio of the average mass of an element to $1 / 100$ of the average mass of copper.

On this scale, the relative average mass of copper is 100 .

- What is the relative average mass of tin on this scale?

- What is the relative average mass of lead on this scale?

4. Suppose that we make a scale of relative masses which lists the ratio of the average mass of an element to $1 / 100$ of the average mass of tin.

- What is the relative average mass of tin on this scale?

- What is the relative average mass of copper on this scale?

- What is the relative average mass of lead on this scale?

The teacher then explains that a particular isotope of carbon has been chosen as the reference. On this scale, the mass of copper for reaction is 5.29 times greater than the carbon isotope. And if we then define the carbon isotope as having a value of 12 , then we have a calculation of relative atomic mass, where copper is 63.5

5. And so to calculate:

- If the average mass of oxygen is 1.33 times greater than the mass of carbon-12, what is the relative atomic mass of oxygen?

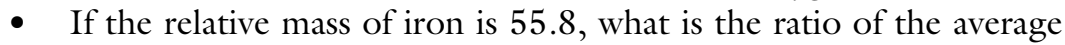
mass of iron to the mass of carbon-12?

This exercise supports students' understanding of the macroscopic - the reality of 'chemical equivalence' and the building up of a ratio concept between substances. In an important way, this example can be identified as comparing molar masses, where the term 'molar' once applied to bulk quantities of a substance (Furió et al., 2000), and the ratio can be named as the 'relative molar mass'. Students can develop a sense of confidence that 
there is a symbolic/mathematical way of representing what can be observed macroscopically. That is, the macroscopic is coordinated with the symbolic.

Ramful and Narod (2014, p. 25) note that the proportionality constructs are often more intricate than found elsewhere in the secondary curriculum; therefore, in relation to the MLISP principles, this activity allows for the expression of teacher demonstration and guidance. The teacher is able to intervene by unpacking and comparing students' approaches to the calculations and then explicitly explaining links with terms such as an 'element', 'average', 'relevant' and 'isotope'. As Taber (2013, p. 159) notes, even though macroscopic, these are abstract and often unfamiliar notions, and that 'conceptual demand is high even at the 'macroscopic' corner of the subject'. Even though this sequence of activities is, in Kozma and Russell's (2005, p. 133) terms, at the lowest level of representational competence, what this does is to make plain some foundational observations and terminology before moving to a more representationally intensive piece of work. Moreover, what this calls the inquiring mind (in the same fashion as a formula approach to concentrations) to is a submicroscopic model and a bridge representation between that model and the mathematical/symbolic to support students' work at higher levels of representational competence. That is the value of 'the mole is 6'.

\subsubsection{Activity: 'the mole is 6'}

This sequence was generated by M3S chemistry teachers, inspired by the CPO model. Whereas each $\mathrm{x}$ in the CPO model represented one mole, in this activity, the learner is invited to view each $\mathrm{x}$ with greater magnification - a next level of detail of how the natural world is comprised and to imagine that each cross represents six objects. Whereas for the CPO model, there was a need to find a mediating tool that enables 'amount of substance' and volume to be visualized, here the visualization challenge is that mass may vary quite differently to 'chemical equivalence', and the explanation is found not in a varying number of particles but in a fixed number of particles but quite varying masses of each type of particle. It is a sequence focussed on a visual representation at the submicroscopic level, emphasizing the relationship between chemical truisms that may also be represented symbolically through mathematical relationships. Those truisms include the invariant ratio combination of atoms in a molecule such as water and the macroscopic presentation of that as both the 'Law of Definite Proportions' and the 'Law of Constant Proportions'.

The teaching sequence commences with the teacher informing the class that ' 1 mole is six items', and providing students with sheets of $1 \mathrm{~mm}$ graph paper. Students are then provided with a sequence of representational challenges.

1. Draw 1 mole of hydrogen atoms.

As a free-form challenge, exactly how students respond is not particularly important, and initial ideas may be refined through subsequent challenges. But they may respond by drawing six dots or colouring in six squares, for instance in Figure 9.6 

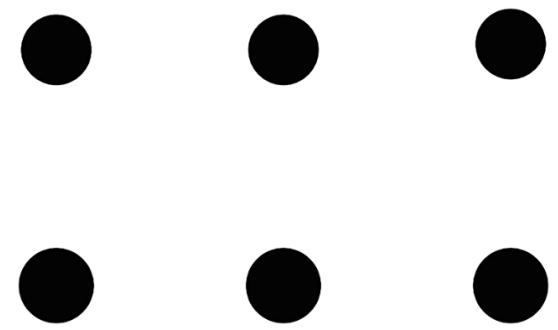

Figure 9.6 A possible initial drawing of 'the mole is 6'.

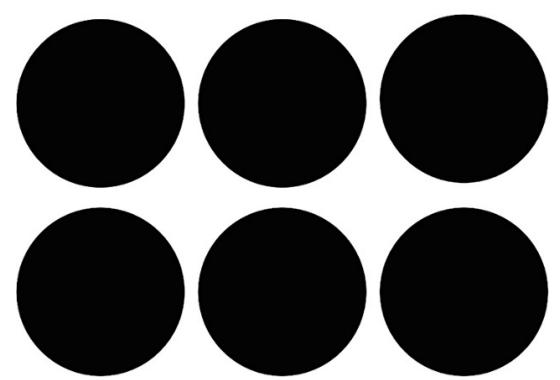

Figure 9.7 A possible second drawing of 'the mole is 6'.

2. It is then explained that oxygen atoms have a greater mass than hydrogen atoms, and students are asked to draw 1 mole of oxygen atoms. Again, as a free-form challenge, students may respond in different ways, but it should be linked to the prior representation, but finding some way to identify that oxygen atoms are different to hydrogen (e.g. using a different colour) and have greater mass (e.g. larger dots or colouring in a larger block of squares) - for instance, Figure 9.7. The class should discuss the various representations made and their strengths and weaknesses. This discussion is then extended through the next two challenges.

3. Lead atoms have a much greater mass than either hydrogen or oxygen draw half a mole of lead.

4. Providing students with a table such as the following, students then revise their representations and similarly represent several other atoms.

Note that it is important that relative values be provided rather than molar masses. Again, this is an open-ended approach, but the objective is for each student or group (possibly the whole class) to arrive at a 'standard approach' to be used from now on.

\begin{tabular}{lr}
\hline Oxygen & 8 \\
Lead & 103 \\
Sodium & 11 \\
Chlorine & 18 \\
Aluminium & 13 \\
Lithium & 3 \\
Hydrogen & 0.5 \\
\hline
\end{tabular}


5. Reminding students that the formula for water is $\mathrm{H}_{2} \mathrm{O}$, the challenge is to use the agreed representations (previously noted) to draw a mole of water.

What is important in students' work is that agreed-upon representations and relative sizes (as previously noted) are used, not the particular geometric shape.

6. From this representation,

a) how many moles of oxygen atoms are there in 1 mole of water?

b) how many moles of hydrogen atoms are there in 1 mole of water?

7. The challenges are now to draw half a mole of water and to inquire how many moles of oxygen and hydrogen atoms there would be, and similarly for other quantities such as 2 moles of water, $2^{1 / 2}$ moles of water and then other molecules such as hydrogen chloride.

8. From this sequence, the idea of chemical equivalence can be revisited: We can say 1 mole of hydrogen atoms reacts with 1 mole of chlorine atoms to produce 1 mole of hydrogen chloride. Therefore, these amounts of the substances are chemically equivalent. Learners are then challenged to write a similar statement about water and other molecules represented, such as, We can say 1 mole of oxygen atoms reacts with 2 moles of hydrogen atoms to produce 1 mole of water. Therefore, these amounts of the substances are chemically equivalent.

9. Complementarily, there is the idea that mass and chemical equivalence are not the same. Using a prompt such as the following, learners should provide an explanation using the representational form decided: Hydrogen will react with both oxygen and chlorine - but for the same mass of hydrogen, will the mass of oxygen it reacts with be the same or different to the mass of chlorine? Will the mass of water produced be the same or different to the mass of hydrogen chloride? If learners have used the squares on the graph paper to represent relative mass, then the explanation could be in terms of counting the squares.

\subsubsection{Multimodal representations as mediating tools for chemistry literacy: the mole}

The strengths of this representation are the explicit connections that are built with the notions of chemical equivalence (and Proust's Law of Multiple Proportions), relative molar mass, stoichiometric combination and Dalton's Law of Definite Proportions. In terms of the MLISP model, it is fundamentally a guided inquiry sequence with phases of challenge, investigation, negotiation and consensus/confirmation. It leads towards learning consolidation for simple stoichiometric and mole ratio calculations. The representation is a bridge between the submicroscopic model and the mathematical/symbolic representation; it is semiotic mediation, being a symbol system to which meaning is ascribed that allows the learner to internalize areas of experience not instantly apparent in the immediate observation. At the higher levels of schooling, concepts become more complex and densely expressed, the representational forms in the various modes becoming more technical and 
discipline specific. An example would be $n=m / M$; bridge representations are necessary to scaffold from common observation towards technical and discipline-specific representations.

To the M3S teachers, the strong advantage in using ' 6 ' was visual its similarity to Avogadro's number $\left(\mathrm{N}_{\mathrm{A}}=6.022 \times 10^{23}\right)$, the number of particles in the group we know as the mole, similar in concept to collective nouns such as 'dozen' or 'ream' but impossibly large to represent visually. So, when asked to work with ' 1 mole' of some substance, they might have a mental picture of what that might be like and so to serve as a kind of mental manipulable rather than working with entirely symbolic figurations. This is not unfamiliar within the chemistry teaching community - Lukins et al. (2006) defines a 'goop' as 8 and talks about a 'goopar mass' as an analogue to 'molar mass' - but the idea of using visual representations seems to be novel. The M3S teachers described the great deal of difficulty students seem to have with proportions and the lack of familiarity with terms such as 'dozen', which makes the notion of 'thinking in groups' quite challenging.

In deference to the actual definition of the mole (De Bièvre \& Peiser, 1992; Fang et al., 2015), it might be argued that an approach which commences by defining the group size and uses area to represent relative size implies to students that this branch of chemistry commenced by defining this and then counting individual atoms of known individual weight. It is not a perfect representation but valuable so long as the teacher is aware of its limitations. The extreme simplification of 'mole is 6 ' is presented as a useful way for students to get a foothold into the field, as the representational sequence allows for the development of ideas of relative mass, chemical equivalence and stoichiometric proportion.

In respect of representational competence (Kozma \& Russell, 2005, p. 133), working with 'the mole is 6' requires students to work at a relatively high level, where representations of the phenomenon based on both observed physical features and unobserved, underlying entities are generated. When it is used to help solve mole ratio or stoichiometric composition problems, then the learner has moved away from the particular structures and syntax of the bridge representation and is using a formal symbol system to represent underlying, non-observable entities and processes. This becomes a synthesis between multimodal disciplinary literacy and scientific practices which is one of the MLISP principles.

\subsection{Chemical literacy}

Teaching both 'concentration' and 'the mole' often reduces to the teaching of procedures. This means that students do not have the flexibility to deal with different challenges associated with the topic. In order to represent the ways of knowing and acquiring disciplinary knowledge, students need to be equipped with the transduction proficiency to 'orchestrate movement' (Lemke, 1998, p. 7) amongst the representational modes (in this case movement between and coordination of submicroscopic/visual and 
mathematical/symbolic modes). In the two cases described, the symbolic mathematical representation selects and abstracts elements of the macroscopic 'referent' representations (Peirce, 1931), with the model as an intermediary between these. Both representations facilitate the coordination of multiple representations across Johnstone's triad and can be seen as a 'chemistry literacy/transduction device'. In other words, we have presented models which support a shift of students' problem-solving skills. Use of such bridging models can support the development of students' 'chemistry literacy'.

To effectively solve problems in both fields of chemistry, students need to learn how to interpret and use the submicroscopic and symbolic modes of representations. This includes their competence in coordinating multiple representations across the domains of Johnstone's triad and different symbol systems within Johnstone's symbolic 'level'. Such representational competence could be seen as evidence of students achieving conceptual chemical literacy. Conceptual chemical literacy requires integrating and organizing information rather than rote learning knowledge or chemical procedures (Shwartz, Dori, Suat Celik \& Treagust, 2013). These teaching sequences support students to explain the mechanism underlying the practical phenomenon using multiple representations. Chemistry literacy, in this aspect, entails an understanding of the particulate nature of matter, laws and theories of chemistry (Barnea, Dori \& Hofstein, 2010).

We have previously established that metalanguage and developing metarepresentational competence is a principle of MLISP. In the case of chemistry, Johnstone's triangle is a principal metarepresentational resource. It provides a 'grammar' that is central to explaining chemical phenomena and problem-solving in chemistry that involves learning how to relate the domains in specific circumstances. Our examples illustrate the pedagogic value in searching for representations that bridge between submicroscopic models and canonical representations, and that the meanings associated with each domain/mode are distinct but enriched through the transduction process.

\section{References}

Barnea, N., Dori, Y. J., \& Hofstein, A. (2010). Development and implementation of inquiry- based and computerized-based laboratories: Reforming high school chemistry in Israel. Chemical Education Research and Practice, 11(3), 218-228.

Bucat, R. B. (1984). Elements of chemistry: Earth, air, fire and water. Canberra, Australia: Australian Academy of Science.

Bucat R., \& Mocerino M., (2009). Learning at the sub-micro level: Structural representations. In J. K. Gilbert \& D. F. Treagust (Eds.), Multiple representations in chemical education. The Netherlands: Springer.

Calik M. (2005). A cross-age study of different perspectives in solution chemistry from junior to senior high school. International Journal of Science and Mathematics Education, 3, 671-696. 
Commons, C., Commons, P., Clarke, W., Derry, L., Hogendoorn, B., Huddart, E., Lennard, L., O'Shea, P., Porter, M., Ross, B., Sanders, P., Sanders, R., Chan, D., Bruns, E., Ellis, V., Freer, E., \& Gooding, S. (2016). Heinemann chemistry 1 (5th ed.). Melbourne, Victoria: Pearson Australia.

de Berg, K. (2012). A study of first-year chemistry students' understanding of solution concentration at the tertiary level, Chemistry Education Research and Practice, 13(1), 8-16.

De Bièvre, P., \& Peiser, H. S. (1992). Atomic weight - the name, its history, definition, and units. Pure and Applied Chemistry, 64(10), 1535-1543.

Devetak, I., Vogrinc, J., \& Glažar, S. A. (2009). Assessing 16-year-old students' understanding of aqueous solution at submicroscopic level. Research in Science Education, 39(2), 157-179. https://doi.org/10.1007/s11165-007-9077-2

Fang, S.-C., Hart, C., \& Clarke, D. (2014). Unpacking the meaning of the mole concept for secondary school teachers and students. Journal of Chemical Education, 91(3), 351-356. https://doi.org/10.1021/ed400128x

Fang, S.-C., Hart, C., \& Clarke, D. (2015). Redefining the mole: The perspective of teaching and learning. Accreditation and Quality Assurance, 20(3), 215-217. https://doi.org/10.1007/s00769-014-1102-3

Fang, S.-C., Hart, C., \& Clarke, D. (2016). Identifying the critical components for a conceptual understanding of the mole in secondary science classrooms. Journal of Research in Science Teaching, 53(2), 181-214. https://doi.org/10.1002/tea.21298

Furió, C., Azcona, R., \& Guisasola, J. (2002). The learning and teaching of the concepts 'amount of substance' and 'mole': A review of the literature. Chemistry Education: Research and Practice in Europe, 3(3), 277-292. http://www.uoi.gr/ cerp/2002_October/pdf/02Furio.pdf

Furió, C., Azcona, R., Guisasola, J., \& Ratcliffe, M. (2000). Difficulties in teaching the concepts of 'amount of substance' and 'mole.' International Journal of Science Education, 22(12), 1285-1304. https://doi.org/10.1080/ 095006900750036262

Giunta, C. J. (2015). The mole and amount of substance in chemistry and education: Beyond official definitions. Journal of Chemical Education, 92(10), 1593-1597. https://doi.org/10.1021/ed5007376

Jensen, W. B. (2004). The origin of the mole concept. Journal of Chemical Education, 81(10), 1409. https://doi.org/10.1021/ed081pl409

Johnstone, A. H. (1982). Macro- and micro-chemistry. School Science Review, 64, 377-379.

Johnstone, A. H. (1991). Why is science difficult to learn? Things are seldom what they seem. Journal of Computer Assisted Learning, 7(2), 75-83.

Johnstone, A. H. (2010). You can't get there from here. Journal of Chemical Education, 87(1), 22-29.

Kozma, R., \& Russell, J. (2005). Students becoming chemists: Developing representational competence. In J. K. Gilbert (Ed.) Visualization in science education (pp. 121-145). Dordrecht, The Netherlands: Springer. https://doi.org/10.1007/ 1-4020-3613-2_8

Kress, G. (2000). Design and transformation: New theories of meaning. In B. Cope \& M. Kalantzis (Eds.), Multiliteracies: Literacy learning and the design of social futures (pp. 153-161). London: Routledge.

Lemke, Jay. (1998). Teaching all the languages of science: Words, symbols, images, and actions. https://doi.org/10.13140/2.1.4022.5608 
Lukins, N., Elvins, C., Lohmeyer, P., Ross, B., Sanders, R., \& Wilson, G. (2006). Heinemann chemistry 1 (4th ed.). Melbourne: Harcourt Education.

Padilla, K., \& Furió-Más, C. (2008). The importance of history and philosophy of science in correcting distorted views of 'amount of substance' and 'mole' concepts in chemistry teaching. Science and Education, 17(4), 403-424. https://doi. org/10.1007/s11191-007-9098-2

Padilla, K., Ponce-de-León, A. M., Rembado, F. M., \& Garritz, A. (2008). Undergraduate professors' pedagogical content knowledge: The case of 'amount of substance'. International Journal of Science Education, 30(10), 1389-1404. https://doi.org/10.1080/09500690802187033

Peirce, C. (1931). Logic as semiotic: The theory of signs. In B. Justus (Ed.), Philosophical writings of Peirce (1893-1910) (pp. 98-119). New York: Dover. Reprint 1955.

Pekdag, B., \& Azizoglu, N. (2013). Semantic mistakes and didactic difficulties in teaching the 'amount of substance' concept: A useful model. Chemistry Education: Research and Practice, 14(14), 117-129. https://doi.org/10.1039/c2rp20132a

Pham, L. (2020). Students constructing representations to problem-solve and learn in senior chemistry. [Unpublished doctoral dissertation]. Deakin University, Melbourne, Australia.

Ramful, A., \& Narod, F. B. (2014). Proportional reasoning in the learning of chemistry: Levels of complexity. Mathematics Education Research Journal, 26(1), 25-46. https://doi.org/10.1007/s13394-013-0110-7

Siemon, D., Bleckly, J., \& Neal, D. (2012). Working with the big ideas in number and the Australian curriculum: Mathematics. In M. Goos, B. Atweh, R. Jorgenson \& D. Siemon (Eds.), MERGA: Engaging the Australian national curriculum: Mathematics - perspectives from the field (pp. 19-46). Wahroonga, Australia: MERGA.

Shwartz, Y., Dori, Y. J., \& Treagust, D. F. (2013). How to outline objectives for chemistry education and how to assess them teaching chemistry. In I. Eilks \& A. Hofstein (Eds.), Teaching chemistry - A studybook (pp. 37-65). Rotterdam, The Netherlands: Sense.

Staver, J. R., \& Lumpe, A. T. (1993). A content analysis of the presentation of the mole concept in chemistry textbooks. Journal of Research in Science Teaching, 30(4), 321-337. https://doi.org/10.1002/tea.3660300402

Taber, K. S. (2013). Revisiting the chemistry triplet: Drawing upon the nature of chemical knowledge and the psychology of learning to inform chemistry education. Chemistry Education: Research and Practice, 14(2), 156-168. https://doi. org/10.1039/C3RP00012E

Talanquer, V. (2011). Macro, submicro, and symbolic: The many faces of the chemistry 'triplet'. International Journal of Science Education, 33(2), 179-195. https:// doi.org/10.1080/09500690903386435

Volkwyn, T. S., Airey, J., Gregorcic, B., \& Heijkenskjöld, F. (2019). Transduction and science learning: Multimodality in the physics laboratory. Designs for Learning, 11(1), 16-29. http://doi.org/10.16993/dfl.118 


\section{Design-based research and teacher professional learning about multimodal literacy}

\subsection{Introduction}

Developing multimodal disciplinary literacy infused pedagogy (MLISP) in senior high school science is a complex and challenging enterprise. Disciplinary contexts are challenging in their own right. Working within these contexts in the senior secondary years of schooling adds layers of complexity. Teachers work within crowded curricula and prepare students for constraining external assessments. Engaging teachers in collaborative projects with researchers is crucial to addressing such challenges in the senior years, but there are also challenges involved in the process of collaboration with researchers. This chapter discusses the experiences of teachers as they engaged with the design-based methodology that underpinned the Multiliteracies in Senior School Science (M3S) project, which gave rise to this book. Three case studies are presented of teachers who enthusiastically engaged with the project and made significant contributions to the development of theory and practice. One of these teachers worked in biology, another in chemistry and the third teacher in physics. Through these case studies of teachers' experiences, we show how design-based research can transform the theoretical perspectives and practices of teachers in the area of multimodal literacy. Reciprocally, the case studies demonstrate how the involvement of practitioners in design-based research can support the building of theory and practice relevant for multimodal disciplinary literacy approaches within science. Together, these perspectives indicate the potential of the MLISP framework, as outlined in Chapter 6 (Figure 6.5), to enhance science learning for all students in senior high school.

The aim of design-based research is to build theory and to improve practice within authentic education environments (Anderson \& Shattuck, 2012; Barab \& Squire, 2004; Collins et al., 2004; Edelson, 2002). Through partnering with senior high school teachers within four metropolitan high schools in a capital city of Australia, the researchers sought to enhance the pedagogies being used within senior high school science. As demonstrated in previous chapters, the senior years of high school involve complex literacies. As students move through schooling, the literacies that they encounter become more technical and specific in many disciplines (Christie, 2012; 
Rose \& Martin, 2012; Schleppegrell, 2004). The degree of technicality increases especially within science, which, in turn, affects the degree of complexity of the written texts and images that students need to navigate to be successful within schooling (Christie, 2012; Rose \& Martin, 2012). The development of a research partnership between science teachers working within the senior years and researchers working in social semiotics and in science education aimed to create pedagogies that focussed on specific literacies within science subjects across a range of modes. As well as transforming their own practices, it was hoped that the work of the teachers involved would provide insights into the 'grammars' of the multimodal texts that students encountered and the pedagogies that could be used to support student interpretation and creation of these texts.

The processes that are inherent in design-based research informed the way in which the researchers worked with the teachers in each of the four schools. Design-based research involves teachers and researchers partnering to produce iterative cycles of planning and implementation within specific education contexts (Anderson \& Shattuck, 2012; Lesh et al., 2008). Teachers and researchers work together to build an understanding of the context of the learning and to design interventions (Anderson \& Shattuck, 2012; Brown, 1992). The interventions that are designed are not imposed by the researchers; rather, researchers and practitioners collaborate to both select and create the interventions (Anderson \& Shattuck, 2012). The interventions that occur are based on professional and research literature, theory and practice, with both researchers and practitioners offering input from what they know and understand (Anderson \& Shattuck, 2012). Over time, a number of interventions occur, with data collection and analysis happening after each intervention (Collins et al., 2004; Edelson, 2002; Sandoval \& Bell, 2004). The data that are collected and analyzed after one intervention are used to refine and improve the next intervention (Anderson \& Shattuck, 2012; Collins et al., 2004).

Within the M3S project, specific researchers were allocated to the subdisciplines of biology, chemistry or physics. The senior high school teachers chose which subdiscipline and year level they would be involved in for the purposes of the project. While most teachers chose to be working within one of the subdisciplines, a few chose to work across two. Most of the teachers worked in more than one year level. For example, a teacher may have a year 11 and 12 class, so both classes were involved in the project. The researchers assigned to a specific subdiscipline then met with the teachers choosing to work in that subdiscipline regularly to plan an initial intervention, analyze data and then plan the next intervention. The meetings with the teachers were also year-level specific, so, for example, one meeting may be for year 10 physics teachers, while another meeting was for year 11 physics teachers. Some teachers attended more than one meeting during a particular part of the planning cycle because they were working on the project across more than one year level. As the project developed across three years, the group meetings continued to occur, but 
the researchers also met at times with individual teachers to follow up with their specific needs and interests.

This chapter provides an account of the kinds of interventions that occurred, as well as the ways in which teachers in the project responded. The three main case studies demonstrate how highly committed teachers negotiated the processes of design-based research to further develop their practice and to help the researchers develop theory. Through these case studies, insights can be gained into how design-based research may be used as effective professional learning for science teachers working within the senior years of schooling. The case studies also demonstrate how effective partnerships between researchers and practitioners can make significant contributions to theory and the development of illustrative practices.

\subsection{Case study 1: Riya - a senior high school biology teacher}

\subsubsection{Riya's initial participation and perspectives}

Riya works as a senior high school biology teacher within the school in the project that has the greatest degree of linguistic and cultural diversity. Another characteristic of the school is that most of the students come from low socio-economic backgrounds. When the project began, Riya had been working at the school for 12 years, and she understood that the linguistic capacities in English of the students within her classes often inhibited their success in senior high school biology. Riya's awareness of her learners' needs had resulted in her seeking training in disciplinary literacy programmes prior to her participation in the M3S project. The training that she undertook introduced her to the concepts and grammar of systemic functional linguistics (Halliday \& Matthiessen, 2004; Martin, 1992). As a result, Riya came to the M3S project having already acquired relevant theoretical and grammatical knowledge.

From the beginning of her participation in the M3S project, Riya demonstrated an understanding that disciplinary contexts involve the representation of knowledge in multiple ways. During an interview within the first year of the project, Riya explained how concepts within biology could be represented through written verbal text and images. She then translated this understanding into an example of classroom practice by explaining how students from English as an additional language/dialect (EALD) background could be supported by asking them to create 'their own visual' which then made it 'much easier for them to understand the concept'. Riya then went on to explain that, once the EALD students had created a visual representation, they could return to the written verbal text, and 'they find it a little bit more easier (sic) to understand and the ability to express it'.

Within the first year of the project, Riya also expressed the view that teachers of senior biology needed to spend more time 'explicitly scaffolding the text as well as the visuals with our students'. Riya thought that it was through this kind of explicit teaching that the students could understand 
how to represent concepts using appropriate grammatical conventions and also how to 'critique'. Riya explained '[i]t teaches students how to write and basically, I would say, critique as well so they learn how to write and critique'.

As a result of Riya's prior training in systemic functional linguistics, she felt confident to experiment with various ideas and practices in her classroom from the first year of the project. Within this first year, the researchers honoured the research-design process by providing extensive opportunities for the teachers to develop specific practices within a broad theoretical framework. The researchers had introduced the key concepts that representations within science are social and cultural constructions, which may afford or limit the representation of knowledge within a disciplinary context. The researchers also used elements from the genre teaching and learning cycle (see Chapter 6, Section 6.2.4) to suggest broadly how representations could be used in various ways in the classroom. The concept of using representations in a variety of modes to build the field knowledge of a topic had been shared, along with the ideas of deconstructing or jointly constructing a representation. At this point in the project, the researchers did not suggest any more specific teaching strategies, as they wanted to see what practices the teachers brought to the work.

Riya's depth of understanding in the first year of the project was not shared by all the biology teachers involved. In contrast, another biology teacher expressed the opinion in the first year

[m]y idea was that you guys would be providing us with different strategies that we could be explicitly having a go, like to teaching literacy to our students.... [The teachers] feel like you're - they're giving all the ideas and the planning etc. and it's not like we're getting best literacy practice.

This teacher struggled with the design-based research process and the concept of codesigning literacy pedagogies. She had entered the project believing that the researchers would provide predesigned literacy strategies that could be immediately implemented in the classroom.

The literacy knowledge and understanding that Riya brought to the project meant that she felt comfortable working with the researchers to codesign pedagogy from the beginning. As the project developed, Riya demonstrated the capacity to translate theoretical ideas into classroom practice and to draw on classroom experiences to help develop theory. One of the areas where Riya made a significant contribution involved the development of pedagogy for writing effective sequential explanations in the form of short-answer responses. Such short-answer responses are highly valued within the formal assessments required in senior high school biology. Students are often required to write succinct sequential explanations that provide a detailed understanding of how entities are involved in a sequence of activities.

Analysis of student work from the first year of the project by the researchers provided insights into the ways in which high-achieving students wrote 
sequential explanations within short-answer examination-style responses. Those who achieved the best results placed key entities within a sequence of processes. Noun groups were used to provide precise and succinct information about the key entities (e.g. complementary RNA nucleotides). A broad range of material processes (action verbs) clearly identified the processes with which the entities were involved (e.g. attaches, copies), while extensive use of circumstances, in the form of prepositional phrases, provided constant clarity about where and from where processes were happening (e.g. from the ribosome, in the cell). Each event within the sequence of activity was presented as a clause (e.g. RNA polymerase attaches to the promoter located on a gene in an anti-sense strand). Key entities were placed in theme position within the clause and often these key entities were repeated in theme position to avoid any ambiguity about the subject of the action being undertaken within the sequence of events. Key entities were also placed in theme position after being previously introduced as a new point.

\subsubsection{Joint construction of written sequential explanations}

Information about the high-achieving student work was shared with the biology teachers during a symposium and also during planning meetings for the project. Riya took the information and incorporated it into her pedagogy when teaching the topic on transcription and translation. The first move that she made within her classroom was to engage students in jointly constructing a brief sequential explanation about transcription. Joint construction involves the teacher guiding the students through the writing of a genre or part of a genre. The teacher invites the students to contribute to the text that is being jointly created (Christie, 2012; Rose \& Martin, 2012). The students called out contributions as Riya wrote the text on the whiteboard. As she wrote, Riya used different colours to represent the various language features. Key entities, in the form of nouns and noun groups, were presented in red, processes in green and circumstances in blue. Through the use of the different colours, Riya presented a transitivity analysis as the text was created. A picture of the jointly constructed text that Riya produced on the whiteboard is shown in Figure 10.1.

Riya then spoke with the class about some of the language patterns included within the sequential explanation. She pointed out that each event is presented in temporal order as a sequence of clauses. Key entities are in the form of noun groups, which may include a classifier, for providing meaning about type or a describer. A broad range of precise material processes is used to clearly depict the kinds of actions that key entities are involved in. Circumstances, in the form of prepositional phrases, are used frequently to provide information about where and from where activity is happening.

Riya then asked the students to consider what language is constantly appearing in theme position in the clause. To help the students with this task, Riya provided the students with a handout about theme and rheme in text, which is included here as Figure 10.2. 


\section{Design-based professional learning}

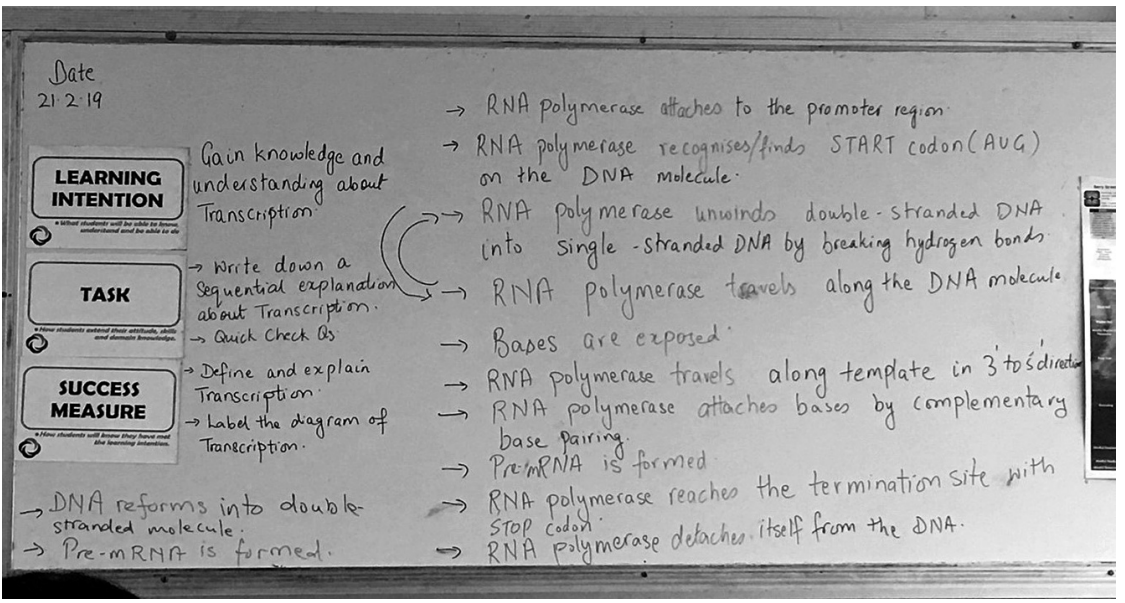

Figure 10.1 Joint construction on transcription that Riya completed with her class.

\section{Theme and Rheme}

Theme - Part of the clause that signals how the topic or information is developed. The theme includes everything up to, but not including, the process (action word). Also referred to as 'sentence opener'.

Rheme -Part of the clause that generally follows the Theme. Whatever is not Theme is called Rheme and is defined as the part of the clause in which theme is developed by providing new information.

\section{Example}

\begin{tabular}{|l|l|}
\hline Theme & Rheme (new information) \\
\hline Transcription & $\begin{array}{l}\text { is the process of copying the coded information } \\
\text { from DNA to mobile mRNA. }\end{array}$ \\
\hline Transcription & $\begin{array}{l}\text { Occurs in 3 stages: Initiation, Elongation and } \\
\text { Termination }\end{array}$ \\
\hline RNA polymerase & attaches to the promoter region. \\
\hline The promoter & $\begin{array}{l}\text { contains specific nucleotide sequences (TATA } \\
\text { box) that are recognised by the RNA } \\
\text { region }\end{array}$ \\
polymerase.
\end{tabular}

Figure 10.2 Information on theme and rheme that Riya provided to her class. 
Riya asked the students to use the definition of 'theme' provided to discuss in pairs what was often appearing in theme position in the text. The students were able to identify that key entities, such as 'RNA polymerase' were in theme position. The students also identified that the theme was often repeated. Riya drew on this observation to point out to the students that reference items, such as 'it' were often not included because this could lead to ambiguity in sequential explanations. She explained that scientists needed to be very precise in their writing, which meant that it was ok to repeat key entities in theme position.

Riya then spoke with the students about how circumstances were being used in the text. She pointed out how the circumstances gave all the additional information in the text. Riya asked the students to consider what kind of information was being given. During the discussion, Riya drew student attention to prepositional phrases that provided information about where events were happening (e.g. to the promoter region), from where they were happening (e.g. from the DNA) and how they were happening (e.g. by complementary base pairing).

Riya effectively applied information from the analysis of high-achieving student work to her pedagogy. Through the jointly constructed text, she modelled key language patterns that can be found within written sequential explanations. Explicit teaching occurred about the language features used to present ideas about key entities, the processes that they are involved in and the circumstances in which these processes are happening. Riya then connected ways in which meanings about ideas in the text were presented to the methods used to structure the sequential explanation and to provide cohesion. She modelled how the noun groups, which carry meaning about key entities, are placed in theme position and repeated throughout the text.

\subsubsection{Modelling of the use of relative pronouns in short-answer responses}

The next move that Riya made in her teaching involved her going beyond the information provided by the researcher. Riya analyzed her own students' work and noticed that her high-achieving students were using relative pronouns to add a clause to a main clause and thereby pack more detail into their written work. Riya initially provided her students with an example that modelled how two clauses could be combined through a relative pronoun to pack information into one sentence:

1. Secretory proteins are proteins.

2. Secretory proteins are exported out of the cell.

3. Secretory proteins are proteins that are exported out of a cell (combined using the relative pronoun 'that').

She explained how the word 'that' was working as a pronoun because it referred back to the entity of 'proteins'. Riya then provided her students with other examples of relative pronouns being used to add a relative clause within 
a sentence. She chose examples of relative pronouns that were common in the high-achieving student work. One example included the following:

Next, the food is pushed into the stomach, where it stays for about three to four hours.

With each example, the students were asked to consider what the pronoun referred back to and also how its use allowed for another clause, with additional information, to be added to the sentence.

Through this work, Riya contributed both theory and practice to the project. She highlighted the importance of relative pronouns within the work of high-achieving students and demonstrated how explicit teaching could be used to provide students with an understanding of the language feature. During planning meetings, Riya could effectively argue against some of the perspectives being offered by other biology teachers within the project. Often, discussions about incorporating explicit language teaching were punctuated by some individual teachers expressing concern about the crowded curriculum and the lack of time available for an explicit focus on language. Through examples, Riya modelled how a focus on language could be incorporated quickly into a lesson. Riya's approach also highlighted for the other teachers how explicit language teaching could be infused into pedagogy and lessons. Riya constantly demonstrated how she chose small elements about language to include within her teaching and learning. This language teaching was then tightly connected to other immediate student needs in the senior secondary years, such as the requirement to pack information into short-answer responses. Riya also consistently presented the opinion that the teaching of language supported concept development, and it was not separate from classroom presentations and discussion of topic-specific knowledge.

\subsubsection{Working with students across modes of representations}

Riya also made a significant contribution to the project when working with written and visual representations in the classroom. Four of the key concepts expressed to the teachers by the researchers, which came from the framework discussed in Chapter 6, were that students needed to be active participants in the construction of representations, they required the opportunity to move between constructing texts in various modes, they needed feedback on their representations and they required opportunities to critique representations. Riya worked with the researchers to incorporate all of these concepts into the work that she did on transcription with her year 12 class.

Near the beginning of the unit on protein synthesis, Riya asked her students to draw individually a diagram that represented the processes involved in transcription. The students had already covered the topic to some extent in year 11, and Riya was asking them to draw on prior knowledge to do this initial task. Riya then asked her students to set aside their individually created visual representations until a later stage in the unit. Riya then undertook 
other work with her class. The class jointly constructed a written sequential explanation on transcription and then compared their construction with written text on the topic from their textbook. At that point, the students were asked to add more information to their sequential explanations on transcription.

The next stage in the unit involved the students using their written sequential explanations to critique and reconstruct their initial visual representations of transcription. First, the students constantly moved from their written texts to the visual images that they had initially constructed to determine what steps they had left out of the initial images and what had not been represented accurately. They then created new visual representations that aimed to include all of the steps, as well as accurate representation of these steps As the students undertook this work individually, the teacher visited each student in turn, asked them about their new visual representations and provided feedback. The following is one example of the dialogue that occurred at this stage in the unit between the teacher and a student:

T: Just go to the diagram. (Teacher pointing at the student's second visual representation that they have started.) How is this one different to your - this one. (Teacher points to the first visual representation completed by the student.) How are you starting? Can you talk me through your diagram?

$S$ : What I'm starting is pretty much the same.

$\mathrm{T}$ : How? What are you trying to show me?

$\mathrm{S}$ : Well in the beginning I am just trying to show an overview of the cell and parts - whatever focussing on the DNA. (Student pointing to the second visual representation that they have started.)

$\mathrm{T}$ : Why the DNA?

$S$ : Because that is where the transcription takes place.

$\mathrm{T}$ : All right yes so the transcription takes place inside. (Teacher points to round circle student has drawn.) What is that?

S: That is part of a nucleus.

$\mathrm{T}$ : That is the nucleus. That's why you started with the nucleus and what's next? (Teacher points to the initial image produced by the student.) I can see that you started this one as well with the cell.

S: And so I was sort of trying to make it a bit more umm kind of clear about what is happening because it is kind of unclear about what is happening. So I am going to add a few more visual indicators as to what is happening and what is doing it.

$\mathrm{T}$ : What goes next then after this? (Teacher focusses attention on the second visual representation).

S: Well next I am going to do the same kind of thing to focus on the DNA and then show the attachment of the polymerase to the promoter and then do the rest of it.

T: And then try to label all the parts.

S: Yeah, yeah. 
Through the discussion, Riya focusses the student's attention on which meanings are the most important to represent for the topic of transcription. The student indicates initially that meanings about composition are key. He suggests that in both his first and second image, he was trying to present the cell and its parts. The student also indicates that foregrounding the DNA within the visual representation is important. The teacher affirms this response before asking the student to elaborate and explain why the DNA needed to be foregrounded in the representation. The student is then able to associate that part of the cell to the activity sequence of transcription. The teacher then asks the student to elaborate further by pointing to the circle surrounding the representation of DNA and asking what it is. When the student provides an answer that is not quite correct ('part of a nucleus'), the teacher redirects and clarifies ' $[t]$ hat is the nucleus'. As a result, the process of creating the images supports the student to clarify key understandings

The next move by the teacher invites the student to critique the first visual representation and to talk about how the second image will be different from the first. As a result, the student makes the observation that the first image presented composition, but not much activity. This observation helps him to clarify that his main goal in the second visual representation is to represent activity more, along with the key entities that are involved in the activity. The teacher then prompts the student to talk more about what activity he will represent, and the student is able to talk about how he will first 'show the attachment of the polymerase to the promoter'.

Through this kind of work in her classroom, Riya demonstrated how engaging students in critiquing their representations could promote thinking about what key meanings are being represented and how. During this exchange, the student recognized that the first visual representation presented meanings about composition, without really providing information about a sequence of activities. Through affirmation and elaboration, Riya was able to help the student to see what needed to be foregrounded in the second image if the representation of activity was the main purpose. Riya then supported the student to clarify what the next event in the activity sequence needed to be within the visual representation.

Involvement in the research-design process for this project enabled Riya to transform her own practices, as well as to provide insights into the grammars of the representations that students grappled with in senior secondary biology. Riya developed a range of practices through the project that helped her to support student interpretation and the creation of written and visual representations. Her teaching strategies included explicitness about the grammars of representations, as well as joint construction, independent construction, critique of representations, dialogic conversations with students, feedback and working between representations of different modes. Riya also contributed to knowledge about the representations that senior high school biology students need to interpret and create. She highlighted the importance of relative pronouns in short-answer responses and the need 
to foreground the nucleus and DNA within visual representations of transcription. By the end of the project, the research team was confident that multimodal disciplinary literacy practices were firmly embedded in Riya's pedagogy.

\subsection{Case study 2: Carmela - a senior high school chemistry teacher}

\subsubsection{Carmela's contribution to analyzing chemistry research posters}

Carmela is a senior high school chemistry teacher who worked closely with the researchers to analyze the linguistic requirements of research posters. Across the subjects of chemistry, biology and physics, senior high school students are required to complete research projects as a major summative assessment task. The value placed on research posters for assessment of learning in the senior school science years reflects the growing concern in science education with engaging students in disciplinary literacy practices, as we have discussed in previous sections. By participating in literacy practices of research investigation, students develop understandings of both scientific concepts and how scientific knowledge is constructed (Tytler, 2007). As discussed in Chapter 5, applied linguistic and rhetorical studies of expert research reports (Swales, 1990) have long been drawn on in tertiary science and literacy contexts to inform rubrics, templates and heuristics to support students to communicate research (Hyland, 2019). All science teachers had been provided with support materials based on this tradition by the state government curriculum authority, and the teachers involved in the M3S project and had been active to some extent in recontextualizing the general advice provided by curriculum authorities on structure and conventions to their own teaching and learning contexts.

Carmela recognized that many of the culturally and linguistically diverse students within her school had not had opportunities to engage with the literacies required to complete successfully the poster work in their senior years. She understood that assuming that students had the knowledge and understandings required to undertake this work could limit their opportunities to learn about the task and to succeed with it. Carmela's concerns about the complexity of the task, as well as the ways in which her students had struggled with the task in the past, resulted in her being a keen participant in the work of the research team dedicated to the research poster assessment task. This section thus focusses on Carmela's commitment to working with researchers in professional learning contexts to develop her own metalanguage and in creating valuable opportunities for one teacher to provide practical and grounded interpretation of metalanguage for fellow teachers.

Carmela, along with some other teachers working in the subject areas of chemistry, biology and physics, initially collaborated with the researchers to collect graded samples of high and lower graded student posters, as well as data related to the pedagogic practices the teachers had implemented to 
support their students' investigative writing. The teachers then met with one of the researchers to share their experiences and expertise related to this assessment task. During the initial discussions, the teachers, including Carmela, identified key challenges that the students had in relation to the success criteria for the task. They concurred that lower graded students were particularly challenged to

- Justify their study and its significance,

- Generalize findings from data,

- Reason from results to principles and

- Evaluate their experimental design.

The challenges identified by the teachers during initial conversations with the researcher highlight the rhetorical complexity of research writing. The level of complexity involved is also evident in the support materials provided to teachers by the state government curriculum authority. For example, in the section about the discussion part of the research poster, there are a number of processes described. To write an effective discussion, the students are required to engage in the three main functions of examine, explore and judge:

This section examines whether the data obtained supports the hypothesis, explores the implications of the findings and judges the potential limitations of the experimental design. It focuses on a question of understanding 'What is the meaning and/or the significance of my investigation results?'

(Victorian Curriculum and Assessment Authority (VCAA), 2017a)

Each of these functions is then further detailed with specific steps that the student needs to take.

As the teachers worked through the assessment task with the researcher, they noted that for some students, scaffolding, by breaking down sections into functions and steps, may be sufficient to focus their attention and encourage them to select linguistic resources from the repertoire they have already developed. However, the researcher pointed out that within the research poster tasks, poster sections do not unfold as a sequence of discrete monofunctional genres but as discourse patterns that are intricately related (Hyland, 2019). For example, professional scientists have been found to weave references to research aspects such as the 'data', 'hypothesis', 'findings' and 'experimental design' across sections and to evaluate them in different ways to develop a coherent argument (Hood, 2010). These initial discussions between the researcher and teachers were designed to promote insight into the complexity of the task and the challenges faced by the students.

In a further excerpt from the supporting document provided by the VCAA, teachers are advised that relationships between sections need to be made explicit. However, the examples of terms are not categorized in a principled way to guide students' selection. 
The relationship between the evidence and the conclusions drawn from the evidence should be made explicit. The terms 'proved', 'disproved', 'correct' or 'incorrect' in relation to the hypothesis should be avoided since this level of certainty may be unlikely in a single investigation; terms such as 'supported', 'indicated' and 'suggested' are more appropriate to evaluate the hypothesis.

(VCAA, 2017a)

Carmela had taken on board the advice from the curriculum authority that her students needed to make clear links between their evidence and the conclusions drawn from the evidence. She had also shared with her class the terms that needed to be used when discussing the results in relation to the hypothesis. Carmela shared with the researcher an example of a research poster that she had graded very highly. The researcher helped Carmela to analyze the example. Table 10.1 presents an excerpt from the discussion section, which has been annotated to show the student's use of terms recommended in the curriculum advice document. In this excerpt, we have also labelled subsections (e.g. findings) and more delicate phases that were identified through linguistic analysis, such as 'comparison'.

As expert science communicators, Carmela and other chemistry teachers used words like 'suggests' and 'indicates' in their own writing and avoided terms such as 'proved', 'disproved', 'correct' or 'incorrect'. However, the teachers recognized that they needed a metalanguage that would allow them to categorize the examples in meaningful ways and explain how they interacted with other linguistic choices across stretches of discourse. In the next

Table 10.1 A linguistic analysis of content from a highly graded research poster

\begin{tabular}{|c|c|}
\hline Phases & $\begin{array}{l}\text { Extracts from chemistry discussion completed by Carmela's } \\
\text { student }\end{array}$ \\
\hline di & sult as the enthal \\
\hline $\begin{array}{l}\text { Confirmation of } \\
\text { hypothesis }\end{array}$ & $\begin{array}{l}\text { change of ethanol was consistently higher than the enthalpy } \\
\text { change of methanol (refer to Figure 1; summary of results). }\end{array}$ \\
\hline Comparison & $\begin{array}{l}\text { The results of this investigation are somewhat consistent } \\
\text { with the standard enthalpy of combustion, as they both } \\
\text { indicate that ethanol has a higher enthalpy than methanol } \\
\text { (Enthalpy, n.d.). However, there is a large discrepancy } \\
\text { between the enthalpies obtained. The standard enthalpy } \\
\text { of combustion indicates that ethanol and methanol have } \\
\text { enthalpies of - } 1366.8 \mathrm{~kJ} \text { ' mol and }-726.1 \mathrm{~kJ} \text {, respectively } \\
\text { ("Enthalpy", n.d.). In contrast, the results of the present } \\
\text { investigation indicate that ethanol and methanol have } \\
\text { enthalpies of }-197 \mathrm{~kJ} / \mathrm{mol} \text { and }-112 \mathrm{~kJ} / \mathrm{mol} \text {, respectively. }\end{array}$ \\
\hline Limitations & $\begin{array}{l}\text { This suggests that the current investigation wasn't conducted } \\
\text { in the same conditions or there were no preventative } \\
\text { measures taken to stop heat loss to the environment. }\end{array}$ \\
\hline Recommendation & $\begin{array}{l}\text { To improve this, the research should be conducted at } 25^{\circ} \mathrm{C} \\
\text { and } 1 \mathrm{~atm} \text {. }\end{array}$ \\
\hline
\end{tabular}




\section{2}

sections, we use the previous examples to demonstrate key aspects of the professional learning Carmela and other teachers engaged in and the mediation of the researcher in supporting them to provide anticipatory guidance for students' composition.

\subsubsection{Developing a bridging metalanguage for classroom use}

The next step in the research collaboration involved the researcher sharing with the teachers work from systemic functional linguistics (SFL) to provide a metalanguage relevant for the research poster assessment task. As discussed in Chapter 3, a major concern of SFL-related educational semiotics has been in developing metalanguage for effective classroom application from the rich descriptions of SFL grammar and discourse systems. In relation to research report writing, SFL researchers have revealed different configurations of ideational, interpersonal and textual meanings across genres of research reports (Hao, 2020; Hood, 2010; Humphrey, Hao \& Rose, 2020). Ideational meanings refer to concepts and experiences, while interpersonal meanings are concerned with building an evaluative stance with the reader or viewer. Textual meanings relate to weaving these meanings into a cohesive text. To apply this research effectively in professional learning, it is crucial that the focus of metalinguistic knowledge relates closely to the concerns of the teachers in relation to their learners' needs and disciplinary and curriculum contexts (Humphrey, 2021). Given the concerns identified by Carmela and the limitations of the advice provided in the curriculum support document, the researcher opened professional learning discussion through examining meanings of the terms 'supported', 'indicated' and 'suggested'. The researcher shared findings of SFL research which have categorized these terms as discourse strategies for expanding dialogic space (Martin \& White, 2005). Expanding resources opens space for alternative views in relation to a proposition. These contrast with terms such as 'proved' and 'disproved', which are categorized as contracting resources. Contracting resources function to close down the negotiability of alternative views by presenting a proposition as already agreed upon (Humphrey, Hao \& Rose, 2020).

The metalanguage of expanding and contracting resources provided an accessible metalanguage for Carmela and other teachers to collaboratively analyze samples of their students' writing such as the text shown in Table 10.1. Teachers were encouraged to explore the dynamic role of these resources and to recognize that contracting resources also played an important role in effective reasoning and evaluation. In Text 1 , for example, the logical connection, 'as' which is underlined in the following sentence, functions to contract dialogic space by adding justification to what is initially presented as negotiable, thus making it less open to challenge. For example,

[t]he hypothesis was supported by the result as the enthalpy change of ethanol was consistently higher than the enthalpy change of methanol. 
Likewise, in the following example from the limitations phase, negative expressions, 'not' and 'no' also contract space for negotiation:

This suggests that the current investigation was not conducted in the same conditions or there were no preventative measures taken to stop heat loss to the environment.

In both of these examples, the proposition begins with or is 'launched' by an expanding strategy and concludes with a contracting strategy, creating a dynamic evaluative wave across the phase. Such waves within and across phases are typical of the objective persuasive voice found in studies of expert scientific writers (Hood, 2010).

The metalanguage of 'expanding' and 'contracting' and 'launching' strategies provided an accessible way for Carmela and her colleagues to reveal the resources for addressing rhetorical challenges they had identified, such as evaluating the experimental design and to justify the study and its significance.

\subsubsection{Sharing the metalanguage with teachers and senior students}

In addition to participating in collaborative investigative work with the M3S researcher to build and apply her own professional knowledge of language, Carmela's contribution to the project extended to organizing a research writing workshop for teachers and students of physics, biology and chemistry. Carmela recognized that teachers needed additional support in implementing the teacher demonstration stage of the MLISP framework and therefore worked with the researcher to prepare deconstruction activities to highlight some of the similarities in the way rhetorical moves were enacted in these subject areas. In these workshops, a range of representations and metaphors were used to show the relationships. For example, the movement from expanding to contracting discussed earlier was acted out by the presenter through firstly opening the classroom door to present a proposition to the students within and then closing the door to 'shut down' further contestation. Carmela and other chemistry teachers worked alongside students to deconstruct excerpts, as we have shown previously, and to include appropriate patterns in joint construction.

The significance of Carmela's work with researchers in the M3S project was manifold. Firstly, she committed valuable time to collecting data and sharing her experience and knowledge of research writing in chemistry with the collaborating researcher. She committed herself to expanding her metalanguage in order to provide tangible and grounded anticipatory guidance for her students and worked alongside the researcher to develop resources for students to engage in deconstruction and joint construction activities. Crucially, Carmela was able to open opportunities for the researcher to mediate further professional conversations with colleagues in chemistry, physics and biology. Such conversation is essential to ensuring consistency in classroom explanations and has opened space for further exploration of disciplinary similarities and differences in research writing. 


\subsection{Case study 3: Paolo - a senior high school physics teacher}

\subsubsection{Paolo's use of multimodal representations as mediating tools}

Paulo showed a high level of commitment to engaging students in the interpretation and creation of the different forms of representation that construct and communicate knowledge in physics. He took a lead in joint teacherresearcher lesson planning sessions and was keen to introduce innovative approaches in his teaching. For example, early in the project in his work with students on electric circuits, he involved the students in a role-play activity to model the movement of charge around a circuit, which he outlined in his lesson planning notes in the following steps:

- Get students to form a circle around the desks and hand out two stock cards to each student.

- Tell them to draw a negative symbol on one and a positive symbol on the other.

- The two cards together (positive and negative) represent a simple atom in the wires of a circuit.

- Teacher acts as the battery source and pushes negative (-) card to person on right while pulling in the negative $(-)$ card from the person on their left. (Note: Demonstrate increase of voltage by moving faster).

- Everyone holds on to the positive card.

- Each student does the same thing. (Note: You cannot pass on the charge until the other person has passed theirs.)

- Exchange the negative symbols as fast as you receive them (break circuit, remove voltage source, etc.).

- Have a stopwatch ready to time how fast charges are moving around this human circuit.

- Students can represent resistance by deliberately slowing the swapping action (standing further away from the group or placing an obstruction on both sides of the student to make it harder to pass on the charge. Give different students a chance at being the resistor). (Note: Does it matter where that resistance is placed in the circuit?)

In Chapter 8, in Section 8.3.1, we indicated how in response to discussions with the researchers about supporting students to understand how the articulation of different modes of representation in relation to each other contributes to an understanding of phenomena, Paulo established, through carefully framed board work and demonstration, the formal expression for the sum of resistors in series. Through strategically utilizing PowerPoint images, language, gesture, material demonstration, whiteboard drawing of diagrams and generation of formulae, he explicated the transduction of meaning across visual and symbolic modes, written text and analogic modelling.

In his work on Newton's laws with year 11 students, Paolo prepared the students to report on their investigations by creating a poster in preparation for meeting this assessment requirement by the state curriculum authority. 


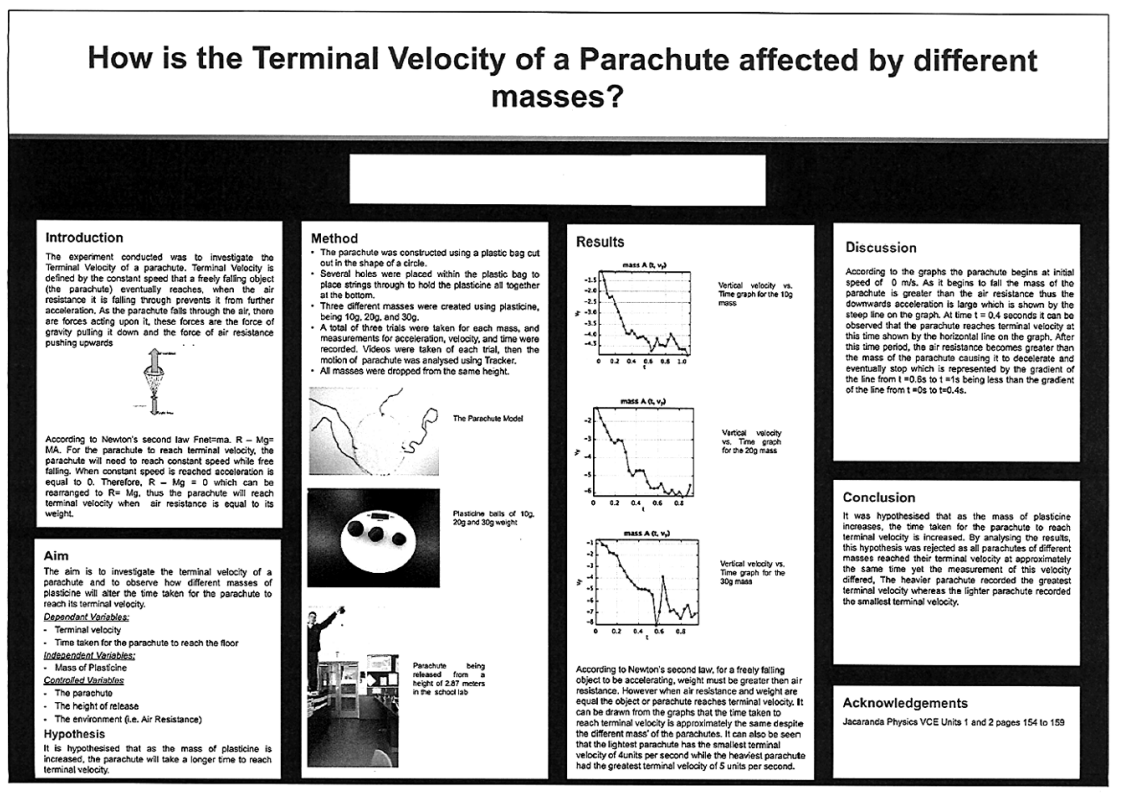

Figure 10.3 A successful physics poster showing the use of multimodal representation.

This case study in physics describes how Paolo engaged with a researcher from the M3S project to develop practice and theory for the major summative assessment task of research posters in senior high school science. While the previous example focussed on the written linguistic requirements of the task, the case study presented from physics includes more on the multimodal nature of the task. An example of a successful poster in physics is provided in Figure 10.3.

At the time of research, limited metalanguage was available to use in explicit teaching about the interactions of verbal and visual elements in posters. However, Paolo's work with other senior physics teachers included a number of pedagogic strategies for integrating multimodal representations as mediating tools. We focus here on strategies he used to recontextualize the more general literacy advice on poster construction to scaffold his students' disciplinary practice in physics.

Paulo had developed an interest in supporting students' representation construction in relation to practical investigations. Paulo had from the start expressed interest in developing materials to support his students' physics understandings and the language focus developed from this during the first year of the project. Initially, he worked with some of the research team to develop learning sequences in electric circuits and force and motion, and as part of this became interested in student practical investigations and the poster work that was new territory for him. Following meetings with the physics group, he volunteered to follow his interest in poster construction to 
produce an exemplar practical challenge, with supporting resource material to scaffold students' poster presentations.

The PowerPoint he produced, which he shared within the project and more widely, while it did not conform to the metalanguage described earlier in Carmela's case study, it nevertheless attended to explicit language forms, with examples of such elements of the report as the 'if...then' structure of a testable hypothesis, the layout of tables with repeat measures of the dependent variable, the conventions associated with different types of graphical display and their analysis and the different dimensions across which the investigation can be evaluated. The device of repeat measures and the association of error bars with uncertainty in measure are particular aspects of the disciplinary literacy of an experimental science like physics, as is the analysis and interpretation of graphs. Within the resource are numerous examples of transduction - of tabular results into graphical displays, or the interpretation of graphs into symbolic expressions. Thus, while not using an explicit metalanguage for describing the poster literacy forms, Paolo's work aimed at providing practical language exemplars for each aspect of the report.

Paolo's reflections of his work with students indicated his recognition of the value of clarifying conceptual difficulties related to motion in the investigation. He talked of the difficulties students had in distinguishing between acceleration and velocity, and how explicit discussion of translation processes between velocity-time and acceleration-time graphs, for different motions, helps students discern the distinction based on crucially different temporal relations.

[T] he investigation poster there's a lot on the acceleration part and the force, but you still manage to have students who say, 'because it went faster' or 'the speed was greater' and it had nothing to do with that. The concept of the change in velocity or the change in speeds still a difficult part of their understanding because we talk a lot about velocity in general life - but very few people discuss acceleration. That's something we need to overcome. The motion time graphs were a great way to introduce those concepts. We looked a lot at the diagrams of motion/time graphs in the lead-up. To make them think about the interpretation of the graph.

Talking out meanings in diagrams with his students alerted Paulo to challenges they faced in developing understandings of the concept of acceleration. Achieving clarity in relating position, velocity and acceleration is crucially dependent on being able to distinguish their temporal interrelations under a variety of conditions involving transduction processes between macro movement, graphical representation and symbolic calculations. This process was illustrated in Paulo's support resource.

They know that it is the slope of a velocity-time graph but they still have difficulty in describing it. They say, 'the acceleration had a faster speed' they kind of get mixed up in the way they want to express it. So, that 
is something that has to be worked on. They seem simple, but they're fairly complex in the long-run. They're going to be still used in year 12 .

Paulo also designed strategies to support students to integrate visual and verbal elements to communicate their investigation in a poster. He initially drew on rhetorical descriptions provided in physics curriculum support materials to model the key elements and functions of report elements, including introduction, methods, results, discussion and conclusion. As is evident in Figure 10.4, Paulo focussed on specific moves within these elements and, in the introduction, to those related to the research activity or epistemic operations. He highlighted terminology that has been identified by SFL researchers (Hao, 2020 ) as 'semiotic entities' (e.g. "research question", "testable hypothesis") to draw explicit attention to the way these configure and distil epistemic operations in professional science.

The scaffolding Paulo provided is illustrative of situated literacy practices that typically attend to modelling the processes of composing the text, rather than focussing on the unfolding functions of the text and on the way the semiotic resources realize the intended meanings. Nevertheless, Paulo's selection and naming of these operations in his planning demonstrate his concern to apprentice students into the discourse of professional scientific practice.

Following modelling of moves across all elements, Paulo designed further representational strategies, such as role-play and film performances for students to act out investigations. In reflecting on these activities, Paulo recognized the relationship of such activities to the practice of scientific communication and supported students to ensure that the presentation had a 'professional look'. A range of representational activities was used to ensure that all students were able to participate in presenting their research. For example, one student who was reluctant to present the report in the spoken mode without support produced a poster that was filmed as he read aloud the information.

\section{INTRODUCTION}

- A one- or two-sentence overview of the aim of the investigation

- What is the research question of interest?

- appropriate background theory including:

- relevant secondary sources of reliable information

- prior investigations

- a testable hypothesis

- Sufficient background information

- definitions and relevant formulas to enable a peer to understand the nature of the investigation.

- photograph or illustration that communicates some aspect of the research question.

Figure 10.4 Paulo's relating of textual moves to epistemic processes. 


\subsubsection{Modelling language of research posters}

In terms of language, Paolo also recognized the need for further scaffolding than was provided in the support materials related to 'style' (VCAA, $2017 \mathrm{~b}$ ). As is evident in the following advice from the curriculum and assessment authority, there is an opportunity for framing this advice more broadly through a metalanguage that clarifies how linguistic choices such as passive voice are related to scientific values of objectivity and clarity.

There is no mandated VCAA style for the use of person or voice in writing a scientific poster, since the scientific community has not reached a consensus about which style it prefers. Increasingly, using first person (rather than third person) and active (rather than passive) voice is acceptable in scientific reports, because arguably this style of writing conveys information more clearly and concisely. However, this choice of person and voice brings two scientific values into conflict - objectivity v. clarity.

(VCAA, 2017b)

While such description shows a recognition that scientific language cannot be reduced to rule-based conventions, Paolo recognized the assumptions made as to students' knowledge about how particular language choices were related to contextual dimensions. He, therefore, modelled different representations of 'person' and 'voice' in what he referred to as 'de-personalizing' scientific writing. Paolo illustrated this with respect to the experimental aim, contrasting active, 'Sarah wants to see if the colour of the light helps plants grow taller', with passive voice, 'To determine which light colour increases a plant's height'. We argue that the introduction of a metalanguage, such as 'passive' and 'active', that could inform explicit instruction as to the structures that enable this distinction, would be a valuable next step in enabling the teacher to talk with his diverse learners about how the rhetorical effect of depersonalization is achieved.

\subsection{Conclusion}

The M3S project was situated within design-based research principles and practices. The project offered to four schools a partnership, in which senior high school science teachers would collaborate with researchers to co-create planning, resources and pedagogies related to multimodal literacies. The three case studies described here provide rich examples of how practices, situated within authentic education contexts can be enhanced when productive partnerships are formed between researchers and practitioners.

All three teachers presented here enthusiastically embraced the research project and their motivations for involvement were similar: They all perceived the literacy requirements for success in senior high school science to be complex and extensive. They wanted to support their students to develop further capacities to interpret and create the multimodal texts that are 
valued within assessments during the final years of schooling. For Paolo and Carmela, these concerns resulted in engagement around work on research posters, while Riya chose to focus on the requirements of short-answer responses in biology.

Through collaborative working relationships with researchers, all three teachers deepened their own knowledge about language and developed practices for working with students on multimodal texts. Analyses of high-achieving student work, provided by the researchers, effectively provided insight into the grammatical features of particular texts. Riya used this kind of knowledge to engage her students in the deconstruction and joint construction of text. Carmela also applied new knowledge about language to the deconstruction of text in her professional conversations and opened space for students to benefit from the research through workshops conducted with the researcher. Paolo also engaged in classroom activities that involved breaking text down into parts. While he did not engage in a metalanguage to the same extent as Carmela and Riya, he effectively produced learning opportunities where the nature of representations was a focus.

The pedagogies of Paolo and Riya also came to involve the engagement of students across modes of representation. Both teachers embraced the idea that students' knowledge of concepts and how these are represented improve when there are opportunities to work across modes of representation. Through such work, both teachers modelled effective pedagogies and learning sequences for engaging students in multimodal interpretation and creation.

\section{References}

Anderson, T., \& Shattuck, J. (2012). Design-based research: A decade of progress in education research? Educational Researcher, 41(1), 16-25.

Barab, S., \& Squire, B. (2004). Design-based research: Putting a stake in the ground. Journal of the Learning Sciences, 13(1), 1-14.

Brown, A. L. (1992). Design experiments: Theoretical and methodological challenges in creating complex interventions in classroom settings. Journal of the Learning Sciences, 2(2), 141-178.

Christie, F. (2012). Language education throughout the school years: A functional perspective. Chichester, West Sussex: Wiley-Blackwell.

Collins, A., Joseph, D., \& Bielaczye, K. (2004). Design research: Theoretical and methodological issues. Journal of the Learning Sciences, 13(1), 15-42.

Edelson, D. C. (2002). Design research: What we learn when we engage in design. The Journal of the Learning Sciences, 11(1), 105-121.

Halliday, M. A. K., \& Matthiessen, C. (2004). An introduction to functional grammar (4th ed.). London: Arnold.

Hao, J. (2020). Analysing scientific discourse from a systemic functional linguistic perspective: A framework for exploring knowledge building in biology. London: Routledge.

Hood, S. (2010). Appraising research: Evaluation in academic writing. London: Palgrave. 
Humphrey, S. (2021). The role of teachers' disciplinary semiotic knowledge in supporting young bi/multilingual learners' academic and reflexive multiliteracies. Language and Education, 35(2), 140-159. doi: 10.1080/09500782.2020.1772282

Humphrey, S., Hao, J., \& Rose, D. (2020). Launching research: A Martinian perspective on science pedagogy. In M. Zappavigna \& S. Dreyfus (Eds.), Discourses of hope and reconciliation: J. R. Martin's contributions to systemic functional linguistics. London: Bloomsbury Academic.

Hyland, K. (2019). Genre and discourse analysis in language for specific purposes. In C. Chapelle (Ed.), The concise encyclopaedia of applied linguistics. Chichester, West Sussex: John Wiley and Sons.

Lesh, R. A., Kelly, A. E., \& Yoon, C. (2008). Multitiered design experiments in mathematics, science and technology education. In A. E. Kelly, R. A. Lesh \& J. Y. Baek (Eds.). Handbook of design research methods in education: Innovations in science, technology, engineering, and mathematics learning and teaching (pp. 131-148). New York \& London: Routledge.

Martin, J. R. (1992). English text: System and structure. Amsterdam: Benjamins.

Martin, J. R., \& P. R. R. White. 2005. The language of evaluation: Appraisal in English. London: Palgrave.

Rose, D., \& Martin, J. R. (2012). Learning to write, reading to learn: Genre, knowledge and pedagogy in the Sydney school. Sheffield: Equinox.

Sandoval, W. A., \& Bell, P. (2004). Design-based research methods for studying learning in context: Introduction. Educational Psychologist, 39(4), 199-201.

Schleppegrell, M. J. (2004). The language of schooling: A functional linguistics perspective. Mahwah, NJ: Lawrence Erlbaum.

Swales, J. (1990). Genre analysis: English in academic and research settings. Cambridge: Cambridge University Press.

Tytler, R. (2007). Re-imagining science education engaging students in science for Australia's future. Camberwell, Victoria. Australian Council for Educational Research.

Victorian Curriculum and Assessment Authority (VCAA). (2017a). Advice for teachers-chemistry: Scientific poster sections. VCE Study Design. https://www.vcaa. vic.edu.au/curriculum/vce/vce-study-designs/chemistry/advice-for-teachers/ Pages/ScientificPosterSections.aspx. Accessed l October 2021.

Victorian Curriculum and Assessment Authority (VCAA). (2017b). Advice for Teachers-Physics: Scientific poster sections. VCE Study Design. https://www. vcaa.vic.edu.au/curriculum/vce/vce-study-designs/Physics/advice-for-teachers/ Pages/ScientificPosters.aspx. Accessed 1 October 2021. 


\section{Student engagement in science learning through multimodal disciplinary literacy}

\subsection{Introduction}

A key aim of multimodal literacy infused science pedagogy (MLISP) is that teachers use texts of many different modes within their classrooms. Scientists constantly make representations of the world which may be in the form of written verbal, visual or multimodal texts. It is through the reading and production of various representations that students engage with the complex concepts of science (Tytler, 2007; Waldrip \& Prain, 2013). However, although providing students with a broad range of representations for a single concept is an important part of MLISP, another key aspect is that students have opportunities to engage in knowledge-building dialogue about representations of scientific concepts.

Past studies about student engagement in science have not focussed on their involvement in representation and tend to examine the role of practical work. Osborne and Collins (2000) report that students' interest increases if they can do experimentation and investigation. Other studies indicate that increasing the amount of practical work in science results in only short-term increases in engagement (Abrahams, 2009; Hampden-Thompson \& Bennett, 2013; Toplis, 2012). One study with a representation focus, Hubber, Tytler and Haslam (2010), suggests that learning sequences that explicitly include analysis of scientific representation result in more teacher-student discussion, which is supportive of ongoing engagement.

The finding by Hubber et al. (2010) indicates that actively involving students in the analysis of representations can foster engagement in science learning. Through such conversations, students are provided with the agency to construct knowledge and teachers can monitor and support student learning as they engage in the dialogue (Hubber et al., 2010; Moje, 2007). Other researchers also report that students' engagement with science increases when students are provided with opportunities to become active participants in the discussion and development of ideas (Chi, 2009; Dewitt \& Osborne, 2008; Lyons, 2006; Tang, 2021; Tytler \& Osborne, 2012).

This chapter examines how a focus on scientific representations in teaching and learning can generate opportunities for students to engage in dialogue about representations. Literature on the use of representations in science 


\section{Student engagement in science learning}

education and genre pedagogy highlights the importance of teachers engaging students in discussions about varying forms of representation (Prain and Tytler, 2013; Rose \& Martin, 2012). Such discussions can develop understandings of the conventions of specific representations and also foster critique of the ways in which they are limited and may be improved (Moje, 2015; Tytler, 2007).

We present and analyze a range of teaching strategies related to multimodal disciplinary literacy that engaged students in dialogue about representations. The key strategies examined include the deconstruction of text, the joint construction of text, independent construction of text, comparing and evaluating texts, cross-mode recasting and collaborative peer construction of text. Video data from the Multiliteracies in Senior School Science (M3S) project are used to analyze how the various strategies engaged the students in discussion about representations of scientific concepts. Moments when teaching strategies could have been used to extend the amount and nature of student engagement in the dialogue are also considered.

All of the teaching strategies examined here supported student engagement in dialogue about text, but the evidence from the M3S study suggests that some additional teacher facilitation at key moments could have enhanced the nature of the dialogue and facilitated greater participation from the more reluctant students. At times, the teaching strategies focussed on the conventions of specific representations and did not then extend the discussion to consider the limitations. Dialogue about specific representations could have involved more effective use of metalanguage, which would support the students to take the learning about representational forms into new contexts. Case studies presented throughout the chapter consider how the teaching strategies used within the project may be extended at times to include more dialogue about critiquing representations and the metalanguage that can be used to discuss scientific texts.

\subsection{Dialogue through deconstruction of text}

Through deconstructing texts, teachers can engage students in dialogue about the affordances and limitations of specific representations. Text deconstruction is a key element within genre pedagogy. It involves teachers making visible to students the ways in which grammatical patterns work in texts to make specific meanings (Rose \& Martin, 2012). If the ways in which texts are working are made visible to students, they can then interpret and create texts more effectively (Rose \& Martin, 2012).

During the M3S project, teachers invited students to break texts into parts and to consider how well the various elements represented concepts. Within a year 10 physics class on motion, the teacher asked students to consider a number of graphs, with each one representing how forces had affected motion. One of the graphs presented to the students represented a toy car being pushed on a flat surface. The teacher explained to the students that the graph told the story of what happened once the toy car had left her hand. 
The students were then invited to debate how accurately the graph represented the motion that would occur. One student was adamant that part of a graph representing this scenario was wrong:

S1: It is going up, or it is going flat. It is not going to increase speed.

S2: Yes it is if it starts with no speed, and you push it.

S1: No, no, no, no. She said it started when it leaves her hand so it starts, and it goes and it can't speed up.

S2: Yeah but it will be gaining speed.

S1: It's not going down; it's just going flat.

$\mathrm{T}$ : But is there force?

S1: No there isn't. It's either flat or up.

$\mathrm{T}$ : Ok so what are the forces acting on this right now. (Teacher points to calculator lying on the student's desk.) We haven't talked about forces but gravity?

S1: Yeah I know I know there would be forces if it was going down though. It's not going down it's only going up.

The teacher then moves to the front of the room where planks are set up. She selects a plank that is lying flat with sandpaper on it and puts the toy car on the plank.

T: So what John is saying is that when I push this from the moment it leaves my hand which is the moment that you are supposed to be graphing, it shouldn't be speeding up. All right it shouldn't be getting faster because there are - how did you describe it?

S1: No other forces.

T: No other forces acting on it. There is the force of gravity, but that is balanced out by the support force of the plank with the sandpaper on it. So in terms of its motion in that direction, there is nothing to speed it up. So he has a really excellent point saying hey why is this speeding up? Why is it in the negative direction (teacher points to part of the graph showing this) speeding up? And you were right John. You were 100\% right.

From the beginning of the dialogue, the teacher invites the students to question the graphical representations that have been presented. The students are asked to enter into a debate about the extent to which the graphs accurately represent the scenarios. To be able to do this, the students need to break the graphical representations into parts. They need to be able to associate downward movement in the graph with an object speeding up and upward movement with an object slowing down. As the students debate with each other and the teacher, they are using language to describe both the scenario and the ways in which the graph is representing the scenario. The student dominating the debate in this example is focussing on the first part of the graphical representation and making the connection that the movement of the graph in a negative direction is representing an increase in speed. 


\section{Student engagement in science learning}

The student then contrasts this to the scenario in which the toy car slowed down after it had been pushed on a flat rough surface. The student correctly identifies that the graph is not an accurate representation of the motion that has occurred. Through the dialogue that is generated, the students have an opportunity to gain a conceptual understanding of how forces affect motion, as well as how graphs represent motion.

A focus on critiquing the graphical representations by the teacher provided opportunity for the students to enter into a dialogue about the nature of the representations. Students were invited to participate actively in a discussion about how well a specific graphical image represented a scientific concept. One student participated enthusiastically in the exchange that occurred. While other students in the class would have benefited from listening to the dialogue about the limitations and affordances of the representation, there were also opportunities generated for the teacher to bring more students actively into the exchange. At numerous points, the teacher could have asked other students for their perspective, which would have involved more students actively in the discussion.

\subsection{Dialogue through joint construction of text}

Before students write or create a text within a disciplinary context, they need guidance on the key meaning-making language and symbols that will make communication effective within that specific context (Rose \& Martin, 2012). One of the teaching strategies that can be used to guide students prior to them independently creating texts in disciplinary contexts is joint construction. This strategy has been discussed previously within Chapters 3 and 6. Within joint construction, the teacher engages students in dialogue about a representation. Through multiple interactions between the students and the teacher, a representative text is created together (Rose \& Martin, 2012). As the text is co-created, the teacher makes visible to the students the grammatical patterns that are required to create an effective text within the disciplinary context (Dreyfus et al., 2016; Schleppegrell, 2004).

One example of joint construction of both written text and visual image occurred within a year 11 biology classroom. Through the process of joint construction, the teacher engages students in dialogic interactions about the social purpose of the genre, the language required to express key ideas and the language choices that could be made to connect ideas through consequence. The first move by the teacher involves the engagement of students in dialogue about the social purpose of the genre. She begins the lesson by presenting a short-answer question about osmosis that is typical of highstakes assessment in senior secondary biology. The question is displayed on the whiteboard, and the teacher also reads it out:

T: Consider an animal cell and a plant cell placed in a hypertonic solution. Explain what will happen to the two kinds of cell. Include a representation of your explanation to support your answer. 
The teacher then focusses the students' attention on the social purpose of the genre that they are being asked to create in response to the question.

T: We need to identify what are our keywords in there that we actually need to be focussing on. So what are my keywords here? What is my command to do?

One student then responds by identifying the social purpose of the genre:

S: Explain.

The teacher then elaborates by explaining further the social purpose of the genre:

T: So I need to explain that process. I need to put some reasoning behind why I consider the solution to be hypertonic.

The teacher then begins to create an explanatory response with her students. She draws on students' prior knowledge, as well as the language contained within the question, to co-construct the explanation short-answer response. First, she identifies a noun group within the question that is conveying meaning about classification.

T: First of all, what do I mean by hypertonic? The solution is hypertonic. Hyper meaning going?

S: Up.

Within this brief interaction, the teacher has focussed student attention on a classifier within a noun group that carries essential meaning within the short-answer response: 'hypertonic'. At the same time, she is drawing attention to a common language pattern within biology of short noun groups consisting of a nominalization 'solution' and a classifying adjective 'hypertonic'. She then rephrases the noun group into an attributive clause that is typical in biology. The clause consists of a basic noun group with a pointer and a nominalization (' $[\mathrm{t}]$ he solution') followed by the relational process 'is' and an attribute 'hypertonic'. The teacher then recasts the technical language to more everyday language by associating the meaning of 'hyper' to the action 'up'. Through the movement from technical to everyday language, the teacher is able to engage a student through dialogic contributions to build meanings that will be central to the short-answer response.

The teacher then continues to focus on language patterns that will be central to building the short-answer explanation response. She refers back to the noun group 'hypertonic solution' and asks the students the following:

T: So it's a higher?

$S$ (MULTIPLE): Concentration. 
$\mathrm{T}$ : Concentration than?

$S$ (MULTIPLE): Lower.

T: Higher concentration than inside the?

S (MULTIPLE): Cell.

Through the initial question in this interaction, the teacher is able to draw multiple students into the dialogue and they are able to respond with the correct nominalized term 'concentration'. The exchange focusses the students' attention on creating classifying noun groups that carry meaning about the kinds of concentration involved: '[h]igher concentration'. The teacher then focusses on elements of language that provide meaning about the circumstances where elements are occurring. She begins to emphasize prepositional phrases about place ['inside the'] and multiple students are able to enter the dialogue and provide the location of the 'cell'. The teacher then reinforces these language patterns in her next summary statement to the class:

T: So we go from high concentration outside the cell to lower concentration inside the cell.

Through this statement, the teacher reinforces the classifying noun groups that provide information about types of concentration, as well as the prepositional phrases providing meaning about where elements exist 'outside the cell' and 'inside the cell'. Students are then invited to enter further into the dialogue as the teacher continues to emphasize the significance of circumstances of place:

S: So the net water is going out of the cell.

$\mathrm{T}$ : So the movement of the net water is going outside the cell.

The next move that the teacher makes invites the students to move from the more everyday language of 'out of the cell' and 'outside the cell' to more technical language appropriate for the disciplinary context. She asks the following:

T: So it goes from a what to a what?

S (MULTIPLE): High concentration.

$\mathrm{T}$ : From a high concentration to a?

$S$ (MULTIPLE): Low concentration.

$\mathrm{T}$ : Now instead of saying high concentration to a low concentration, what word did I mention last time?

$S$ (MULTIPLE): Concentration gradient.

T: Beautiful - along the concentration gradient.... So we are going down the concentration gradient, along the concentration gradient or with the concentration gradient. Remember you can use any of these.

Through this interaction, the teacher invites the students to use the disciplinary-specific technical noun group 'concentration gradient'. She also 
provides students with a range of prepositions for providing circumstantial meaning about how the water travels: 'down', 'along' or 'with'.

The students' contributions to the dialogue that has occurred are then used by the teacher to write a short-answer explanation response on the board. As she does this, she draws on the key language patterns that have been emphasized within the dialogue. Classifying noun groups are used along with nominalizations. Prepositional phrases are inserted to provide information about where and how activities are happening. As the teacher puts the information on the board, she engages the class in dialogue about ways to connect ideas through consequence.

T: What is going to be my result? What am I going to see? So resulting in. If I am going to see something resulting in or consequently or what other words could you use as a linking word?

S: Therefore.

T: Therefore. Ok. There are so many different words you could use to build that next part.

T: So the water moves outside the cell. What word do you want to use?

S: Therefore.

$\mathrm{T}$ : Therefore (teacher writes the word on the board).

$S$ : Resulting in the cell.

T: All right. Therefore or resulting in but we don't use both ok.

S: Therefore the...

T: The cells. Ok.

It is the guided dialogue between the teacher and the students that functions to focus the students' attention on the language that could be used to join ideas through consequence. This kind of language is central to the consequential explanation that is being co-constructed on the board. The teacher guides the students to conjunctions (therefore, consequently) and also to logical metaphors (resulting). Through the use of the logical metaphor 'resulting', the teacher indicates that consequence can be provided through connectives or the notion of consequence may be within the clause as a verb 'resulting'.

The consequential explanation that is written on the board by the teacher is constructed through guided dialogue between the teacher and her students. Throughout the dialogue, there is a focus on language. The social purpose of the genre is identified, followed by a focus on the language used to present key ideas within the text. Noun groups consisting of classifiers and nominalized terms are emphasized (hypertonic solution, higher concentration, lower concentration). The teacher also demonstrates how a classifying noun group may be rewritten as an attributive clause. Prepositional phrases for providing ideas about where and how activities are happening are also highlighted. The teacher also moves back and forth along a continuum from everyday language to more technical language that is appropriate for the discipline. For example, the concept of high and low concentrations, and the 
effects they have, are summarized in the noun group 'concentration gradient'. The dialogue about language generated during the joint construction supports concept development, as well as knowledge of the grammatical patterns relevant for the expression of meaning within the genre and topic.

The dialogue in which the teacher engages the students is about language. Throughout, the teacher is supporting the students to use and think about the language patterns that are relevant for consequential explanations within the discipline of biology. As a result, the students are engaged in metalanguage throughout the joint construction of the written text (refer to Figure 6.5 in Chapter 6). There are ways in which this dialogue about metalanguage could have been extended. The teacher could have pointed out when terms had been nominalized and how this enabled activities in biology to be named (e.g. concentration gradient). The teacher also could have named the classifiers within noun groups as classifiers. The prepositions within the prepositional phrases about circumstances of place and manner could also have been named. The language used to connect ideas through consequence could have been referred to as conjunctions and verbs. By naming the specific elements of the language patterns, the teacher would have supported the development of knowledge about language that the students could transfer beyond the immediate topic. For students from linguistically diverse and low socio-economic backgrounds, such work supports their apprenticeship into the disciplinary-specific ways of making meaning.

Once the written text is completed, the teacher moves on to constructing a visual representation of osmosis with her students. During the dialogue that is generated, the students are guided to consider the symbolic conventions involved in representing elements of the topic.

$\mathrm{T}$ : What is the shape we normally give a plant cell?

$S$ (MULTIPLE): Circle. Rectangle.

$\mathrm{T}$ : A plant cell. A plant cell is probably a rectangle (draws a rectangle on the

board). Why do I give it a rectangle shape? To represent what? S (MULTIPLE): Cell wall.

In this initial interaction, the teacher effectively guides the students to understand that there is a convention for representing plant cells. Many students within the learning community already seem to understand the convention, and the teacher's use of questioning here helps to gain the involvement of multiple students in the dialogue. The teacher also explains how the symbolic representation is associated with the naturalistic feature of plant cells. The teacher then invites the students to consider how animal cells can be represented.

T: All right. So this one is going to be my animal cell. Just do a circle yeah? $S$ (MULTIPLE): Yeah. Yes.

T: (Draws a circle on the board). It doesn't have to be a sphere. Remember they come in different shapes and sizes. 
Through this part of the interaction, the teacher focusses students' attention on the conventions for representing animal cells. She indicates that they are usually spherical and that in the natural world there are different kinds that may look slightly different from each other. The teacher is guiding the students to the conventions used, as well as indicating that these conventions are generalized to some extent and mask the variety of phenomena in the natural world.

The teacher then asks the students to consider how to represent activity within the visual image.

T: What other information do I need to draw?

s: The net movement.

$\mathrm{T}$ : The net movement of what?

S: Water.

T: Now all the things that you have written here need to go into your diagram. Everything that is written in here needs to go into your diagram. I cannot stress that enough. So net movement is going in which direction. $S$ (MULTIPLE): Outside.

T: Outside the cell. So I am going to draw net movement. So how do I draw net movement?

S: Arrow. A bigger arrow.

$\mathrm{T}$ : A bigger arrow. (Teacher draws a large bolded arrow from the animal cell to outside the cell).

The dialogue involves students in consideration of how to represent activity within images. One student already knows that arrows are used to indicate the direction of movement and that the size of the arrow can be used to represent quantity. The teacher models the symbol on the board for all the students.

Throughout the dialogue about the image, the teacher guides the students towards the conventions used to symbolically represent aspects of the topic. She also invites the students to critique the conventions at one point by focussing on the fact that different types of animal cells will look different from each other. Through this part of the dialogue, the teacher is asking the students to consider that symbolic representations will be limited as they tend to generalize and do not provide exact replication of the natural world. The teacher also focusses the students' attention on the way in which activity is represented in visual images. The use of arrows is highlighted. The teacher models how arrows can be drawn in ways that represent both direction and quantity.

As with the dialogue involving the written text, the interactions about the visual representation engage students in metalanguage. The teacher effectively involves them in discussion about the grammatical patterns used to represent meaning in written and visual forms for the topic of osmosis. As with the dialogue for the written text, the dialogue about the image could have been extended. The teacher could have talked about arrows being 
vectors that carry meaning about activity that could be occurring within various topics. There could also have then been discussion of other ways activity may be represented in other topics, such as the use of multiple lines to indicate vibration. In the case of osmosis, the vector represented the movement of water, along with the relative volume of water. However, in other topics, such as transcription, an arrow may represent the activity of splicing. Extending the dialogue in this way would have supported the students more to carry their understanding of symbolic patterns beyond the immediate topic.

The example of joint construction presented here indicates that the process can engage multiple students within the class. On a number of occasions, multiple students respond to the teacher and they are able to enter the classroom dialogue as the texts are built together. At the same time as providing opportunities to engage in dialogue, the teacher successfully guided the students to consider the conventions of written and visual texts. While discussion of the limitations of these conventions could have been extended, the teacher did also begin to guide the students towards critique. The opportunity to extend this kind of work with students was clearly created through the use of joint construction.

\subsection{Dialogue after the independent construction of text}

Teachers also demonstrated through the M3S project that dialogue could be generated after the students have been involved in the independent construction of text. Once a representation has been completed by a student, the teacher can encourage the student to talk about their representation and to discuss its affordances and limitations. Through such discussions, negotiations occur and consensus is reached, as we outlined in Chapter 6. Within a year 11 physics topic on resistor circuits, the teacher engages individual students in dialogue about the representations they have created as various circuits are trialled. The student involved in the dialogue with the teacher had completed two trials. For each, the student had first drawn the resistor circuit, then presented their working out for that circuit and finally written a brief consequential explanation for what had occurred. The teacher begins by inviting the student to explain what they have done.

T: Ok so work me through again what you, how you worked through this resistance. (Teacher points at the first visual representation of a resistor current).

S: Umm so I knew that I had the 20 ohms by itself, so I knew that I had to find 40 in this series. (As the student talks he points to where in the diagram he has represented $20 \mathrm{ohms}$ and also where he has represented the series.)

T: Ok yeah.

S: So whatever this was going to equal to if it didn't equal to 40 , I knew that it was going to give me the incorrect answer. 
T: Good, yeah.

S: Because 20, 40, 60 .

T: Yip, yip.

S: (Points to the second image he has drawn for the first trial.) So I think in the capacity I pulled out I turned that into the one big resistor as you showed us in class and tried to figure out what it would be as a total.

T: Ok yip. So what did you come up with?

S: So I came up with 14.287.

T: Ok.

S: Which was 100 over 7. So I knew that that wasn't the 40 that I needed.

$\mathrm{T}$ : You left out the units there too (teacher points to where the student has written the value 14.287).

S: Oh yeah.

T: That's all right I am just pointing it out. That's ok. But that's ok so you worked out 14.28 so that's ok. As soon as you got that what did you think?

S: So I put in the comments here. (Student points to the last section where he has written a consequential explanation.) I put in that more resistance was needed for it to work.

T: To give you a total of 60 .

S: Yeah so I was going to try and substitute the 50 ohms with the 20 .

T: Yeah so that would be your next attempt.

$S$ : Yeah I was going to - in the next one that's what I did I swapped it (student turns over the page and reveals his second trial) around, and I made it umm I put in a 50 ohms resistor by itself and then in the series I put 40, 20 and 40 again.

T: So this time what were you looking in the parallel arrangement. So you have 40 at the front?

S: Ah 50 .

T: Oh 50 so what were you looking at here? (Teacher points to the representation of the series in the student's first diagram for trial 2.)

S: So here I was trying to get a total of ten resistance.

T: Yeah.

S: So I tried to figure it out, and I ended up making that ten resistance. Ten ohms resistance.

T: And you got it.

S: Yeah and process of substituting the 20 with the 50 worked and therefore I managed to get a correct result of 9 volts and .15 amps and 60 ohms of resistance.

T: Ok very good. Probably lay that out a little differently. (Teacher points to the last part where the student has their consequential explanation for Trial 2.) I think maybe just say like: The voltage was this, the current was this, the resistance was that. Ok it verifies it.

S: Yeah I wasn't too sure how to lay them out like you know.

T: That's ok. No that's ok you did a really good job on this. You could try maybe a third trial even though you got the amp there. 
S: Yeah.

$\mathrm{T}$ : Just to see if there is another possibility.

S: Ok.

T: That you had not thought of. Another arrangement.

From the beginning of the dialogue, the teacher invites the student to verbalize their reasoning about the resistor circuits. The student is asked to transfer what they have drawn and written on paper into verbal spoken language. As this occurs, language for expressing consequence and causation is emphasized within the dialogue. Both the student and the teacher use the conjunction 'so' throughout. During this process of transduction, opportunities for expressing causation that were not in the diagram are realized in the spoken language. As a result, the reasoning that is occurring is consequential and appropriate for the disciplinary context. The student is also required to use noun groups that are appropriate for expressing meaning about the entities involved in the consequential explanation. Often, the noun groups used consist of a numerative (e.g. 50) and a technical term for a unit of measurement (e.g. ohms).

The teacher's invitation for the student to discuss their independent construction of a task presents rich opportunities for the student to be actively engaged in dialogue about representations of concepts. The dialogue about the independent construction also opens up the opportunity for the teacher to provide feedback to the student on the paper-based representation. At one stage, the teacher points out that the student has not included a unit of measurement after their final calculation. At the end of the dialogue, the teacher provides advice on how to present the conclusions of the calculations that have occurred. He models attributive clauses that will provide clear statements of results: 'The voltage was this, the current was this, the resistance was that'.

Teachers talking with students about their independently constructed texts provides opportunities to clarify thinking about concepts and to discuss representational forms. The student and the teacher effectively rehearse the language of consequence that could then be used within an extended written text. The staging of a written conclusion is also modelled as the teacher provides the examples of the attributive clauses that can be used.

\subsection{Dialogue through comparing texts}

Another way in which the teachers in the project engaged students in dialogue about representations was to set up activities that involved comparing and contrasting representations. One of the biology teachers in the project used this strategy in a year 12 class on transcription and translation. At the beginning of the unit, the students were asked to independently draw a diagram of transcription. Later in the unit of work, the teacher asked the students to draw independently another diagram of transcription. The teacher then engaged in dialogue with each student independently and asked them 
what changes they had made between the first and second diagrams and why. The following is an example of the dialogue that occurred with one student:

T: Do you want to go through this? How is it different compared to this and this? (Teacher is pointing at the visual image produced at the beginning of the unit and the visual image produced later in the unit, which the student is currently working on. The first image is of a static cell with its parts. The second image includes multiple parts depicting different activity sequences.)

S: Umm I have added process. So you have the gene and the RNA polymerase binding to the promoter sequence. (The student points to the relevant parts of his second visual image as he talks.)

T: Yes.

$S$ : That's where it starts. The start triplet is here and then that is allowing the (student points to the relevant part of the second visual image).

T: DNA to unwind yeah.

$S$ : Yeah and then the RNA polymerase is moving across the template strand.

(Student points to the relevant parts in the second visual image.)

T: Good, very good. That is better.

While the first diagram is static and only presents a cell and its components, the second diagram produced by the student depicts activity sequences. Within the dialogue with the teacher, the student focusses on the activities in which the key entities are engaged. During the dialogue, the student uses relevant processes that are important within sequential explanations on transcription (e.g. binding, moving). Circumstances are also used within the student's talk to explain where the processes are happening (e.g. across, to the promoter sequence). Throughout, the student also draws on classifying noun groups to be specific about the types of entities involved (e.g. RNA polymerase, the template strand, the start triplet, the promoter sequence).

The strategy of comparing an initial visual representation with one completed later in a unit of work provides a structured and supportive way to engage students in dialogue about a complex topic. The students can draw on their work to explain the activity sequences involved. By referring to their visual representation the student was able to engage in dialogue with the teacher that effectively rehearsed what could later become a written verbal text on transcription.

In this example, the teacher keeps the focus of the dialogue on key entities and their activities. However, there was also scope within the activity to engage the student in dialogue about the nature of their representation, its affordances and also its limitations. Within the second visual representation, the student had used a number of effective strategies to depict activity. Each moment in the activity sequence had been drawn, with arrows used to indicate the movement from one activity to the next within a temporal sequence. The dialogue could have been extended so that the teacher and the student analyzed the key differences between the methods of representation in the 


\section{Student engagement in science learning}

first static image and the second one depicting activity. Extending the dialogue in this way would have supported the student's understanding of strategies for representing activity within biology, as well as continued to build knowledge of transcription.

Through engaging students in the process of independently constructing texts that can be compared and contrasted, the teacher emphasizes for the students the need to revise representations as conceptual understanding develops. The students learn that texts are representations of knowledge in one moment in time and that they will be modified as knowledge is built. By engaging in one-on-one conferencing with the students, the teacher is indicating that she values their independent constructions as representations of their growing understanding, and there is an emphasis on progress in learning within the class.

\subsection{Dialogue through cross-mode recasting}

Teachers within the M3S project found that the process of transduction was an effective way to involve students in dialogue about representational forms. Teachers across the project agreed that learning within science involves students being able to interpret and create a range of texts that use different modes to represent the same phenomena. Within the biology subject area, the teachers involved in the project co-designed the curriculum with the researchers that often engaged the students in moving between modes of representations when interpreting and creating text. This kind of work exposes students to conceptual meaning that is presented in a variety of ways and also opens up opportunities for dialogue about representational forms.

In one year 11 biology classroom, the teacher used cross-mode recasting to support student understanding of mitosis and also to engage the students within dialogue about how the knowledge was being represented. First, the teacher provided the students with extracts from the textbook that included written descriptions of the different stages of mitosis. The students were then asked to work in small groups of two or three to read the extracts and to use this information to draw the stages of mitosis. The following dialogue occurred between two students.

S1: Wait so just draw lines here (Student has already drawn a circle to represent a cell and also a circle in the middle to represent the nucleus. Student begins now to draw wavy lines in the nucleus to represent the loose DNA strands.)

S2: (Reading from the textbook extract on interphase.) Before mitosis begins, centrioles are visible in many animal cells. Where would you draw the centrioles?

S1: The centrioles would be on either side wouldn't they?

S2: Yeah. Wouldn't they be like coming together to help duplicate it?

S1: I reckon they would be on the sides first. (The two students read the written text together and S2 reads aloud 'would be visible in many animal cells'.) 
S1: All right so.

S2: Later (Student points to part of the written text that explains how the centrioles will be involved in the separation of chromosomes).

S1: Yeah that is later.

S2: So that would be around here and around here. (Student points to parts of the visual representation they are drawing.)

S1: So would we draw the centrioles?

S2: Yeah we would have to draw that. Everything else is irrelevant.

S1: So we draw the centrioles on the side? (Student positions pencil to one side of the cell.)

S2: Yeah.

S1: Circles?

S2: Yeah.

S1: (Draws two circles on either side of the cell to represent the centrioles.)

S1: And this is interphase. (Writes a heading for the visual representation 'Interphase')

Throughout the dialogue, the two students are making decisions about what to include from the written text. The movement from the written text to the visual representation supports them to focus on the key entities, and the activities in which they are involved, and the two students make decisions about what information from the written text is peripheral to the sequence of activities that they are representing within the visual image. The dialogue that occurs between the students also includes how to represent the written information visually. The two students discuss the shape that should be used to represent the centrioles. They also talk throughout the dialogue about where entities should be positioned in relation to each other. Together, they decide that the centrioles should be on the sides of the cell opposite each other. In making this decision, the students have moved beyond the stage of interphase into prophase. Within the dialogue, one student was ambivalent about the decision to put the centrioles at opposite ends of the cell during interphase and suggests that they would be 'coming together first'. However, the other student convinces him that they should be placed at opposite ends. The two students then continue to represent the stage of prophase.

S2: Now we do prophase yeah?

S2: OK prophase in the top right corner. (Sl draws another cell next to the diagram of interphase. Within the cell, he draws a circle to represent the nucleus).

S2: (Reads the first part of the written text on prophase where it states that the chromatin threads start to become visible.)

S2: I reckon make these lighter. (Points to the DNA strands that they have drawn in the diagram of interphase.)

S1: (Writes the heading prophase above the drawing of the second cell.)

S1: So the chromatin threads condense and become visible. 


\section{Student engagement in science learning}

S2: Yeah it's when the DNA like actually becomes more visible.

S1: Yeah.

S2: Like on the chromosome.

S1: So just draw them in pairs yeah?

S1: (Draws six pairs of chromatids in the nucleus of the cell).

S2: Oh hey the nucleus disappears from view. (S2 is continuing to read and gain information from the written text).

S2: So the nucleus disappears from view as the nuclear membrane breaks down.

S1: Ok so I'll just (rubs out the circle that represents the nuclear membrane).

S2: Really, really light.

S1: Yeah I'll rub it out like that. I'll rub it out completely because it doesn't rub out all the way so you can still slightly see it.

S2: I reckon make it a bit darker and later on make it a bit lighter.

S1: Oh do you want to do that?

S2: Yeah because it eventually breaks down.

S1: Ok I'll draw it really lightly (draws a light circle to represent the nuclear membrane).

S2: Perfect now metaphase. Oh you still need to draw the centrioles.

S1: Oh and we draw the...

S2: Spindle.

S1: So I'll just draw the spindle (draws the two centrioles at opposite ends of the cell). All right so there are lines right?

S2: Yeah.

S1: (Draws microtubules going from the centrioles to the nucleus).

S1: Ok (goes back to the drawing of interphase and rubs out the centrioles that are drawn at opposite ends of the cell). I'll draw these more to the bottom or more like to the sides because eventually they move to opposite sides.)

S2: Yeah so draw them there and eventually they move.

S1: (Draws the centrioles in the middle of the cell near the nucleus).

During the dialogue, the two students continue to draw on the written text to inform their visual representation of a stage of mitosis. The dialogue supports conceptual understanding, as well as knowledge of the ways to represent the key entities and the activities that are occurring. Part of the discussion involves ideas about how to represent the nucleolus that is beginning to disappear from view. Initially, the circle representing the nuclear membrane is rubbed out completely, but the two students decide to replace it with a lighter circle to represent the activity of disappearance. During the process of representing prophase, the two students realize that they have misrepresented the position of the centrioles in the diagram for interphase. They return to the first diagram, rub out the centrioles and then redraw them in the correct position for that phase of mitosis.

The case study of the two biology students presented here demonstrates how cross-mode recasting can engage students in representation work and 
also support conceptual understanding. Both students are committed to the task, and they support each other throughout. During the interaction, meanings are negotiated, and they move towards a shared understanding of concepts and how to represent them visually. Throughout the process, the two students need to identify first the key entities and activities occurring within the written text. Both students read from the written text at times, and they constantly make decisions about which entities are central to the activities that are occurring. The close reading of the text is required to support the creation of the images for interphase and prophase. The students then need to make decisions about how to represent entities and the activities in which they are involved. Much of the dialogue concerns the best way to represent entities and activities. Together, the students arrived at decisions that they were happy with.

Engagement in cross-mode recasting also supports the students to correct initial misconceptions about the content. Initially, the two students do not represent interphase correctly. The centrioles were positioned as they would be for prophase. Through the process of closely reading the written text and then transferring the information into a visual form, the students have the opportunity to go back to their initial diagram to make an important correction. As a result, their conceptual understanding of the phases of mitosis grows, and the two students would be unlikely to misrepresent the position of the centrioles during interphase in the future.

The process of cross-mode recasting presented here also affords multiple opportunities for the teacher to provide individualized feedback. The importance of feedback for individual students is emphasized in the framework presented in Chapter 6. Through providing feedback on the visual representations, the teacher could support further conceptual understanding. For example, when representing prophase, the two students drew the microtubules as separate threads. Input from the teacher at this point could have shown the two students how some of the microtubules join to form the spindle. Discussion of how to represent the spindle would have supported the students to extend their understanding of the activities and entities involved during prophase. Throughout the process of recasting from the written text to the visual image, the students reveal their degree of understanding of entities and processes. At every point, teaching opportunities about concepts arise.

Multiple opportunities also exist for the teacher to provide input about the limitation of representations of the natural world. In this example, the two students struggle to represent the activity of disappearance. They want to represent how this was happening over time, but they are struggling to do this within the set task, where they had to present one static image of prophase. There is enormous opportunity here for the teacher to discuss with the students the limitations of a static image when representing a stage in the natural world that is fluid and ever changing. The teacher then could have modelled how a sequence of small images within each stage of mitosis could have better represented the activities occurring. 


\subsection{Conclusion}

The M3S project strived to support teachers to involve students actively within the creation and interpretation of representations in many different modes. The approach built on research that advocates for students to make active contributions to the building of knowledge within science classrooms (Chi, 2009; Dewitt \& Osborne, 2008; Lyons, 2006; Tang, 2021; Tytler \& Osborne, 2012). The teachers in the project were asked to infuse their pedagogies with representational work and to engage students in dialogue about representations. Students' active participation in talk about representations was achieved as teachers used representations in their classrooms in a range of ways. Through classroom talk about representations, opportunities for conceptual understanding increased, as did opportunities to develop knowledge of appropriate conventions within disciplinary contexts and the limitations of these conventions.

Invitations to pull representations apart and to debate the merits of how concepts have been represented within certain sections opened up opportunities to engage students in dialogue about texts. In the example from year 11 physics, a focus on interpreting parts of graphs generated enthusiastic debate about the extent to which the beginning of a particular graph represented a concept within a topic on motion adequately. In addition, the dialogue that occurred provided insights into how the graphs were working as representations of motion. Students listening to the dialogue and engaged within it had the opportunity to think about this representational form and to consider how the various parts of the graph worked together to represent a motion scenario.

Joint construction of text also afforded many opportunities for the students to engage in dialogue about representations. Within a year 11 biology classroom, the teacher effectively used joint construction to highlight particular language patterns and to move between everyday and more technical discipline-specific language. Students within this class had opportunities to consider how nominalizations classifying noun groups and circumstances of where and how activities are happening are used to convey meaning within the topic of osmosis. They also had an opportunity to see how conjunctions and logical metaphor combined ideas within consequential explanations. Dialogue generated through joint construction also supported representational work with visual images. The teacher effectively guided the students to consider how arrows could be used to represent activity.

Teachers within the M3S project also successfully demonstrated how independent construction of representations could be used to generate dialogue. The teacher working in the final year of schooling engaged students in the independent construction of text when she asked students to draw an image of transcription at the beginning of a unit of work and then towards the end of the unit. Students were then asked to compare their first and final images when talking with her. The exercise of comparing images provided a supportive opening for the dialogue. Students spoke about key differences between their first and final images and then outlined what they had included in their 
final image and why. As a result of this work, the teacher gained a detailed understanding of the progress being made by individual students, and she could affirm or redirect understandings during the dialogue.

All of the strategies used within the M3S project engaged students in both representational work and dialogue about this work. Through the dialogue, opportunities to learn about key concepts and the ways in which they are represented were afforded. The case studies presented here also indicate that working in this way in senior secondary classrooms can be extended. At times, the teachers could have taken the dialogue in directions that allowed for more metalanguage to be used. The language and symbolic patterns being used to represent meanings were always a focus in the dialogue, but endless opportunities were generated to build a metalanguage for the students. At times, for example, language features, such as nominalization could have been named as nominalization and discussed specifically. Such discussion would support students to understand how activity sequences are often summarized using technical naming words. Discussion of the use of arrows to represent activity could have been extended to talk about how arrows generally represent activity, but the nature of this activity in different topics may differ. By extending the dialogue at times, the teachers could have built the metalanguage further so that it could be more readily transferred across topics. While there were opportunities to extend the work that occurred, the teachers presented here effectively infused their pedagogy with learning and discussion about representation within senior secondary science.

\section{References}

Abrahams, I. (2009). Does practical work really motivate? A study of the affective value of practical work in secondary school science. International Journal of Science Education, 31(17), 2335-2353.

Chi, M. T. H. (2009). Active-constructive-interactive: A conceptual framework for differentiating learning activities. Topics in Cognitive Science, I(1), 73-105.

Dewitt, J., \& Osborne, J. (2008). Engaging students with science in their own words. School Science Review, 30(331), 109-116.

Dreyfus, S. J., Humphrey, S., Mahboob, A., \& Martin, J. R. (Eds.). (2016). Genre pedagogy in higher education. London: Palgrave Macmillan.

Hampden-Thompson, G., \& Bennett, J. (2013). Science teaching and learning activities and students' engagement in science. International Journal of Science Education, 35(8), 1325-1343.

Hubber, P., Tytler, R., \& Haslam, F. (2010). Teaching and learning about force with a representational focus: Pedagogy and teacher change, Research in Science Education, 40(1), 5-28.

Lyons, T. (2006). Different countries, same science classes: Students' experiences of school science in their own words. International Journal of Science Education, $28(6), 591-613$.

Moje, E. B. (2007). Developing socially just subject-matter instruction: A review of the literature on disciplinary literacy. In L. Parker (Ed.), Review of research in education (Vol. 31, pp. 1-44). Washington DC: American Educational Research Association. 


\section{Student engagement in science learning}

Moje, E. B. (2015). Doing and teaching disciplinary literacy with adolescent learners: A social and cultural enterprise. Harvard Educational Review, 85(2), 254-278.

Osborne, J., \& Collins, S. (2000). Pupils' and parents' views of the school science curriculum. London: Kings College London.

Prain, V., \& Tytler, R. (2013). Representing and learning in science. In R. Tytler, V. Prain, P. Hubber \& B. Waldrip (Eds.), Constructing representations to learn in science (pp. 1-14). Rotterdam: Sense Publishers. https://doi. org/10.1007/978-94-6209-203-7

Rose, D., \& Martin, J. R. (2012). Learning to write, reading to learn: Genre, knowledge and pedagogy in the Sydney school. Sheffield: Equinox.

Schleppegrell, M. J. (2004). The language of schooling: A functional linguistics perspective. Mahwah, NJ: Lawrence Erlbaum.

Tang, K.-S. (2021). Discourse strategies for science teaching and learning: Research and practice. New York: Routledge.

Toplis, R. (2012). Students' views about secondary school science lessons: The role of practical work. Research in Science Education, 42(3), 531-549.

Tytler, R. (2007). Re-imagining science education: Engaging students in science for Australia's future. Camberwell, Vic.: Australian Council for Educational Research.

Tytler, R., \& Osborne, J. (2012). Student attitudes and aspirations towards science. In B. Fraser, K. Tobin \& C. McRobbie (Eds.), Second international handbook of science education (pp. 597-625). Dordrecht, Netherlands: Springer.

Waldrip, B., \& Prain, V. (2013). Teachers' initial response to a representational focus. In R. Tytler, V. Prain, P. Hubber \& B. Waldrip (Eds.), Constructing representations to learn in science (pp. 15-30). Rotterdam: Sense Publishers. https://doi. org/10.1007/978-94-6209- 


\section{Advancing multimodal literacy transdisciplinary research and teaching}

\subsection{Introduction}

The collaborative authorship of this book involving researchers in science education, social semiotics and literacy education reflects an important and long-standing commitment amongst scholars working in diverse contexts to transdisciplinary research and pedagogy development in science education (Doran, 2017, 2019; Jewitt, Kress, Ogborn, \& Tsatsarelis, 2001; Jones, Turney, Georgiou \& Nielsen, 2020; Kress, Jewitt, Ogborn \& Tsatsarelis, 2001; Kress \& Ogborn, 1998; Kress, Ogborn \& Martins, 1998; Lemke, 1990, 2004; Doran \& Martin, 2021; Nielsen, Georgiou, Jones \& Turney, 2020; Nielsen, Jones, Georgiou, Turney \& Macken-Horarik, 2019; Ogborn, Kress, Martins \& McGillicuddy, 1996). Transdisciplinary research is very different from 'inter-' or 'multidisciplinary' research (Halliday, 2003 [1990]). The latter implies research pursued within the disciplines while building bridges between them and/or assembling the research efforts into a 'collection', whereas transdisciplinary research seeks to transcend disciplinary boundaries to achieve the integrated focus necessary for investigating the multimodal literacies of science education. This means that researchers need to commit to reading and participating in discourses of research beyond the discipline(s) that they were trained in, and that become their principal disciplinary career focus through which their prestige is established (Unsworth, 2008). We believe the further development of this ongoing commitment amongst a substantial and increasing number of science education, social semiotic and literacy education researchers is crucial to a sustained enhancement of science education as new and evolving forms of infographic and digital animated representations continue to emerge in science research, community and educational communications (Falkner \& Vivian, 2015; Polman \& Gebre, 2015; Tang, Won, Mocerino, Treagust \& Tasker, 2020).

A key concern of this transdisciplinary enterprise is explicating the nature of multimodal representations as mediating tools and facilitating their strategic deployment in science pedagogy while simultaneously developing students' metarepresentational competence through a functional, accessible metalanguage shared amongst teachers and students. Developing science teachers' knowledge of the processes of semiosis underpinning multimodal 


\section{2}

literacy will empower them to engage critically and creatively with current and emerging forms of representation in the rapidly evolving nature of multimodal disciplinary literacy. In this chapter, we highlight examples of the kinds of transdisciplinary research agendas that are addressing contemporary and emerging multimodal literacies in school science, and are contributing to determining pedagogic pathways for teachers and students to optimize science learning through navigating the evolving nature of multimodal representations as mediating tools.

In the following sections of the chapter, we discuss two rapidly evolving forms of representation in increasingly widespread use in science education which warrant more than the limited research afforded them to date. The first of these we refer to as infographics, which are image-language ensembles consisting of one or more images of various kinds (e.g. photographs, diagrams, graphs, maps) that may be annotated and/or include interpolated text blocks, as well as an identifying caption. Such infographic portrayals epitomize the current emphasis on the image as the rhetorical locus of paper and digital media texts and characterize many contemporary science textbooks, brochures on science/health topics for public communication, popular science websites and may also be included in scholarly scientific writing (Bateman, 2008; Bezemer \& Kress, 2010; Danielsson \& Selander, 2016; Gebre \& Polman, 2016; Kress, 2005; Peterson, 2016; Polman \& Gebre, 2015). Student-constructed responses to short-answer questions in finalyear science examinations also frequently require a succinct form of infographic presentation. The second of these evolving, popular representations are science animations, which are increasingly used in scientific research, on digital complements to contemporary textbooks, on popular public internet platforms such as 'YouTube', as part of science learning in schools and in school science assessments (Unsworth, 2020c). Recognizing the epistemological integrity of the sub-disciplines of physics, chemistry and biology and the consequent distinctive aspects of the multimodal literacies they entail (along with some commonalities), we know that emphases in the various infographic and animation genres will vary with the discipline area. This means that representational choices from the meaning-making resources of language and image may be skewed according to the epistemological orientation of the discipline to the phenomena being portrayed. However, a key unifying factor with respect to disciplinary literacy for all science teachers is the underlying knowledge of the semiotic descriptions of the meaningmaking resources of language and image, which enables discussion amongst teachers and students as to how such resources are deployed in their particular disciplinary literacies. This underlines the significance in our framework of a shared metalanguage amongst teachers and students to facilitate discussion of the semiotic affordances of different kinds of representations and the building of students' metarepresentational competence as key to their disciplinary literacy development (see Figure 6.5). In our discussion of infographics and animations, we will focus on two interrelated and central inter-semiotic relations that have received little research or pedagogic 
attention. The first of these is image-language integration - how the distribution of meaning-making is coordinated across these two semiotic modes and the second is transduction of meaning - how the meanings related to a particular phenomenon that are committed in one representational mode, such as a diagram/drawing, are augmented/complemented/diminished/ reformulated, etc., when that phenomenon is represented in a different mode such as a language (or a symbol, graph, formula, etc.) or, for example, how the meanings committed in the dynamic representation of an animation are transduced in a static diagrammatic representation (Bezemer \& Kress, 2016; Kress, 2010; Volkwyn, Airey, Gregorcic \& Heijkenskjöld, 2019). While image-language integration and transduction are established as crucial semiotic processes in the multimodal communication of scientific meanings, the paucity of research and pedagogic attention they have received to date and their significance in the use of infographics and animations in scientific discourse sharpens their importance as an immediate agenda for advancing transdisciplinary research to inform the development of multimodal disciplinary literacy in 21 st-century science pedagogy.

We conclude this chapter and the book by envisioning possibilities for further developments in researching multimodal literacy infused science pedagogies (MLISPs) that have been beyond the scope of the present work, such as a learning progressions perspective (Jin, Mikeska, Hokayem \& Mavronikolas, 2019; Lehrer \& Schauble, 2015) on the role of metalanguage in developing students' metarepresentational competence (diSessa, 2004). Drawing on our experience in the Multiliteracies in Senior School Science (M3S) project, we emphasize the potential of transdisciplinary researchoriented, intra-subject, cross-grade collaborations within and amongst schools and research communities in pursuing such agendas.

\subsection{Infographics - constructing meaning through image-language integration}

\subsubsection{Deployment of image and language in infographic design}

Infographics are image-language ensembles composed of one or more images as their rhetorical locus, which may be annotated in a variety of ways, and optionally interpolated text blocks within the infographic frame, as well as an optional identifying caption. Such portrayals are increasingly widely used in science education. However, little research or pedagogic attention has been given to how these image and language components of infographics combine in the construction of meaning. Consequently, there is a dearth of information to support the development of students' critical reading to learn from such representations and the development of their effective creation of science infographics (Gebre \& Polman, 2016; Polman \& Gebre, 2015; Walsh \& McGowan, 2017).

Recent and ongoing semiotic research analyzing infographics in high school science textbooks and related websites has started to document the 


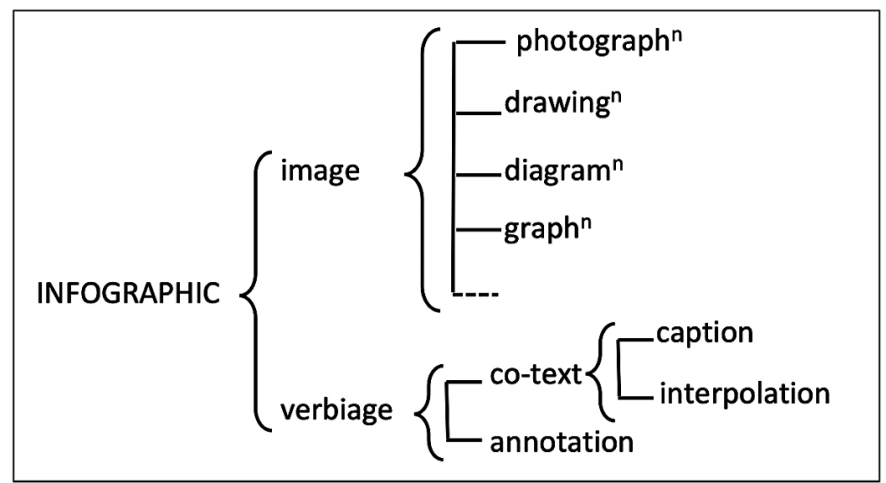

Figure 12.1 Simplified summary of options for the deployment of images and language in infographics.

repertoire of options for ways in which images and language are deployed in these multimodal representations (Martin \& Unsworth, forthcoming; Martin, Unsworth, \& Rose, in press; Unsworth, 2020a). A simplified representation of these options is indicated in Figure 12.1.

Figure 12.1 indicates that the image component of infographics can consist of one or a combination of one or more of the several types of images such as photographs, drawings, diagrams or graphs. The verbiage components can include annotations and/or co-text, which can consist of a caption and/or one or more interpolated text blocks. The co-text as caption or interpolated text block relates to the image as a whole, whereas annotations relate to specific parts of the image. Examples of interpolated text blocks can be seen in Figure 12.2.

Both images and verbiage construe what we can refer to as the field of the representation. Field is a resource for construing phenomena as activities alongside the taxonomies of items involved in these sequences (organized by both classification and composition), along with associated properties (Doran \& Martin, 2021). Some images depict only compositional meanings (part-whole relations) and some only classification or only activity, but in some cases, images can depict combinations of these and likewise with annotations or interpolated text blocks. In Figure 12.3, for example, the image depicts only composition, but the annotations construe composition, activity and property, while classification does not occur in either the image or the verbiage.

Composition construed by the annotations in Figure 12.3 usually names the item and its component parts. For example, the ossicles are composed of the hammer, anvil and stirrup. The realizations of activity in the annotations can be as figures (clauses) such as, 'It (the outer ear) funnels sound into the ear canal' - or, 'Sound reaching the eardrum makes it vibrate'. But activity can also be realized by an activity entity (in the form of a noun group) such as, 'Vibrations of the eardrum' in the annotation of the ossicles, which is a condensation of the construction of this activity as a figure or clause in 

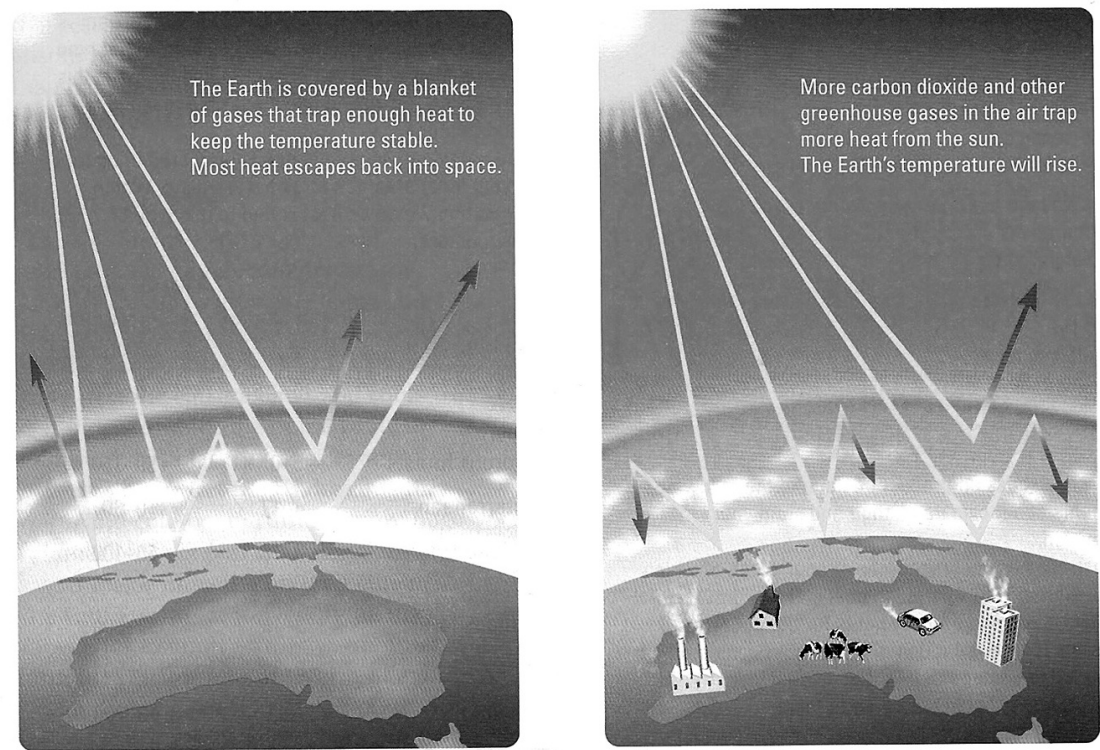

Greenhouse gases and the enhanced greenhouse effect

Figure 12.2 The greenhouse effect (Lofts \& Evergreen, 2015, p. 228).

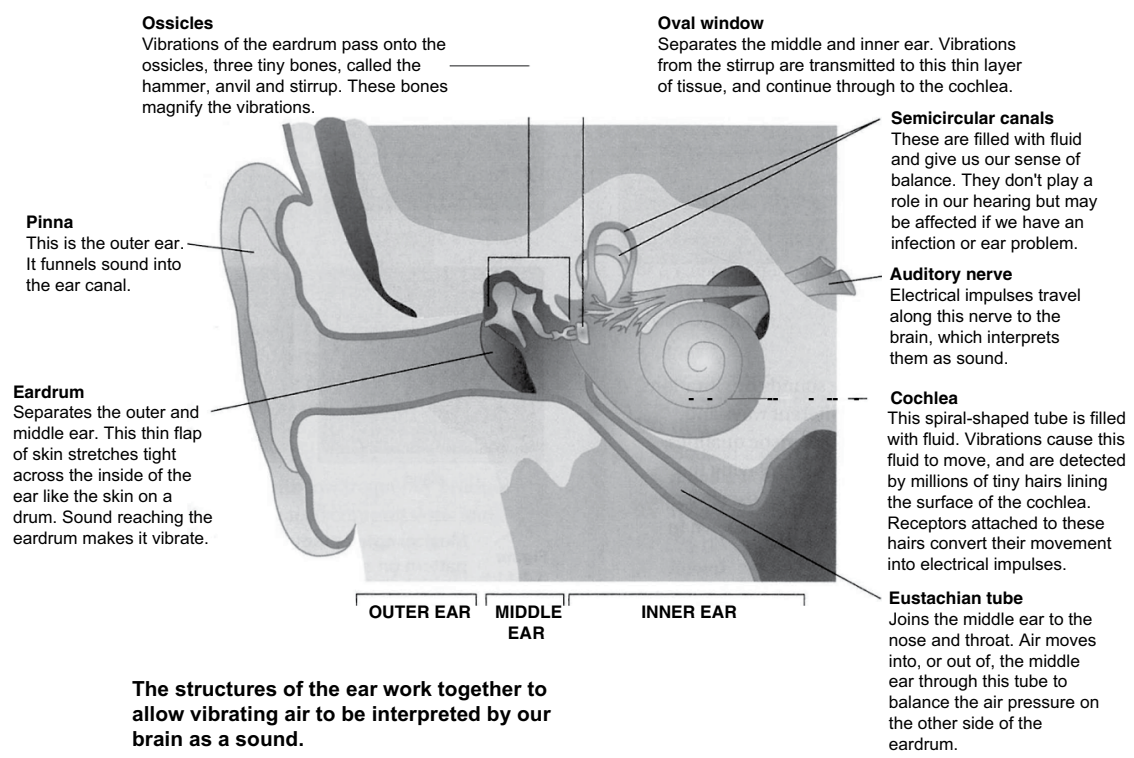

Figure 12.3 Infographic representing the composition and functioning of the ear Rickard, G. (2017, p. 108). Pearson Science 9. Melbourne, Pearson. 


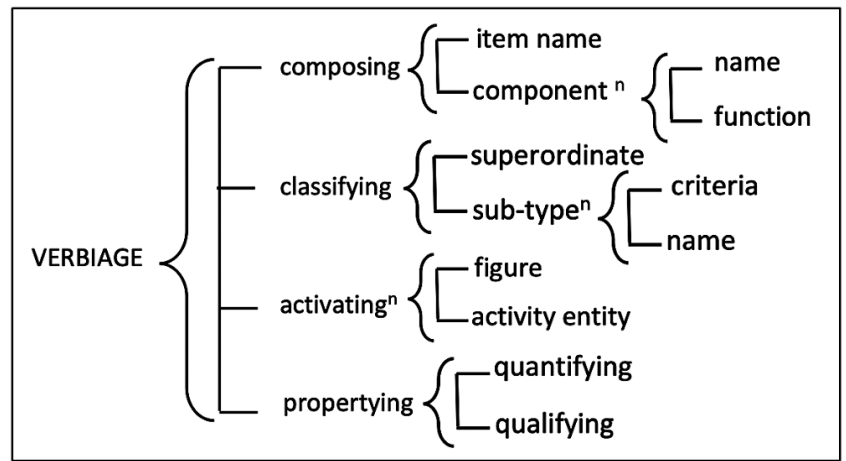

Figure 12.4 Simplified summary of options for construing field through verbiage in infographics.

the eardrum annotation ('Sound reaching the eardrum makes it vibrate'). The annotations also construct properties such as the tightness of the skin stretched over the eardrum or the oval window as a 'thin' layer of tissue. In images that depict classification, the verbiage identifies the superordinate item, names the subordinate category and optionally indicates the criteria for membership of sub-categories. We can summarize these options for field construal in infographics as indicated in Figure 12.4.

Additional to the construal of these aspects of field, the verbiage can also realize causal relations. In Figure 12.3, for example, in the annotation on the cochlea, 'Vibrations cause this fluid to move...'

In infographics some meanings may be constructed by the image(s) only, and some meanings may be constructed by the verbiage only. In Figure 12.3, activity associated with the functioning of the ear is constructed only in the verbiage. In Figure 12.2, the activity of the energy radiated from the sun to the earth and the reflection of some radiation from the earth's surface is realized only in the images. The coordination of this distribution of meaning-making across the two modes and the maintenance of inter-modal coherence is crucial to the interpretability of the infographic.

\subsubsection{Student coordination of image and language in infographic representations}

Few studies of student-created multimodal representations have addressed the nature and extent of the co-articulation of image and language, and where this has been addressed, the semiotic basis for its examination has been severely limited. Somewhat peripherally related to image-language co-articulation, a study of high school students' creation of science infographics sought to determine the extent to which the non-text representations communicated distinctive meanings related to the topic that were not also communicated in other non-text representations or that were not already communicated by textual descriptions (Gebre \& Polman, 2016). 
A different approach that considered the linking of image and language taken by McDermott and Hand $(2013,2016)$ was adopted in a number of related studies reported in Hand, McDermott and Prain (2016). McDermott and Hand $(2013,2016)$ showed that middle and high school students in biology and chemistry were not able to optimally articulate images and language in their multimodal representations. They designed a one-lesson intervention to build student awareness of ways to improve the integration of non-text modes in their multimodal representations. This lesson culminated with a joint student- and teacher-generated checklist for assessing what they called the embeddedness of multimodal science representations, which students then used to self-evaluate their work. In the researchers' scale for assessing the average embeddedness, each use of a non-text mode was awarded a point for any of the following characteristics: next to the text, referred to in the text, including a caption, scientific accuracy, completeness (amount of detail) and originality (created by the student and not adopted from another source). The first three are inter-modal linking devices, but it is not clear whether the text refers to main text accompanying the multimodal representation, interpolated text as part of the multimodal ensemble or an annotation. There is also no mention of lines or arrows, which are frequently used to link image and text in these kinds of multimodal representations. Nor was there any consideration of the ways in which the combination of image and language constructed the ideational meanings relevant to the topic. Another form of inter-modal linking refers to meanings that are committed in image or language alone and those that may be committed in both modes. This was taken up in the infographics study (Gebre \& Polman, 2016) but was not considered in the research by McDermott and Hand (2016). A very broad notion of linking image and language incorporating some indication of meaning-making was included in the communication section of a rubric evaluating students' learning about osmosis as indicated in their construction of a computerized model or a paper media multimodal representation (Fuhrmann, Schneider \& Blikstein, 2018). According to the rubric, points were allocated to student responses on the following basis:

(0) No label or text in proximity to the drawing

(1) Student includes a word, words or arrows in the drawing, indicating an understanding of the value of labelling and illustrative graphic elements in visual representations of scientific explanations

(2) Student describes the movement of particles in a sentence or more and includes arrows and labels in drawings

In these studies, the lack of theorization of the available options for the textual forms in which language can be incorporated into infographic representations, and how these textual forms could be linked to images, as well as the very limited attention to how meaning is distributed between the language and image(s), severely constrained the capacity of the research findings to inform pedagogy that would improve students' interpretation and creation 


\section{8}

of infographic representations. In this section, we note the centrality of the co-articulation of image and language in student-created multimodal representations in science learning and assessment and outline approaches in the few studies that have sought to develop this aspect of students' infographic creation. We then provide a brief case study from the M3S project comparing the co-deployment of image and language in high- and low-achieving infographic responses to an examination question by year 11 students in order to show how the uptake of options for image-language deployment in Section 12.2.1 are reflected in the different achievement level responses and the potential of the MLISP framework (Figure 6.5) to inform the pedagogy needed to improve this aspect of all students' infographic creation.

The use of multimodal student-created representations linking image and language has been increasingly advocated over recent years as a core aspect of student inquiry to enhance science learning (McDermott \& Hand, 2013; Tytler, Prain \& Hubber, 2018). Substantial evidence has accrued as to the efficacy of learning experiences in multimodal representation construction in developing students' scientific understanding (Hubber \& Tytler, 2017; McDermott \& Hand, 2013). Support for such approaches in science pedagogy has also been based on the widely acknowledged view that the processes of creating and coordinating different modes of representation reflect the practices of scientific research and hence are central to the processes of student induction into the disciplinary literacy of science (Hubber \& Tytler, 2017; McDermott \& Hand, 2016). While representation construction approaches in science pedagogy have included a wide range of different kinds of representations, such as role plays and 3D constructions, the majority involve students' construction of images with text and frequently one or more images with one or more different forms of text, such as annotations of drawings, captions and interpolated text blocks often aligned with (adjacent, above or below) the image(s). This kind of image-prominent combination of various forms of visualizations and verbiage also typifies the expected form of student-constructed responses to many of the short-answer questions in senior high school final-year science examinations in countries like the United Kingdom, Singapore, Australia and New Zealand.

While the multimodal representations students are encouraged to construct in science learning rely on the effective co-articulation of image and language, and when they are used in science assessments, crucially combining this with precision in visual and verbal communication, very few studies have addressed how students learn to accomplish this inter-modal co-articulation and precision of expression (McDermott \& Hand, 2013, 2016). Recognition of 'the absence of research literature to inform the design process about ways and means of reading and creating "quality" infographics'(Polman \& Gebre, 2015, p. 874) has prompted science education researchers to work with expert infographic creators and scientists to derive criteria and advice about the intersection of the multimodal semiotic design of infographics and the validity, accuracy and clarity of their conceptual representations, and to use peer and expert feedback to support students in refining and 
improving their infographics (Gebre \& Polman, 2016; Polman \& Gebre, 2015; Walsh \& McGowan, 2017).

Key aspects for attention included the following:

- Re-orienting students' image creation from the iconic or depictive to more abstract visualizations,

- Ensuring the coherence of infographics through the interdependence of visual and verbal representations,

- Deploying text succinctly without hindering communication through omission,

- Labelling visualizations where they are essential and purposeful only and

- Developing dexterity and clarity in visual and verbal representations.

In the M3S project, it was very clear that these issues of multimodal literacy distinguished the multimodal representations of the higher-achieving students from those of their lower-achieving peers. In Chapter 6, we exemplified this differentiation in students' multimodal responses to an explanation task about electric motors. Here we further illustrate this multimodal literacy differentiation between high- and lower-achieving students in their responses to a short-answer assessment item in chemistry.

A year 11 chemistry class in the M3S project was required to answer the following question as part of the culminating assessment at the conclusion of a sequence of lessons dealing with ionic bonding:

When an experimenter adds $50 \mathrm{~g}$ of solid sodium nitrate $\left(\mathrm{NaNO}_{3}\right.$, an ionic salt) to $100 \mathrm{ml}$ room temperature water it will all readily dissolve. Explain how this occurs with reference to the bonding between particles.

(Use a diagram to aid your explanation)

We will compare the responses of a higher-achieving student, Amri, and a lower-achieving student, Sim. Noting the conceptual errors in Sim's response, we draw attention to the more apposite choice and more dexterous creation of diagrams by Amri, as well as the more effective use of annotation for multiple purposes and appropriate use of different grammatical forms. The answer provided by Amri is shown in Figure 12.5 and that of Sim in Figure 12.6.

The mention by both students of ion-dipole bonding suggests their understanding that when an ionic compound such as sodium chloride or sodium nitrate is added to water, the positive ends of the water molecules are attracted to the negatively charged chloride or nitrate ions, and the negative ends of the water molecules are attracted to the positively charged sodium ions. The attraction between the water molecule's dipoles and the oppositely charged ions in the sodium nitrate is made explicit in the second clause of Amri's explanation

The water molecules' dipoles gradually pull each ion from the ionic lattice with the oppositely charged dipole. 
The 50 g of $\mathrm{NaNO}_{3}$ will readily dissolve in water cos a result of the ion-diple bonding that is promoted. The water molecules' dipoles gradually pull each iop from the ionic lattice with the oppositely charged dipole.

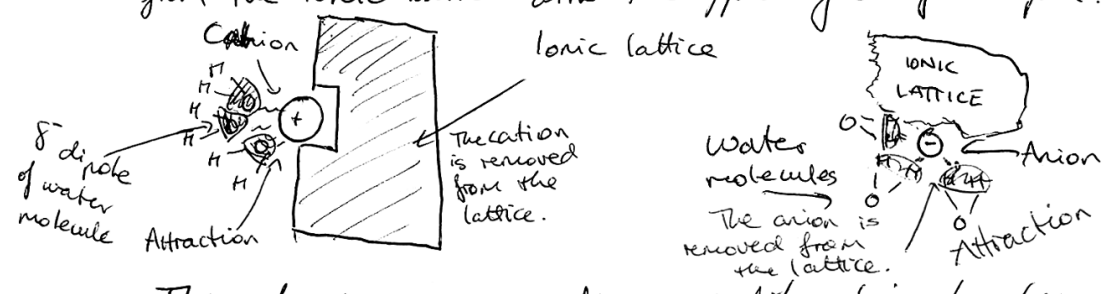

The above process continues until eachion has been stringed from the lattice by the water or if there is a greaber anount of the ionic substance than water molecules with which to bond.

Figure 12.5 Amri's explanation of water as a solvent for sodium nitrate.
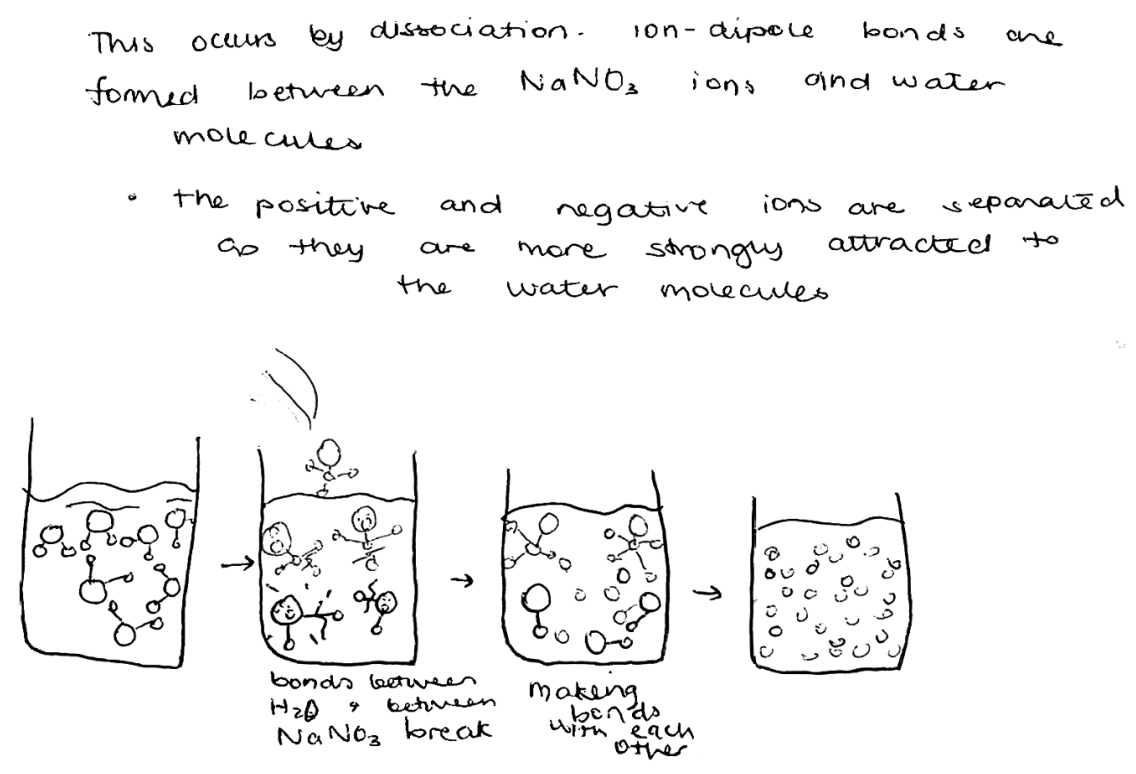

Figure 12.6 Sim's explanation of water as a solvent for sodium nitrate.

But this ion-dipole attraction is not as clearly specified in Sim's text.

The positive and negative ions are separated as they are more strongly attracted to the water molecules.

A key limitation of Sim's explanation is the omission of the ionic lattice in either the language or the image. This is evident in the very different 
approaches to diagrammatic representation by each student, their very different choices of image types and the differences in the precision of their representation of image elements. Amri's diagrams (Figure 12.5), albeit non-canonical, are two quite separate, highly abstract and decontextualized conceptual sub-microscopic depictions of the processes of dissociation. The separation of the depictions of what happens with the cation and the anion in two discrete drawings emphasizes the focus on communicating a conceptual explanation. Both of these drawings include the representation of an ionic lattice for sodium nitrate, albeit in a minimalist highly schematic form with no detail, which may reflect the unfamiliarity of students with the complex nature of the sodium nitrate lattice. The drawings emphasize the cation and anion being removed from the edge of the lattice, and detailed depiction indicates the activity through the wavy lines implying movement between the cation and the oxygen end of the water molecule, in the left-hand diagram. The water molecules are accurately represented, and colour is used to further distinguish the hydrogen and oxygen. Sim's diagrams (Figure 12.6), although also representing a sub-microscopic view, include more macroscopic contextualization in the form of a container and include arrows to show the sequence of the experiment rather than focussing on the activity involved in dissociation. The only activity that might be inferred from drawing two to drawing three is that the previously represented water molecules appear to no longer be intact in drawing three and there appear to be some detached nitrate ions also in drawing three. The first of Sim's drawings includes a fair representation of the water molecules. In the second drawing, Sim attempts to represent the sodium nitrate in a similar fashion to the water molecule rather than as a lattice. The inaccuracy of the annotation below this drawing, indicating that the 'bonds between $\mathrm{H}_{2} \mathrm{O}$ and $\mathrm{NaNo} 3$ break making bonds with each other', betrays Sim's lack of understanding of dissociation. This is also reflected in the third drawing, which has several depictions of what appears to be one oxygen atom connected to one hydrogen atom. It is not clear what is being represented by the blue and green circular depictions in the fourth diagram.

The extensive and varied types of annotation in Amri's diagrams deal with composition as well as activity. Key items represented are named or indicated by symbols such as $\mathrm{H}$ or $\mathrm{O}$. In addition, activity is either named as an activity entity ('attraction') or the action is described as a figure (clause) as in 'the cation is removed from the lattice'. The latter is positioned as an unnumbered caption adjacent to the left-hand image. A similar un-numbered caption, 'the anion is removed from the lattice' is located below and to the left of the right-hand image. The other annotations are connected to the relevant image elements by arrows. By contrast, Sim uses almost no annotation at all except for a one-sentence sub-posed caption-like annotation 'bonds between $\mathrm{H}_{2} \mathrm{O}$ and NaNo3 break making bonds with each other'. Amri includes some information in the diagram which is not mentioned in the main text, such as the naming of the cation and anion. No additional information is provided in Sim's diagram. The positioning of the diagrams in Amri's response in relation to the text blocks is also highly cohesive. 


\section{2}

The final sentence of the top text block indicating the activity of the water molecule dipoles pulling the ions from the lattice is then elaborated visually and verbally in the diagrams below it by 'momenting' - showing diagrammatically the constituting sub-activity. Cohesion is also achieved in the bottom text block as the beginning of the first sentence 'condenses' the prior multimodal explanation succinctly as, 'The above process'.

In seeking to provide an explanation of the phenomenon described in the assessment task, Amri was able to choose a more effective type of image apposite to the task and was able to depict the detailed elements of the image with clarity. Amri made more extensive use of a variety of types of annotation to construct both composition and activity relations, whereas Sim made very minimal use of annotation. The commonality and complementarity of meaning representation across image and language were effective in Amri's deployment of these modes, whereas Sim's diagram showed only the structure of the water molecule and the sequence of the experiment in addition to what was in the text. Amri's coordination of annotated diagrams and interpolated text blocks was also highly cohesive. Amri was more effectively able to deploy the resources of language and of image to construct a clear and accurate representation, albeit avoiding the challenge of including a detailed representation of the ionic lattice for sodium nitrate. While Sim's apparent misconceptions about the nature of dissociation and lack of knowledge about the sodium nitrate lattice are central to the inadequacy of the response, it is also clear that Sim doesn't understand what to focus on to form a convincing explanation, nor has his explanation the precision needed in coordinating text and image to create a clear causal explanation.

In the case of the work of the physics students discussed in Chapter 6 and that of the chemistry students discussed here, it is clear that the student responses at the higher rank of achievement differ from those at a lower rank in relation to the strategic choice of apposite image types, the dexterous depiction of image elements, the extent and variety of annotation, the functional distribution of meaning across the modes of image and language and the nature and extent of the linking of the images to the explanatory text blocks. Such examples underline the importance of a dual focus on pedagogic attention to developing students' scientific knowledge and how it is constructed and communicated through multimodal representations. By managing opportunities for collaborative sharing, the teacher could jointly emphasize both the 'what' and the 'how' of Amri's successful response, thereby demonstrating to all students how drawing on their scientific knowledge and deploying their representational competencies are intertwined in creating successful infographic explanations.

\subsection{Evolving dimensions of animation and novel contexts for transduction of meaning}

Animation is now pervasive in science as an evolving resource for scientific investigation and for the representation and communication of 
knowledge about complex processes in new areas of scientific discovery (Unsworth, 2020b). In science education, animations have been used to support science teaching and learning for several decades (Smetana \& Bell, 2012). However, while a prodigious amount of research has accumulated on the use of animation in science education, little attention seems to have been given to the semiotics of animation either as a resource for informing pedagogy or as explicitly taught facilitative knowledge for enhancing science animation interpretation and creation. In this section, we focus on frontier issues for semiotic and science education research dealing with the nature and role of transduction of meaning from one representational mode to another (Bezemer \& Kress, 2016; Kress, 2010) in the use of student-created animation in a representation construction approach to science pedagogy (White, Tytler \& Nielsen, 2020) and in student learning through interacting with $3 \mathrm{D}$ animations in the context of immersive virtual reality (IVR; Tang et al., 2020). We firstly outline the nature of transduction and its significance for science education, noting recent studies and examples of our experience of transduction in high school physics and chemistry classes in the M3S project. Following from this, we briefly illustrate the importance of transduction in student learning from creating their own animations in year 11 biology and then the role of transduction in innovative contexts for student learning through their experience of animation in IVR.

\subsubsection{Transduction in science learning and teaching}

Transduction involves relating the representation of a phenomenon in one mode, such as an image, to its representation in another mode, such as speech or writing (Kress, 2010, p. 125). Because the representational resources (semiotic affordances) in one mode differ from those available in other modes the representation of a phenomenon in any mode is always and inevitably partial with variation in the nature of that partiality with each mode (Bezemer \& Kress, 2016; Kress, 2010). Hence, transduction from one mode to another can never mediate full understanding of the phenomenon represented and what is required is a multimodal ensemble of representations leveraging the affordances of different semiotic systems to optimize understanding of the phenomenon (Volkwyn et al., 2019). Transduction is inherent in science practice as indicated in the accounts by Latour and Woolgar (2013) describing scientific instrumentation as 'inscription devices' for transforming the materiality of scientific work through a series of progressive representations into literacy products, as we noted in Chapter 2. Volkwyn et al. indicated that 'physicists tacitly use the changes in meaning potential that transduction entails to both do physics and teach physics' (Volkwyn et al., 2019, p. 16). From a pedagogic perspective, Airey and Linder, drawing on data from university physics students, indicated that re-representation across modes offers students 'the possibility of opening up further facets of a disciplinary way of knowing that a learner was previously unaware of, or unable to fruitfully access' (Airey \& Linder, 2009, p. 39). Science learning entails students negotiating 


\section{Advancing multimodal literacy}

the relationships amongst representations of observable macro-phenomena, unobservable sub-microscopic or abstract phenomena and symbolic representations (Johnstone, 1993), so relating the representations of phenomena in different modes is an essential process in science learning.

However, research on transduction has largely focussed on how modes are mutually supportive when presented in textbooks or presentations (e.g. Svensson \& Eriksson, 2020), or on how multiple representations are conscripted to develop understanding, without specifying how the meanings inherent in each mode are transferred, aligned or coordinated. Recent research has probed the nature of processes involved in students' negotiation of transduction as involving imaginative reasoning to align elements of each representation, or in attending to coherence and correspondence across modes in the transductive process (Prain \& Tytler, under review). In the M3S project, as discussed in Chapter 8 (Section 8.3.1), we pursued this agenda with Paulo, a senior physics teacher, in his teaching of equivalent resistance in a series circuit. We described Paulo's strategic use of gesture and talk, demonstrating attention to the explicit linking of elements of symbolic equations, multiple versions of circuit diagrams aligned to emphasize links with the equations and a material demonstration to link conceptually to the construct of gravitational potential energy. We argued that the coordination of these different representations addresses transduction across modes and involves reinterpreting symbolic expressions in spatial terms, which entails analogy and reinterpretation of elements of the representations if these are to be flexibly understood in ways that enable problem-solving. In this way, the flexible, creative pedagogic processes of the teacher supported students in negotiating these disciplinary transductions across modes. Further examples of teacher explication of transduction involved relating a visual simulation of a simple electric motor to a verbal explanation of its functioning (see Chapter 8, Section 8.3.2) and relating macro representations of motion to tables, figures, and graphs and then equations of motion, in a topic on kinematics involving representations of displacement, velocity and acceleration-time graphs (see Chapter 8, Section 8.3.3). In Chapter 4, we introduced aspects of a doctoral study on transduction in teaching senior chemistry by our co-author Lam Pham (2020), which was further investigated in the M3S project, as discussed in Chapter 9. This involved year 11 students coordinating a 'bridging model' to help them read and solve problems involving molar concentration. The model uses crosses to represent moles, and boxes to represent litres of solute, to coordinate with mathematical calculations of concentration. This 'cross and portion' model is used by these students to underpin the symbolic mathematical calculations predicting the concentration of a solution formed by mixing two solutions of different specified concentrations. In this case, the 'cross and portion' visual model supports the students' negotiation of transduction across different representational modes by providing an anchor to the quantities represented in the mathematical representation. These emerging insights into transduction in science learning and teaching warrant further development of this research 
trajectory. As current and emerging forms of animation are increasingly used in science and science education, additional novel contexts for transduction assume a highly significant role in digital multimodal disciplinary literacy.

\subsubsection{Animation and transduction in the digital multimodal discourse of science education}

Research on animation in science education has predominantly dealt with student learning from expert-created animations - with generally positive effects (Berney \& Bétrancourt, 2016). However, few studies have investigated the effects of student-created animations. This may have been partly due to the complex and time-consuming animation methods available to students, but a novel approach to animation creation, known as 'slowmation' introduced to pre-service teacher education students has been widely taken up in schools (Hoban, 2020; Hoban, Loughran \& Nielsen, 2011; Hoban \& Nielsen, 2013; Hoban, Nielsen \& Shepherd, 2015). In Chapter 4, we briefly outlined a study in which year 11 biology students re-interpreted a biology textbook segment about digestive processes, which they had previously studied, to construct a slowmation movie (White et al., 2020). We drew attention to the challenges the students confronted in the cross-modal translation from the text and static images of the textbook to represent activity in the slowmation animation as a temporal account of various processes, such as the breaking down of macroscopic food into sub-microscopic sugars, visualizing the physical operation of the bolus's passage through the pyloric sphincter and representing the sequence of events as chyme is broken down. Through negotiating this transduction across representational modes, dealing with the different semiotic affordances of the textbook representation and the slowmation animation, the students' engaged with complementary dimensions of meaning and developed an enriched reinterpretation of the phenomena. While student-created animation in science classrooms is not yet widely adopted, slowmation is increasingly popular, and as animation software for students is becoming more readily accessible and usable, and more students are learning to code animations from early primary school, it is clear that animation creation is likely to become as prominent in science education as it is in science research and practice (Hoban, 2020; Unsworth, $2020 \mathrm{~b}$ ). From our observation, the use of expert-created animations in science teaching appears ubiquitous. This clearly entails students negotiating transduction of dynamic representations in the animations from which they are learning to the static representations in textbooks, examination papers and their paper media inscriptions as part of their learning or formative assessment responses. To date, we have not encountered any research into how these transductions are managed by students or supported in teaching practice. This is an important agenda that warrants take-up by researchers in multimodal disciplinary literacy in science education.

Until recently, the default perceptions of animations in science education have tended to fall rather dichotomously into students learning by 


\section{6}

responding to expert animations or actively creating their own animations, but the advent of animation in the context of IVR involves students learning by interacting with $3 \mathrm{D}$ animations. IVR involves wearing a head-mounted display over the user's eyes, which tracks user position and projects stereo images for each eye corresponding to where the user is looking in the virtual environment so that users perceive themselves as located within the virtual environment (Jensen \& Konradsen, 2018; Pottle, 2019).

An exploratory investigation by Kok-Sing Tang and his colleagues using IVR was designed to support first-year university students' understanding of molecular interactions (Tang et al., 2020).

Through analysis of video recordings, researchers determined how students coordinated the various modes (e.g. words, images, body movement) in conjunction with their chemistry meaning. The IVR provides users with 360-degree, all-around viewing so that users can view the objects from different perspectives. Two users can view objects from different perspectives, simultaneously providing different observations and information to address problem-solving, facilitating a form of collaboration distinctive to IVR. Users can also manipulate the objects in the virtual environment via hand controllers. In the Tang et al. study (2020), students could walk around the enzyme, rotate it and change its size to the extent that they could enter inside the enzyme. The students could also toggle between different animated models of the enzyme (surface, mesh, ball-and-stick, cartoon and ribbon models). By switching models, they could compare across the different representations how meanings were made about the characteristics of the atoms or molecules. This is facilitated by the spatial correspondence that is maintained in toggling, enabling users to notice the corresponding relationship from a specific part of a model to the same part of another model. Of course, two or more physical models can be compared but IVR toggling allows students to seamlessly compare different models.

It is the distinctive combination of semiotic affordances of animation in IVR enabling users to experience and move back and forth between multiple representations of the same phenomena that provides practical support for, and leverages the effect of, negotiating the transductions across representational modes in building students' understanding of the representational bases of scientific concepts. The pedagogic advantage of the interaction of the various affordances of this application of animation in IVR is further illustrated succinctly by the authors of this study by comparing the representation of the protein structure of acetylcholinesterase on a flat screen and as an IVR experience. They point out that seeing the individual atoms and bonds on a flat screen is challenging because without the resolution of depth, the large number of atoms and bonds surrounding the object of interest makes it difficult to distinguish an individual atom from its surrounding. However, since in IVR the user is located inside the protein structure with a sense of depth such that as the user zooms into or out of the structure, the position of every atom and bond in relation to the object of interest is clearly visible. The authors note instances of the students' metarepresentational focus on 
the process of transduction. One pair of students in the Tang et al. study (2020), discussed the advantage of being able to observe the entire reaction in terms of the activity of individual molecules, atoms and bonds, comparing this to the use of arrows in traditional textbook depictions of chemical reactions. This study suggests that IVR is an important learning environment in supporting students' negotiation of transductions across representational modes, which underpins the advantages of using multiple representations in science pedagogy.

Students are already responding to and interacting with online animations as part of mandatory state-wide assessments in science in years 6,8 and 10 in government schools in New South Wales, Australia (English, 2020). The incorporation of online published animations in science teaching is very widespread in schools. Student-created animations are becoming more popular in representation construction approaches to science education (White et al., 2020; Yaseen, 2020), and while IVR applications in science education are in their infancy, especially in school systems, they are clearly emerging as important aspects of 2lst-century science teaching (Southgate et al., 2018). The crucial role of transduction in relating representations of science concepts in different modes, and different digital media, in teaching and learning practices needs to be a key agenda item in current and future science education research.

\subsection{Further developments}

In this concluding section of our book, it is salutary to reflect on the many aspects of an agenda for infusing multimodal disciplinary literacy into science pedagogy in senior high school that remain to be addressed. We have located multimodal representations as mediating tools at the core of our pedagogic framework and have emphasized the encompassing role of an accessible functional metalanguage shared amongst the teacher and students to facilitate the development of students' metarepresentational competence underlying their science learning through induction into the multimodal disciplinary discourse of their subjects. An important aspect of metarepresentational competence that needs to be clarified is what progression in this competence entails. However, it has been beyond the scope of the present work to address the important and complex issues of how our proposals relate to the concepts associated with learning progressions (Jin et al., 2019; Lehrer \& Schauble, 2015). Research on learning progressions has been concerned with the continuity of conceptual development and cumulative learning across grade levels focussing on 'big ideas' in the sub-disciplines of science. A highly regarded approach in science pedagogy reflecting science education researchers advocacy of using multiple representations is the representation construction approach (Tytler et al., 2018; Tytler, Prain, Hubber \& Waldrip, 2013). Proponents of this approach agree on the importance of students coming to understand the 'form and function' of visual and verbal representational resources, albeit with some debate as to how 
this should occur. However there has been scant attention to cross-grade progression in students' development of multimodal disciplinary literacy and metarepresentational competence, which would appear to be a lynchpin for enhancing science learning outcomes for students over the period of their experience in the school systems.

Determining an accessible and functional form of metalanguage that accommodates the multiple modes of representation involved in science education and determining how, when and to what extent such a metalanguage can be optimally productively infused into science pedagogy remain open questions. We have sought to bring together and seek areas of consensus amongst the various research endeavours addressing these questions but determining the nature of cross-grade scope and sequence for developing this kind of metalanguage of multimodality in relation to image-language integration and to transduction, is a crucial dimension yet to be included in these investigations. The transdisciplinary, design-based research methodology adopted for the M3S project with participating teachers as partner investigators seems to hold great potential for pursuing these challenging issues. The reasoning for this derives from our experience in the project of bringing together in their discipline areas, teachers of years 10-12 physics, chemistry and biology from four high schools in fairly close proximity to each other, for meetings to jointly plan teaching programmes of about two to three weeks duration on different topics for each grade level. Some of the teachers in each discipline area worked enthusiastically with the researchers and each other to do this planning. Some biology teachers had prior experience in professional learning concerning linguistic descriptions of science discourse and the role of metalanguage in multimodal disciplinary literacy development, and the classroom programmes planning for this group reflected this experience (see Chapter 7). In physics and chemistry, knowledge about the meaning-making resources of image and language as basis for multimodal literacy development was broached more generally; however, metarepresentational aspects were nevertheless incorporated in some of the teaching as outlined in Section 12.3.1. In our work, familiarizing teachers with matters of metarepresentational competence and metalanguage was at best introductory and tentative; however, as teachers had the opportunity to consider and actively implement some of the ideas we were proposing, it appeared that if more time were available the teacher collaboration with the transdisciplinary research team had the potential to progress pedagogic pathways for enhancing students' metarepresentational competence through grounded approaches to determining the nature, extent and timing of the use of appropriate metalanguage. While our project focussed on working with teachers within grade levels, these cross-grade planning groups, especially if extended to include all high school grades, could, over time, also examine issues of continuity and cumulative learning with respect to the introduction and development of appropriate metalanguage and cross-grade progression in multimodal disciplinary literacy. Such planning might embrace key representational matters such as student interpretation and creation of infographics and various 
forms of animation in conjunction with implications of learning progressions research for enhancing students' science learning throughout their school lives. Our hope is that ideas such as these, along with the framework discussed in this volume, will encourage, either through formal funded projects or school-education, authority-university co-operatives, further collaborative transdisciplinary initiatives for advancing multimodal literacy infused transdisciplinary research and teaching.

\section{References}

Airey, J., \& Linder, C. (2009). A disciplinary discourse perspective on university science learning: Achieving fluency in a critical constellation of modes. Journal of Research in Science Teaching, 46(1), 27-49.

Bateman, J. (2008). Multimodality and genre: A foundation for analysis. London: Palgrave Macmillan.

Berney, S., \& Bétrancourt, M. (2016). Does animation enhance learning? A meta-analysis. Computers \& Education, 101, 150-167.

Bezemer, J., \& Kress, G. (2010). Changing text: A social semiotic analysis of textbooks. Designs for Learning, 3, 10-29.

Bezemer, J., \& Kress, G. (2016). Multimodality, learning and communication: A social semiotic frame. London and New York: Routledge.

Danielsson, K., \& Selander, S. (2016). Reading multimodal texts for learning-a model for cultivating multimodal literacy. Designs for Learning, 8(1), 25-36.

diSessa, A. A. (2004). Metarepresentation: Native competence and targets for instruction. Cognition and Instruction, 22(3), 293-331.

Doran, Y. J. (2017). The discourse of physics: Building knowledge through language, mathematics and image. London: Routledge.

Doran, Y. J. (2019). Building knowledge through images in physics. Visual Communication, 18(2), 251-277.

Doran, Y. J., \& Martin, J. R. (2021). Field relations: Understanding scientific explanations. In K. Maton, J. R. Martin, \& Y. J. Doran (Eds.), Teaching science: Knowledge, language, pedagogy (pp. 105-133). London: Routledge.

English, J. (2020). Animation in online school science assessment: The validation of assessment for learning and individual development program. In L. Unsworth (Ed.), Learning from viewing and creating animations in science education: Innovative developments in semiotic and educational research (pp. 251-277). Cham, Switzerland: Springer.

Falkner, K., \& Vivian, R. (2015). Coding across the curriculum: Resource review.

Fuhrmann, T., Schneider, B., \& Blikstein, P. (2018). Should students design or interact with models? Using the Bifocal Modelling Framework to investigate model construction in high school science. International Journal of Science Education, 40(8), 867-893.

Gebre, E. H., \& Polman, J. L. (2016). Developing young adults' representational competence through infographic-based science news reporting. International Journal of Science Education, 38(18), 2667-2687.

Halliday, M. A. K. (2003 [1990]). New ways of meaning: The challenge to applied linguistics. In J. Webster (Ed.), On language and linguistics. volume 3 in the collected works of M.A.K. Halliday (pp. 139-174). London/New York: Continuum. 


\section{Advancing multimodal literacy}

Hand, B., McDermott, M., \& Prain, V. (Eds.). (2016). Using multimodal representations to support learning in the science classroom. New York: Springer.

Hoban, G. (2020). Slowmation and blended media: Engaging students in a learning system when creating student-generated animations. In L. Unsworth (Ed.), Learning from viewing and creating animations in science education: Innovative developments in semiotic and educational research. (pp. 193-208). Cham, Switzerland: Springer.

Hoban, G., Loughran, J., \& Nielsen, W. (2011). Slowmation: Preservice elementary teachers representing science knowledge through creating multimodal digital animations. Journal of Research in Science Teaching, 48(9), 985-1009.

Hoban, G., \& Nielsen, W. (2013). Learning science through creating a 'slowmation': A case study of preservice primary teachers. International Journal of Science Education, 35(1), 119-146.

Hoban, G., Nielsen, W., \& Shepherd, A. (2015). Student-generated digital media in science education: Learning, explaining and communicating content. London and New York: Routledge.

Hubber, P., \& Tytler, R. (2017). Enacting a representation construction approach to teaching and learning astronomy. In D. Treagust, R. Duit \& H. Fischer (Eds.), Multiple representations in physics education (pp. 139-161). Cham, Switzerland: Springer.

Jensen, L., \& Konradsen, F. (2018). A review of the use of virtual reality headmounted displays in education and training. Education and Information Technologies, 23(4), 1515-1529.

Jewitt, C., Kress, G., Ogborn, J., \& Tsatsarelis, C. (2001). Exploring learning through visual, actional and linguistic communication: The multimodal environment of a science classroom. Educational Review, 53(1), 5-18.

Jin, H., Mikeska, J. N., Hokayem, H., \& Mavronikolas, E. (2019). Toward coherence in curriculum, instruction, and assessment: A review of learning progression literature. Science Education, 103(5), 1206-1234.

Johnstone, A. H. (1993). The development of chemistry teaching: A changing response to changing demand. Journal of Chemical Education, 70(9), 701.

Jones, P., Turney, A., Georgiou, H., \& Nielsen, W. (2020). Assessing multimodal literacies in science: Semiotic and practical insights from pre-service teacher education. Language and Education, 34(2), 153-172.

Kress, G. (2005). Gains and losses: New forms of texts, knowledge, and learning. Computers and Composition, 22(1), 5-22.

Kress, G. (2010). Multimodality: A social semiotic approach to contemporary communication. London: Routledge.

Kress, G., Jewitt, C., Ogborn, J., \& Tsatsarelis, C. (2001). Multimodal teaching and learning: Rhetorics of the science classroom. London: Continuum.

Kress, G., \& Ogborn, J. (1998). Modes of representation and local epistemologies: The presentation of science in education. SISC Working Papers, 2, 2-22.

Kress, G., Ogborn, J., \& Martins, I. (1998). A satellite view of language: Some lessons from science classrooms. Language Awareness, 7(2-3), 69-89.

Latour, B., \& Woolgar, S. (2013). Laboratory life: The construction of scientific facts. Princeton: Princeton University Press.

Lehrer, R., \& Schauble, L. (2015). Learning progressions: The whole world is NOT a stage. Science Education, 99(3), 432-437.

Lemke, J. (1990). Talking science: Language, learning and values. Norwood, NJ: Ablex. 
Lemke, J. (2004). The literacies of science. In E. W. Saul (Ed.), Crossing borders in literacy and science instruction: Perspectives on theory and practice (pp. 33-47). Newark, DE: International Reading Association.

Lofts, G., \& Evergreen, M. J. (2015). Science quest 10: Australian curriculum (2nd ed.). Milton, Qld.: Jacaranda.

Martin, J. R., \& Doran, Y. J. (in press/2021). Seeing knowledge through field: Understanding scientific explanations. In K. Maton, J. R. Martin \& Y. J. Doran (Eds.), Studying science: Knowledge, language, pedagogy. London: Routledge.

Martin, J. R., \& Unsworth, L. (forthcoming). Reading images for knowledge building: Analyzing infographics in school science. London: Routledge.

Martin, J. R., Unsworth, L., \& Rose, D. (in press). Condensing meaning: Imagic aggregations in secondary school science. In G. Parodi (Ed.), Multimodality: From corpus to cognition. London: Bloomsbury.

McDermott, M. A., \& Hand, B. (2013). The impact of embedding multiple modes of representation within writing tasks on high school students' chemistry understanding. Instructional Science, 41(1), 217-246.

McDermott, M. A., \& Hand, B. (2016). Modeling scientific communication with multimodal writing tasks: Impact on students at different grade levels. In B. Hand, M. McDermott \& V. Prain (Eds.), Using multimodal representations to support learning in the science classroom (pp. 183-211). Cham, Switzerland: Springer.

Nielsen, W., Georgiou, H., Jones, P., \& Turney, A. (2020). Digital explanation as assessment in university science. Research in Science Education, 50(6), 2391-2418.

Nielsen, W., Jones, P., Georgiou, H., Turney, A., \& Macken-Horarik, M. (2019). Learning science through generating multimodal digital explanations: Contributions to multimodality in educational practice. In J. P. Janina Wildfeuer, John Bateman, Ognyan Seizov \& Chiao-I Tseng (Ed.), Multimodality: Disciplinary thoughts and the challenge of diversity (pp. 247-276). Berlin/Boston: de Gruyter.

Ogborn, J., Kress, G., Martins, I., \& McGillicuddy, K. (1996). Explaining science in the classroom. Buckingham: Open University Press.

Peterson, M. O. (2016). Schemes for integrating text and image in the science textbook: Effects on comprehension and situational interest. International Journal of Environmental and Science Education, 11(6), 1365-1385.

Pham, L. (2020). Students constructing representations to problem-solve and learn in senior chemistry [Doctorat dissertation]. Deakin.

Polman, J. L., \& Gebre, E. H. (2015). Towards critical appraisal of infographics as scientific inscriptions. Journal of Research in Science Teaching, 52(6), 868-893.

Pottle, J. (2019). Virtual reality and the transformation of medical education. Future Healthcare Journal, 6(3), 181.

Prain, V., \& Tytler, R. (2021). Theorising learning in science through integrating multimodal representations. Research in Science Education, September, 1-13. doi: 10.1007/s11165-021-10025-7

Rickard, G. (2017). Pearson science 9. Melbourne: Pearson.

Smetana, L. K., \& Bell, R. L. (2012). Computer simulations to support science instruction and learning: A critical review of the literature. International Journal of Science Education, 34(9), 1337-1370.

Southgate, E., Buchanan, R., Cividino, C., Saxby, S., Eather, G., Smith, S. P., ... Scevak, J. (2018). What teachers should know about highly immersive virtual reality: Insights from the VR school study.Svensson, K., \& Eriksson, U. (2020). Concept of a transductive link. Physical Review: Physics Education Research, 16(2), 026101. Tang, K.-S., Won, M., Mocerino, M., Treagust, D., \& Tasker, R. (2020). 


\section{Advancing multimodal literacy}

Multimodal affordances of immersive virtual reality for visualising and learning molecular interactions. In L. Unsworth (Ed.), Learning from viewing and creating animations in science education: Innovative developments in semiotic and educational research (pp. 75-101). Cham, Switzerland: Springer.

Tytler, R., Prain, V., \& Hubber, P. (2018). Representation construction as a core science disciplinary literacy. In K.-S. Tang \& K. Danielsson (Eds.), Global developments in literacy research for science education (pp. 301-318). Cham, Switzerland: Springer.

Tytler, R., Prain, V., Hubber, P., \& Waldrip, B. (2013). Constructing representations to learn in science. Rotterdam, The Netherlands: Sense.

Unsworth, L. (2008). Multiliteracies and metalanguage: Describing image/text relations as a resource for negotiating multimodal texts. In D. Leu, J. Corio, M. Knobel \& C. Lankshear (Eds.), Handbook of research on new literacies (pp. 377-405). Mahwah, NJ: Erlbaum.

Unsworth, L. (2020a). Intermodal relations, mass and presence in school science explanation genres. In Michele Zappavigna \& S. Dreyfus (Eds.), Discourses of hope and reconciliation: J. R. Martin's contributions to systemic functional linguistics (pp. 131-152). London: Bloomsbury Academic.

Unsworth, L. (2020b). A multidisciplinary perspective on animation design and use in science education. In L. Unsworth (Ed.), Learning from animations in science education: Innovating in semiotic and educational research (pp. 3-23). Cham, Switzerland: Springer.

Unsworth, L. (Ed.). (2020c). Learning from animations in science education: Innovating in semiotic and educational research. Cham, Switzerland: Springer.

Volkwyn, T. S., Airey, J., Gregorcic, B., \& Heijkenskjöld, F. (2019). Transduction and science learning: Multimodality in the physics laboratory. Designs for Learning, 11(1), 16-29.

Walsh, E. M., \& McGowan, V. C. (2017). 'Let your data tell a story': climate change experts and students navigating disciplinary argumentation in the classroom. International Journal of Science Education, 39(1), 20-43.

White, P., Tytler, R., \& Nielsen, W. (2020). Animation construction as cross-modal translation in senior biology. In L. Unsworth (Ed.), Learning from viewing and creating animations in science education: Innovative developments in semiotic and educational research (pp. 209-228). Cham, Switzerland: Springer.

Yaseen, Z. (2020). Using animation in the representation construction approach in senior high school chemistry. In L. Unsworth (Ed.), Learning from viewing and creating animations in science education: Innovative developments in semiotic and educational research (pp. 159-190). Cham, Switzerland: Springer. 


\section{Index}

Pages in italics refer figures and pages in bold refer tables.

Airey, J. 25, 67, 71, 112-113, 115$116,118,253$

analytic literacy 41

animations in science education: dimensions of 252-253; online 257; and transduction 255-257

Aranda, G. 89, 94, 98

argument-based inquiry models $\mathbf{8 7}, 88$ assessment regimes 63-64, 77-79

Bateman, J. 47

Bernstein, B. 8, 23

Bezemer, J. 5

biology, chemistry and physics 44 ; energy and matter 45 ; graphical information 47,47 ; 'mechanistic' explanation 45-46; polymers 45-46; protein synthesis explanation 46

Bleckly, J. 190

Britt, M. A. 41

Brown, J. S. 23-24

Brown, W. 41

Bucat, R. B. 190

chemical literacy 195-196; the mole 194-195; see also senior school chemistry

Chen, Y.-C. 113

Christie, F. 62

Clarke, D. 189

classroom pedagogy 113-118, 117

cognitive apprenticeship models 87,88

Collins, A. 23-24

Collins, S. 26, 221

conditional explanations 42

conjunctive relations 44

consequential explanations 41
Cribb, G. 41

cross-and-portion (CPO) model 182, 185-189, 185, 187-188

cross-mode recasting 234-237

D'Avanzo, C. 45

De Bièvre, P. 189

De Cock, M. 71

decoupling 53

Delpit, L. 12

design-based research: aim of 199; case study l: Riya 201-209; case study 2: Carmela 209-213; case study 3: Paulo 214-218; M3S project 199, 201, 209, 213, 215, 218; processes of 200-201

disciplinary literacy: of biology, chemistry and physics 44-46; competencies 40; and fundamental literacy 2; genre-based 29-31; as multimodal 24-25; practices 41; through participation in practice 26-29

discipline-specific language of biology: from everyday language to 134-135; sequential explanations within protein synthesis 136-137

discipline-specific literacy 40-41

discourse of biology 52-53

diSessa, A. A. 54

distillation 52

Doran, Y. J. 47

Duguid, P. 23-24

Duschl, R. 24, 26, 31

Elkins, J. 23

Elvins, C. 195 


\section{Index}

English as an additional language/ dialect (EALD) 201

Eriksson, U. 67, 72

expressive literacy 41

factorial explanations 41

Fang, S.-C. 189

Faraday, Michael 22

Faraday's law 157, 157

field of knowledge see knowledge building

Forey, G. 50

form/function relationships 49

'fundamental literacy,' 2

Gee, J. P. 11

genre-based disciplinary literacy research 29-31

genres: descriptions of written 3-4; 'not time structured,' 41, 42; 'time structured,' 41-42, 42

genres principal: in school history textbooks 42-43, 43; in school science textbooks $41-42,42$

George, M. 41

Gilbert, J. 32, 71

Goddiksen, M. 45-46

Goldman, S. R. 41

Gooding, D. 22, 31

Graham, A. C. 41

graphical literacy 172-175, 173

Greenleaf, C. 41

Gregorcic, B. 71

Grosslight, L. 32

guided inquiry: classroom interaction strategies 88-89; models 87, 87-88; pedagogies 92, 109-112, 110 ; reading strategies $89-91$; writing strategies 91-92

guided inquiry pedagogy: squence of processes in 92; taching/learning sequences for 109,110

Halliday, M. A. K. 3, 29, 47

Hand, B. 26, 48, 113-114, 247

Hao, J. 47, 100

Hart, C. 189

Hartley, L. M. 45

Haslam, F. 221

Hertzsprung-Russell (HR) diagram $67-68,75$

high-stakes assessment regimes 63 , 76-77

Hubber, P. 26, 54, 221 image-language integration: infographic design 243-246; infographic

representations $246-252$

'image obsessed,' 23

immersive virtual reality (IVR): 3D

animations in 253, 256; applications in science education 257

infographics through image-language integration 243-252

'inscriptions,' 1, 6, 21

intermediate literacy 40

IVR see immersive virtual reality

Jay, E. 32

Jewitt, C. 47

Johnstone, A. H. 179

Johnstone triangle 68-69, 69, 179-181, 184-185, 188-189, 196

joint and independent construction 143 ; independent construction 146148; on mitosis and meiosis 144; on natural selection 144-146; peer joint construction 146

joint construction $53-54$; of causal explanation 169-172; of written sequential explanations 203-205, 204

Kerkhoff, S. N. 41

Keys, C. 26

Kim, M.-J. 93

Klein, U. 22

knowledge building 21-31; deconstructing representations 138-143; joint and independent construction 143-148; using representations to $133-138$

Konold, C. 93

Kozma, R. 25, 71, 181, 184, 186, 192

Kress, G. 5, 47, 93, 100

language of history 44

language of science: characterization 43 ; sub-disciplines 44-47, 47

Latour, B. 21-22, 112, 253

Lave, J. 23

learning complexity at senior level 6163; biology 64-65; chemistry 68-71; physics and astronomy 66-68

Lee, J. K. 41

Lehrer, R. 26, 93

Lemke, J. 3, 6, 11, 25, 47, 51

Linder, A. 71

Linder, C. 25, 67, 71, 112-113, $115-116,118,253$ 
literacy: competencies 40 ; disciplinary see disciplinary literacy

Lohmeyer, P. 195

Lukins, N. 195

Macnaught, L. 52-54, 114

macrogenre 138

Martin, J. 3

Martin, J. R. 29-31, 41-42, 44, 47, $52-54,114,156$

Martins, I. 47

Maskiewicz, A. 45

Maton, K. 51-54, 114

Matruglio, E. 52-54, 114

Mayaba, N. 71

MCA see metarepresentational competence

McDermott, M. A. 247

MDL development, contextual challenges of: assessment in shaping disciplinary literacy practices 78-80; developing pedagogies to support MDL 80-81; high-stakes assessment regimes 76-77; language issues with special groups 76; prior knowledge and literacy skills of students 73-74; teachers' disciplinary literacy knowledge and perspectives 75-76; working with teachers in M3S project $72-73$

metalanguage: developing 148-149; establishing 177; and metarepresentational competence 118-120, 120; R2L model 97-99; SFL-derived see SFL-based metalanguage; shared by teachers and students 48-49; TLC model 94-97, 95 metarepresentational competence (MCA) 51, 55; developing students' 241, 257

MLISP see multimodal literacy infused science pedagogy

Mocerino, M. 256-257

modelling language of research posters 218

Mody, C. C. 111-112

Moje, E. 26

Momsen, J. 45

multiliteracies in senior school science

(M3S) project 8, 28-30, 222; biology teachers 132-134, 142-143, 148; chemisty teachers 181, 189; on literacy development 64 ; physics teachers 159-169; student engagement in dialogue about text see student engagement in dialogue; working with teachers in 72-73, 77, 79

multimodal disciplinary literacy (MDL):

biology 132-151; chemisty see senior

school chemistry; 'fundamental

literacy,' 2; literacy complexity see

learning complexity at senior level;

M3S project see multiliteracies

in senior school science (M3S)

project; and MLISP 1; modes 6;

multimodality in science $4-5$; outline

of volume 13-15; physics see senior

school physics; representational

construction approaches 92-94;

and science learning 31-33; verbal

language in science $2-4$

multimodality 46-47; research 5-6; in science $4-5$; science reasoning and

knowledge building 21-31

multimodal literacy: design-based research and professional learning see design-based research; disciplinary see multimodal disciplinary literacy; infused into pedagogy 39 ; in science classroom 31-33; transdisciplinary research, advancing for 241-243

multimodal literacy infused science pedagogy (MLISP) 1, 13, 39, 85, 221; fundamental bases for 109; guidance perspectives to 87 ; guided inquiry pedagogy 109-112, 110; interpretations of semiotic mediation 11-12; mapping dimensions of pedagogic orientations 8-10, 9; MDL in school science see multimodal disciplinary literacy; metalanguage and metarepresentational competence 118-120; pedagogy of synthesis, between MDL and scientific practices 112-113, 114; semiotic mediation and scientific knowledge 108, 109; teacher demonstration and guidance 113-118, 117

multimodal representational proficiency: comparison of student responses with explanations 123-126, 124; students' multimodal demonstration of scientific knowledge through 126-129; students' short-answer examination questions 118-120, 120

Narod, F. B. 192

Neal, D. 190

Nielsen, W. 64-65

Nitz, S. 71 
'nominalization,' 52-53,91

Norris, S. 24

Ogborn, J. 47

O'Halloran, K. 47

Osborne, J. 221

Painter, C. 12

Park, S. 113

Parodi, G. 46

pedagogies: for biology 132-133; development 99-102; guided inquiry $92,110,110$; mapping in science education and literacy $85-87,86$; teacher-student engagement 113 118,117

Peiser, H. S. 189

Pham, L. 181, 254

Phillips, L. 24

Pickering, A. 22

Prain, V. 11, 26-27, 48, 54, 68, 114, 247

premise-reasoning-outcome (PRO) framework 74

procedural recount genre 42

procedure genre 42

'prophase,' image redescription of 100 , 101

Putra, G. B. S. 100

Ramful, A. 192

RCA see representation construction approach

RCA pedagogy 92-94

reading to learn (R2L) 97-99

'recontextualization,' 23

Redfors, A. 67

representational competence 71-72

'representational passes,' 21

representational tools 21,27

representation construction approach (RCA) 48, 54, 92-94

Rickard, G. 245

'Role of Representation in Learning Science' (RiLS) project 73-74

Rose, D. 31, 41-42, 47, 50, 76, 156

Ross, B. 195

Russell, J. 25, 71, 181, 184, 186, 192

Sanders, R. 195

Schauble, L. 26

school learning into science literacy practices 23-24

Schwarz, C. V. 32

science classroom: argumentation 31 ; modelling 32-33; visualization 31-32 science education: animations 252-257;

MDL see multimodal disciplinary

literacy; student engagement in see student engagement in dialogue

Science Writing Heuristic (SWH) 9l-92

scientific reasoning 4 ; and knowledge building 21-31

semantic density $51-52$; representations of molecules 69,70

semantic gravity $51-52$

semantic waves: downward 51-52; upward 52

semiosis 65,65

semiotic mediation 11-12

senior school chemistry: chemical literacy 195-196; CPO model 185, 185-189, 187-188; dilution and concentration 182-185, 183-184; Johnstone triangle levels/domains 179-181, 188; the mole 189-195

senior school physics: graphical literacy in a kinematics 172-175, 173; joint construction of causal explanation 169-172; literacy demands of 153159; teaching and learning sequence on electric circuits 159-169, 160-

163, 164, 167, 169

sequential explanations 41

SFL see systemic functional linguistics

SFL-based metalanguage: classroom adaptations of 50; explanatory power of 100; 'only a fraction of SFL,' 50 ; teachers and students 49 ; use of $54-55$ SFL-oriented literacy 49

SFL-oriented semiotic knowledge 49

Shanahan, C. 40-41

Shanahan, T. 40

'shunting,' teacher-student negotiated $5 \mathrm{l}-55$

Siemon, D. 190

Smith, C. 32

social semiotic research 25

source literacy 41

Spires, H. A. 41

'spontaneous generation,' 91

student engagement in dialogue: after the independent construction of texts 230-232; comparing texts 232-234; cross-mode recasting 234-237; deconstructing texts 222-224; joint construction of texts 224-230

SWH see Science Writing Heuristic

systemic functional linguistics (SFL) 47; extravagance of 49; metalanguage see SFL-based metalanguage; 
perspective 49; social semiotic theory of 3 ; versatility of theory 49

Taber, K. S. 180, 192

Tang, K.-S. 74, 85, 100, 111-112, 115, 256-257

Tasker, R. 256-257

teaching learning cycle (TLC) 94-97, 95

'the mole is 6,' 192-195

Thompson, I. 41

$3 \mathrm{D}$ animations 253,256

$3 \mathrm{D}$ images $22-23$

Tippett, C. D. 71

TLC see teaching learning cycle

transduction: and animation 255-257; in science learning and teaching 253-255

Treagust, D. 256-257

Tsatsarelis, C. 47

Tytler, R. 11, 26-27, 54, 64-65, 68, $89,94,98,221$

Unger, C. 32

Unsworth, L. 4, 30, 47 van Leeuwen, T. 5, 47, 100

Veel, R. 30

verbal language in science $2-4$

visual representations 47,47

Volkwyn, T. S. 71

Vygotsky, L. 11

Vygotsky, L. S. 27-28

Waldrip, B. 26, 54

Webb, P. 71

Wenger, E. 23

White, B. Y. 32

White, P. J. 64-65

Wilson, G. 195

Won, M. 256-257

Woolgar, S. 21, 112, 253

written language 3-5

written scientific research 2-4

written text and visual representation 234-237

year 12 physics students assessment: comparison of explanations 123126, 124; electric motor task and explanation 121-123, 121-123 